\title{
Modeling the Performance and Cost of Lithium-Ion Batteries for Electric-Drive Vehicles
}

THIRD EDITION

Electrochemical Energy Storage Department Chemical Sciences and Engineering Division 


\section{About Argonne National Laboratory}

Argonne is a U.S. Department of Energy laboratory managed by UChicago Argonne, LLC under contract DE-AC02-06CH11357. The Laboratory's main facility is outside Chicago, at 9700 South Cass Avenue, Argonne, Illinois 60439. For information about Argonne and its pioneering science and technology programs, see www.anl.gov.

\section{DOCUMENT AVAILABILITY}

Online Access: U.S. Department of Energy (DOE) reports produced after 1991 and a growing number of pre-1991 documents are available free at OSTI.GOV (http://www.osti.gov/), a service of the US Dept. of Energy's Office of Scientific and Technical Information.

Reports not in digital format may be purchased by the public from the National Technical Information Service (NTIS):

U.S. Department of Commerce

National Technical Information Service

5301 Shawnee Rd

Alexandria, VA 22312

www.ntis.gov

Phone: (800) 553-NTIS (6847) or (703) 605-6000

Fax: (703) 605-6900

Email: orders@ntis.gov

\section{Reports not in digital format are available to DOE and DOE contractors from the}

Office of Scientific and Technical Information (OSTI):

U.S. Department of Energy

Office of Scientific and Technical Information

P.O. Box 62

Oak Ridge, TN 37831-0062

www.osti.gov

Phone: (865) 576-8401

Fax: (865) 576-5728

Email: reports@osti.gov

Disclaimer

This report was prepared as an account of work sponsored by an agency of the United States Government. Neither the United States Government nor any agency thereof, nor UChicago Argonne, LLC, nor any of their employees or officers, makes any warranty, express or implied, or assumes any legal liability or responsibility for the accuracy, completeness, or usefulness of any information, apparatus, product, or process disclosed, or represents that its use would not infringe privately owned rights. Reference herein to any specific commercial product, process, or service by trade name, trademark, manufacturer, or otherwise, does not necessarily constitute or imply its endorsement, recommendation, or favoring by the United States Government or any agency thereof. The views and opinions of document authors expressed herein do not necessarily state or reflect those of the United States Government or any agency thereof, Argonne National Laboratory, or UChicago Argonne, LLC. 


\section{Modeling the Performance and Cost of Lithium-Ion Batteries for Electric-Drive Vehicles}

THIRD EDITION

prepared by

Paul A. Nelson, Shabbir Ahmed, Kevin G. Gallagher, and Dennis W. Dees

Electrochemical Energy Storage Department

Chemical Sciences and Engineering Division, Argonne National Laboratory

March 2019 



\section{TABLE OF CONTEN'TS}

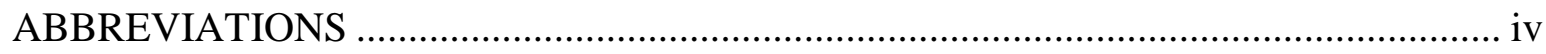

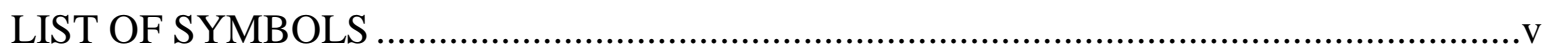

ACKNOWLEDGEMENTS ...................................................................................... viii

PREFACE TO THE THIRD EDITION ................................................................... ix

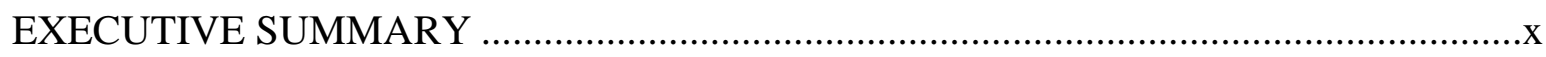

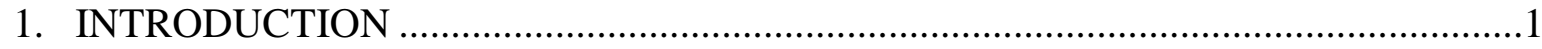

2. CELL AND BATTERY PACK DESIGN FORMAT …..................................................

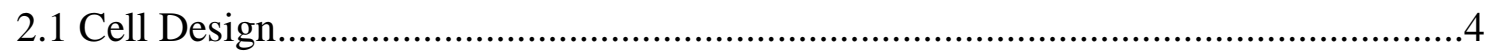

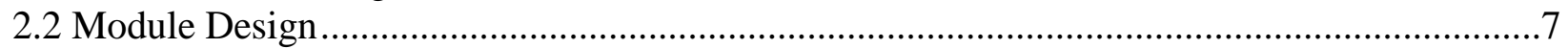

2.2.1 Modules Using Liquid Thermal Management .................................................

2.2.2 Modules Using Air Thermal Management ...........................................................

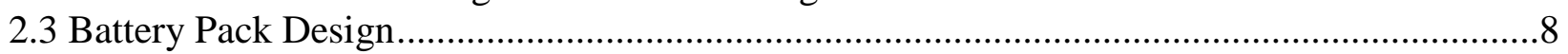

2.3.1 Batteries Using Liquid Thermal Management...................................................8

2.3.2 Batteries Using Air Thermal Management .....................................................10

2.3.3. Venting Gas Buildup......................................................................................11

3. DESCRIPTION OF THE SPREADSHEET MODEL AND INSTRUCTIONS FOR USE 12

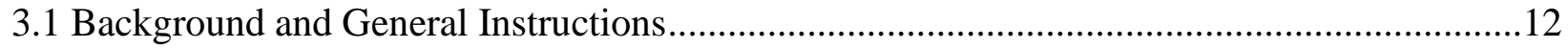

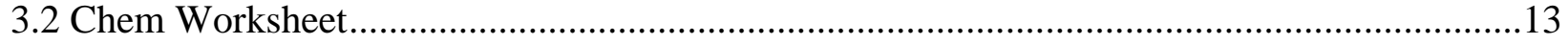

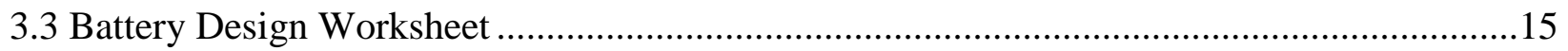

3.3.1 Battery Format Input............................................................................ 16

3.3.2 Control of the Iteration Procedures and Evaluation of Results............................20

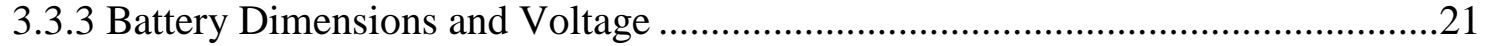

3.3.4 Parallel Packs, Modules and Cells .....................................................................22

3.3.5 Troubleshooting and General Advice .............................................................22

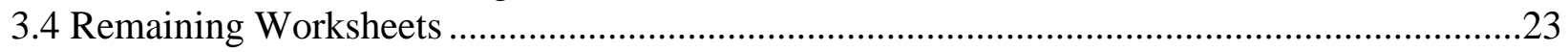

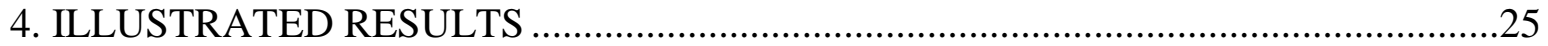

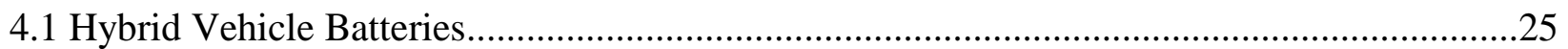

4.1.1 Batteries for Mild Hybrid Vehicles.................................................................25

4.1.2 High-Powered Batteries for Hybrid Vehicles .....................................................26

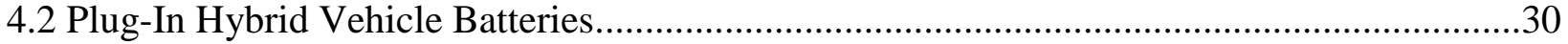

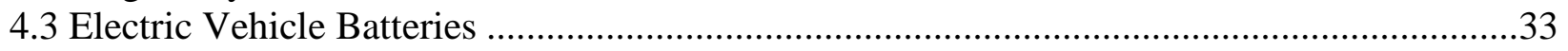

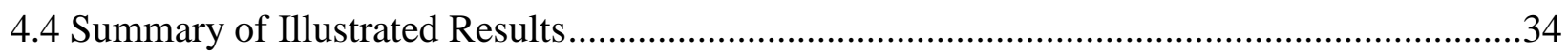

5. MODELING OF BATTERY DESIGN AND PERFORMANCE ................................37

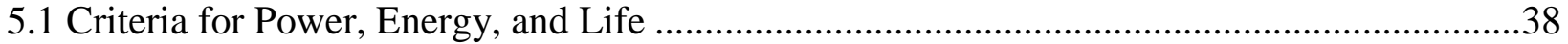

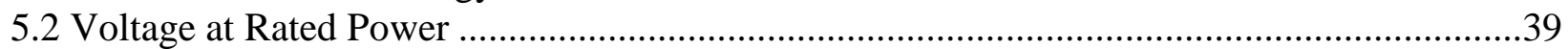

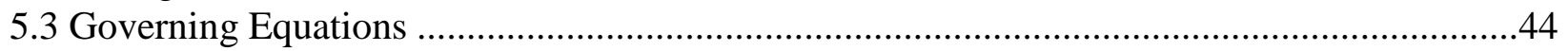

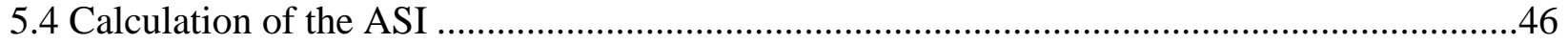

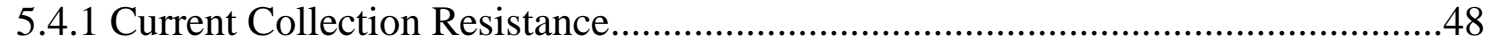

5.4.2 Potential and Current Distribution in the Current Collection Foils .......................49

5.4.3 Sizing of Module Terminals, Battery Terminals, and Module Inter-connects .......52 


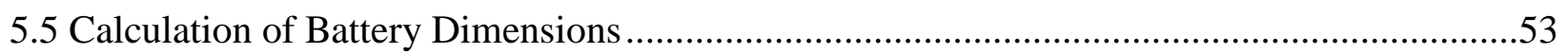

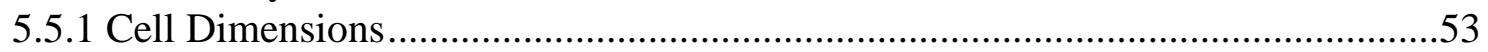

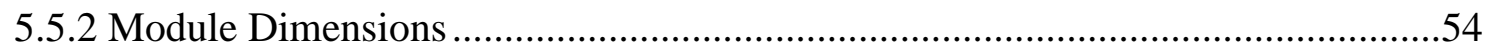

5.5.3 Battery Pack Dimensions ....................................................................................54

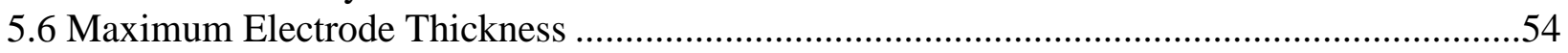

6. THERMAL MANAGEMENT ………………………..............................................60

6.1 Heat Generation Rates in the Battery Pack during Driving ......................................................60

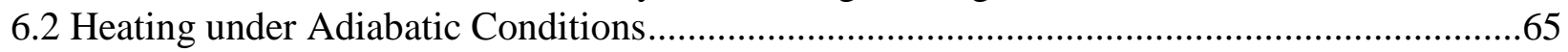

6.3 Active Thermal Management Systems ..................................................................................66

6.3.1 Thermal Management with Ethylene-Glycol/Water Solution ..................................67

6.3.1.1 Heat Transfer from Cell to Module Wall................................................................67

6.3.1.2 Heat Transfer from Module Wall to Flowing Coolant ........................................69

6.3.2 Thermal Management with Cabin Air .........................................................................73

6.3.2.1 Temperature Drop from Cell Center to Cell Wall at Steady State ......................73

6.3.2.2 Heat Transfer from Aluminum Cell Sleeve to Flowing Air .................................73

6.4 Cooling and Heating Required to Maintain Pack Temperature..................................................74

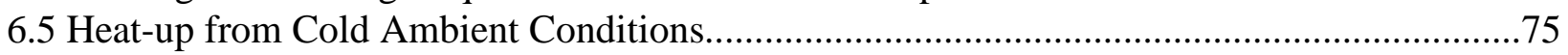

7. HIGH-RATE CHARGING OF ELECTRIC VEHICLE BATTERIES..............................76

7.1 Restrictions on the Charging Rate ....................................................................................76

7.1.1 Overpotential Limits ............................................................................................76

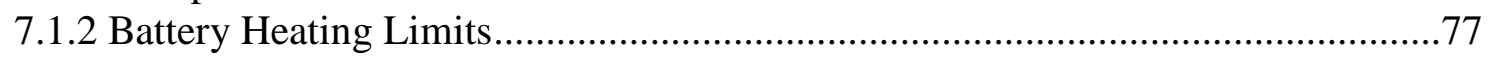

7.1.3 BatPaC Calculations for High-Rate Charging ………….........................................77

8. MODELING OF BATTERY PACK MANUFACTURING COST....................................82

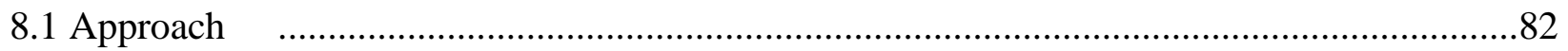

8.2 Materials Costs, Purchased Items, and Pack Integration ..........................................................83

8.2.1 Battery Specific Materials Cost ............................................................................83

8.2.1.1 Positive Electrode Active Materials........................................................................83

8.2.1.2 Negative Electrode Active Materials .....................................................................84

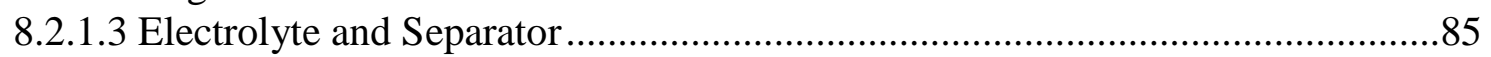

8.2.1.4 Current Collector Foils …………...........................................................................85

8.2.1.5 Additional Electrode Components ......................................................................86

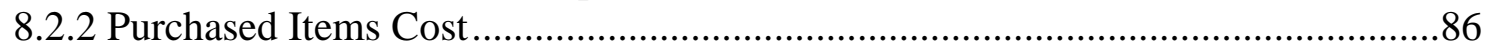

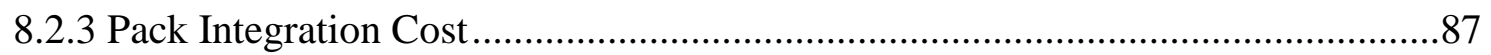

8.2.3.1 Battery Management System ............................................................................87

8.2.3.2 Manual and Automatic Disconnec..................................................................8

8.2.3.3 Balance of Thermal Management System ..........................................................89

8.3 Baseline Manufacturing Plant............................................................................90

8.3.1 Receiving and Shipping .................................................................................92

8.3.2 Electrode Materials Preparation and Delivery to Coating .....................................92

8.3.3 Electrode Coating on Current-Collector Foil...........................................................92

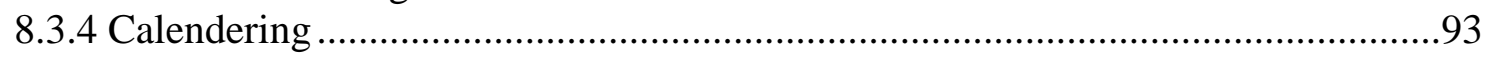

8.3.5 Inter-Process Materials Handling .........................................................................94

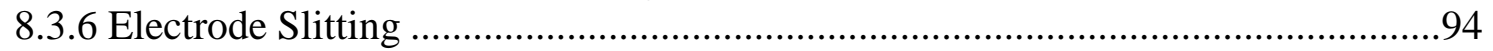

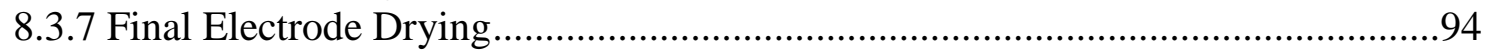

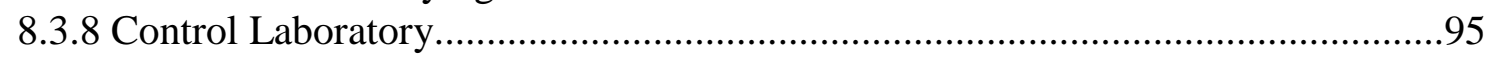

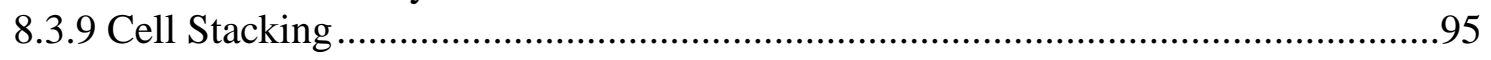


8.3.10 Current Collector Welding...............................................................................96

8.3.11 Enclosing Cell in Container .................................................................................96

8.3.12 Electrolyte Filling and Cell Sealing...................................................................96

8.3.13 Dry Room Management........................................................................................96

8.3.14 Formation Cycling, Charge Retention Testing and Final Cell Sealing ................97

8.3.15 Module and Battery Assembly.............................................................................98

8.3.16 Rejected Cell and Scrap Recycle ......................................................................99

8.4 Adjustment of Costs for Varying Production Volumes .........................................................100

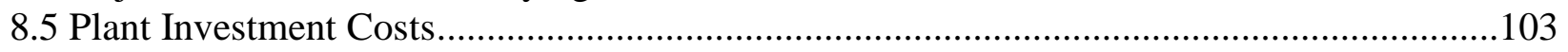

8.6 Unit Costs for Battery Pack ..............................................................................................103

8.6.1 Variable Costs .....................................................................................................103

8.6.2 Fixed Expenses ...........................................................................................104

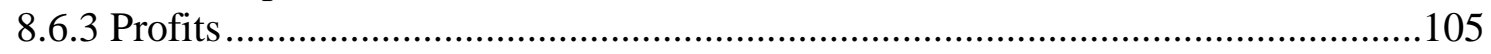

8.6.4 Battery Pack Warranty Costs ..................................................................................105

8.7 Uncertainties in Price Estimates .................................................................................105

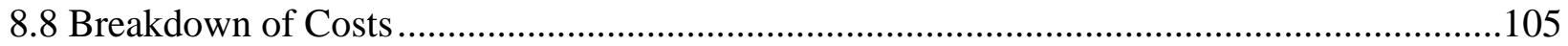

9. RECOVERABLE MATERIALS AT THE END OF BATTERY LIFE ..........................111

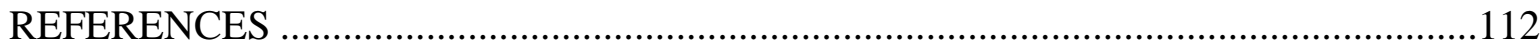




\section{ABBREVIATIONS}

ASI area specific impedance

BOL beginning of life

DMC dimethyl carbonate

EC ethylene carbonate

EG/W ethylene-glycol/water heat transfer fluid

EMC ethyl methyl carbonate

EOL end of life

EV electric vehicle

Gr graphite

GSA General, Sales, and Administration

HEV hybrid electric vehicle

HEV-HP high-power assist hybrid electric vehicle

LCO lithium cobalt oxide

LFP lithium iron phosphate

Li lithium

Li-ion lithium-ion

LMO lithium manganese spinel

LMR lithium and manganese rich

LTO lithium titanate spinel

microHEV micro or mild power assist hybrid electric vehicle

MW molecular weight

NCA lithium nickel cobalt aluminum oxide

NMC lithium nickel manganese cobalt oxide

NMP N-Methyl-2-pyrrolidone

OCV open-circuit voltage

OEM original equipment manufacturer

PE polyethylene

PET polyethylene terephthalate

PHEV plug-in hybrid electric vehicle

PP polypropylene

SOC state of charge 


\section{LIST OF SYMBOLS}

\section{Section 3, 5 and 6}

\begin{tabular}{|c|c|}
\hline$a$ & ratio of interfacial area to electrode volume, $\mathrm{cm}^{-1}$ \\
\hline$A_{\text {pos }}$ & area of the positive electrode, $\mathrm{cm}^{2}$ \\
\hline$A_{\text {term }}$ & area of the terminal, $\mathrm{cm}^{2}$ \\
\hline ASI $I_{\text {energy }}$ & area specific impedance for energy, ohm $\mathrm{cm}^{2}$ \\
\hline$A S I_{\text {power }}$ & area specific impedance for power, ohm $\mathrm{cm}^{2}$ \\
\hline C & cell capacity, Ah \\
\hline$C_{p}$ & specific heat capacity, J/g K \\
\hline$d_{H}$ & hydraulic radius, cm \\
\hline$e$ & battery to wheels efficiency \\
\hline$E$ & total energy, Wh \\
\hline$\dot{E}$ & energy usage rate, $\mathrm{Wh} / \mathrm{mile}$ \\
\hline$f_{P d}$ & vehicle drag factor, $\mathrm{kW} / \mathrm{mph}^{3}$ \\
\hline$f_{P f}$ & rolling friction factor, $\mathrm{kW} / \mathrm{mph}$ \\
\hline$F$ & Faraday constant, $96485.3 \mathrm{C} / \mathrm{mol}$ \\
\hline$G$ & mass flowrate, $\mathrm{g} / \mathrm{s}$ \\
\hline$h$ & heat transfer coefficient, $\mathrm{W} / \mathrm{cm}^{2} \mathrm{~K}$ \\
\hline$H_{j}$ & height of $j$, cm \\
\hline$H / W$ & aspect ratio of pouch cell \\
\hline$i_{O}$ & exchange current density related to the interfacial area, $\mathrm{A} / \mathrm{cm}^{2}$ \\
\hline$I$ & average current density, $\mathrm{A} / \mathrm{cm}^{2}$ \\
\hline$I_{\text {lim }}^{\text {ionic }}$ & ionic limiting current density, $\mathrm{A} / \mathrm{cm}^{2}$ \\
\hline$I_{n}$ & local current density, A/cm² \\
\hline Itotal & total current density, A \\
\hline$k$ & thermal conductivity, W/cm K \\
\hline$l_{j}$ & length of $j$, cm \\
\hline$L_{j}$ & thickness of $j, \mathrm{~cm}$ \\
\hline$m_{j}$ & mass of $j, \mathrm{~g}$ \\
\hline$n$ & parameter \\
\hline$N_{j}$ & number of $j$ \\
\hline$[\mathrm{N} / \mathrm{P}]$ & negative to positive capacity ratio \\
\hline
\end{tabular}




\begin{tabular}{|c|c|}
\hline$P$ & battery power, W \\
\hline$P_{\text {batt }}$ & maximum designed battery power (rated power), $\mathrm{W}$ \\
\hline$P_{a}$ & accessory power, $\mathrm{kW}$ \\
\hline$P_{d}$ & aerodynamic drag power, $\mathrm{kW}$ \\
\hline$P_{f}$ & rolling friction power, $\mathrm{kW}$ \\
\hline$P_{s}$ & battery power to sustain speed $S, \mathrm{~kW}$ \\
\hline$q$ & heating rate, $\mathrm{W}$ \\
\hline$Q$ & specific capacity of the electrode, $\mathrm{mAh} / \mathrm{g}$ \\
\hline$r_{C}$ & C-rate, $h^{-1}$ \\
\hline$r_{C, \text { lim }}$ & limiting C-rate, $\mathrm{h}^{-1}$ \\
\hline$r_{j}$ & radius of $j, \mathrm{~cm}$ \\
\hline $\bar{R}$ & universal gas constant, $8.3144 \mathrm{~J} / \mathrm{mol} \mathrm{K}$ \\
\hline$R_{j}$ & resistance of $j$, ohm \\
\hline$S$ & vehicle speed, mph \\
\hline$t$ & time, $\mathrm{s}$ \\
\hline$T$ & temperature, $\mathrm{K}$ \\
\hline$U_{o c v, P}$ & open-circuit voltage at SOC for power, V \\
\hline$U_{o c v, E}$ & open-circuit voltage at SOC for energy, V \\
\hline$v$ & square root of dimensionless exchange current \\
\hline$V_{\text {cell }}$ & cell voltage, $\mathrm{V}$ \\
\hline$[\mathrm{V} / \mathrm{U}]$ & fraction of the open-circuit voltage \\
\hline$W_{j}$ & width of $j$ \\
\hline$x$ & Cartesian coordinate, $\mathrm{cm}$ \\
\hline$X_{\text {comp }}$ & compression factor \\
\hline$\alpha$ & constant, ohm $\mathrm{cm}^{3}$ \\
\hline$\beta$ & constant, ohm cm² \\
\hline$\varepsilon_{\text {act }}$ & volume fraction of active material \\
\hline$\eta^{1 \mathrm{st}}$ & first cycle efficiency \\
\hline$\mu$ & fluid viscosity, g/cm s \\
\hline$\Phi_{1, \mathrm{k}}$ & metal potential of foil $k, \mathrm{~V}$ \\
\hline$\rho_{\mathrm{j}}$ & density of $j, \mathrm{~g} / \mathrm{cm}^{3}$ \\
\hline$\sigma_{\mathrm{j}}$ & conductivity of $j, \mathrm{~S} / \mathrm{cm}$ \\
\hline
\end{tabular}


MW molecular weight of lithiated compound, g/mol

\section{Section 8.4}

C

$C_{o}$

$p$

$R$

$R_{O}$ capital cost of installed equipment for the designed battery, \$

capital cost of installed equipment for the baseline plant battery, \$

power factor

designed battery processing rate for specific process step

baseline plant processing rate for specific process step 


\section{ACKNOWLEDGEMENTS}

The authors wish to thank David Howell and Tien Duong of the U.S. Department of Energy's, Energy Efficiency and Renewable Energy, Vehicle Technologies Office for supporting the development of the BatPaC model. The authors wish to thank Danilo Santini, Ira D. Bloom, and Gary Henriksen of Argonne National Laboratory. The authors wish to thank Ralph Brodd, Fritz Kalhammer and Haresh Kamath of the Electric Power Research Institute. The authors express their gratitude to the many industrial partners that privately reviewed our work resulting in a much improved final product. 


\section{PREFACE TO THE THIRD EDITION}

The BatPaC model and report were first openly distributed to the public, free of charge, in November 2011 from the website www.cse.anl.gov/batpac. The model was updated late in 2012 to BatPaC v2.1 and a Second addition of the Manual (ANL-12/55) was made available. Since then the model has been frequently updated and the new versions have been made available on the same website with brief descriptions of the improvements. There have been more than 1000 downloads from government agencies, leading universities, laboratories and companies around the world. Some have modified the model for their own use, while others use it as is.

The extent of the changes to the model has warranted this new addition of the manual, which we hope will provide useful explanations to all users of the model and a good starting point for new users. The major updates included in BatPaC v3.1 from the BatPaC v2.1 model include the following:

- Provision was made in the battery pack design for release of excessive pressure from the pack to the street below in case of a battery malfunction.

- A mixed cathode containing both LMO and NMC was added to the selection of default materials that can be selected.

- Improvements were made in the calculation of the effects of electrode thickness on areaspecific impedance (ASI).

- Improvements were made in the calculation efficiency to obtain the finished design in fewer iterations than previously and with less need for input from the user.

- The cell design model was improved to provide an exact integer number of bicell layers rather than the less exact design of the previous version.

- A fast charging option was provided for EVs and PHEVs with selection of the desired charging time, which places an additional restriction on the electrode thickness.

- Thermal design calculations were improved so that most battery designs need no input by the user on the Thermal worksheet.

- The baseline plant, which serves as the basis from which the cost of production is projected for each plant under study, was increased in size from $0.87 \mathrm{MWh} /$ year to $6.0 \mathrm{MWh} / \mathrm{year}$ improving the accuracy in projecting the cost of large manufacturing plants.

- The speed of the baseline electrode-coating equipment was increased as a result of discussions with manufacturers.

- Calculations on the cost of the dry room in the manufacturing plant were improved as a result of a recent ANL study.

- The calculated costs and plant floor area estimates for formation cycling, charge retention testing and final cell sealing were reduced as a result of automation and consolidation of these functions.

- A worksheet was added to provide results of special interest to the United States Advanced Battery Consortium (USABC).

- A worksheet was added to provide data on recyclable materials in used batteries. 


\section{EXECUTIVE SUMMARY}

This Manual details the Battery Performance and Cost model (BatPaC) developed at Argonne National Laboratory for lithium-ion battery packs used in automotive transportation. The model designs the battery for a specified power, energy, and type of vehicle battery. The cost of the designed battery is then calculated by accounting for every step in the lithium-ion battery manufacturing process. The assumed annual production level directly affects each process step. The total price to vehicle manufacturers calculated by the model represent both our estimates for the present-day costs and projected costs for up to ten years in the future, depending upon the designated scale of production. BatPaC assumes that future plants with production volumes of up to 500,000 EV batteries per year would be highly automated resulting in lower capital equipment and labor costs per unit produced than present day plants that have lower production volumes. All costs are calculated in US\$ for the year of the estimate with all input costs for that same year.

BatPaC is the only publicly available model of which we are aware that performs a bottom-up lithium-ion battery design and cost calculation. The original model and Manual were publicly peerreviewed by battery experts assembled by the U.S. Environmental Protection Agency. This revised model and Manual include changes made in response to the comments received from the users; most of the changes were made over a number of years and are summarized here.

The purpose of the report is to document the equations and assumptions from which the model has been created. A user of the model will be able to recreate the calculations and perhaps more importantly, understand the driving forces for the results. Instructions for use and illustrations of the model results are also presented. Almost every variable in the calculation may be changed by the user to represent a system different from the default values pre-entered into the program.

The distinct advantage of using a bottom-up cost and design model is that the entire power-toenergy space may be traversed to examine the correlation between performance and cost. The $\mathrm{BatPaC}$ model accounts for the physical limitations of the electrochemical processes within the battery. Thus, unrealistic designs are penalized in energy density and cost, unlike cost models based on linear extrapolations. Additionally, the consequences on cost and energy density from changes in cell capacity, parallel cell groups, and manufacturing capabilities are easily assessed with the model. New proposed materials may also be examined to translate bench-scale values to the design of full-scale battery packs providing realistic energy densities and prices to the original equipment manufacturer. 


\section{INTRODUCTION}

The recent penetration of lithium-ion (Li-ion) batteries into the vehicle market has prompted interest in projecting and understanding the costs of this family of chemistries being used to electrify the automotive powertrain. The model described here-in is a calculation method that was developed at Argonne National Laboratory (Argonne) for estimating the manufacturing cost and performance of Li-ion batteries for electric-drive vehicles including hybrid-electrics (HEV), plugin hybrids (PHEV), and pure electrics (EV). To date, a number of cost models of various levels of detail have been published in different forms [1-11]. The cost of a battery will change depending upon the materials chemistry, battery design, and manufacturing process [12-14]. Therefore, it is necessary to account for all three areas with a bottom-up cost model. Other bottom-up cost models exist but are not generally available and have not been explicitly detailed in a public document. The motivation for this work is based on a need for a battery cost model that meets the following requirements:

1. Open and available to the entire community

2. Transparent in the assumptions made and method of calculation

3. Capable of designing a battery specifically for the requirements of an application

4. Accounts for the physical limitations that govern battery performance

5. Based on a bottom-up calculation approach to account for every cost factor

The Battery Performance and Cost model (BatPaC) described here-in is the product of long-term research and development at Argonne. Over a period of years, Argonne has developed methods to design Li-ion batteries for electric-drive vehicles based on modeling with Microsoft ${ }^{\circledR}$ Office Excel spreadsheets [12-20]. These models provided all the data needed to estimate the annual materials requirements for manufacturing the batteries being designed. This facilitated the next step, which was to extend the effort to include modeling of the manufacturing costs of the batteries. In the following sections of this document, a model is presented that meets the above criteria and may be used to analyze the effect of battery design and materials properties on the cost of the final battery pack. Use of BatPaC requires some basic knowledge of battery packs; however, a user does not need to be an expert. For instance, the number of cells and thus battery pack voltage must be specified by the user. However, default values are available for more specific requirements such as experimentally measured values. In this way, a person with reasonable knowledge of batteries may be able to conduct cost comparisons and "what if" studies.

The battery pack design and cost calculated in BatPaC represent our projections for up to ten years in the future. We assume that the degree of compactness for the cell and pack designs in BatPaC will be achieved in future commercial battery designs, but only after much engineering effort and trial-and-error testing at great cost. The resulting reduction in the mass of the structural materials and pack volume, would add to the value of the finished product, but would have only a little effect on the calculated cost of the battery. The unit costs of materials, labor, and capital equipment are based upon our estimates of 2018 values. Thus, if $\mathrm{BatPaC}$ is used to calculate the current costs of batteries at current production levels (say 30,000 all-electric (BEV) packs per year) we expect it to provide good estimates of current battery prices to OEMs. Estimates done for ten years in the future should be at production levels of 100,000 to 500,000 units per year, which will result in lower pack prices because of the assumed increase in the degree of plant automation. Estimates of 
future battery prices are for current dollars, not reflecting future inflation. As BatPaC is updated in the future, the unit costs of materials, labor, and capital equipment will be updated and the degree of automation of the plant will reflect both new trends in processing and the scale of production both for the time when the estimates are being made and for the future. Thus, it is planned that $\mathrm{BatPaC}$ can always be used to estimate both current and future prices of batteries; the differences in the prices should be primarily because of differences in scale of manufacture.

The battery pack price to the OEM calculated by the model inherently assumes the existence of mature, high-volume manufacturing of Li-ion batteries for transportation applications. Current manufacturers face high costs partly because of low manufacturing rates, which is taken into account by the model. However, other cost factors they face such as high materials cost, inefficient designs, low yields, and high failure rates would require special adjustments to the model.

Establishing the validity of the model calculation is important in justifying the conclusions drawn from exercising the model. The report and model have been subjected to a public peer-review by battery experts assembled by the U.S. Environmental Protection Agency. Changes have been made in response to the comments received during the peer-review. The design methodology used has been previously validated against cylindrical wound cell formats [20]. The calculated materials quantities agreed with the actual values within $3 \%$. Moving to a prismatic format simplifies the current collection calculation while leaving the governing equations unchanged. The new approach developed for calculating the cell impedance has been validated against experimental measurements from electrodes up to $100 \mu \mathrm{m}$ in thickness [15].

Validation of the input material and capital costs are more difficult to achieve as few values are publicly available. We have relied, to a large extent, on private communications from equipment manufacturers, materials suppliers, cell manufacturers, and original equipment manufacturers (OEM). Variation does exist amongst the communicated values and we have maintained a practical level of skepticism for their accuracy. Experts from all aspects of battery development have reviewed the model both privately and as part of a formal peer-review process. While the largest uncertainty in calculated values will exist in point cost estimates, the most instructive information may be gained by examining ranges in parameter values and relative changes between material properties. 


\section{CELL AND BATTERY PACK DESIGN FORMAT}

Various cell and battery design concepts are under development at battery manufacturers. Based upon experience gained from extensive previous work, we have found the exact design of the battery does not have an important effect on the cost for a set cell chemistry system; the amounts of electrode materials and the number, capacity and electrode area of the cells, are the determining cost factors. The most common cell designs for batteries in large-scale production are cylindrical wound cells, flat wound cells, and prismatic cells with flat plates. Cylindrical cells probably have a slight advantage for the assembly of the electrode-separator unit because of the ease of making a cylindrical winding. For the different cell designs, there are small differences in the weights of the terminal extensions and the procedures for connecting these extensions to the current collector sheets, with a small advantage for flat plate cells. The flat-wound and flat-plate cells form a more compact module and have better heat rejection capabilities than the cylindrical cells. These small differences would have minor effects on the cost of batteries produced in high volume in a mature, automated production plant and all of the cell designs can be adequately cooled for most applications. We conclude that the cost calculations would be relevant for batteries differing considerably from the selected design approach.

To provide a specific design for the calculations, a prismatic cell in a stiff-pouch container was selected. The terminals are almost as wide as the full width of the cell with the positive terminal at one end of the cell and the negative terminal at the opposite end. The electrical performance of a cell with this construction is near optimum, with a very low fraction of the resistance in the current collection structure. This cell design is amenable to either liquid or air based thermal management approaches. In this study, most of our attention has been directed to batteries using liquid thermal management. For that approach, the cells are enclosed in hermetically sealed modules, which are cooled on their exterior surfaces by ethylene glycol-water solution. The module enclosure protects the cell terminals from the heat transfer fluid, which is an electrolyte. As an additional safety precaution, a dielectric liquid could be used as the heat transfer fluid, such as a transformer coolant, but that approach has not been studied in the work of this report.

For air thermal management, the broad cell area must be individually contacted by the fluid due to the poorer heat transfer properties of air. Therefore, the cells are enclosed in an aluminum sleeve which provides air flow channels; the module enclosure is open at the bottom and top to accommodate upward flow of air through these channels. Both the liquid and the air thermal management designs are configured to be compact, light-weight and amenable to low-cost manufacture. It is unlikely that we have selected the most viable designs in this limited study; there may be serious flaws in some details. However, the calculated overall performance and low cost for the selected design will be challenging to match in actual production and will only be met by the most successful manufacturers, those that will dominate the market.

The paragraphs below in section 2, provide the overall cell, module and battery pack design formats. Additional design details and methods of calculations are provided in sections 5 and 6 . 


\subsection{Cell Design}

The prismatic cell of this design embodies individual positive and negative electrodes consisting of current collector foils coated with electrode materials on both sides. The current collectors are usually solid copper and aluminum foils for the positive and the negative electrodes, respectively. An illustration of a segment of the cell is detailed in Figure 2.1. Each electrode is made up of active material particles held together by a polymeric binder. A conductive additive, carbon black and/or graphite, is added to the positive electrode and sometimes to the negative electrode. The electrodes and separator each have porosity that is filled with the electrolyte solution. During charge or discharge, the Li-ions move from the electrode particles into the electrolyte, across the separator, and then insert into the particles composing the opposite electrode. The electrons simultaneously leave the cell through the current collection system and then enter through the opposite side after doing external work. The materials currently used in Li-ion cells are based on an intercalation process. In this process, the $\mathrm{Li}$-ion is inserted into or removed from the crystal structure of the active material. The oxidation state of the active material, or host, is concurrently changed by gaining or losing an electron. The intercalation process causes little change in the volume of the electrode over the entire state-of-charge range on both charge and discharge.

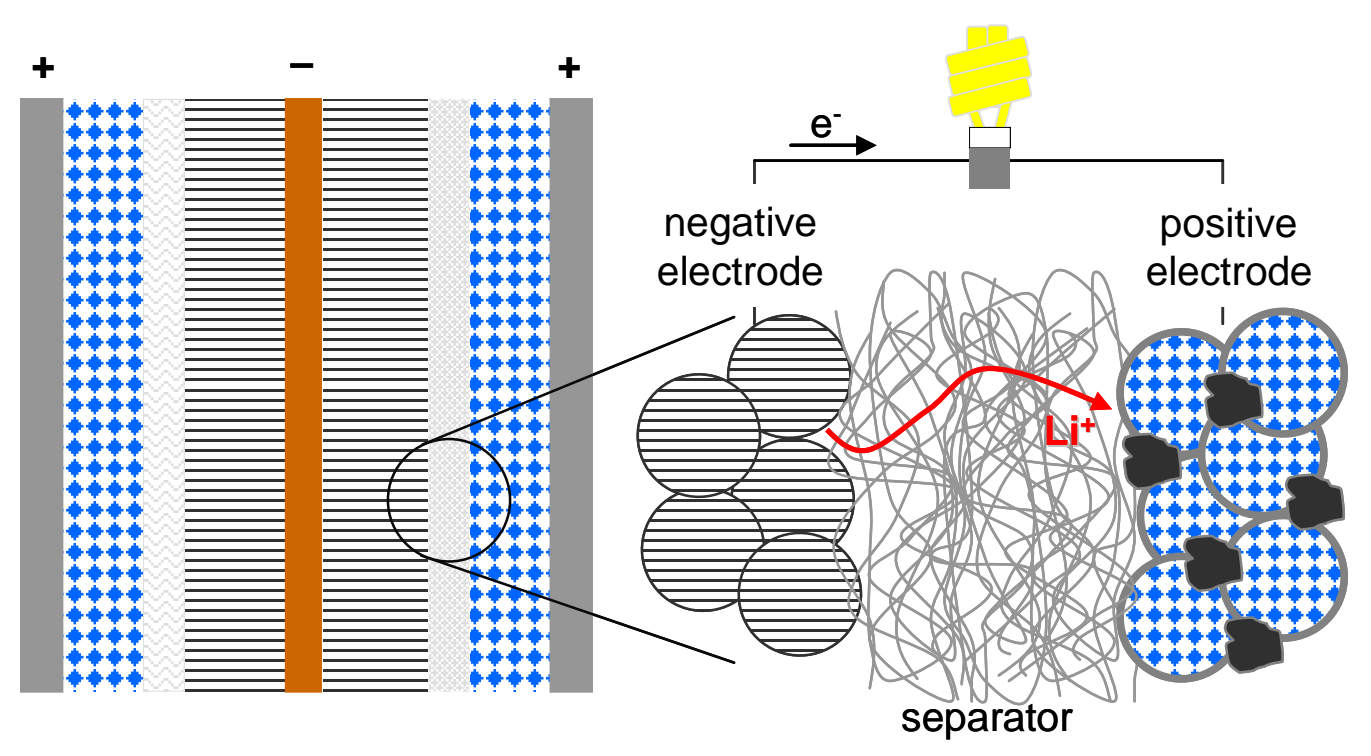

Figure 2.1. Cell sandwich inside of prismatic pouch cells.

The electrodes are easily and efficiently prepared by coating wide sheets of foil up to 2-meters in width with uncoated strips running the lengths of the foil being coated. The individual electrodes can be cut from these sheets with little waste of electrode coating material or foil (Fig. 2.2).

The separator for these cells can be handled as a single sheet that is folded back and forth as the electrodes are inserted. The electrodes are inserted so that all of the positive tabs extend beyond the separator sheet in one direction and the negative tabs extend in the opposite direction. The design model selects the number of electrodes to meet a set cell thickness determined by the type of cell: microHEV, $6 \mathrm{~mm}$; HEV-HP, $12 \mathrm{~mm}$; PHEV, $16 \mathrm{~mm}$; EV, $20 \mathrm{~mm}$. These cell thicknesses are default values and may be changed to suit the designer. 


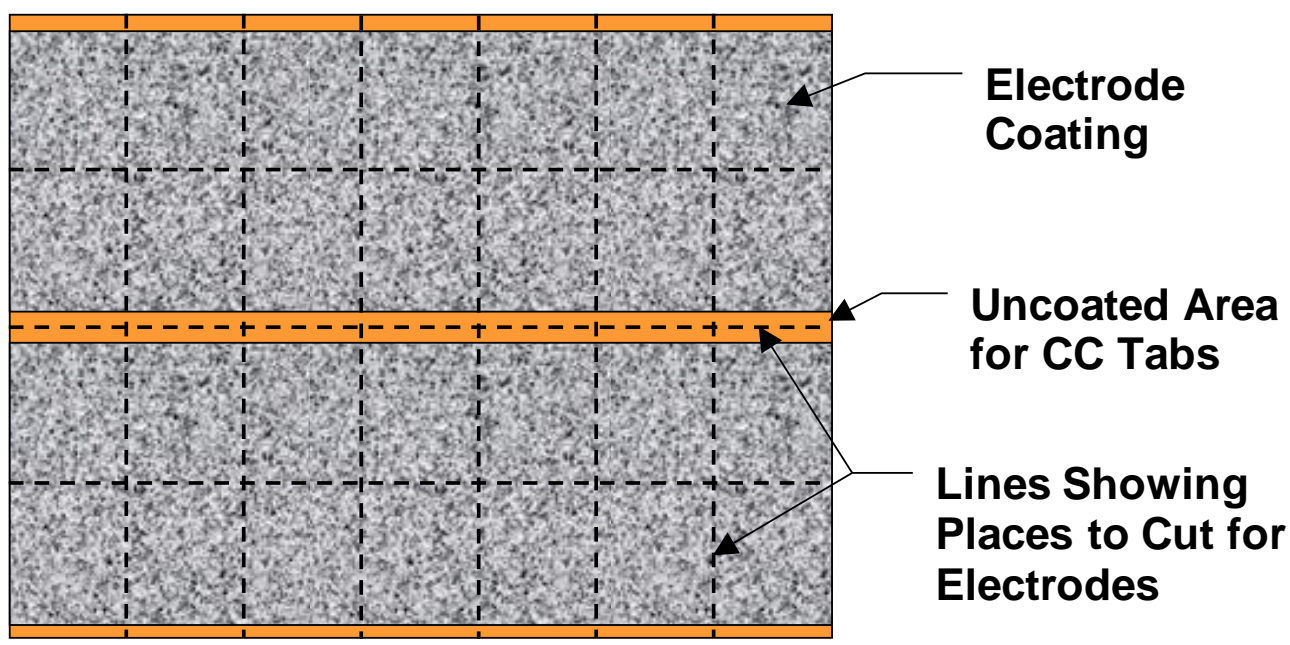

Figure 2.2. Illustration of coated current collector foil showing four rows of prismatic electrodes before slitting or stamping into individual electrodes

The stiff-pouch containment for the cell and the terminal seal is illustrated in Fig. 2.3. The cell terminals are formed from flat stock to be almost as wide as the entire cell. They are bent to the required shape and ultrasonically welded to the current collector tabs. The cell stack is then sealed between the two halves of the cell container. The cell housing material is a tri-layer consisting of an outer layer of polyethylene terephthalate (PEP) for strength, a middle layer of 0.1-mm aluminum for stiffness and impermeability to moisture and electrolyte solvent vapors and an inner layer of polypropylene (PP) for sealing by heating $[21,22]$. The two halves of the cell container are pre-shaped to facilitate assembly. The aluminum foil in the cell container material provides stiffness and it may be increased in thickness to assist in conducting heat to the module container. After sealing the edges of the cell, the edges are flattened along the sides of the cell to form a compact shape. For liquid based thermal management, an aluminum conduction channel is added to assist in heat rejection at the sides of the cells (Fig. 2.3).

For batteries utilizing air based thermal management, the cell design format is the same as for liquid-based systems. To provide space for air flow between the cells, the cells are enclosed in an aluminum sleeve that provides the flow passages as illustrated in Fig. 2.4. The ridges between the air flow passages are 2-mm wide. The passages themselves are about 10 to 20 -mm wide, the exact width being calculated to provide an integer number of passages of the same width across the length of the cell stack. 


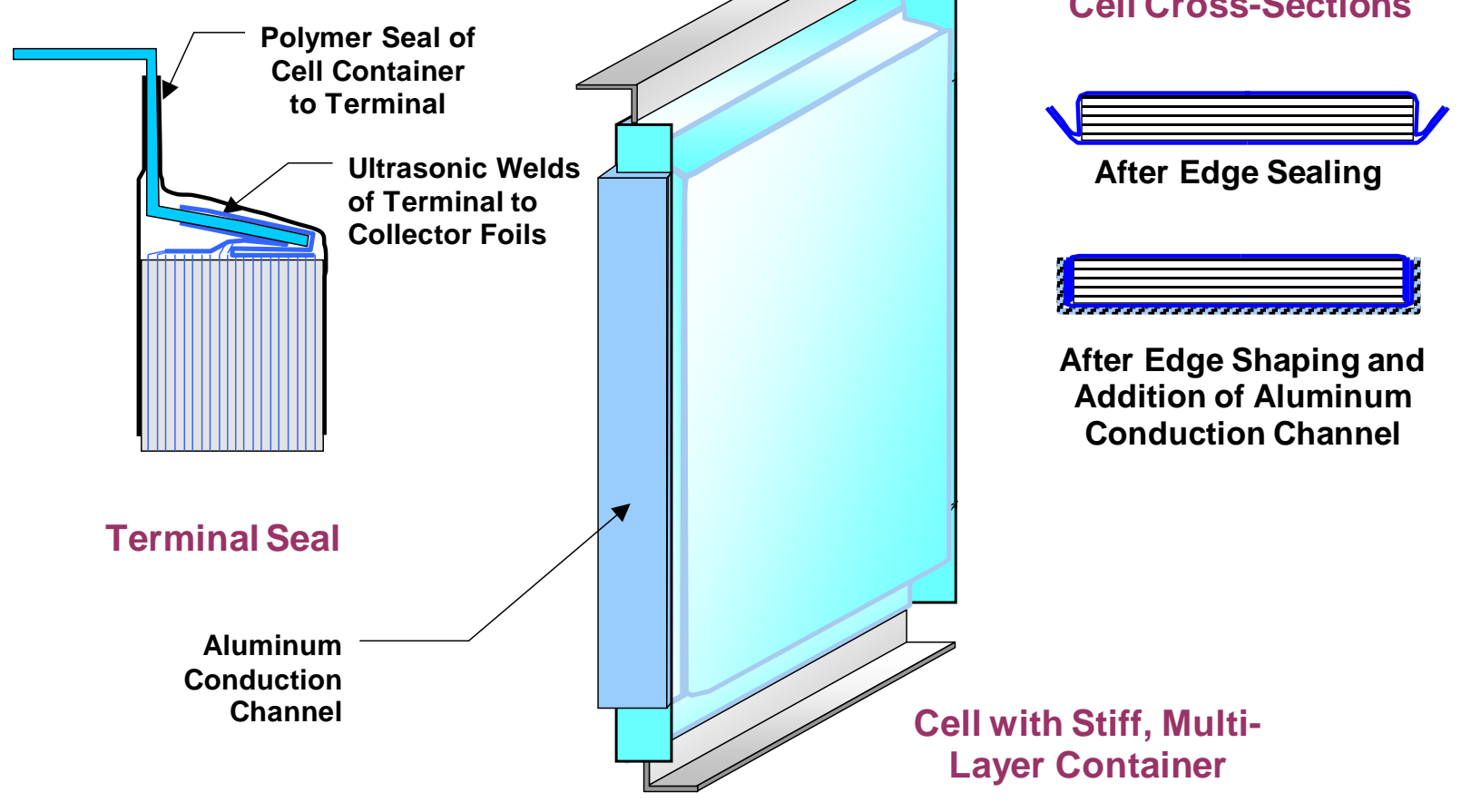

Figure 2.3. Prismatic cell in stiff pouch container with aluminum conduction channel added for heat rejection from a liquid cooled module

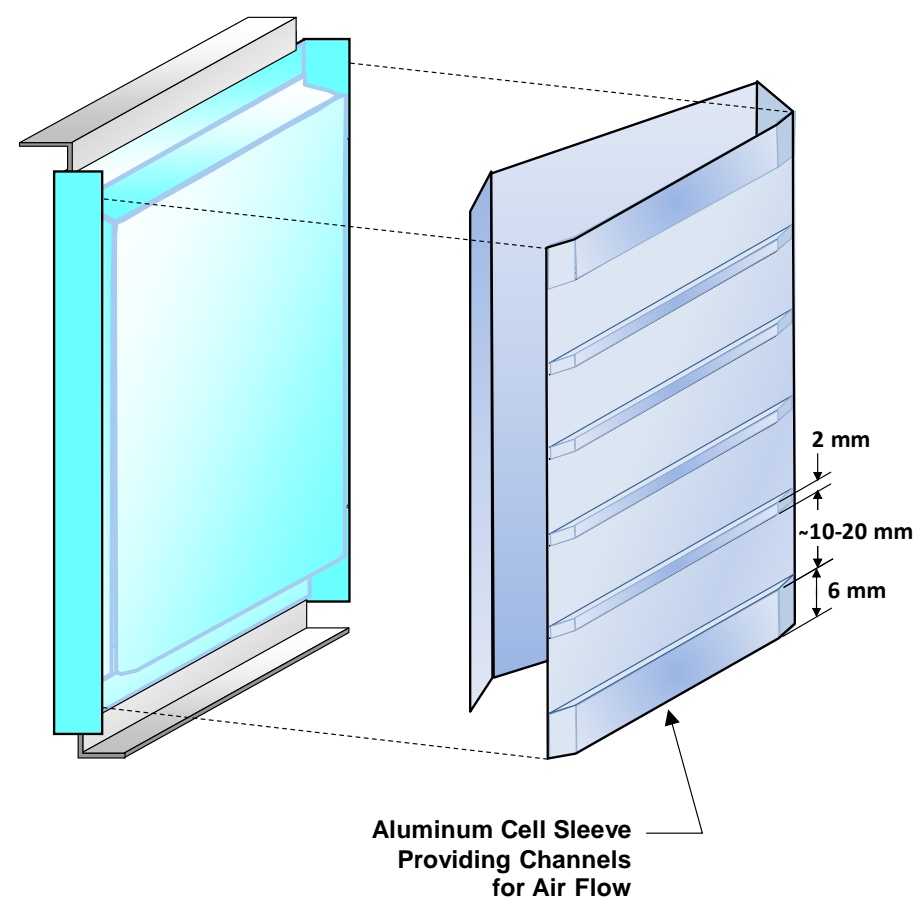

Figure 2.4. Provision for cooling cells with cabin air 


\subsection{Module Design}

\subsubsection{Modules Using Liquid Thermal Management}

The module format is based on a casing of $0.5-\mathrm{mm}$ thick aluminum that is sealed by double seaming, a process that is well established and inexpensive because it is automated, rapid, and uses low-cost equipment that is common in the container industry. The sealing of the module provides an additional barrier to the loss of electrolyte solvent from the cells and the entrance of water vapor. These deleterious transfers by diffusion through the seals of pouch cells may shorten their lives to less than the desired fifteen years [22].

The cells are placed on their sides in the module and the terminals of adjacent cells are connected either mechanically with rivets and flat springs to maintain contact or by laser welding. Space is provided within the module casing on the left side, as sketched in Fig. 2.5, for an electronics package that includes cell monitoring for malfunctions (temperature and voltage) and for state-ofcharge (SOC) control. The SOC control is activated whenever the battery is at rest and it diverts charge from the cells at highest voltage to those at lowest voltage.

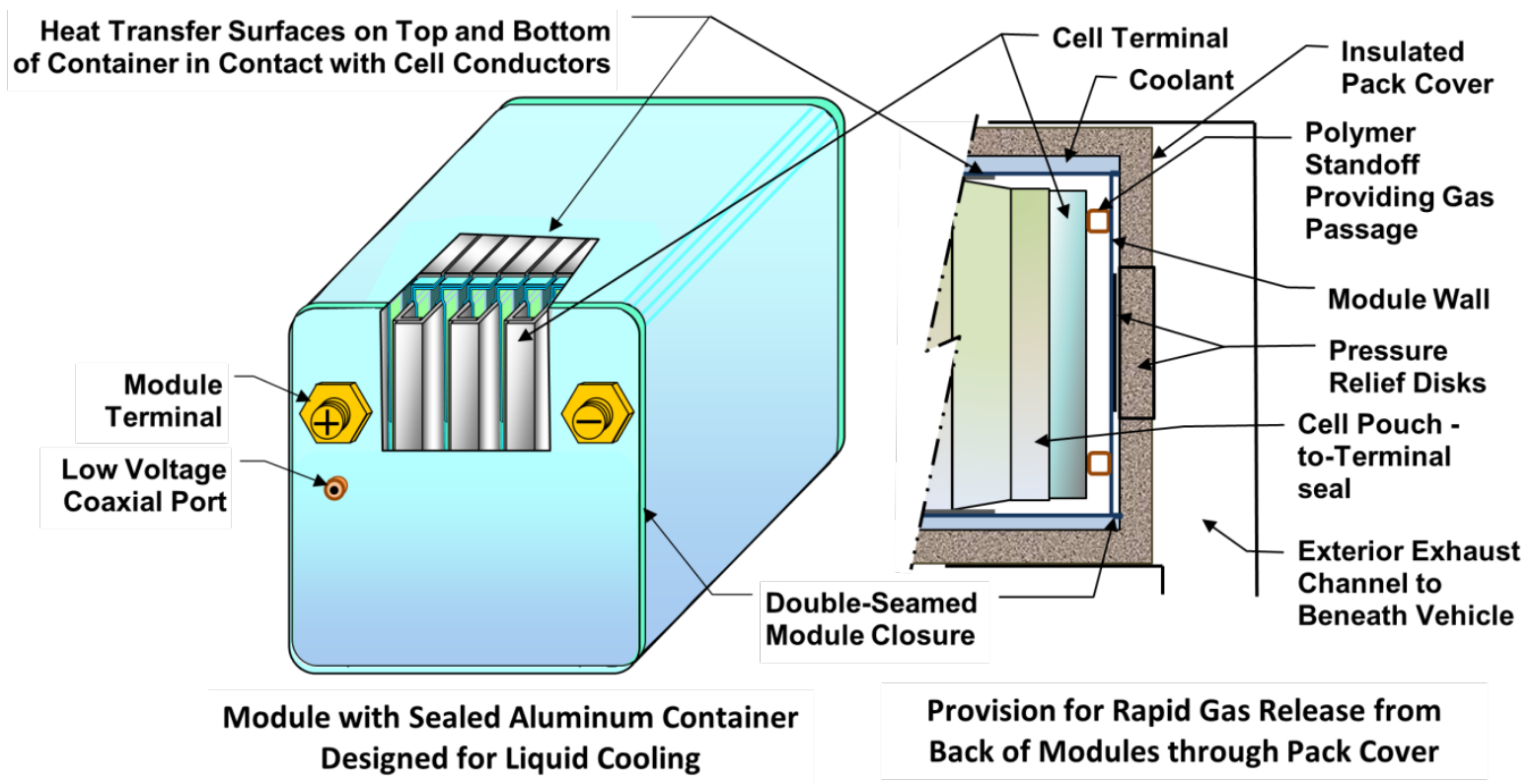

Figure 2.5. Module with hermetically sealed aluminum container for batteries utilizing a liquid thermal management system showing gas-release system

\subsubsection{Modules Using Air Thermal Management}

For systems using air as the heat transfer fluid (Fig. 2.6), the top and bottom of the module must be open to allow air to flow between the cells utilizing the air passages provided by the cell sleeves to cool the large flat sides of the cells. 


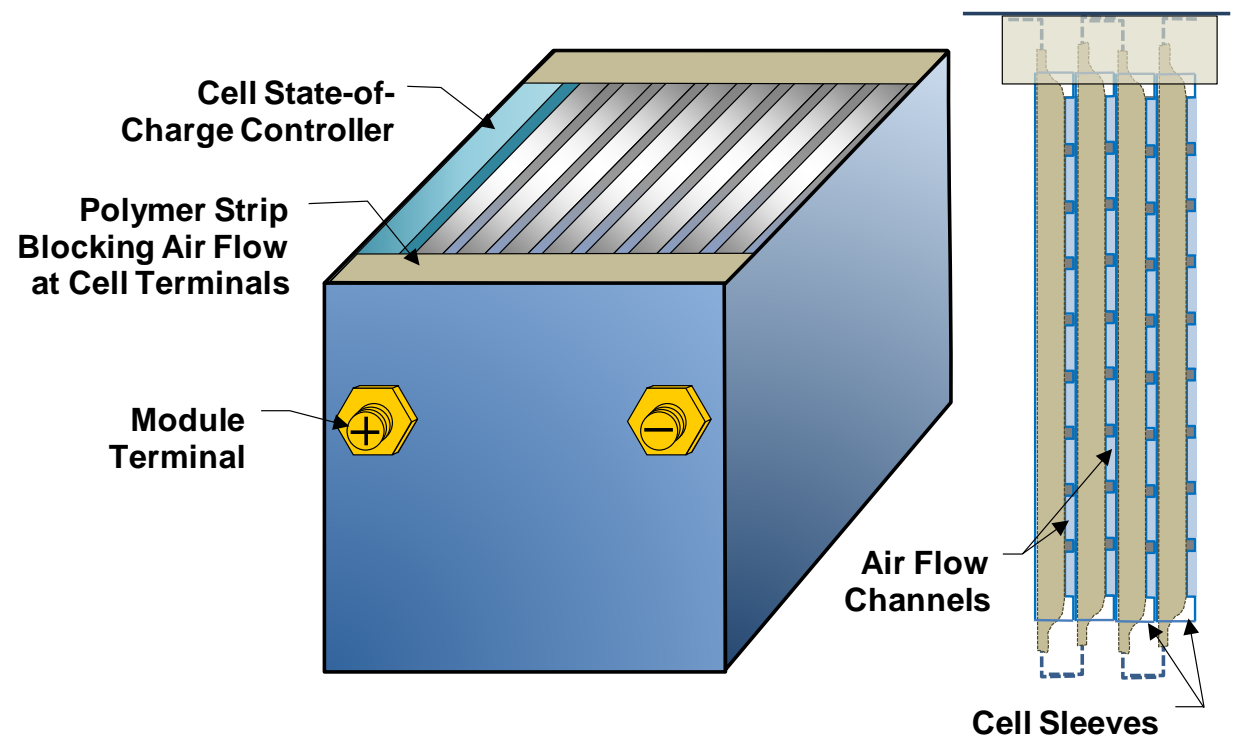

Figure 2.6. Module using air heat transfer fluid with polymer container open at top and bottom

\subsection{Battery Pack Design}

\subsubsection{Batteries Using Liquid Thermal Management}

The model designs the battery pack (Fig 2.7) in sufficient detail to provide a good estimate of the total weight and volume of the pack and the dimensions of the battery jacket so that its cost can be estimated. The modules are arranged within the battery jacket either in a single row, with the terminals facing the same side of the pack, or in an even number of rows with the terminals in one row facing the terminals of an adjacent row. For a pack with a single row of modules, a busbar must be provided to carry the current to the front of the battery pack. This feature results in an additional cost for the busbar. For batteries with more than one row of modules (Fig. 2.7), the terminals are laid out in the module so as not to interfere with those on the opposite row of modules, thus conserving space in the battery pack. The modules in a row are interconnected, negative to positive terminals, by copper connectors. The modules casings are compressed together between steel sheets at each end of the battery pack. A compression force is applied by steel bands wrapped around the top and bottom of the row of modules. The compression is necessary to ensure intimate contact between the active layers that make up the pouch cells that are tightly fit into the modules. The compressive force also serves to add structural support to the module casings.

The modules are supported by a tray that positions the modules mid-way between the inside top and bottom of the pack jacket and provides space for heat transfer fluid to flow so that it cools or heats the top and bottom of each module. The rows of modules are assembled, compressed between end plates, interconnected and attached to the module tray. The module tray is attached to the pack closure at the front of the pack so that all connections to the pack terminals that lead to the exterior of the pack and signal wire feedthroughs can be made before inserting the attached modules into the jacket and making the final closure. The bolts depicted in the diagram (Fig 2.7) for making this closure are only illustrative. 
The battery jacket consists of a sheet of aluminum on each side of a 10-mm thick layer of ridged, light-weight high-efficiency insulation. The thickness of each of the aluminum layers is selected by the modeling program to be 1- to 2-mm thick, depending on the total volume of the modules. The insulation slows the interaction of the battery with the external environment that cools the battery in winter and heats it in hot summer weather [13].

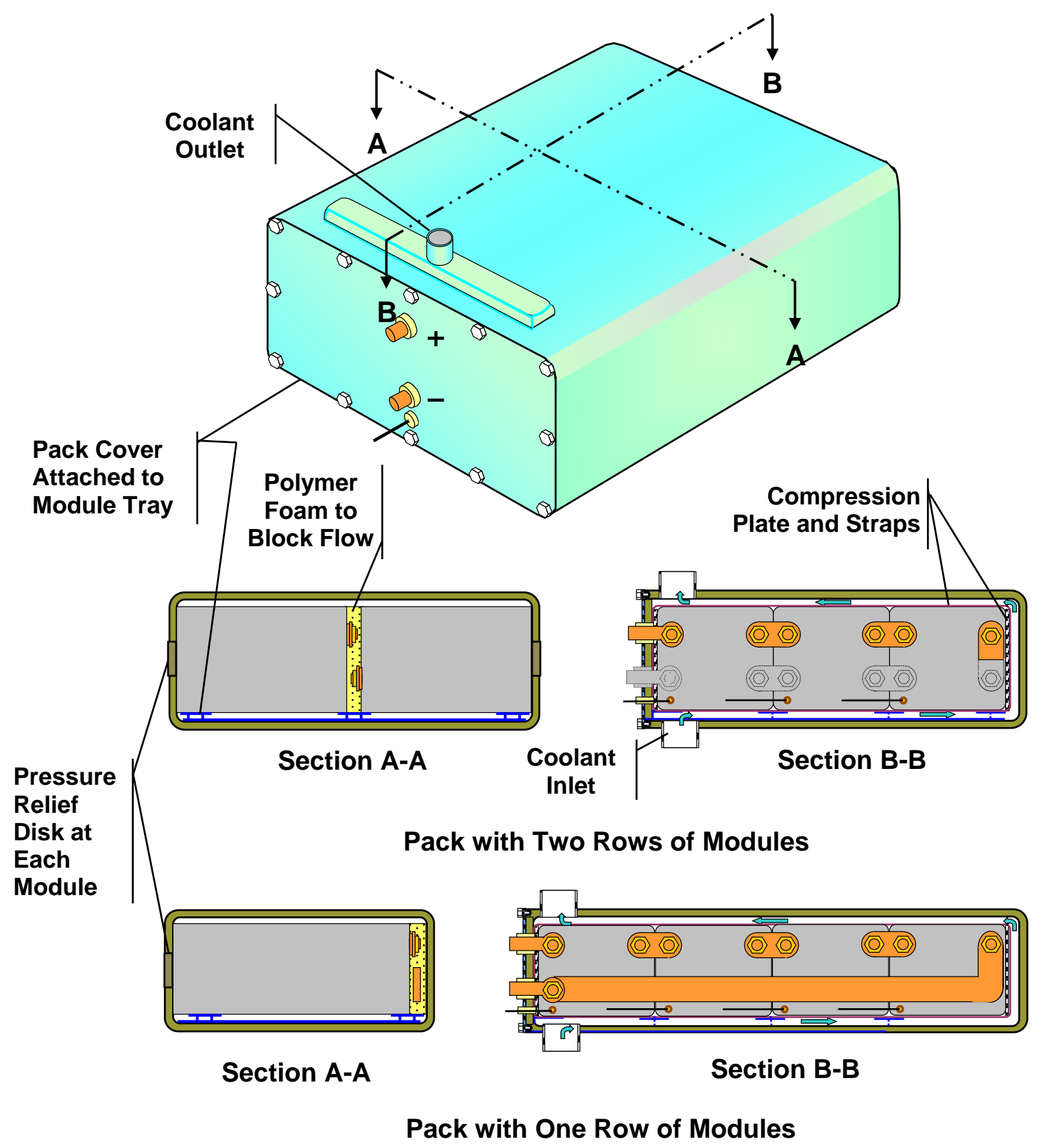

Figure 2.7. Insulated battery jacket with enclosed modules that are exposed on their upper and lower surfaces to an ethylene glycol-water heat transfer fluid. 
Although the main purpose of the battery pack design for the model is to provide a plausible list of materials to estimate the manufacturing cost of the battery, the overall design approach permits the battery to be shaped by the designer to fit dimensional objectives. If there is a height restriction for the battery pack, a high ratio of length-to-width for the positive electrode will result in a battery of low height. Because the cell terminals are nearly as wide as the electrodes in the cell design selected for this model, the current collector structure adds very little to the total cell impedance for electrodes with length-to-width ratios as high of 3.0, the default value used in the model. Even higher ratios are feasible. If the cell terminals were both brought out of the same end of the cell and, therefore had to be narrow, the resistance of the terminals and of the current collector foil in the vicinity of the terminals would be high, especially for long, narrow cells. Further discussion of the means of adjusting the shapes of the modules and the pack is provided in section 3.3.3.

\subsubsection{Batteries Using Air Thermal Management}

The air thermal management battery format is similar to the liquid thermal management format in that the cells are the same and the modules casings are held together by steel sheets at the ends of the row of modules and compressed by steel straps. The battery pack for air thermal management differs, however, in that much more space must be allotted for air flow than for liquid flow (Fig. 2.8).

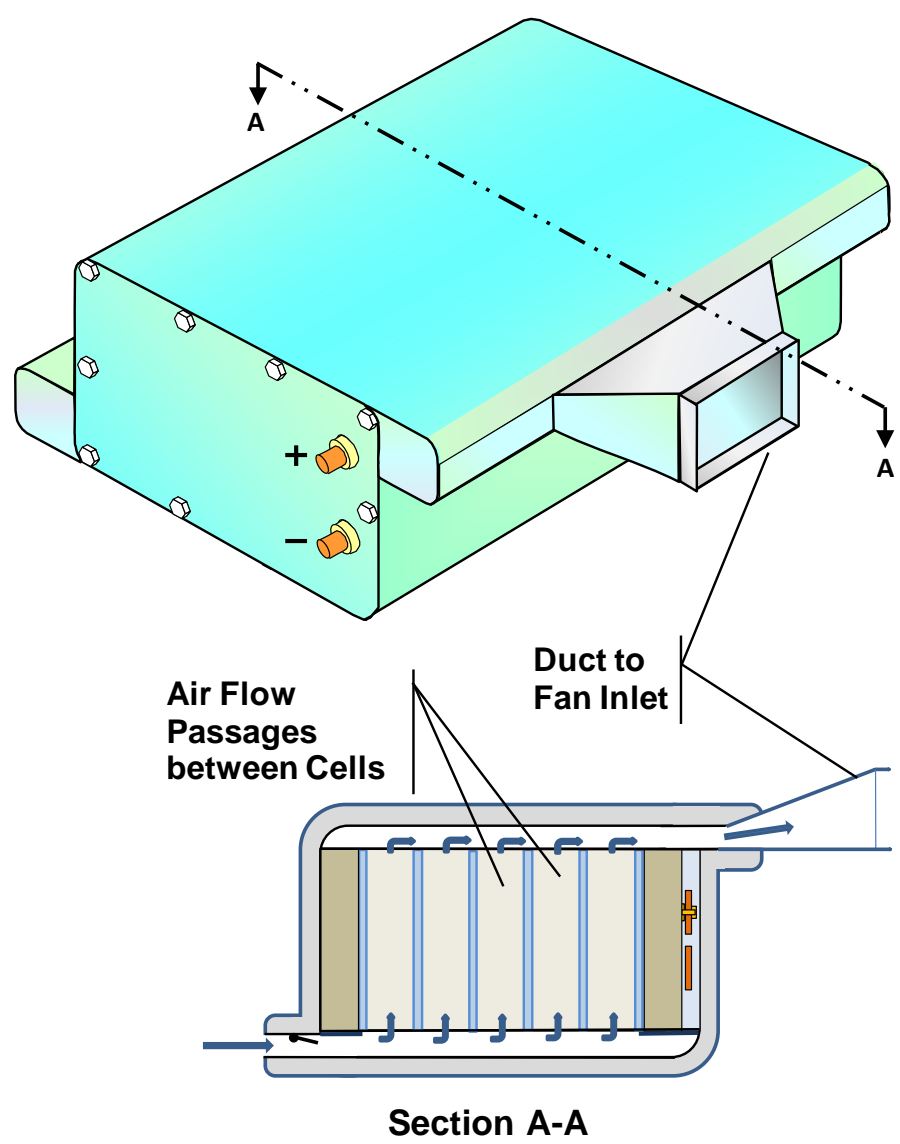

Figure 2.8 Battery pack utilizing air thermal management approach. 
Air is admitted along the entire length of the bottom of the pack to minimize the thickness of the flow passages above and beneath the modules. The air leaving the module is directed to the inlet side of the fan, which can be located nearby to suit the vehicle design. The pack-long entrance and exit passages are insulated for thermal efficiency. These additions and the air passages between the cells and the thick passages required above and below the modules add considerable volume to air thermal management packs over that required by liquid thermal management packs. The thermal calculations described in section 6 indicate that cabin air-cooling is sufficient for HEV battery packs and for some larger battery packs, but it may limit the driving profiles that are feasible.

\subsubsection{Venting Gas Buildup}

Progress is being made in developing lithium-ion cell chemistries that reduce the likelihood of high temperature excursions caused by runaway reactions resulting in rapid gas build-up. Nevertheless, lithium-ion batteries are being designed to minimize the injury to vehicle passengers and the damage to the vehicle in the unlikely event of rapid release of gases.

The BatPaC model estimates the cost of lithium batteries that will be the most successful in meeting battery cost targets that are compatible with electric-drive vehicles capturing a large fraction (>30\%) of the vehicle market. Thus, it is assumed that the release of gases from rapid oxidation reactions within the batteries will be rare events and that provision for such occurrences will be inexpensive. We do not attempt to design batteries that will solve the problem of pressure build-up, but we merely suggest design strategies that show promise of meeting this challenge at low cost and assume that battery manufacturers will achieve this goal at about the same cost.

In the event of excessive pressure, gas will be released from the BatPaC cells by the unsealing of the cell pouch at the terminal seal at the back end of the module (Fig. 2.5). A gas passage is provided beyond the end of the cell terminals. This passage permits gas to be released through pressure relief disks on the module wall and the thermally insulated pack housing (Fig. 2.5). The gas is released to a channel that is less than $30 \mathrm{~mm}$ from the escape point at the cell, and which directs the rapid release down to the street directly beneath the battery, which is presumed to be located on the floor of the vehicle such as under the rear seat.

This method of providing for gas release adds little to the volume of the battery, only the space that is occupied by the gas passage between the cell terminals and the back of the module (approximately $6 \mathrm{~mm}$ ) for packs with one or two rows of modules. However, a flow passage leading down to the street of 20-mm width must be provided outside of the battery pack next to the back of the modules and for large batteries with four rows of modules a similar passage must be provided down the center of the pack. The cost of providing for the sudden release of gas is expected to be small if the proposed mechanism or a similar simple approach is shown to be satisfactory.

To allow for gas venting by the means described above, additional volume is added to the pack, which increases the cost of the pack jacket and $\$ 3.00$ per module is added to the cost of the pack for the additional features. 


\section{DESCRIPTION OF THE SPREADSHEET MODEL AND INSTRUCTIONS FOR USE}

\subsection{Background and General Instructions}

The model is based on the use of Microsoft ${ }^{\circledR}$ Office Excel spreadsheets. The flexibility afforded by a spreadsheet approach has been extremely useful to the development of the calculations. From its inception, the model had been in a constant state of development. Changes to parameters and equations have been made rapidly and frequently. Advances will continue to be made with the model, and will be reported in future updates.

The following subsections are a brief explanation of how one may operate the spreadsheet-based model. The user is advised to save the original document separately as a back-up copy. Corruption of the calculations is possible and will likely occur during use by someone unfamiliar with the model.

This Microsoft ${ }^{\circledR}$ Office Excel workbook requires the use of iteration. The iterative function may be enabled by going to File > Options > Formulas. Check the box next to "Iteration" and change the maximum number of iterations to 1000 (Fig. 3.1). (The latter change is less important for this version than in the past because the calculations almost always come to the final answer in well under the default Excel value of 100 iterations.) If the iteration setting is not turned on, the software will present an error complaining about circular references. If the model is opened while a different Excel spreadsheet is in use, the software may also warn of an error. Simply close all Excel windows except for the model; alternatively, one could re-enable the iterative function as discussed above. 


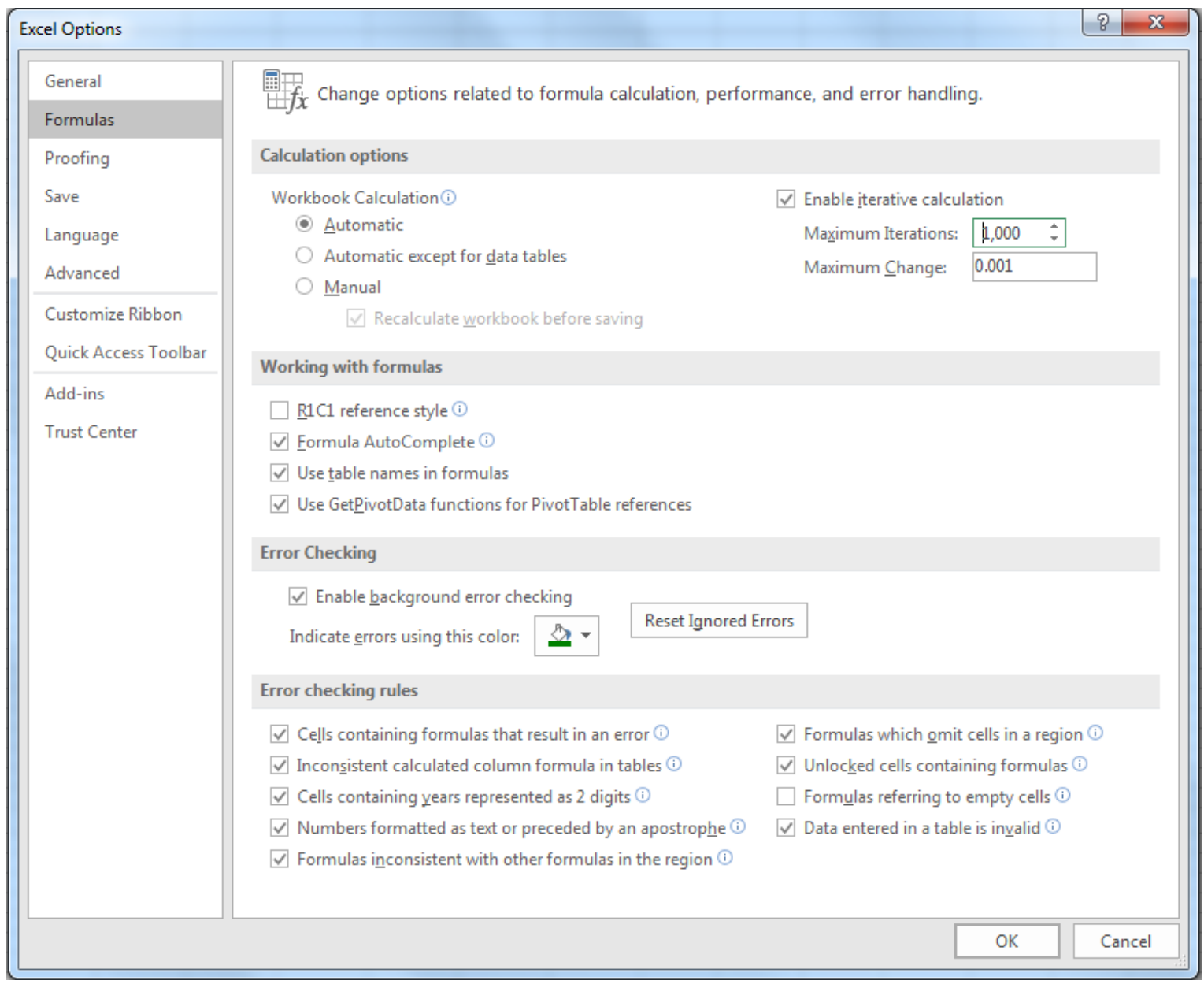

Figure 3.1 Automatic iteration must be enabled for the spreadsheet model to function.

\subsection{Chem Worksheet}

The cell chemistry is selected in the Chem worksheet (Fig. 3.2) by copying the system designated at the top of a column, for instance NMC622-G in cell G4 or NMC333/x\% LMO-G in cell L4, and pasting it into cell E4. The default cell chemistry values listed in the column under the desired system are automatically also listed in column $\mathrm{E}$ and these are the selected system values used for the balance of the calculations in BatPaC. If the selected system has the mixed positive electrode NMC333/x\% LMO, the fraction of LMO in the electrode (x \%) must also be designated. BatPaC will then automatically calculate specific capacity, voltages, specific particle area, ASI values and material cost for this mixed system that are needed for the subsequent calculations and list them in column $\mathrm{L}$ (and column $\mathrm{E}$ if the mixed system is chosen). 


\begin{tabular}{|c|c|c|c|c|c|c|c|c|c|c|c|c|c|c|}
\hline$\Delta$ & A & B & c & D & $\mathrm{E}$ & $\mathrm{F}$ & G & H & 1 & J & K & L & M & N \\
\hline 1 & \multicolumn{12}{|c|}{ Cell Chemistry } & & \multirow[b]{3}{*}{ Override } \\
\hline 2 & & & & & \multicolumn{4}{|l|}{ Selected System } & \multicolumn{4}{|c|}{ Default Values } & & \\
\hline 3 & & & & & & & & & & & & $75 \%$ & & \\
\hline 4 & & & & & NMC622-G & NCA-G & NMC622-G & NMC333-G & LFP-G & LMO-LTO & LMO-G & NMC/x\%LMO-G & Other & Values \\
\hline 5 & \multicolumn{3}{|c|}{ Positive Electrode } & & & & & & & & & & & \\
\hline 6 & \multirow{2}{*}{\multicolumn{3}{|c|}{$\begin{array}{l}\text { Active material molecular weight } \\
\text { Active material capacity, } \mathrm{mAh} / \mathrm{g} \text { : }\end{array}$}} & & 94.38 & 96.08 & 94.38 & 93.93 & 157.77 & 187.74 & 187.74 & 164.3 & & \\
\hline 7 & & & & & 180.00 & 200 & 180 & 155 & 150 & 108 & 100 & 113.8 & & \\
\hline 8 & \multicolumn{3}{|l|}{ Weight \% } & & & & & & & & & & & \\
\hline 9 & \multicolumn{2}{|c|}{ Active material } & & & 89 & 89 & 89 & 89 & 89 & 89 & 89 & 89 & & \\
\hline 10 & Carbon & & & & 6 & 6 & 6 & 6 & 6 & 6 & 6 & 6 & & \\
\hline 11 & Binder & & & & 5 & 5 & 5 & 5 & 5 & 5 & 5 & 5 & & \\
\hline 12 & \multicolumn{2}{|l|}{ Binder solvent } & & & NMP & NMP & NMP & NMP & NMP & NMP & NMP & NMP & & \\
\hline 13 & \multirow{2}{*}{\multicolumn{2}{|c|}{$\frac{\text { Void. Vol\% \% }}{\text { Density. } \mathrm{g} / \mathrm{cm}^{3}}$}} & & & 32 & 32 & 32 & 32 & 50 & 32 & 32 & 32 & & \\
\hline 14 & & & & & & & & & & & & & & \\
\hline 15 & \multicolumn{2}{|c|}{$\frac{\text { Density. } \mathrm{g} / \mathrm{cm}}{\text { Active material }}$} & & & 4.65 & 4.78 & 4.65 & 4.65 & 3.45 & 4.23 & 4.23 & 4.34 & & \\
\hline 16 & Carbon & & & & 1.825 & 1.825 & 1.825 & 1.825 & 1.825 & 1.825 & 1.825 & 1.825 & & \\
\hline 17 & Binder & & & & 1.77 & 1.77 & 1.77 & 1.77 & 1.77 & 1.77 & 1.77 & 1.77 & & \\
\hline 18 & \multicolumn{3}{|c|}{ Maximum thickness limit, $\mu \mathrm{m}$} & & 200 & & & & & & & & & \\
\hline 19 & \multirow{2}{*}{\multicolumn{3}{|c|}{ Minimum thickness limit, $\mu \mathrm{m}$}} & & 15 & & & & & & & & & \\
\hline 20 & & & Negative Electrode & & & & & & & & & & & \\
\hline 21 & \multirow{2}{*}{\multicolumn{3}{|c|}{$\begin{array}{l}\text { N/P capacity ratio after formation } \\
\text { Active material capacity, } \mathrm{mAh} / \mathrm{g} \text {. }\end{array}$}} & & 1.25 & 1.25 & 1.25 & 1.25 & 1.2 & 1.10 & 1.2 & 1.2 & & \\
\hline 22 & & & & & 360 & 360 & 360 & 360 & 360 & 170 & 360 & 360 & & \\
\hline 23 & \multicolumn{3}{|c|}{ Weight \% } & & & & & & & & & & & \\
\hline 24 & \multicolumn{3}{|l|}{ Active material } & & 95 & 95 & 95 & 95 & 95 & 89 & 95 & 95 & & \\
\hline 25 & Carbon & & & & 0 & 0 & 0 & 0 & 0 & 6 & 0 & 0 & & \\
\hline 26 & Binder & & & & 5 & 5 & 5 & 5 & 5 & 5 & 5 & 5 & & \\
\hline 27 & \multicolumn{2}{|l|}{ Binder solvent } & & & Water & Water & Water & Water & Water & Water & Water & Water & & \\
\hline 28 & \multicolumn{2}{|l|}{ Void. Vol\% \% } & & & 34 & 34 & 34 & 34 & 34 & 40 & 34 & 34 & & \\
\hline 29 & \multicolumn{2}{|c|}{ Density. $\mathrm{g} / \mathrm{cm}^{3}$} & & & & & & & & & & & & \\
\hline 30 & Active materi & & & & 2.24 & 2.24 & 2.24 & 2.24 & 2.24 & 3.40 & 2.24 & 2.24 & & \\
\hline 31 & Carbon & & & & 1.95 & 1.95 & 1.95 & 1.95 & 1.95 & 1.95 & 1.95 & 1.95 & & \\
\hline 32 & Binder & & & & 1.1 & 1.10 & 1.10 & 1.10 & 1.10 & 1.10 & 1.10 & 1.10 & & \\
\hline 33 & Positive Fo & & & & & & & & & & & & & \\
\hline 34 & Material & & & & Aluminum & Aluminum & Aluminum & Aluminum & Aluminum & Aluminum & Aluminum & Aluminum & & \\
\hline 35 & Thickness, $\mu \mathrm{r}$ & & & & 15 & 15 & 15 & 15 & 15 & 15 & 15 & 15 & & \\
\hline 36 & Negative $F$ & & & & & & & & & & & & & \\
\hline 37 & Material & & & & Copper & Copper & Copper & Copper & Copper & Aluminum & Copper & Copper & & \\
\hline 38 & Thickness, $\mu \mathrm{r}$ & & & & 10 & 10 & 10 & 10 & 10 & 15 & 10 & 10 & & \\
\hline 39 & Separator & & & & & & & & & & & & & \\
\hline 40 & Thickness, $\mu r$ & & & & 15 & 15 & 15 & 15 & 15 & 15 & 15 & 15 & & \\
\hline 41 & Void, Vol\% \% & & & & 50 & 50 & 50 & 50 & 50 & 50 & 50 & 50 & & \\
\hline 42 & Density, $\mathrm{g} / \mathrm{cm}$ & & & & 0.46 & 0.46 & 0.46 & 0.46 & 0.46 & 0.46 & 0.46 & 0.46 & & \\
\hline 43 & Electrolyte & densi & $/ \mathrm{cm}^{3}$ & & 1.2 & 1.20 & 1.20 & 1.20 & 1.20 & 1.20 & 1.20 & 1.20 & & \\
\hline
\end{tabular}

Figure 3.2 The specific cell chemistry for the battery design is selected on the Chem worksheet.

Any of the values in column E can be overridden by entering the desired value in column N. For example, the N/P capacity ratio may be overridden by placing a new value in cell N21. The selection of the cell chemistry also includes the associated prices as shown on the lower portion of the Chem worksheet Fig. 3.3. These prices can also be overridden by entering the desired values in column $\mathrm{N}$ and the scale factors can be overridden by entering values in column "O." 


\begin{tabular}{|c|c|c|c|c|c|c|c|c|c|c|c|c|c|c|c|}
\hline 4 & A & $\mathrm{B}$ & c & $\mathrm{D}$ & $E$ & $\mathrm{~F}$ & G & $\mathrm{H}$ & 1 & J & K & L & M & N & 0 \\
\hline 1 & \multicolumn{12}{|c|}{ Cell Chemistry } & & \multirow[b]{3}{*}{ Override } & \\
\hline 2 & & & & & Selected Systen & & & & Default V & Values & & & & & \\
\hline 3 & & & & & & & & & & & & $75 \%$ & & & \\
\hline 4 & & & & & NMC622-G & NCA-G & NMC622-G & NMC333-G & LFP-G & LMO-LTO & LMO-G & NMC/X\%LMO-G & Other & Values & \\
\hline 44 & \multicolumn{4}{|c|}{ Cell Voltage and Resistance Parameters } & & & & & & & & & & & \\
\hline 45 & \multirow{2}{*}{\multicolumn{4}{|c|}{$\begin{array}{l}\text { Open circuit voltage at } 20 \% \mathrm{SOC}, \mathrm{V} \\
\text { Open circuit voltage at } 50 \% \mathrm{SOC}, \mathrm{V}\end{array}$}} & 3.565 & 3.551 & 3.565 & 3.516 & 3.246 & 2.408 & 3.826 & 3.637 & & & \\
\hline 46 & & & & & 3.750 & 3.680 & 3.750 & 3.671 & 3.282 & 2.514 & 3.954 & 3.891 & & & \\
\hline 47 & \multicolumn{4}{|c|}{ Open circuit voltage at $80 \%$ SOC (mid SOC-HP), } & 4.000 & 3.836 & 4.000 & 3.900 & 3.500 & 2.593 & 4.020 & 3.995 & & & \\
\hline 48 & \multirow{2}{*}{\multicolumn{4}{|c|}{$\begin{array}{l}\text { Open circuit voltage at } 100 \% \text { SOC, V } \\
\text { Solid state diffusion limiting C-rate }(10-s) \text {, AlAh }\end{array}$}} & 4.200 & 4.100 & 4.200 & 4.100 & 3.800 & 2.660 & 4.100 & 4.100 & & & \\
\hline 49 & & & & & 120 & 120 & 120 & 120 & 120 & 200 & 120 & 120 & & & \\
\hline 50 & \multicolumn{4}{|c|}{$i_{\mathrm{g}} \mathrm{FiRT}$ estimate, $1\left(\right.$ ohm- $\left.\mathrm{cm}^{2}\right)$} & 0.00917 & & & & & & & & & & \\
\hline 51 & \multirow{2}{*}{\multicolumn{4}{|c|}{ Negative electrode specific area $" \mathrm{a} ", \mathrm{~cm}^{2} / \mathrm{cm}^{3}$}} & 100,000 & 100,000 & 100,000 & 100,000 & 100,000 & 500,000 & 120,000 & 120,000 & & & \\
\hline 52 & & & & & 10,000 & 10,000 & 10,000 & 10,000 & 420,000 & 50,000 & 50,000 & 40,000 & & & \\
\hline 53 & \multicolumn{4}{|c|}{$\begin{array}{l}\text { Positive electrode specific area "a", } \mathrm{cm}^{2} / \mathrm{lm}^{3} \\
\text { ASl associated with interfacial effects, ohm- } \mathrm{cm}^{2}\end{array}$} & 3 & 3 & 3 & 3 & 1.5 & 1.5 & 2 & 2.25 & & & \\
\hline 54 & \multicolumn{4}{|c|}{ Ratio of electrode thickness to penetration,y } & 0.4 & & & & & & & & & & \\
\hline 55 & \multirow{2}{*}{\multicolumn{4}{|c|}{ Dofil (1-t+t), Alom }} & 0.236 & & & & & & & & & & \\
\hline 56 & \multicolumn{2}{|c|}{ Electrode system ASI for power, ohm-cm ${ }^{2}$} & & & & & & & & & & & & & \\
\hline 57 & \multicolumn{4}{|c|}{ Selected ASI value } & 14.3 & & & & & & & & & & \\
\hline 58 & \multirow{2}{*}{\multicolumn{4}{|c|}{$\begin{array}{l}\text { At } 50 \% \text { SOC, } 2 \text {-sec burst } \\
\text { At } 50 \% \text { SDC, } 10-\text {-sec burst }\end{array}$}} & 12.0 & 12 & 12 & 12 & 20 & 6 & 10 & 10.5 & & & \\
\hline 59 & & & & & 13.0 & 13 & 13 & 13 & 25 & 8 & 12 & 12.25 & & & \\
\hline 60 & At 20 ; & DC range, & -sec burst & & 14.3 & 14.3 & 14.3 & 14.3 & 27.5 & 8.8 & 13.2 & 13.475 & & & \\
\hline 61 & At 20 : & DC range, & 1-sec burst & & 15.0 & 14.95 & 14.95 & 14.95 & 28.75 & 9.2 & 13.8 & 14.0875 & & & \\
\hline 62 & Maximun & low able AS & or limiting c: & & 21.5 & & & & & & & & & & \\
\hline 63 & Electrod & Istem ASI f & energy, ohr & & 16.9 & 16.9 & 16.9 & 16.9 & 32.5 & 10.4 & 15.6 & 15.9 & & & \\
\hline 64 & Maximun & harging our & nt density, I & $\mathrm{cm}^{2}$ & 9.0 & 9 & 9 & 9 & 9 & 18 & 15 & 13.5 & & & \\
\hline 65 & Availab & battery er & ergy, \% of & & & & & & & & & & & & \\
\hline 66 & Select & \% energy & & & 85 & & & & & & & & & & \\
\hline 67 & HEV- & & & & 60 & 60 & 60 & 60 & 60 & 60 & 60 & 60 & & & \\
\hline 68 & PHEV & & & & 70 & 70 & 70 & 70 & 70 & 75 & 70 & 70 & & & \\
\hline 69 & EV & & & & 85 & 85 & 85 & 85 & 85 & 90 & 85 & 85 & & & \\
\hline 70 & Lithium & ontent & & & & & & & & & & & & & \\
\hline 71 & Positive & otrode, $g \mathrm{Li}$ & active mat & & 0.0735 & 0.0722 & 0.0735 & 0.0739 & 0.0440 & 0.0370 & 0.0370 & 0.0422 & & & \\
\hline 72 & Negative & ctrode, gl & gactive ma & & 0.0000 & 0.0000 & 0.0000 & 0.0000 & 0.0000 & 0.0604 & 0.0000 & 0.0000 & & & \\
\hline 73 & Electroly & 1.2MLiPFG & gLilL elect & & 8.3280 & 8.3280 & 8.3280 & 8.3280 & 8.3280 & 8.3280 & 8.3280 & 8.3280 & & & \\
\hline 74 & Transit & Metal Cc & tent & & & & & & & & & & & & \\
\hline 75 & Nickel, g & otive mate & & & 0.3731 & 0.4887 & 0.3731 & 0.2083 & 0.0000 & 0.0000 & 0.0000 & 0.0298 & & & \\
\hline 76 & Cobalt, 9 & active mate & & & 0.1249 & 0.0920 & 0.1249 & 0.2092 & 0.0000 & 0.0000 & 0.0000 & 0.0299 & & & \\
\hline 77 & Mangan & glg active & naterial & & 0.1164 & 0.0000 & 0.1164 & 0.1949 & 0.0000 & 0.5852 & 0.5852 & 0.2786 & & & \\
\hline 78 & & & & & & & & & & & & & & & \\
\hline 79 & Cell Ma & rials $\operatorname{Cos}$ & & & & NCA-G & NMC622-G & NMC333-G & LFP-G & LMO-LTO & LMO-G & NMC/X\%LMO-G & & Override & lalues \\
\hline 80 & Positive & atrode, \$ikg & & & p & & & & & & & & & Cost & $\bar{p}$ \\
\hline 81 & Active & terial & & 1300 & 990: & 24.00 & 17.00 & 20.00 & 14.00 & 10.00 & 10.00 & 12.50 & & & \\
\hline 82 & Carbo & & & 6.50 & $100:$ & 6.60 & 6.60 & 6.60 & 6.60 & 6.60 & 6.60 & 6.60 & & & \\
\hline 83 & Binder & & & 9.50 & $100:$ & 9.50 & 9.50 & 9.50 & 9.50 & 9.50 & 9.50 & 9.50 & & & \\
\hline 84 & Binder & Ivent (NMP & & $3 ; 10$ & 100 & 3.10 & 3.10 & 3.10 & 3.10 & 3.10 & 3.10 & 3.10 & & & \\
\hline 85 & Negative & ectrode ma & rial, \$lkg & & & & & & & & & & & & \\
\hline 86 & Active & terial & & 51250 & $095:$ & 12.50 & 12.50 & 12.50 & 12.50 & 12.00 & 12.50 & 12.50 & & & \\
\hline 87 & Carbo & & & 660 & $100:$ & 6.60 & 6.60 & 6.60 & 6.60 & 6.60 & 6.60 & 6.60 & & & \\
\hline 88 & Binder & & & 1000 & $100:$ & 10.00 & 10.00 & 10.00 & 10.00 & 10.00 & 10.00 & 10.00 & & & \\
\hline 89 & Binder & went & & 000 & $100:$ & 0.00 & 0.00 & 0.00 & 0.00 & 0.00 & 0.00 & 0.00 & & & \\
\hline 90 & Positive & rent colleat & foil, $1 \mathrm{~m}^{2}$ & 030 & 100 & 0.30 & 0.30 & 0.30 & 0.30 & 0.30 & 0.30 & 0.30 & & & \\
\hline 91 & Negative & Irrent collec & or foil, \$ $\mathrm{m}^{2}$ & 120 & 100 & 1.20 & 1.20 & 1.20 & 1.20 & 0.30 & 1.20 & 1.20 & & & \\
\hline 92 & Separat & $\$ m^{2}$ & & ij & $100:$ & 1.10 & 1.10 & 1.10 & 1.10 & 1.10 & 1.10 & 1.10 & & & \\
\hline 93 & Electroly & & & 1500 & 100 & 15.00 & 15.00 & 15.00 & 15.00 & 15.00 & 15.00 & 15.00 & & & \\
\hline
\end{tabular}

Figure 3.3 Lower portion of Chem worksheet

\subsection{Battery Design Worksheet}

The Battery Design worksheet designs seven or more batteries for any type of electric-drive vehicle (Fig. 3.4-3.8). The calculated designs are specific for the end battery requirements specified by the user. From the result, the amounts of materials and the purchased items required for manufacture are easily available to be used in the manufacturing cost calculations found on subsequent worksheets. A cell and module construction is assumed, but the exact cell format (prismatic, pouch, can, etc.) of the battery does not have a dominant effect on the cost for a set cell chemistry system. Our experience teaches us that the amounts of electrode materials and the number, capacity and electrode area of the cells are the determining cost factors. Nevertheless, a specific design format was selected and is shown on the Cell Design, Module and Battery worksheets (discussed in section 2. Cell and Battery Pack Design Format) to provide a basis for calculating the entire cell and battery related costs. 
The Battery Design worksheet automatically receives input from the Chem worksheet. These values are shown in purple and must not be altered on the Battery Design worksheet. As explained above, cell chemistry values may be adjusted on the Chem worksheet.

\begin{tabular}{|c|c|c|c|c|c|c|c|c|c|c|c|c|}
\hline$\Delta$ & A & $\mathrm{B}$ & $\mathrm{C}$ & $\mathrm{D}$ & $E$ & $\mathrm{~F}$ & $\mathrm{G}$ & $\mathrm{H}$ & 1 & $J$ & K & $\mathrm{L}$ \\
\hline 1 & \multicolumn{12}{|c|}{ Program for Calculating Performance and Materials Requirements } \\
\hline 2 & \multicolumn{12}{|c|}{ Li1.05(Ni0.6Mn0.2Co0.2)0.9502-Graphite } \\
\hline 3 & & & & & & Battery 1 & Battery 2 & Battery 3 & Battery 4 & Battery 5 & Battery 6 & Battery 7 \\
\hline 4 & \multicolumn{3}{|c|}{ Parameters for Finished Cell } & & & & & & & & & \\
\hline 5 & \multicolumn{3}{|c|}{ Positive Electrode, $\mathrm{g}$} & Weight $\%$ & Density & & & & & & & \\
\hline 6 & \multicolumn{2}{|c|}{ Active material } & & 89 & 4.65 & 328.24 & 401.22 & 474.21 & 547.21 & 250.04 & 492.44 & 425.51 \\
\hline 7 & Carbon & & & 6 & 1.825 & 22.13 & 27.05 & 31.97 & 36.89 & 16.86 & 33.20 & 28.69 \\
\hline 8 & Binder & & & 5 & 1.77 & 18.44 & 22.54 & 26.64 & 30.74 & 14.05 & 27.67 & 23.91 \\
\hline 9 & Void & Vol. $\%$ & 32 & & & - & - & - & - & - & - & - \\
\hline 10 & Total & & & 100 & 2.693 & 368.81 & 450.80 & 532.81 & 614.84 & 280.94 & 553.30 & 478.10 \\
\hline 11 & \multicolumn{3}{|c|}{ Negative Electrode, g } & Weight $\%$ & Density & & & & & & & \\
\hline 12 & \multicolumn{2}{|c|}{ Active material } & & 95 & 2.24 & 212.11 & 258.45 & 304.74 & 350.98 & 162.38 & 316.29 & 273.87 \\
\hline 13 & Carbon & & & 0 & 1.95 & - & - & - & - & - & - & - \\
\hline 14 & Binder & & & 5 & 1.10 & 11.16 & 13.60 & 16.04 & 18.47 & 8.55 & 16.65 & 14.41 \\
\hline 15 & Void & Vol. \% & 34 & & & - & - & - & - & - & - & - \\
\hline 16 & Total & & & 100 & 1.406 & 223.28 & 272.06 & 320.78 & 369.45 & 170.92 & 332.94 & 288.28 \\
\hline 17 & \multicolumn{2}{|c|}{ Balance of Cell } & & Thick., $\mu \mathrm{m}$ & Density & & & & & & & \\
\hline 18 & \multicolumn{2}{|c|}{ Positive foil, $\mathrm{m}^{2}$} & Al & 15 & 2.70 & 1.320 & 1.598 & 1.874 & 2.149 & 1.031 & 1.943 & 1.690 \\
\hline 19 & \multicolumn{2}{|c|}{ Negative foil, $\mathrm{m}^{2}$} & $\mathrm{Cu}$ & 10 & 8.92 & 1.386 & 1.672 & 1.956 & 2.239 & 1.087 & 2.027 & 1.767 \\
\hline 20 & \multicolumn{2}{|c|}{ Separator, $\mathrm{m}^{2}$} & & 15 & 0.46 & 2.546 & 3.090 & 3.633 & 4.174 & 1.977 & 3.768 & 3.271 \\
\hline 21 & Electroly & & & & 1.20 & 0.1244 & 0.1517 & 0.1789 & 0.2062 & 0.0952 & 0.1857 & 0.1607 \\
\hline 22 & \multicolumn{3}{|c|}{ Positive terminal assembly, $g$} & & & 9.5 & 10.7 & 11.7 & 12.6 & 8.2 & 11.9 & 11.0 \\
\hline 23 & \multicolumn{3}{|c|}{ Negative terminal assembly,g } & & & 31.5 & 35.2 & 38.6 & 41.7 & 27.1 & 39.4 & 36.4 \\
\hline 24 & \multicolumn{4}{|c|}{ Thickness of cell container aluminum layer, $\mu \mathrm{m}$} & & 100 & 100 & 100 & 100 & 100 & 100 & 100 \\
\hline 25 & \multicolumn{4}{|c|}{ Thickness of cell container (PET-Al-PP), $\mu \mathrm{m}$} & & 150 & 150 & 150 & 150 & 150 & 150 & 150 \\
\hline 26 & \multicolumn{4}{|c|}{ Density of cell container, glcm 3} & & 2.2 & 2.2 & 2.2 & 2.2 & 2.2 & 2.2 & 2.2 \\
\hline 27 & \multicolumn{3}{|c|}{ Cell container (PET-Al-PP), g } & & & 21.9 & 25.5 & 29.1 & 32.7 & 17.8 & 30.0 & 26.7 \\
\hline 28 & Cellmas & & & & & 999 & 1,211 & 1,423 & 1,634 & 772 & 1,476 & 1,282 \\
\hline 29 & Length- & width ratio fo & positive elec & ode & & 3.00 & 3.00 & 3.00 & 3.00 & 3.00 & 3.00 & 3.00 \\
\hline 30 & Default & thicknessta & get, mm & & & 20 & 20 & 20 & 20 & 20 & 20 & 20 \\
\hline 31 & Dverride & Al thicknesst & grget, $\mathrm{mm}$ & & & & & & & & & \\
\hline 32 & Cell thict & $s s, \mathrm{~mm}$ & & & & 19.857 & 19.857 & 19.857 & 19.857 & 20.028 & 19.857 & 19.857 \\
\hline 33 & Thickne & of cell edge $\mathrm{f}$ & om positive el & ctrode to out & de of fold, $\mathrm{mr}$ & 1.0 & 1.0 & 1.0 & 1.0 & 1.0 & 1.0 & 1.0 \\
\hline 34 & Thickne & of terminal m: & terial, mm & & & 1.00 & 1.00 & 1.00 & 1.00 & 1.00 & 1.00 & 1.00 \\
\hline 35 & Top of $p$ & ive electrode & to top of term & nal, mm & & 15 & 15 & 15 & 15 & 15 & 15 & 15 \\
\hline 36 & Cell Ca & city Param & eters & & & & & & & & & \\
\hline 37 & Positive & tive material & apacity, mÂh & & & 180 & 180 & 180 & 180 & 180 & 180 & 180 \\
\hline 38 & Positive & ctrode capa & sity, Ahlom ${ }^{3}$ & & & 0.431 & 0.431 & 0.431 & 0.431 & 0.431 & 0.431 & 0.431 \\
\hline 39 & Negative & tive material & capacity, mA & & & 360 & 360 & 360 & 360 & 360 & 360 & 360 \\
\hline 40 & Negative & ectrode cap & geity, Ahicm ${ }^{3}$ & & & 0.481 & 0.481 & 0.481 & 0.481 & 0.481 & 0.481 & 0.481 \\
\hline 41 & Negative & -positive ca & pacity ratio af & formation & & 1.25 & 1.25 & 1.25 & 1.25 & 1.25 & 1.25 & 1.25 \\
\hline 42 & Cell Vo & ge and $R e$ & istance $\mathrm{Pa}$ & imeters & & & & & & & & \\
\hline 43 & DCV atf & power, $V$ & & & & 3.565 & 3.565 & 3.565 & 3.565 & 3.565 & 3.565 & 3.565 \\
\hline 44 & Open cir & it voltage at 5 & $0 \% \mathrm{SOC}, \mathrm{V}$ & & & 3.750 & 3.750 & 3.750 & 3.750 & 3.750 & 3.750 & 3.750 \\
\hline 45 & Electrod & ystem ASI for & energy, ohm & & & 16.9 & 16.9 & 16.9 & 16.9 & 16.9 & 16.9 & 16.9 \\
\hline 46 & Excess & lative area, $:$ & & & & 3.39 & 3.07 & 2.82 & 2.62 & 3.91 & 2.77 & 2.98 \\
\hline 47 & Cell term & l contact vol & age loss, \% o & cellOCV & & 0.01 & 0.01 & 0.01 & 0.01 & 0.01 & 0.01 & 0.01 \\
\hline 48 & Rate of $\mathrm{t}$ & ninal temper & ture rise at ful & oower, "Clse & & 0.05 & 0.05 & 0.05 & 0.05 & 0.05 & 0.05 & 0.05 \\
\hline 49 & Target: & CV at full pon & & & & 80 & 80 & 80 & 80 & 80 & 80 & 80 \\
\hline 50 & $\% \mathrm{DCV}$ & All power adju & isted for thick & ess limit & & 95.8 & 95.6 & 95.5 & 95.4311 & 93.8 & 93.21545 & 96.3 \\
\hline 51 & Battery & stem ope & n circuit vol & age, $V$ & & 900.0 & 900.0 & 900.0 & 900.0 & 525.0 & 900.0 & 810.0 \\
\hline
\end{tabular}

Figure 3.4 Top portion of Battery Design worksheet.

\subsubsection{Battery Format Input}

The operator provides battery design input in the aqua-colored cells (Figures 3.4-3.8). To the right of the body of the Battery Design worksheet are shown some sample input parameters that are used in illustrating the use of BatPaC in Section 4. Illustrated Results. These values may be used as starting points for a study by the user. 


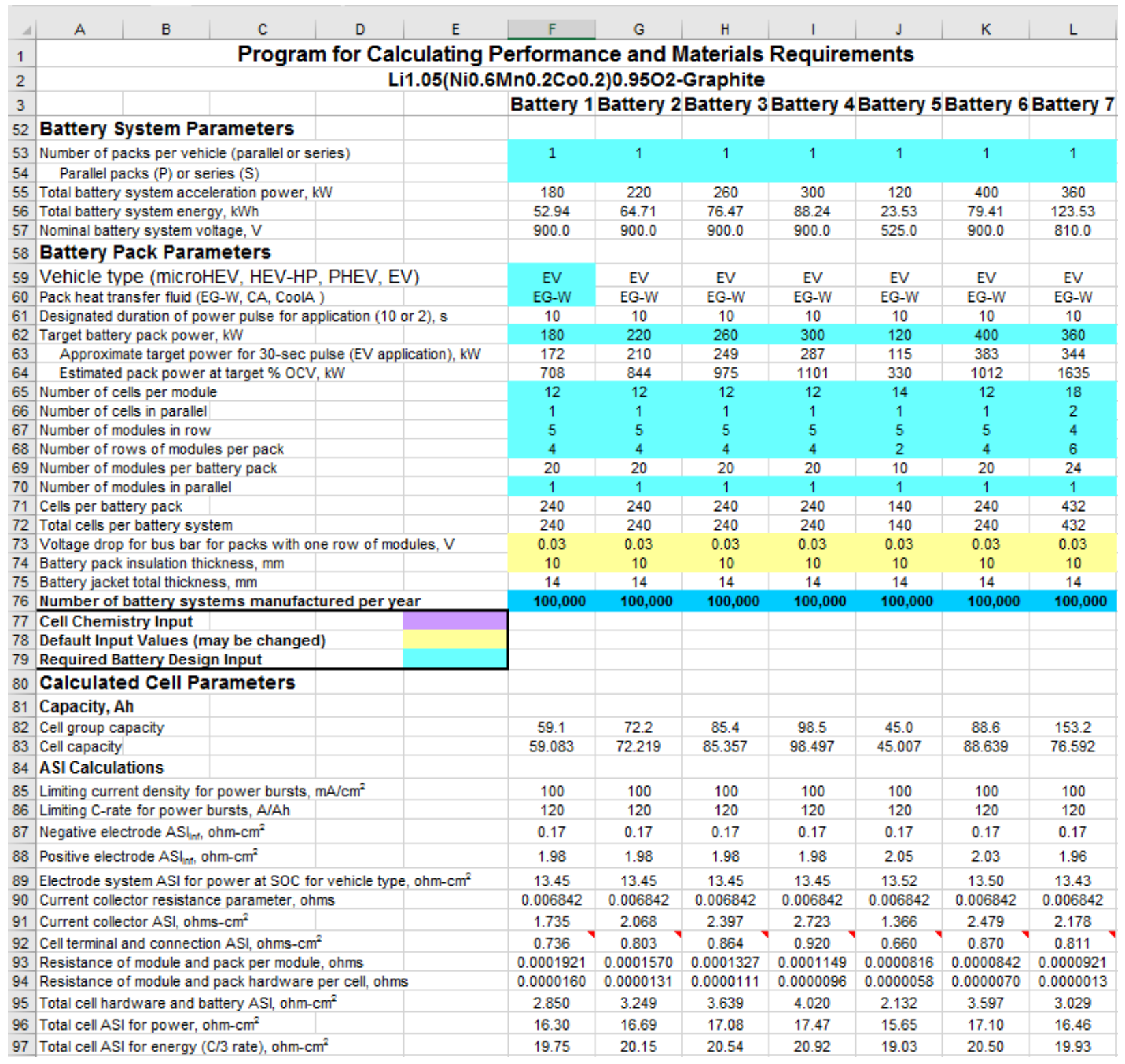

Figure 3.5 Second portion of Battery Design worksheet

The battery input parameters are on aqua-colored cells between lines 59 and 70 (Fig. 3.5) and lines 196 and 202 to 204 (Fig. 3.8); these are the only input values that the operator is required to provide to study a group of batteries. The type of vehicle battery (microHEV, HEV-HP, PHEV, or EV) on line 59 in Figure 3.5, is an important variable to be specified. One performs the selection by typing the name of the vehicle battery type in cell F59. While the correct spelling is important, capitalization is not. This selection automatically determines the state of charge at which full power is designated (thus, the open-circuit voltage and ASI for full power) and the length of the power burst ( 2 seconds for microHEV and 10 seconds for all others). The thermal management approach 
is selected on line 60 (Fig. 3.5). One can select from among three thermal management fluids: liquid (solution of ethylene glycol and water, EG-W), cabin air (CA), or conditioned cabin air (CoolA). The different module and battery designs for air and liquid cooling are displayed in the Cell Design, Module and Battery worksheets.

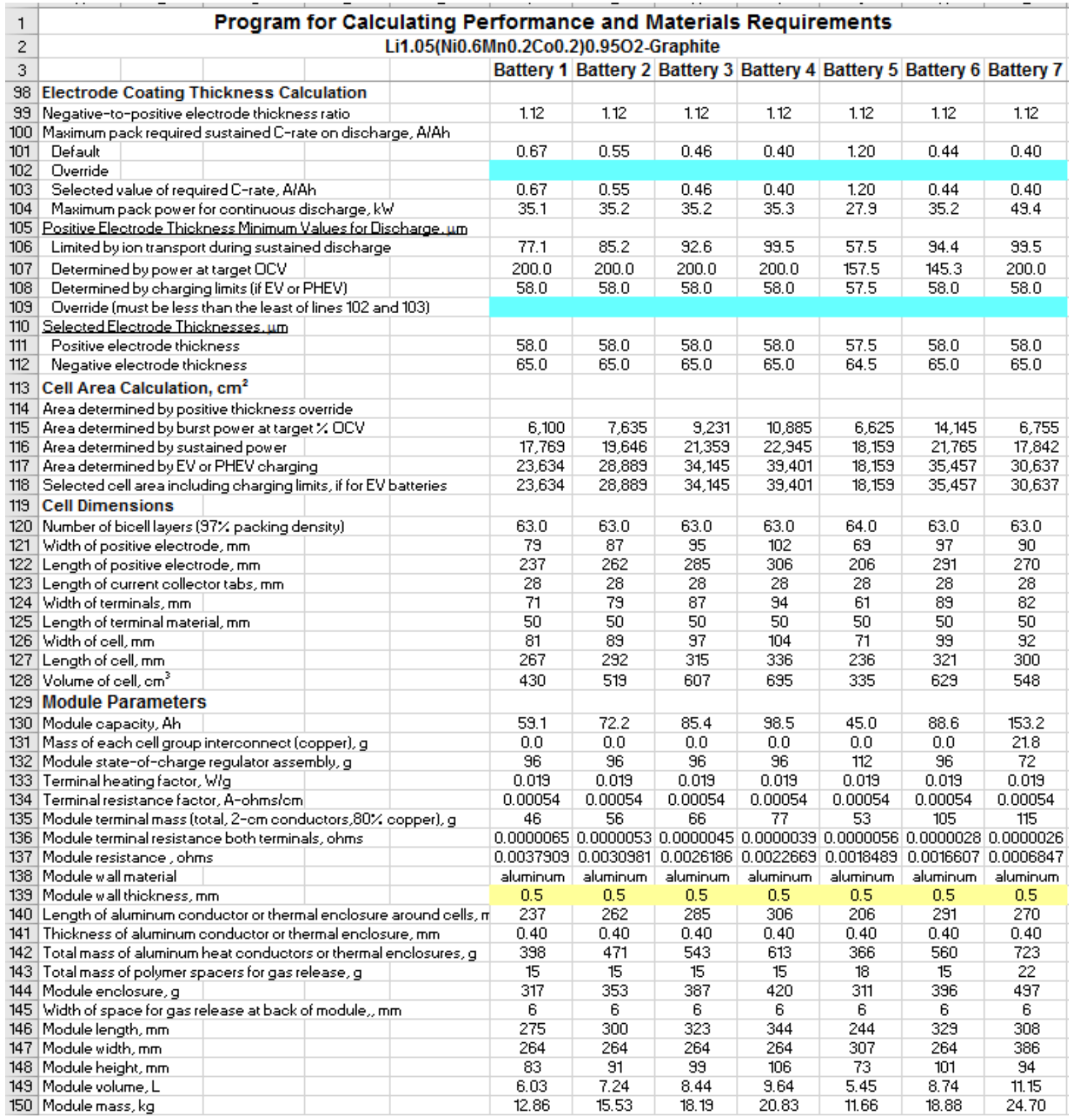

Figure 3.6 Third portion of Battery Design worksheet

The pack capacity (lines 202 to 204 in Fig. 3.8) can be set in any of three ways: (1) directly specifying the capacity (Ah) on line 202, (2) specifying the total battery energy on line 203 or (3) specifying the electric range of the vehicle on line 204. Only one of the three lines should be filled 
in and the others should be blank. The model will follow the directions of the top-most line with non-zero values. It is expected that the majority of the default values on yellow cells should serve well for most batteries; however, the user may change these values to their exact specifications. The number of batteries manufactured per year is selected on line 76 (Fig. 3.5). Changing this value from the default value of 100,000, which is the manufacturing rate for the baseline plant, will change the manufacturing cost, but not the battery design.

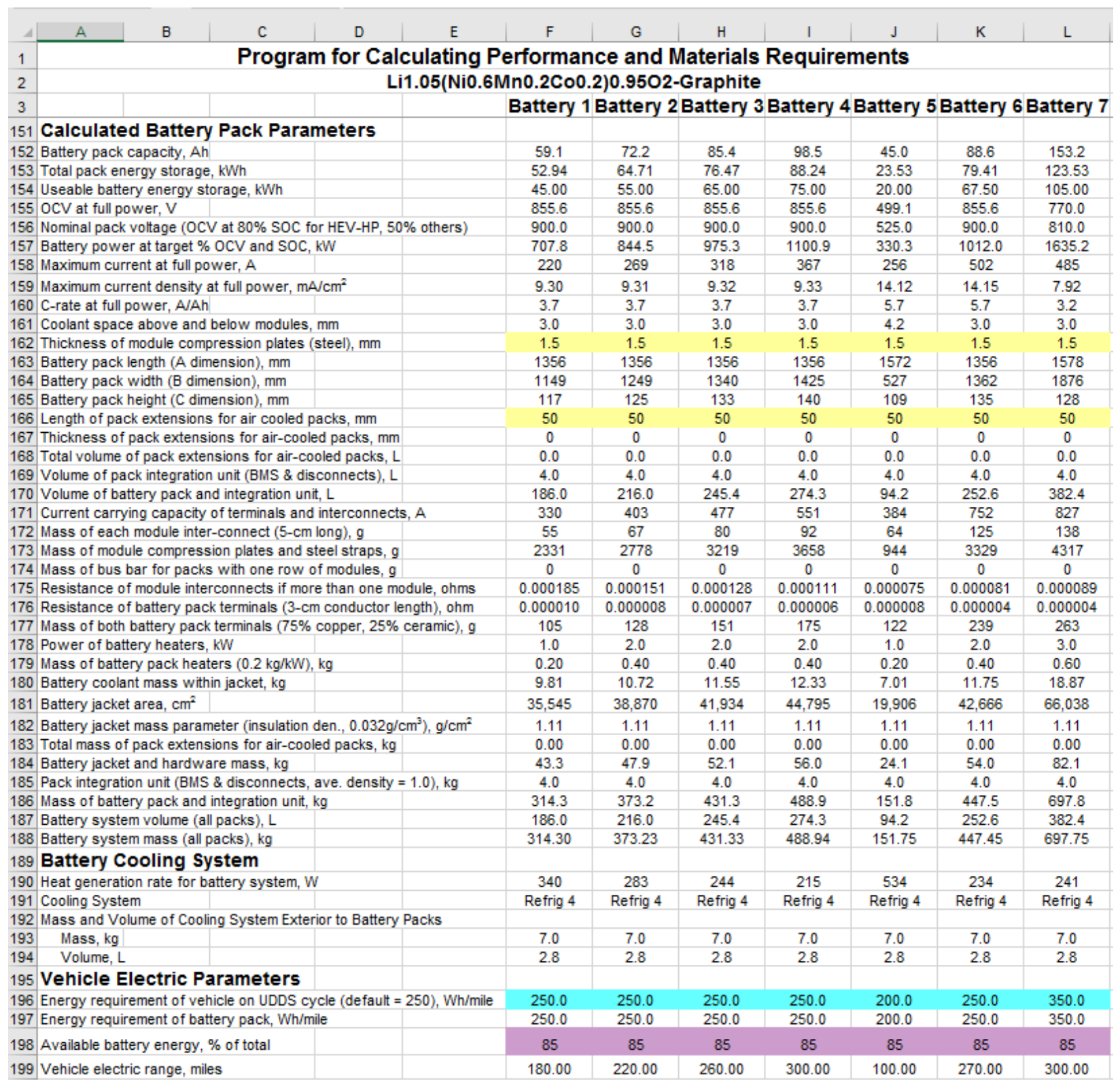

Figure 3.7 Fourth portion of Battery Design worksheet

If it is desired to study more than seven batteries in the same workbook it is only necessary to add additional columns by copying the "Battery 7" column to the right as many times as desired. Care 
should be taken that the appropriate values are maintained when the cells are copied over. The aqua colored cells are typically the source of any problems. The same column additions must also be done for all other worksheets containing calculations.

\subsubsection{Control of the Iteration Procedures and Evaluation of Results}

The calculations on the Battery Design worksheet that require iteration are listed together near the bottom of the Design worksheet in the section headed "Pack Capacity Calculation" starting on line 200 (Fig. 3.8). Preliminary results are listed for the battery system at the bottom of the Battery Design worksheet (Fig. 3.8) to assist the user in adjusting the input values to achieve improved results. More detailed results are shown in the worksheet Summary of Results.

The calculations in BatPaC are complex in that there are many interacting variables whose values must be determined to solve the sets of equations that define the battery performance as described in section 5. Much effort has been required to develop the present method of iteration to arrive at a solution with a moderate number of iterations (typically 20 to 80 ) for a wide variety of input parameters that include all of the types of vehicle batteries.

An example of iterative calculations is demonstrated in how BatPaC determines the capacity of the pack. The user may select one of three factors that determine the pack capacity: (1) the capacity, (2) the pack energy or (3) the vehicle range. If the vehicle range is selected, for instance, the capacity is iterated until the calculated range of the vehicle (line 199) equals the desired range entered on line 204. If any of the input values on the spreadsheet is changed, the iteration process will start. Sometimes this causes an error message to appear in a large fraction of cells in the column where the change was made. That situation requires that the calculation process must be reset by entering a value of "0" (zero) in cell F215, which will enter a starting value in about 15 cells in each column and the error messages will disappear. Immediately after, a value of " 1 ” should be entered in cell F215 to initiate the calculation process. During the iterations, all of the variables that are affected by pack capacity (electrode thickness, cell area, cell power, number of bicell layers in a cell stack, etc.) also iterate. The user may study the equations on line 206 to see how this is done.

To arrive at a solution in a moderate number of iterations, it is important to start with a good estimate of the final answer. The starting value for the capacity calculation is on line 205. When this value is used in the first iteration to calculate the vehicle range, the difference between the desired and calculated values of the range is used to estimate the next estimate of the capacity with the help of a convergence constant on line 208. The convergence values listed on lines 208, 211 and 214 have been tested for a wide variety of batteries and found to work well. It is possible that the user may select a set of input variables that does not immediately lead to a solution. In that case, the user should consider adjusting the convergence values for that particular study. 


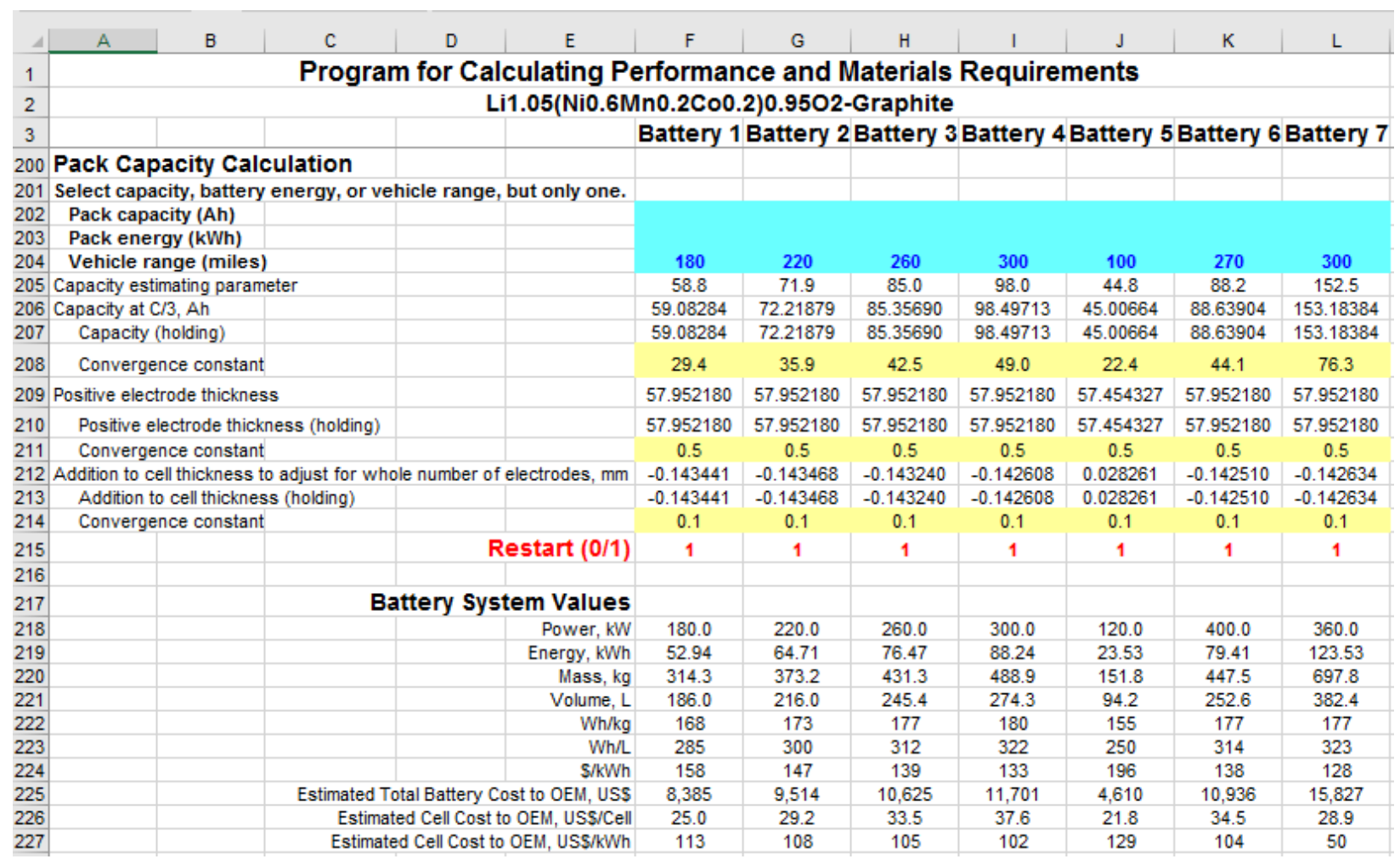

Figure 3.8 Bottom portion of Battery Design worksheet

\subsubsection{Battery Dimensions and Voltage}

The dimensions of the calculated battery pack and its voltage should be examined. It is important that the battery fit the space that is available in the vehicle. The user may change the input values for the pack, such as the number of cells per module and the arrangement of the modules into rows to change both the pack dimensions and the pack voltage while meeting the set criteria for pack energy and power. In addition to changing the battery input values, the pack dimensions can be further adjusted by changing the thickness of the cell (line 31) or even the length-to-width ratio of the positive electrode (line 29), to fit the end-use application. The main adjustments to the voltage are by changing the number of cells or by reducing the voltage by using parallel connections. If the calculated cell capacity is higher than 80 to $100 \mathrm{Ah}$ and increasing the number of cells will raise the voltage above $1000 \mathrm{~V}$, the user should consider the inclusion of one or more of the variety of parallel connection schemes offered by BatPaC (lines 53, 66 and 70) and discussed in the next section. 
Some guidelines (not imperatives) on parameters for vehicle batteries are shown in Table 3.1.

Table 3.1 General suggestions for range of input parameters that change with battery type

\begin{tabular}{|l|c|c|c|c|}
\hline \multicolumn{1}{|c|}{ Battery Type } & No. of Modules & OCV at 50\% SOC & Power (kW) & Energy (kWh) \\
\hline HEV-25 & 1 & $60-80$ & 25 & $0.6-1.5$ \\
\hline HEV-HP & $2-4$ & $220-320$ & $100-300$ & $4-10$ \\
\hline PHEV & $4-6$ & $240-440$ & $100-300$ & $8-15$ \\
\hline EV & $8-20$ & $500-1000$ & $200-400$ & $25-125$ \\
\hline
\end{tabular}

\subsubsection{Parallel Packs, Modules and Cells}

BatPaC provides the user the opportunity to design for multiple packs connected in parallel or series (Battery Design, lines 53 and 54), which might be needed in a large vehicle that does not have space for a single very large battery pack. The design of the interconnecting hardware and the calculation of its cost are not provided because the design would be unique for every case. However, the user should not overlook these factors.

Modules may also be arranged in parallel (Battery Design, line 70) with interconnects between each set of parallel modules or only across the ends of strings of modules in series. Provision is made in $\mathrm{BatPaC}$ for the interconnects between modules in the same string as is done for packs with a single string of modules, but the cross-linking interconnects between multiple strings is not provided and the user would need to design such cross-links and estimate their cost. These crosslinking connections should be designed for much lower currents than the main series connectors between the modules. The cross-linking connectors should be designed to realign the module voltages which may shift during a power surge due to the difference in impedances of the modules. The current surges through the cross-linking connectors would be moderate and of short duration. In designing for parallel modules, the user should select the number of strings and modules so that the pack terminals are on the same face of the pack. As with any battery design, limits on the capacity of the cells and the voltage of the pack are key factors and the addition of parallel modules adds to the complexity.

The most commonly used parallel connection is between cells within a module. This approach has been used in Tesla batteries to accommodate small cylindrical cells for which manufacture is well established and is utilized in $\mathrm{BatPaC}$ for prismatic cells to avoid the need for either cells of excessively high capacity or for high pack voltage. The weight and cost of the connectors between parallel cells are calculated in $\mathrm{BatPaC}$, so that the cost for this type of parallel connection is complete.

\subsubsection{Troubleshooting and General Advice}

The spreadsheet iterates to find the solution and this sometimes causes error messages to appear after an entry is changed. These errors can usually be removed by first correcting any erroneous entries (non-numeric, two decimal points, etc.) or unattainable design parameters. Then the cells may be reset to default values by entering a "0" (i.e. zero) in the restart cell, F215 (Fig. 3.8). Finally, entering a " 1 " in F215 restarts the iteration process leading to a successfully converged 
answer. Note that all the values on line 215 are linked to cell F215 in the as-provided version of BatPaC.

At some point, a user will ask the model to design a battery that is outside the bounds of what is allowable for the selected cell chemistry. An example is when the P/E ratio is too large. Two different physical limitations are approached with increasing $\mathrm{P} / \mathrm{E}$ ratio. First, the electrode thickness is shrinking. At some point, the value will become unrealistic and eventually approach 0 crashing the calculation. At the same time, the C-rate for the active material is approaching the limiting C-rate defined in the Chem worksheet. As this value is approached, the ASI will increase to larger and larger values, which thus demands smaller and smaller electrode thicknesses. Eventually, the calculation will crash.

Warnings have been added to BatPaC in rows 81 and 200 of the Battery Design worksheet. A red " $X$ " will appear on these lines for any battery for which the capacity is too low to meet the power required by the user. The warning is triggered if the ASI for power is calculated to be more than $150 \%$ of the chemical system ASI (see cell E62 on Chem worksheet) or if either the positive or negative thicknesses are less than the minimum (cell E19 on Chem worksheet). Common sense approaches to resolve these issues are to use lower designed power or higher designed energy.

Tables for presentations or for preparing graphs of the data can be assembled at the bottom of either the Battery Design or the Summary of Results worksheet. These tables can be transferred to a blank worksheet for more complex studies.

\subsection{Remaining Worksheets}

The remaining worksheets do not require input by the user; they will support the calculations with default values, but changes to the default values can be made on some of these worksheets.

For all-electric vehicles (EVs), the default charging rate is 3.6C, which results in $60 \%$ additional charge in 10 minutes. For a different rate of charging, the user should make adjustments in the EV Charging worksheet with guidance from section 7. High-Rate charging of Electric Vehicle Batteries. Similarly, the Thermal worksheet, which is discussed in section 6. Thermal Management, requires no attention from the BatPaC use but many of the default input values may be changed.

The cost calculations are discussed in section 8. Modeling of Battery Pack Manufacturing Costs, and the calculations are done in the Manufacturing Cost Calculation and Prices of cells and Modules worksheets with data drawn from the Cost Input worksheet. The results of these calculations are summarized on the Summary of Results worksheet. No parameters need to be entered on these worksheets by the user; all of the input for these worksheets is from the Battery Design and the Cost Input worksheets.

The Cost Breakdown worksheet is described in more detail in Section 8.8. this worksheet breaks the costs down by presentations in several ways to help the user to find the most expensive items for which cost reduction will make a significant impact on the overall cost. Pie charts of the results are presented for Battery 1 and Battery 7 of the seven batteries designed on the Battery Design 
worksheet. The user may change a pie chart from one of the two selected batteries to another by clicking on the chart and changing the column containing the numerical values (column " $F$ " for Battery 1 or column " $L$ " for Battery 7) to the column dedicated to the battery selected for study. The four sets of cost breakdown are the following:

1. Overall cost breakdown. The total cost is distributed to the major cost items.

2. Materials and purchased items. The expenses in this category are distributed to the individual items.

3. Overhead distributed to processes. Total costs of the pack are assigned to the overall categories of (a) materials, (b) purchased items, and (c) manufacturing costs with the manufacturing cost items of direct labor, capital equipment and plant area distributed to the individual processing steps. The overhead manufacturing costs, which are calculated in $\mathrm{BatPaC}$ as functions of these same three cost items are also distributed to the individual processing steps.

4. Breakdown of costs to basic cost factors. The basic cost factors for this chart are materials, purchased items, labor and investment (capital equipment and plant area are combined).

The Recycle worksheet provides the distribution of materials in the battery pack. This information is useful in designing processes for recovering materials from spent batteries. It may also be used for determining the requirements for less plentiful materials for manufacturing batteries. For instance, the tons of cobalt per million vehicles can be estimated by multiplying the mass (kg) of cobalt in one vehicle (Recycle, line 20) by 1100 , which is $2.2 \mathrm{lb} / \mathrm{kg} / 2000 \mathrm{lb} / \mathrm{ton} \times 10^{6}$ vehicles. It should be noted that the materials calculated in the Recycle worksheet are for one pack; for multiple-pack batteries, multiply the results by the number of packs per vehicle to obtain the total masses of materials for the entire battery system. On the final worksheets in BatPaC, sketches are provided of the baseline plant and the designs of the cell, module, and battery pack, which are discussed in section 2 . 


\section{ILLUSTRATED RESULTS}

The BatPaC model may be used to study the effects of battery parameters on the performance and the manufactured cost of the designed battery packs. The results illustrated below are for the different types of vehicle batteries for which $\mathrm{BatPaC}$ was developed: (1) hybrids, both mild (microHEV) and high-powered (HEV-HP), (2) plug-in hybrids (PHEV) and (3) all electrics (EV). Other examples were provided in the Second Edition of this manual, to which the reader may refer.

\subsection{Hybrid Vehicle Batteries}

The energy requirement for hybrid vehicle batteries is moderate and, thus the electrode materials do not require high specific capacity. However, HEV batteries may be designed for very high power for which the maximum achievable power-to-energy ratio $(\mathrm{P} / \mathrm{E})$ for the cell couple is a key factor in determining the battery cost. Each cell chemistry has a characteristic maximum P/E for the system at its operating state-of-charge range. Batteries with power ranging from low to high (25-250 kW) are needed to provide hybrid-vehicle drivetrains that, with the addition of the engine power, can match the power of the drivetrains for most conventional gasoline-powered vehicles.

\subsubsection{Batteries for Mild Hybrid Vehicles}

The lowest battery power requirement is for mild hybrids such as those which were initially powered by $25-\mathrm{kW}$ nickel-metal hybrid batteries. For such batteries which would power small vehicles requiring energy of about $250 \mathrm{Wh} / \mathrm{mile}$, we have set a minimum energy of $1.0 \mathrm{kWh}$ to allow flexibility in the timing of charging and discharging, which will accommodate traffic conditions the vehicle may encounter. This results in a P/E requirement for mild hybrid vehicles of $25 \mathrm{~kW} / \mathrm{kWh}$. The characteristics of batteries of several cell chemistries that meet this requirement are shown in Table 4.1 .

Table 4.1 Battery packs of 18 cells for mild hybrid vehicles for packs manufactured in plants producing 100,000 packs per year. Maximum power at 50\% SOC for 2 seconds: $25 \mathrm{~kW}$.

\begin{tabular}{|c|c|c|c|c|}
\hline Cell Couple & $\begin{array}{c}\text { Positive } \\
\text { Thickness, } \boldsymbol{\mu m}\end{array}$ & $\begin{array}{c}\text { Cell ASI, } \\
\mathbf{o h m}^{\mathbf{c}} \mathbf{\mathbf { c m } ^ { 2 }}\end{array}$ & Pack Voltage, V & Price, $\mathbf{\$}$ \\
\hline LMO-G & 88 & 11 & 71 & 646 \\
\hline LFP-G & 43 & 24 & 59 & 748 \\
\hline NMC622-G & 40 & 14 & 68 & 649 \\
\hline NCA-G & 33 & 15 & 66 & 670 \\
\hline
\end{tabular}

These packs operate near 50\% SOC and are cooled with cabin air. All have 18 cells in a single module, which results in nominal pack voltages in the range of 59 to $71 \mathrm{~V}$ and currents at maximum power of less than $530 \mathrm{~A}$. Lower currents at higher voltages can be achieved with a larger number of cells in the packs, which would result in higher battery cost as illustrated in Figure 4.1. However, the lower current would also result in greater ease in converting to the high-voltage AC current required by the electric motor and lower cost for the controller. Thus, a study is required to determine the optimum number a battery cells and the resulting current at full battery power. 


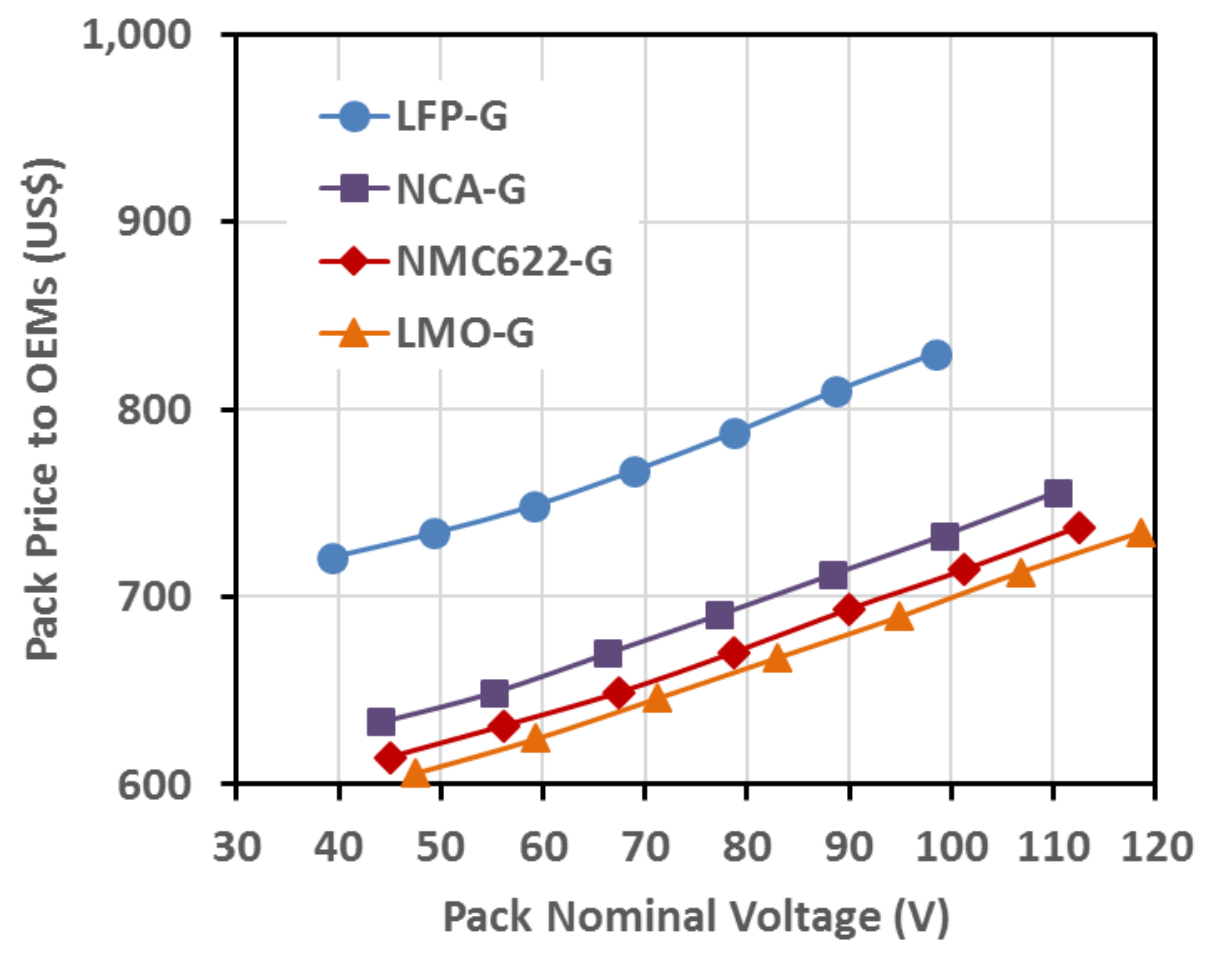

Figure 4.1 Cost of mild hybrid batteries (25-kW) as a function of pack voltage for various cell chemistries with 12 to 30 cells per pack in a single module; 100,000 packs per year manufactured in dedicated plant.

The cost of the battery, which includes the battery management unit and disconnects, is lower for manganese spinel-graphite (LMO-G) packs than for the other cell chemistries. A potential problem for this option, is their operating life. This is addressed in the following section.

A plant producing 100,000 of these small packs per year is only producing at a rate of $0.1 \mathrm{GWh} /$ year, whereas the baseline plant produces $16-\mathrm{kW}$ batteries at a more economical level of $1.6 \mathrm{GWh} /$ year. Increasing the production of the batteries of Table 4.1 to 500,000 units /year ( $0.5 \mathrm{GWh} /$ year, still uneconomically low) would lower the cost of the batteries from by about 16 to18\%. If produced in large flexible plants that also produced EV or PHEV batteries, the cost would be even lower [23].

\subsubsection{High-Powered Batteries for Hybrid Vehicles}

Development of hybrid vehicles that can compete in performance and price with most conventional gasoline-powered vehicles would be an important achievement. It would provide energy- efficient vehicles to those city dwellers who do not have garages for recharging or access to other convenient charging facilities. Designing hybrid vehicles with sufficient power to match that of the entire spectrum of gasoline-powered vehicles can be done in two ways: (1) use a powerful engine with a mild-hybrid electric system (microHEV) as discussed above or (2) use a low- 
powered gasoline engine and a high-powered electric system (HEV-HP). BatPaC offers the capability of evaluating the second approach because of these arguments in its favor.

- A powerful battery (>100 kW) would operate at higher efficiency (higher \% OCV) at every power level than a micro-HEV battery and allow EV mode travel at higher speeds, improving overall fuel economy. Hybrid vehicle batteries may use up to $100 \%$ of their rated power to assist the engine during rapid acceleration. During most EV-mode travel, however, it is impractical to use more than about 20 to $30 \%$ of the maximum battery power to drive the vehicle. For a mild hybrid battery of $25-\mathrm{kW}$, the power available at normal EVmode travel is only 5-6 kW, which limits the speed to about $35 \mathrm{mph}$ in EV-mode. At these low power levels, the battery is very efficient discharging at more than $95 \%$ of the opencircuit voltage and much vehicle fuel can be saved. At higher levels of power with this low-powered battery, the overall efficiency for the electric system is much lower because of losses in the battery on discharge and charge and in the ac-dc conversion system; it is more efficient to drive the vehicle directly from the engine. A powerful battery does not limit the EV-mode of the vehicle to low-speed travel and, thus results in higher fuel economy than for a low-powered battery.

- Some hybrid vehicles gain fuel economy by using an Atkinson engine, which has higher efficiency than a conventional engine, but lower torque at low speeds. The low torque is often accommodated by the use of an electrical, continuously variable transmission to achieve the needed torque at the driveshaft. This transmission is expensive and its efficiency is as low as $70 \%$ under some circumstances. With a high-powered electric system, the transmission can be eliminated. The electric system could provide torque and power for maximum acceleration at speeds up to 30 to $45 \mathrm{mph}$, depending on the vehicle mass and the electric power available. At higher speeds, maximum acceleration can be provided by adding the engine power to the electric power with a clutch that engages the engine when its rpm is the same as that of the driveshaft. Because of the high power of the electrical system for the proposed $\mathrm{HEV}$, maximum power with engagement of the engine for that purpose would seldom be needed.

- The use of a powerful battery for the HEV-HP system permits operating the battery at a high state of charge, because the battery can easily accept regen breaking energy even at a high state of charge. For the HEV-HP system, BatPaC uses $80 \%$ SOC as the center of SOC with normal operation of the battery within about 5\% SOC of that central value. For hill climbing, the battery can deliver extra energy by being discharged to as low as 20\% SOC, providing extra power to assist a small, inexpensive engine. Thus, for the rare occasion when there is a long hill to climb, the available energy is about $60 \%$ of the total pack energy ( $~ 80 \%-20 \%$ SOC). Normally the battery utilizes about $10 \%$ of its energy (85\%-75\% SOC) between charges.

To study the use of batteries for this application, we have selected the same four cell chemistries as were used for the mild-hybrid batteries and show some of the pertinent characteristics in Table 4.2. In this new version of BatPaC, the mid-range state of charge for these batteries is $80 \% \mathrm{SOC}$ rather than $50 \%$ as we have done in the past and the cell voltages have been increased accordingly, but the system ASI for these cells is about the same as at 50\% SOC. 
Table 4.2 Parameters of various cell couples for HEV-HP batteries

\begin{tabular}{|c|c|c|c|c|c|c|}
\hline \multirow[b]{2}{*}{ Cell Couple } & \multirow{2}{*}{$\begin{array}{c}\text { Mid-range } \\
\text { SOC, \% }\end{array}$} & \multirow[b]{2}{*}{ Cell OCV, V } & \multirow{2}{*}{$\begin{array}{c}\text { System ASI, } \\
\text { ohm-cm }\end{array}$} & \multirow{2}{*}{$\begin{array}{c}\text { Positive } \\
\text { Cap., } \mathrm{mAh} / \mathrm{g}\end{array}$} & \multicolumn{2}{|c|}{$\begin{array}{l}\text { P/E (10-s), } \\
\text { W/Wh }\end{array}$} \\
\hline & & & & & Max. & Selected \\
\hline NCA-G & 80 & 3.836 & 13 & 200 & 37 & 32 \\
\hline NMC622-G & 80 & 4.000 & 13 & 180 & 43 & 36 \\
\hline LFP-G & 80 & 3.500 & 25 & 150 & 32 & 28 \\
\hline LMO-G & 80 & 4.020 & 12 & 100 & 63 & 55 \\
\hline
\end{tabular}

The maximum P/E that the couple can achieve is an important factor in determining the cost and volume of the pack. Low system ASI and high cell voltage contribute to a high maximum P/E ratio. Other minor factors also effect the Max P/E and thus, the Max P/E ratios in Table 4.2 were determined in $\mathrm{BatPaC}$ by trial and error. This was done for each couple by selecting a value of the energy for a set value of power. For a selected power (line 62 on the Battery Design worksheet), the result of setting the value of pack energy too low (line 203) is an error message (line 200) indicating that the energy should be raised. The energy was raised until the error message disappeared, thus determining the maximum P/E ratio for the couple, which was found to be almost independent of power over the range of interest. The P/E values selected for illustration of the capability of the couples were slightly lower than the maximum values to allow for some aging of the battery. Also, it was noted that slightly lower P/E values than the Max P/E had little effect on cost of the battery pack. Seven batteries were designed in BatPaC for each of the four cell couples of Table 4.2 with the input values shown in Table 4.3. The number of cells per pack was increased with increasing power to increase the pack voltage and to mitigate the increase in the maximum current. Increasing the number of cells increases the cost of the pack (other inputs unchanged), but increasing the current, increases the cost of the inverter.

Table 4.3 Input parameters and resulting pack voltages for high-powered hybrid vehicle batteries for the cell chemistries of Table 4.2. Two modules per pack, 250 Wh energy per mile of travel.

\begin{tabular}{|c|c|c|c|c|c|c|c|}
\hline Battery & $\mathbf{1}$ & $\mathbf{2}$ & $\mathbf{3}$ & $\mathbf{4}$ & $\mathbf{5}$ & $\mathbf{6}$ & $\mathbf{7}$ \\
\hline Pack Power, kW & 100 & 125 & 150 & 175 & 200 & 225 & 250 \\
\hline Cells per Pack & 52 & 56 & 60 & 64 & 68 & 72 & 76 \\
\hline Pack Voltage & $182-$ & $196-$ & $210-$ & $224-$ & $238-$ & $252-$ & $266-$ \\
Range, V & 209 & 225 & 241 & 257 & 273 & 289 & 306 \\
\hline
\end{tabular}

The wide range of pack power values makes possible powertrains with 220 to $400 \mathrm{HP}$ output all with small inexpensive engines ( 80 to120 hp). The pack voltage is affected by the electrode chemistry and hence reported as a range in Table 4.3. The pack voltage ranges reflect the number of cells selected for each power level and the average open-circuit voltages of the couples at the middle of the normal operating range, which is $80 \%$ SOC. 
The results of designing batteries with the selected parameters is shown in Figure 4.2. With the parameters currently in BatPaC, the energy storage and volume are very similar for NCA-G and NMC622-G packs for the power range shown in Fig 4.2. The LFP-G packs are much more voluminous, but even the largest of these packs, the $250 \mathrm{~kW}, 58-\mathrm{L}$ pack was configured (985 mm x $386 \mathrm{~mm}$ x $144 \mathrm{~mm}$ ) to fit under the back seat of a sedan and extend only slightly into the trunk space. The masses of the packs are also acceptable, ranging from 58 to $108 \mathrm{~kg}$ for the four $250-\mathrm{kW}$ packs. The LMO-G system is the most compact and requires the least energy storage of the four systems.
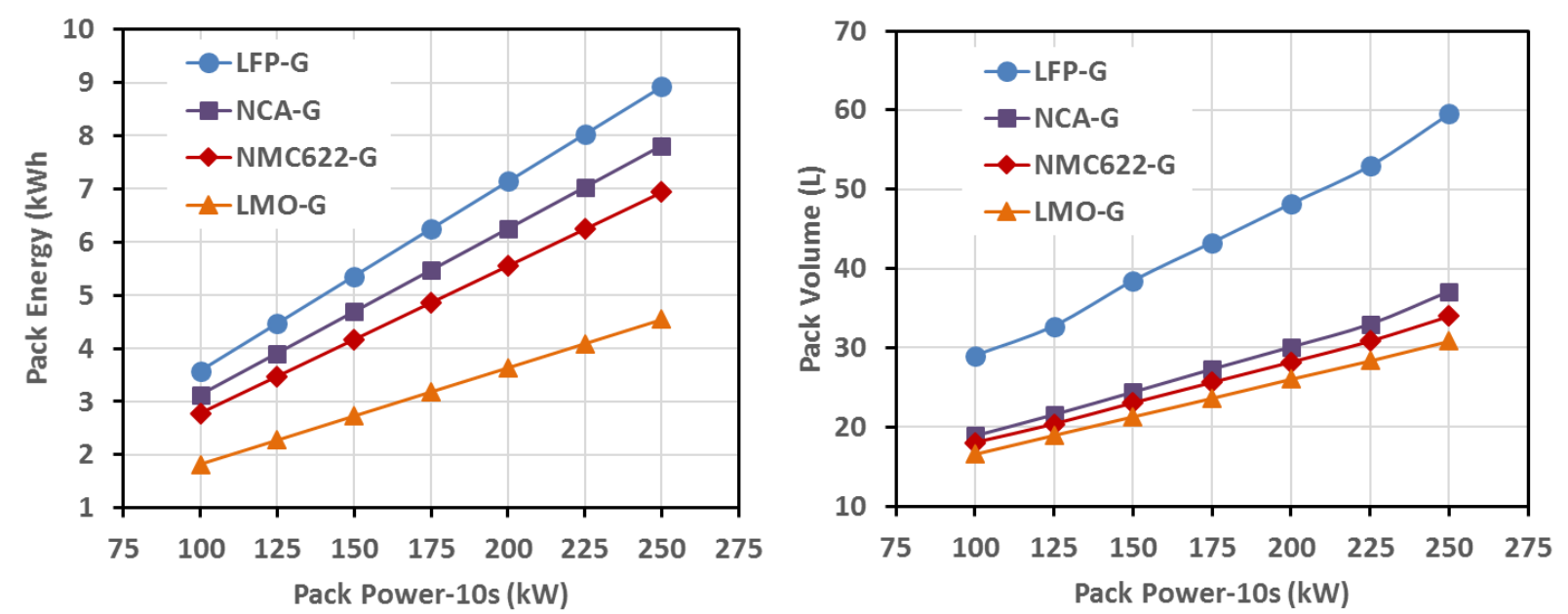

Figure 4.2. Energy storage and pack volume as functions of pack power for high-powered hybrid vehicle batteries.

Favorable design features also result in lower cost (Fig. 4.3); the prices of the battery packs for the four systems remain in the same order as their energy storage requirements and pack volumes. The costs of the high-powered hybrid batteries were determined for dedicated plants producing 100,000 units per year or only $0.2 \mathrm{GWh}$ /year for the $100-\mathrm{kW}$ LMO-G battery to $0.9 \mathrm{GWh}$ /year for the 250$\mathrm{kW}$ LFP-G battery. If manufactured in a large flex plant with other larger batteries the prices would be 10 to $15 \%$ lower. 


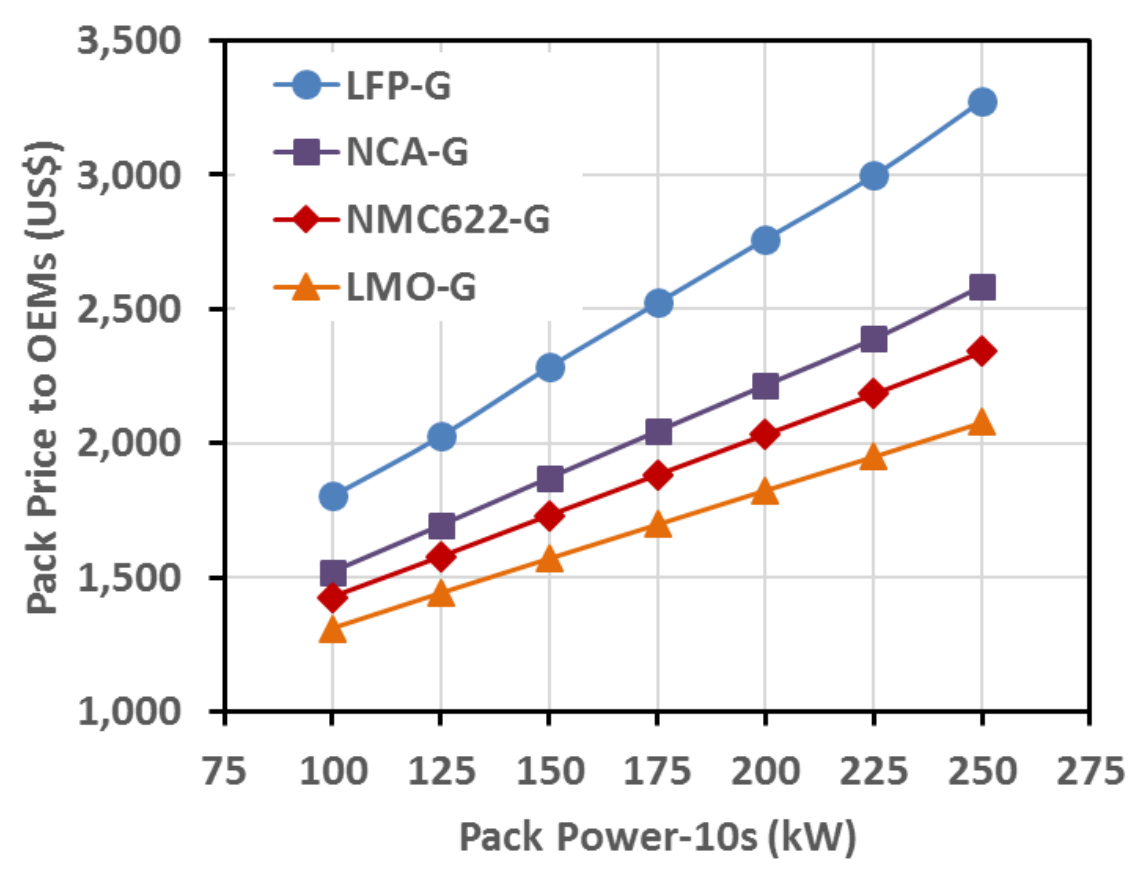

Figure 4.3 Prices to OEMs for packs including battery management units and disconnects for highpowered hybrid-vehicle batteries manufactured at a rate of 100,000 units per year.

The NCA-G or NMC622-G couples appear to be very promising for high-powered battery packs for hybrid vehicle batteries. If HEV-HP batteries could achieve long life with the LMO-G couple, the cost of a pack would be about $20 \%$ lower than for a NMC622-G pack. Whether sufficiently long life can be achieved with the LMO-G couple is uncertain, even with operation only at high voltages as we have proposed. For this application, the cost advantage for the LMO-G system may warrant considerable research effort to improve its life.

Another approach for the near term is to use the LFP-LTO couple. This couple has been shown to provide very long cycle life (in excess of 20,000 full cycles with no capacity loss) and to be capable of discharges and charges at very high C-rates [24]. However the voltage of this couple at $80 \%$ SOC is only about 2.1 V compared with about 4.0 V for NMC622-G and LMO-G and $3.5 \mathrm{~V}$ for LFP-G. As a result, LFP-LTO batteries would be 20-25\% more costly than LFP-G batteries. However, the high voltage of LTO vs. Li $(1.5 \mathrm{~V})$ makes possible the use of a more stable electrolyte-dissolved salt combination that is more resistant to decomposition at high temperature than the standard LiPF6 dissolved in EC-DEC [24].

\subsection{Plug-In Hybrid Vehicle Batteries}

Plug-in hybrid vehicles (PHEV) can achieve very high fuel economies even for electric vehicle ranges as short as 20 miles; a driver living 20 miles from his workplace may use only half as much fuel in a round trip to work with a PHEV20 as with a HEV-HP. However, for both vehicles the annual fuel costs would be low; the extra annual fuel savings for the PHEV20 over that of the HEV-HP would warrant only a slightly higher price for the PHEV battery including its charger. 
The group of cell chemistries from which good PHEV batteries can be assembled is more limited than for HEV-HP batteries. PHEV batteries are required to discharge continuously over a wide state-of-charge range and provide thousands of deep-discharge cycles with little loss in capacity. We have selected NMC622-G to illustrate the use of BatPaC for PHEV batteries. It is instructive to compare HEV-HP and PHEV batteries of the same power and cell chemistry that are designed by the BatPaC model (Table 4.4). We calculated the results for two levels of power and for two electric ranges for the PHEV batteries, 20 and 40 miles.

Table 4.4 Comparison of NMC622-G batteries designed for HEV-HP and PHEV vehicles with energy requirements of $250 \mathrm{Wh} /$ mile. Battery Prices are for dedicated plants producing 100,000 units/yr.

\begin{tabular}{|c|c|c|c|c|c|c|}
\hline Vehicle Type & \multicolumn{2}{|c|}{ HEV-HP } & \multicolumn{2}{|c|}{ 20-Mile PHEV } & \multicolumn{2}{|c|}{ 40-Mile PHEV } \\
\hline Battery power (10s), kW & 125 & 250 & 125 & 250 & 125 & 250 \\
\hline Pack energy, kWh & 3.47 & 6.94 & 7.14 & 7.14 & 14.3 & 14.3 \\
\hline Number of cells & 56 & 76 & 56 & 76 & 56 & 76 \\
\hline Cell thickness, mm & 12 & 12 & 16 & 16 & 16 & 16 \\
\hline Positive thickness, mm & 24 & 23 & 32 & 15 & 45 & 41 \\
\hline ASI for power, ohm-cm² & 18 & 19 & 18 & 24 & 17 & 18 \\
\hline Cell area, $\mathrm{m}^{2}$ & 1.60 & 2.44 & 2.51 & 3.85 & 3.56 & 2.85 \\
\hline Total battery area, $\mathrm{m}^{2}$ & 89 & 186 & 141 & 292 & 199 & 217 \\
\hline Battery volume, $\mathrm{L}$ & 20.7 & 34.0 & 35.7 & 45.7 & 53.4 & 57.8 \\
\hline Battery mass, kg & 34.4 & 63.8 & 60.8 & 91.0 & 95.5 & 111.2 \\
\hline Battery price to OEM, \$ & 1,580 & 2,340 & 2,300 & 3,000 & 3,030 & 3,310 \\
\hline
\end{tabular}

For the PHEV batteries the power is calculated at 20\% SOC, whereas for the HEV-HP batteries the power is calculated at $80 \%$ SOC, about where it normally operates. At this higher state of charge, the HEV-HP battery voltage is higher and the ASI is lower than at $20 \%$ SOC. The ASI is also affected by the thickness of the electrodes, which determines the ratio of the interfacial particle area to the electrode area as explained in section 5 (Fig. 5.8). This effect is especially important for the 250-kW PHEV20 battery for which the positive electrode is only slightly more than $15 \mu \mathrm{m}$. That thickness is the lower limit accepted by BatPaC, because below that thickness, the ASI increases very rapidly. By contrast, the PHEV40 batteries have thicker positive electrodes than the PHEV20 batteries and for that reason alone their cells have lower ASI.

On the other hand, the ASI for the HEV-HP batteries is lower than that for the PHEV20 batteries, despite the fact that this PHEV battery has higher total electrode area. This is because the power for the HEV-HP is measured at $80 \%$ SOC where the voltage is higher and the system ASI is lower than at $20 \%$ SOC at which the PHEV power is specified.

In our graphs for the PHEV batteries (Fig. 4.4), we have used the same battery-power range, 100$250 \mathrm{~kW}$, and the same number of cells at each power level as for the HEV-HP batteries (Fig. 4.2 and 4.3) to simplify the comparison of the battery types. Over this power range, both of these battery types with the aid of a small engine (80-120 hp) will provide total drivetrain power of about 220 to $400 \mathrm{hp}$, sufficient for a large fraction of the sedan and SUV markets. 
There are sharp changes in slope of the curves in Figure 4.4 at acceleration power (10-s) levels of $157.7 \mathrm{~kW}$ for the PHEV-20 battery and at $233.3 \mathrm{~kW}$ for the PHEV40 battery. For acceleration power requirements less than at these points of change, the thickness of the positive electrode for sustained power (line 106 in Battery Design) is less than that for acceleration power (line 107). Because BatPaC selects the thinnest, most restrictive value for the electrode thickness, the power that is set for acceleration has little effect on the price of the battery in this zone of comparatively low acceleration power. (The only effect on the pack price of increasing the power in this low power zone results from the cost of larger module interconnects and module terminals.) At acceleration power requirements above the points of sharp reduction in the electrode thickness, the value set for the acceleration power requirement determines the electrode thickness and the volume of the pack and its price increases with power more rapidly than at lower power levels.
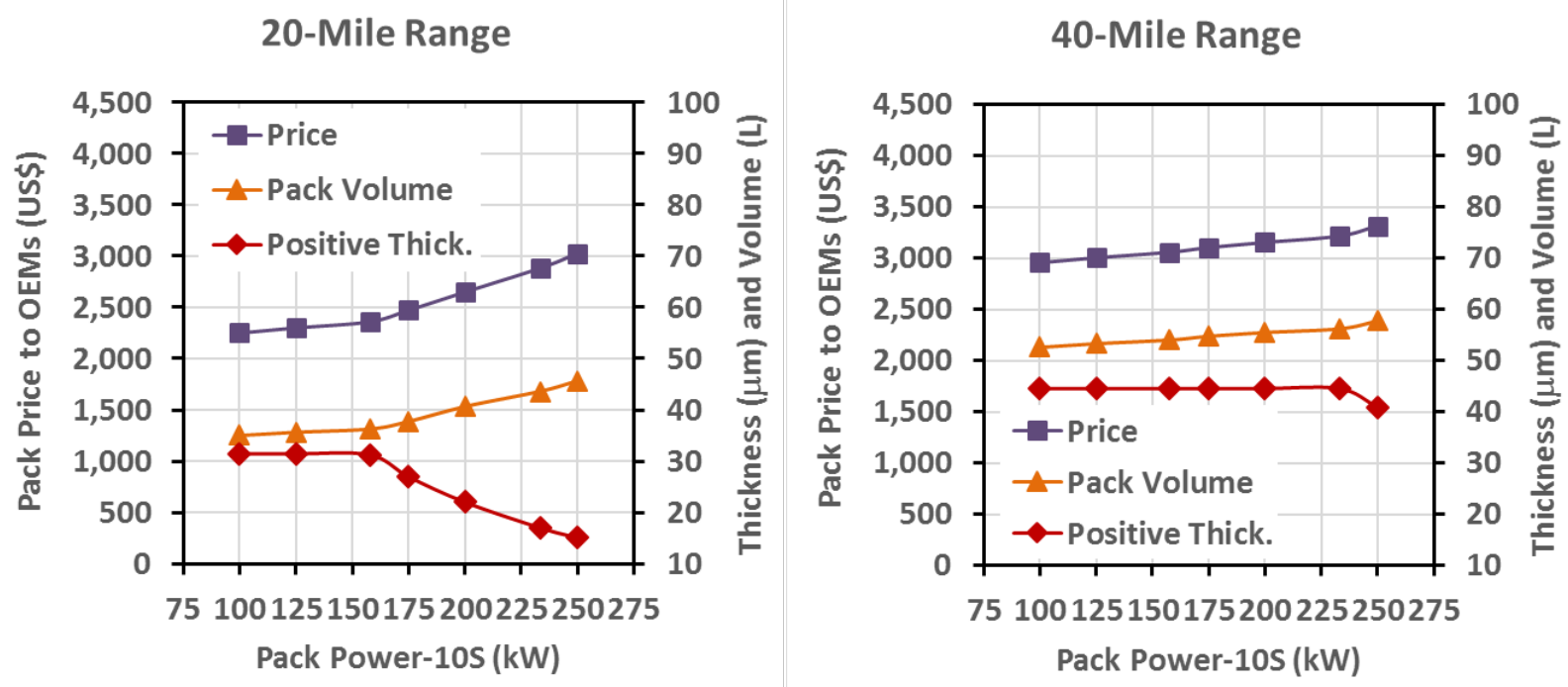

Figure 4.4 Performance and price for NMC622-G PHEV20 and PHEV40 batteries as a function of battery power.

All of the batteries in Fig. 4.4 have two modules with a total of 56 to 76 series-connected cells of $16-\mathrm{mm}$ thickness. The vehicles require energy of $250 \mathrm{Wh} / \mathrm{mile} ; 7.14 \mathrm{kWh}$ for the PHEV20 vehicle and 14.3 for the PHEV40 vehicle.

As a result of these considerations, it is clear that for a given selection of (1) cell chemistry, (2) vehicle energy requirement (Wh/mile) and (3) vehicle range, there is an "ideal" value of acceleration power (10-s), which results in near minimum battery price. For pack power of $125 \mathrm{~kW}$, the PHEV20 is about 24\% less expensive than the PHEV40. However, as the power increases the advantage in cost for the shorter range vehicle decreases and it is only $11 \%$ less expensive at $250 \mathrm{~kW}$ power. 


\subsection{Electric Vehicle Batteries}

The thickness of the electrodes in batteries for HEV and PHEV vehicles is often determined by the acceleration power (10-s) requirement as noted in the sections above. For EV batteries, which operate at low $\mathrm{P} / \mathrm{E}$ ratios, the thickness of the electrodes is determined either by the sustained power requirement or the need for fast charging. A discussion of fast charging is provided in Section 7 for several types of vehicles. Here the discussion is limited to the first four batteries in the example cases given for EV batteries (table at far right side of the Battery Design worksheet), which are designed for sedans of various vehicle ranges (Table 4.5 and Fig 4.5).

All of the battery packs illustrated here are designed for a power-to-energy ratio of about $3.4 \mathrm{~kW} / \mathrm{kWh}$. However, this power is delivered at a voltage of well over $90 \%$ OCV rather than at $80 \%$ OCV, the minimum voltage for power pulses set in BatPaC. These batteries could all deliver much higher acceleration power than called for in Table 4.5 simply by providing larger module interconnects and battery terminals to accommodate the higher current than in the cases shown here. This illustrates the ease of achieving high acceleration power for EV batteries.

To meet the charging rate current density limit of $9.0 \mathrm{~mA} / \mathrm{cm}^{2}$, which is set as the default in $\mathrm{BatPaC}$, the electrodes for packs designed for the high charging rate, $60 \% \Delta \mathrm{SOC}$ in $10 \mathrm{~min}$, must be even thinner than to meet the driving requirements. Charging at a rate to provide $60 \% \Delta \mathrm{SOC}$ in 10 minutes has only a moderate effect on the mass, volume and price of the battery pack (Fig. 4.5), but the effect is much greater for charging $80 \% \Delta \mathrm{SOC}$ in 10 minutes as illustrated in section 7. High-Rate Charging of Electric Vehicle Batteries.

Table 4.5 The effects of changing the vehicle range and charge capability on the design of NMC622-graphite sedan batteries. Energy usage, $250 \mathrm{Wh} / \mathrm{mile}$; useable energy, $85 \%$ of total. Slow charge: $1 \mathrm{C}$ rate, $60 \% \Delta \mathrm{SOC}$ in $36 \mathrm{~min}$; fast charge: $3.6 \mathrm{C}$ rate, $60 \% \Delta \mathrm{SOC}$ in $10 \mathrm{~min}$.

\begin{tabular}{|l|c|c|c|c|}
\hline \multicolumn{1}{|c|}{ Battery Pack } & $\mathbf{1}$ & $\mathbf{2}$ & $\mathbf{3}$ & $\mathbf{4}$ \\
\hline Range, miles & 180 & 220 & 260 & 300 \\
\hline Energy, kWh & 53 & 65 & 76 & 88 \\
\hline Power, kW & 180 & 220 & 260 & 300 \\
\hline Nominal battery voltage, V & 900 & 900 & 900 & 900 \\
\hline Design for Slow Charge & & & & \\
Positive thickness, $\mu \mathrm{m}$ & 77 & 85 & 93 & 100 \\
Negative thickness, $\mu \mathrm{m}$ & 86 & 96 & 104 & 112 \\
\hline Design for Fast Charge & & & & 58 \\
Positive thickness, $\mu \mathrm{m}$ & 58 & 58 & 58 & 65 \\
Negative thickness, $\mu \mathrm{m}$ & 65 & 65 & 65 & \\
\hline
\end{tabular}




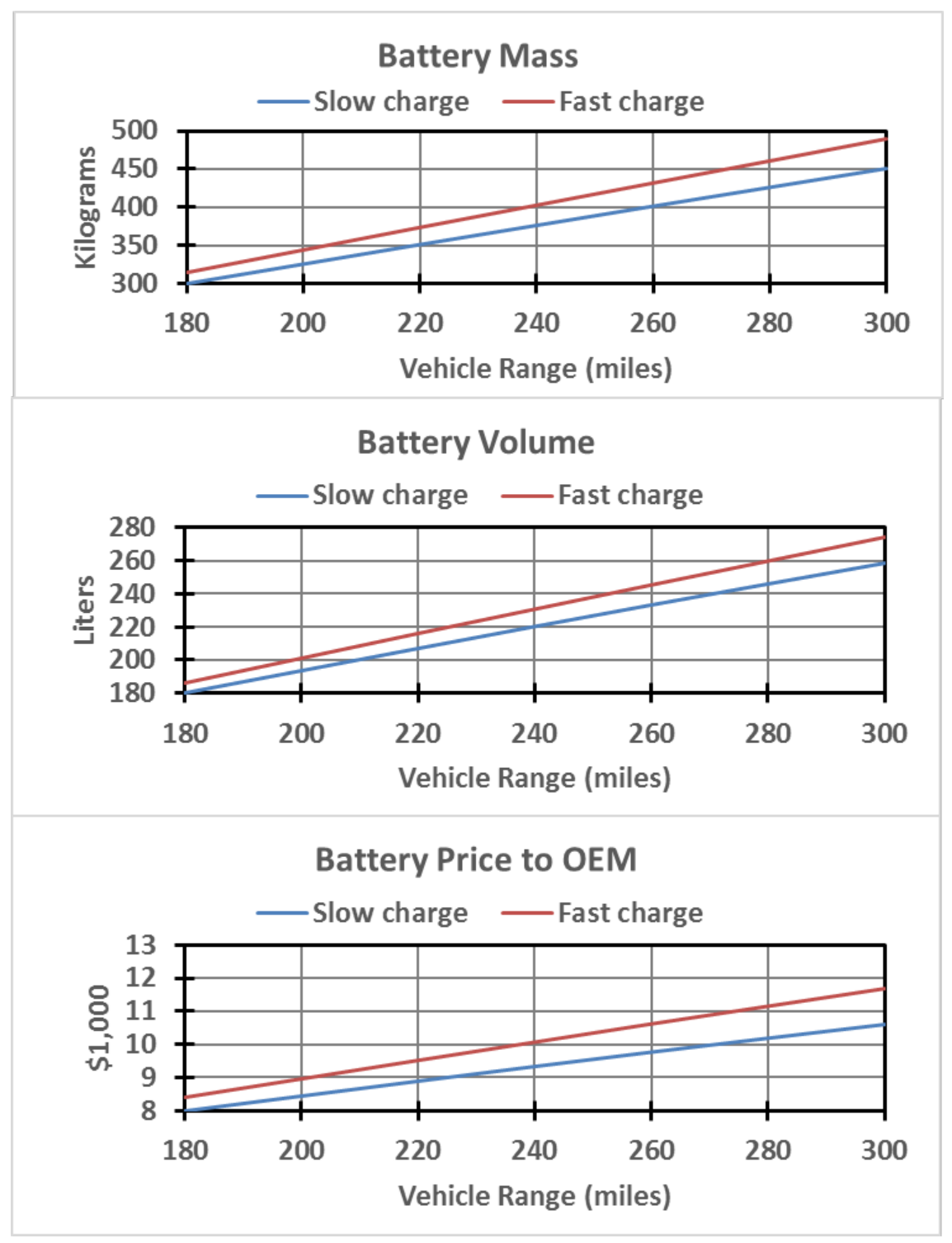

Figure 4.5 Effects of slow charge (1C rate) and fast charge (3.6C rate) on sedan battery parameters.

\subsection{Summary of Illustrated Results}

The results for these illustrated examples show that each type of vehicle has unique advantages. A comparison of the battery characteristics is shown in Table 4.6 for $250 \mathrm{~kW}$ batteries. The drivetrains for each of these vehicle types could deliver substantially more than $250 \mathrm{~kW}$. For the $\mathrm{HEV}-\mathrm{HP}$ and PHEV systems, the drivetrains could also receive power from their engines at speeds above 20 mph even without a transmission although the power from the engine would be limited below speeds of about $40 \mathrm{mph}$. As noted above in section 4.3, the EV batteries could deliver considerably more than the rated power at voltages greater than $90 \% \mathrm{OCV}$. Thus, the drivetrains for all three vehicles could deliver at least 350 to $400 \mathrm{HP}$ as designed by BatPaC for this illustration. 
Table 4.6 Comparison of battery and vehicle characteristics for high-powered electric-drive vehicles of similar performances. Battery chemistry, NMC622/graphite; EV charged at 3.6C.

\begin{tabular}{|l|c|c|c|}
\hline & HEV-HP & PHEV & EV \\
\hline Vehicle energy usage, Wh/mile & 250 & 250 & 250 \\
\hline Vehicle electric range, miles & $\sim 2$ & 40 & 300 \\
\hline Battery power, kW & 250 & 250 & $>400$ \\
\hline Battery energy, kWh & 6.94 & 14.3 & 88.2 \\
\hline Pack mass, kg & 64 & 111 & 489 \\
\hline Pack volume, L & 34 & 58 & 274 \\
\hline Require deep discharge & No & Yes & Yes \\
\hline Require charge from outlet & No & Yes & Yes \\
\hline Cobalt content & & & 18.59 \\
Mass per pack, kg/pack & 1.46 & 3.00 & 20,450 \\
Tons per 1,000,000 packs & 1,610 & 3,300 & No engine \\
\hline Engine power, HP & 120 & 120 & 0 \\
\hline Fuel usage, gal/10,000 miles & 200 & 100 & None \\
\hline Transmission & None & None & \$11,700 \\
\hline Battery price at 100,000/year & $\$ 2,340$ & $\$ 3,310$ & \\
\hline
\end{tabular}

The battery/vehicle combinations of Table 4.6 are of very high power (400 HP) suitable for much of the luxury class of vehicles. Batteries of all three types could be designed for lower cost vehicles. Such batteries would have lower power and the PHEV and EV batteries would provide less range. Thus, all of these types of electric-drive vehicles can be designed to meet the performances of almost the entire spectrum of conventional gasoline-powered vehicles now being sold.

\section{Comparison of types of electric-drive vehicles and their batteries:}

\section{HEV-HP}

- It is easier to achieve long life for this battery application than for any other; the SOC operating range is narrow and the overall vehicle performance is least affected by decline of battery power and capacity with aging.

- The mass and volume of the battery pack are the least for the three types of vehicles.

- The cobalt content per pack is the least for the three types of batteries. Also, the use of cobalt-free positive electrodes is more feasible for the HEV-HP than for the other two types of electric-drive vehicles.

- No recharging station is required, a considerable first-cost savings; vehicle owners do not need a garage nor a convenient access to a charging facility

- The battery cost is the least for the three types; with elimination of the transmission, future vehicles of this type may have a first cost that is less than that of a conventional vehicle of similar performance, at least for the more powerful versions.

- The fuel economy (50 mpg) is better than that of conventional vehicles but the poorest for these types of electric vehicles and thus $\mathrm{CO}_{2}$ release would be greater than desired. 


\section{PHEV}

- While not as low as for the HEV-HP type, the battery mass, volume, cobalt content and battery price are very favorable.

- The annual fuel usage is only about half of that of the HEV-HP (100 mpg vs 50 mpg) for a typical driver.

- The battery usage is more stressful than for the other two types with many deep discharges required per year of travel, possibly resulting in shorter battery life.

\section{EV}

- No liquid fuel is required, making it the most environmentally friendly of the three vehicle types, especially in the long run when batteries might be charged without use of fossil fuels.

- The battery mass and volume require a more expensive glider than for the other two types and may also result in higher energy use per mile of travel than that assumed here.

- The vehicle must be recharged at high-rate charging stations on long trips of more than about 250 miles. The EV battery of Table 4.6 is capable of receiving a charge of $60 \%$ $\triangle \mathrm{SOC}$ (71\% of useable capacity) in 10 minutes. High rate charging may shorten battery life.

- The battery is considerably more expensive than those for the other vehicle types of equal performance, this additional cost may not be recovered by accounting for the lower cost of electricity than that of gasoline over the lives of these electric-drive vehicles.

- The EV requires almost 13 times as much cobalt as the HEV-HP of equal performance. $5,000,000$ of the EVs of Table 4.6 would require $90 \%$ of the world's 100,000-ton current annual production of cobalt. 


\section{MODELING OF BATTERY DESIGN AND PERFORMANCE}

The design portion of the model calculates the physical properties of a battery based on userdefined performance requirements and minimal experimental data. An illustration of the model is shown in Figure 5.1. The user is asked to enter a number of design parameters such as the battery power, number of cells and modules, and target voltage at maximum power, etc. In addition, the user must enter one of the following three measures of energy: battery pack energy, cell capacity, or vehicle electric range. Defining one of these values will determine the value of the other two. An iterative procedure then solves for the user defined energy parameter (energy, capacity, or range) and remaining battery properties by varying the cell capacity and electrode thickness. The result is the dimensions, mass, volume, and materials requirements for the cells, modules, and battery pack.

\section{Battery Design Model}

\author{
Pack Requirements \\ - power \\ - energy or range \\ - number of cells
}

Key Constraints

- max electrode thickness

- target cell potential, $\mathrm{V}$, at peak power

- assumed cell/module format

\section{Iterative Spreadsheet}

Solves for cell capacity

and designs battery pack

by varying:

1. Cell area

2. Electrode thickness

3. Internal resistance

\section{Cell Chemistry}

Measured Properties

- pulse power ASI

- sustained discharge ASI

- $\mathrm{mAh} / \mathrm{g}, \mathrm{g} / \mathrm{cm}^{3}$

- electrode porosity

- SOC window

- physical properties

ASI = area specific impedance

Calculated Battery

Properties

- volume \& mass

- specific energy, power

- materials required

Figure 5.1 Summary flow of the design model 
The model has been designed to allow the user to enter as many customized values as desired. In this way, the model allows flexibility in the battery chemistries studied and some of the cell, module, and battery design aspects. Hence, the focus of this section is on the method of calculation and not the exact values chosen for a specific capacity or cell thickness. However, the default cell design parameters as well as experimental data measured at Argonne National Laboratory, for a number of different battery chemistries both commercial and developed at Argonne, are available for use within the model. There are five governing equations for battery performance that calculate the current density, battery energy, electrode area, electrode thickness, and resistance. The voltage at maximum power and the area specific impedance (ASI) are two important parameters in the design model for calculating the battery performance. Most of the discussion will be spent on these two properties.

\subsection{Criteria for Power, Energy, and Life}

In order to fully specify a battery design, the user of BatPaC must supply criteria for power, energy, and life. These criteria will depend on the application for which the battery will be used. While the users may change some of the settings as they prefer, we list the BatPaC default values in Table 5.1. The battery type is defined by the end-use application. Hybrid electric vehicles (HEVs), plug-in hybrid electric vehicles (PHEVs), and electric vehicles (EVs) have increasing levels of electrical energy storage for use by the vehicle drivetrain. The model will use Table 5.1 or the user's explicit inputs to size the battery correctly for the chosen application.

Table 5.1 Criteria for designing batteries for a specific end-use application

\begin{tabular}{|l|c|c|c|c|}
\hline Battery Type & microHEV & HEV-HP & PHEV & EV \\
\hline SOC for Rated Power, \% & 50 & 85 & 20 & 20 \\
\hline Power Duration, sec & 2 & 10 & 10 & 10 \\
\hline SOC Range for Useable Energy, \% & $40-65$ & $80-90 *$ & $20-90$ & $10-95$ \\
\hline Cell Thickness, mm & 6 & 12 & 16 & 20 \\
\hline
\end{tabular}

*For occasional hill climbing, the battery may be discharged to 20\% SOC.

The microHEV is a micro or mild-hybrid that provides a moderate power level, $\sim 25 \mathrm{~kW}$, for two seconds. In this revised version of BatPaC, the electric system for the HEV-HP hybrid is typically more powerful than the engine and is capable of accelerating the vehicle in most cases without the aid of the engine. The HEV-HP battery provides the rated power for a full 10 second pulse. The battery operates at a high state of charge (80-90\%), where the cell voltage and ASI are favorable for operation at high power. The energy of the HEV-HP cells is determined by the very high power needed and the P/E capability of the selected cell chemistry; only a small fraction of the energy is needed between charges. The PHEV battery utilizes a much larger portion of the total energy, $70 \%$. At the end of discharge, the PHEV battery is operated in a charge sustaining mode. Therefore, the power rating for the battery is determined at $20 \%$ SOC. PHEV cells typically need to be larger than HEV-HP cells and thus their default cell thickness is16 mm. Finally, EV batteries use $85 \%$ of their total energy with their power rated near the end of discharge and their cell thickness is the largest: $20 \mathrm{~mm}$. 
In doing the iterations, $\mathrm{BatPaC}$ determines the thickness of the electrodes, and their area and the number of bicell layers per cell. If the thickness of the bicell layers does not permit a whole number of cells to fit into the set thickness of the cell, the cell thickness is slightly altered until there is an exact fit.

The use of negative electrodes operating at potentials high above the lithium metal potential may extend the upper end of the available SOC range from 95 to $100 \%$. The lithium titanate spinel, $\mathrm{Li}_{4} \mathrm{Ti}_{5} \mathrm{O}_{12}$ (LTO), negative electrode is an example of an intercalation electrode with almost no risk of plating lithium metal during a charge pulse. On this basis, the available percent of the energy content for LTO-based Li-ion cell is increased by $5 \%$ to be $75 \%$ for PHEVs and 90 \% for EVs. In an established factory, the fixed design parameter is most likely the electrode area for a single layer rather than a set cell thickness. To make higher capacity cells, more layers of the predetermined footprint are stacked, thus increasing the cell thickness. In our model, the plant is constructed for the sole purpose of building the battery being designed. Flexibility to produce other products, may substantially reduce the cost [23], but this is not taken into account in BatPaC.

Accounting for capacity and power fade in the battery requires the user to design the battery with the appropriate excess energy and power at the beginning-of-life (BOL). Achieving rated end-oflife (EOL) power at a high fraction of the open-circuit voltage at BOL is one way to set the allowable power fade over the life of the battery. This is discussed in detail in the following section. Capacity or energy fade may be managed in multiple ways. The BOL SOC range for useable energy in Table 5.1 may be considered one approach to oversizing. As the battery capacity is reduced resulting from fade mechanisms, substantial losses in total capacity and energy may have only a moderate effect on vehicle performance because the battery is cycled over a fraction of the total SOC range. In addition, the SOC window may shift to different defined pack voltages to obtain a near constant useable energy value. Current practices by the OEMs suggest that the customer will accept some degree of capacity fade from the battery over the life of the vehicle. The Chevrolet Volt battery warranty states the capacity may fade by 10 - $30 \%$ over the warranty period. Certainly, the customers' previous experience with consumer electronics devices has prepared them for a reduction in battery capacity with the life of the product. However, we do not hold the same opinion on power fade. We have allotted for significant power fade by designing EOL power to be achieved at a high fraction of the open circuit voltage at BOL. The design model does not attempt to predict fade rates or even suggest an allowable fade for a specific application, other than the SOC window for useable energy. It is our view that many aspects of materials chemistry, cell design, and battery use directly affect the decay rate of the battery pack. Hence, we allow the user to make any additional accommodations for decay believed to be necessary by entering larger total energy content than what is calculated from the useable SOC windows.

\subsection{Voltage at Rated Power}

The fraction of the open-circuit voltage at which a cell reaches the rated power is one of the most important factors in the design of a battery. However, this specification is one of the least discussed aspects of battery design. Our design approach assumes the drivetrain will never draw a power level greater than the rated power over the entire life of the battery. The voltage at rated power is a measure of the largest polarization the cell will undergo during operation at the BOL. This initial value has a direct effect on round-trip battery efficiency, heat removal requirements, cold-cranking power, and allowable power fade. The maximum achievable power for a battery at BOL is at $50 \%$ 
of the open-circuit voltage (OCV). Operating at these conditions would result in an inefficient battery and require a significant cooling system to reject heat. More importantly, the battery will never be able to reach this power level after any increase in impedance occurs. With all certainty, the impedance of a battery will rise with time and the power rating of battery will no longer be accurate.

We design the battery to achieve EOL power capabilities (rated power) at a specified fraction of the open-circuit voltage, [V/U], at BOL. This approach is unique when compared to current design practice of OEMs and cell manufacturers. However, a characteristic value of [V/U] exists for all batteries regardless of the battery design process. One may determine this value for an existing system in a straightforward manner. The voltage at rated power is measured at the end of a $10 \mathrm{~s}$ pulse at the EOL power rating and the SOC used for the power rating of a specific battery type (HEV, PHEV or EV). The designed [V/U] value is the measured potential at the end of the pulse divided by the open-circuit potential reached long after the pulse. This design point then captures the degree to which the battery has been oversized to enable long-life, cold-start, and efficient operation. The remainder of this section presents a discussion for setting the BOL voltage at rated power at no less than $80 \%$ of the open-circuit voltage, $[\mathrm{V} / \mathrm{U}]=0.8$. Defining the voltage as a fraction of the OCV, allows for direct calculation of all the necessary battery properties (see for example Eq. 5.6 or 5.8 in the section 5.3).

The allowable increase in battery resistance over the life of the battery is a function of the designed voltage for rated power. In general, designing the battery to achieve rated power at a higher [V/U] allows for larger resistance or impedance increases over the lifetime of the battery. Figure 5.2 created from Eq 5.1 displays how the voltage at rated power will change to meet the designed power as the internal resistance of the battery increases. Clearly, achieving BOL power at a high fraction of the OCV allows for greater degradation within the usable lifetime of a battery. $R_{1}$ is the initial resistance of the battery at BOL while $R_{2}$ is the resistance as the battery ages. If the minimum voltage is $55 \%$ of the OCV, the allowable increase in resistance for batteries designed for BOL rated power at 70,80 , and $90 \% \mathrm{OCV}$ is 18,55 , and $175 \%$. The consequence of achieving the power at lower and lower fractions of the open-circuit voltage is that both electric current and heat generation will increase over the lifetime of the battery, Figure 5.2b and Figure 5.3. The proper design of a battery will account for the changes over the entire lifetime and not just desired behavior at BOL.

The level of heat production is significantly different at BOL for batteries designed to meet rated power at differing fractions of the open-circuit voltage. We may compare the differences in designed $[\mathrm{V} / \mathrm{U}]$ by assuming the resistive heating (joule heating) is the most significant factor in determining the heat generation, Eq. 5.2. This assumption is true for moderate to high rate applications. We also reasonably assume the ASI will not change significantly in the range of current densities and electrode thicknesses we vary in the comparisons. We can analyze the difference in heat generation for different [V/U] values, Eq 5.3. 

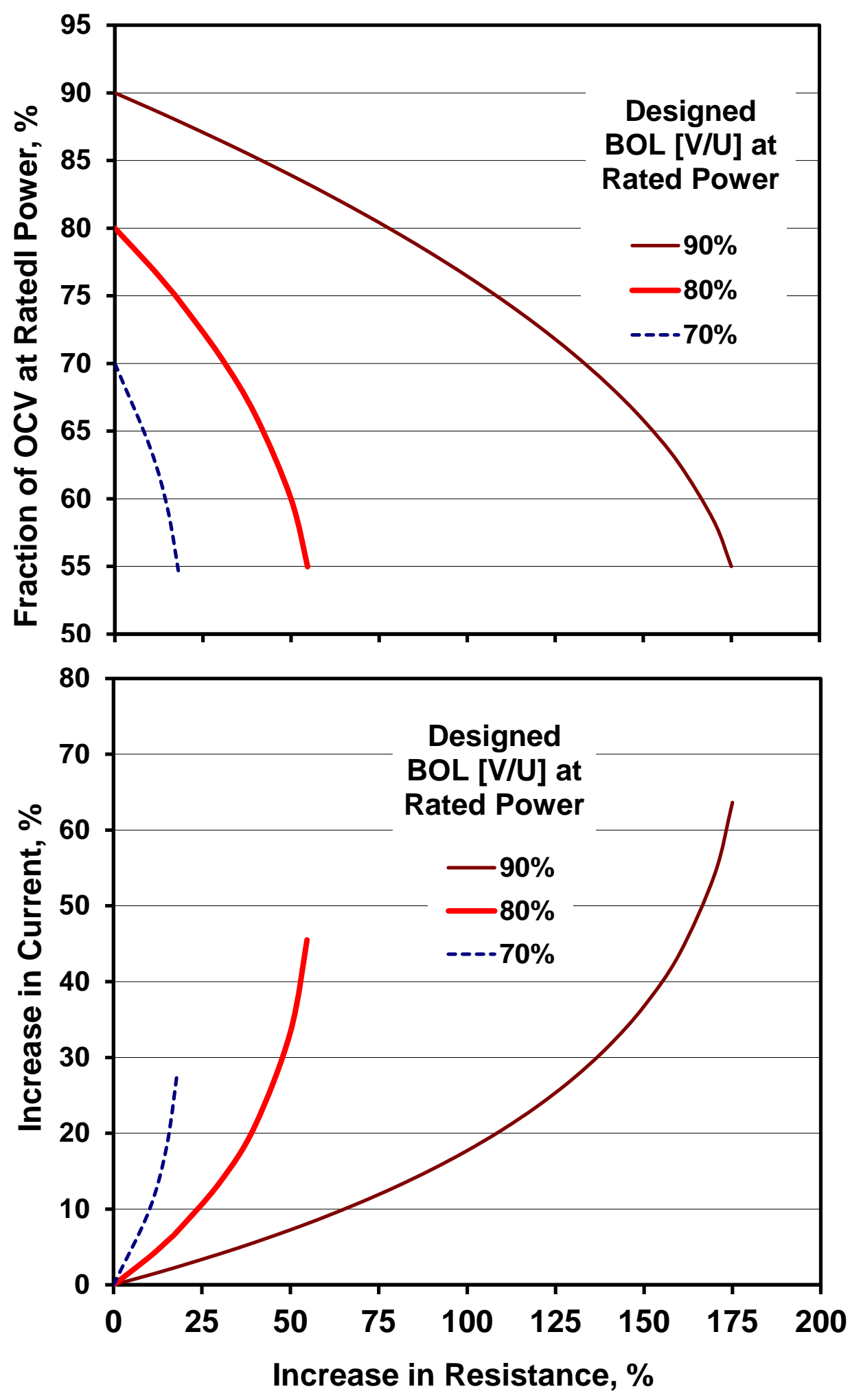

Figure 5.2 a) Required change in [V/U] to maintain rated power with increases in internal resistance over the life of the battery. b) Increase in current due to lowered [V/U]. 


$$
\begin{gathered}
{\left[\frac{V}{U}\right]_{2}=\frac{1}{2}\left\{1+\sqrt{1-4 \frac{R_{2}}{R_{1}}\left[\frac{V}{U}\right]_{1}\left(1-\left[\frac{V}{U}\right]_{1}\right)}\right\}} \\
q_{j}=\left(A_{\text {pos }} I\right)^{2} R_{j}=I_{\text {total }} U\left(1-\left[\frac{V}{U}\right]_{j}\right)=\frac{U^{2}\left(1-\left[\frac{V}{U}\right]_{j}\right)^{2}}{R_{j}} \\
\frac{q_{2}}{q_{1}}=\frac{R_{1}\left(1-\left[\frac{V}{U}\right]_{2}\right)^{2}}{R_{2}\left(1-\left[\frac{V}{U}\right]_{1}\right)^{2}}
\end{gathered}
$$

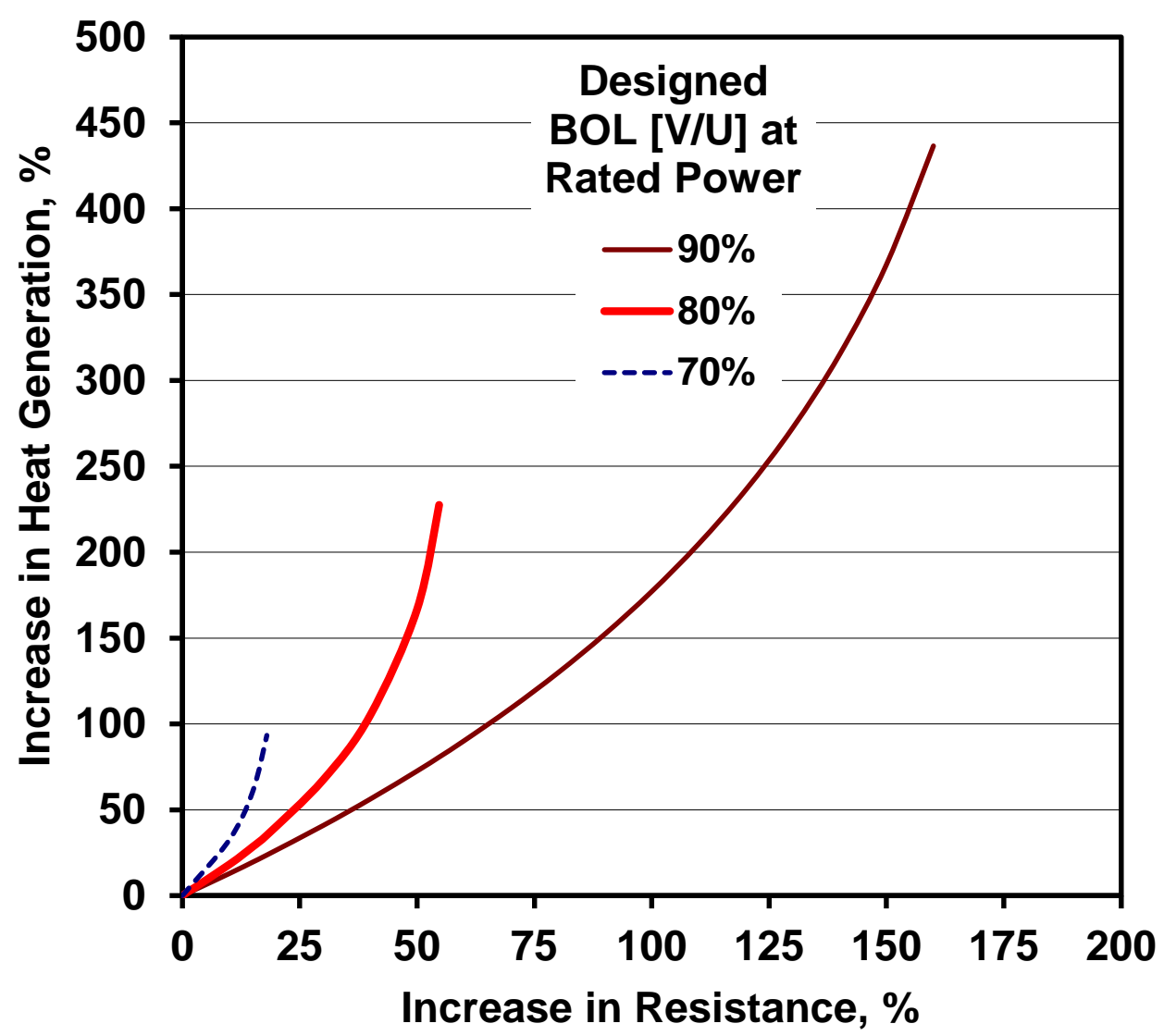

Figure 5.3 Change in heat rejection requirement from increases in resistance for batteries with different designed voltages at rated power. 
The ratio of resistances may be found by equating the power for the two cases. Then the resistances, and areas if the ASIs are equivalent, are determined solely by the fraction of the opencircuit voltage at which they achieve rated power, Eq 5.4. Then substitution will give the ratio of heat production at rated power for the two cases, Eq. 5.5. A battery that achieves rated power at $80 \%$ of OCV will have a heat production at rated power that is 2.3 times higher than one designed at $[\mathrm{V} / \mathrm{U}]=90 \%$. A battery producing power at $70 \%$ of the OCV will have 5.9 time higher heat generation than at $[\mathrm{V} / \mathrm{U}]=90 \%$.

$$
\begin{gathered}
\frac{R_{1}}{R_{2}}=\frac{A S I_{\text {power } 1} A_{\text {pos } 2}}{A S I_{\text {power } 2} A_{\text {pos } 1}}=\frac{\left[\frac{V}{U}\right]_{1}\left(1-\left[\frac{V}{U}\right]_{1}\right)}{\left[\frac{V}{U}\right]_{2}\left(1-\left[\frac{V}{U}\right]_{2}\right)} \\
\frac{q_{2}}{q_{1}}=\frac{\left[\frac{V}{U}\right]_{1}\left(1-\left[\frac{V}{U}\right]_{2}\right)}{\left[\frac{V}{U}\right]_{2}\left(1-\left[\frac{V}{U}\right]_{1}\right)}
\end{gathered}
$$

Two different design changes would enable operating a battery at $90 \%$ of OCV compared to 80 $\%$ while maintaining the same power output. First, a second identical battery may be connected in parallel to the original battery. This will lower the resistance of the battery pack by one half but will also double the energy and increase the cost of the battery. A more cost-effective approach is to reduce the electrode thickness by coating a larger electrode area with the same amount of active material. The capacity of the cell is maintained while minimizing increases in cost from the larger areas of the separator, current collector and packaging. This approach is feasible as long as the reduced electrode thickness is above that which results in increase in the ASI (about 20 microns as discussed in detail below).

The efficiency of a battery defines the heat rejection requirements and may be measured or calculated. Measurement of round-trip efficiency of a battery is best performed by using a calorimeter to measure the heat given off during the cycling of the battery. The calorimeter removes the requirement of knowing the exact SOC of a battery during the entire drive cycle. Calculation of the round-trip efficiency of a battery requires a detailed transient battery model within a vehicle simulation program to exercise the battery over the many acceleration and deceleration periods that occur during a drive cycle. The interesting result is that the same battery will have different power ratings depending on what level of round-trip efficiency the user is willing to accept.

Figure 5.4 shows the efficiency of a battery as a function of the designed potential at which the battery reaches rated power. The figure is created using Equations 5.1 and 5.4 above. Each line may be considered a different drive cycle, or duty load, for a battery with the same energy but different impedance (changing separator area). The straight, solid black line represents the efficiency of the battery operated only at rated power, $P / P_{\max }=1$. In example, a battery designed 
at $[\mathrm{V} / \mathrm{U}]=0.8$ will have $80 \%$ efficiency for a single discharge pulse at rated power. Likewise, a battery designed at 0.9 will be $90 \%$ efficient at rated power. Batteries are normally operated in the area above the line of the rated power. Therefore, the other curves represent the efficiency of discharging a battery at power levels below rated power (typical driving conditions). Consider two batteries each designed for a rated power of $100 \mathrm{~kW}$ although one achieves this power at a [V/U] $=0.9$ and the other at 0.7 . If the two batteries are discharged at $45 \mathrm{~kW}, P / P_{\max }=0.45$, the battery designed at $[\mathrm{V} / \mathrm{U}]=0.9$ will be $6.4 \%$ more efficient. This is significantly less than the $20 \%$ efficiency improvement realized when operated at rated power. The efficiency penalty is reduced as the battery operates less and less near the rated power.

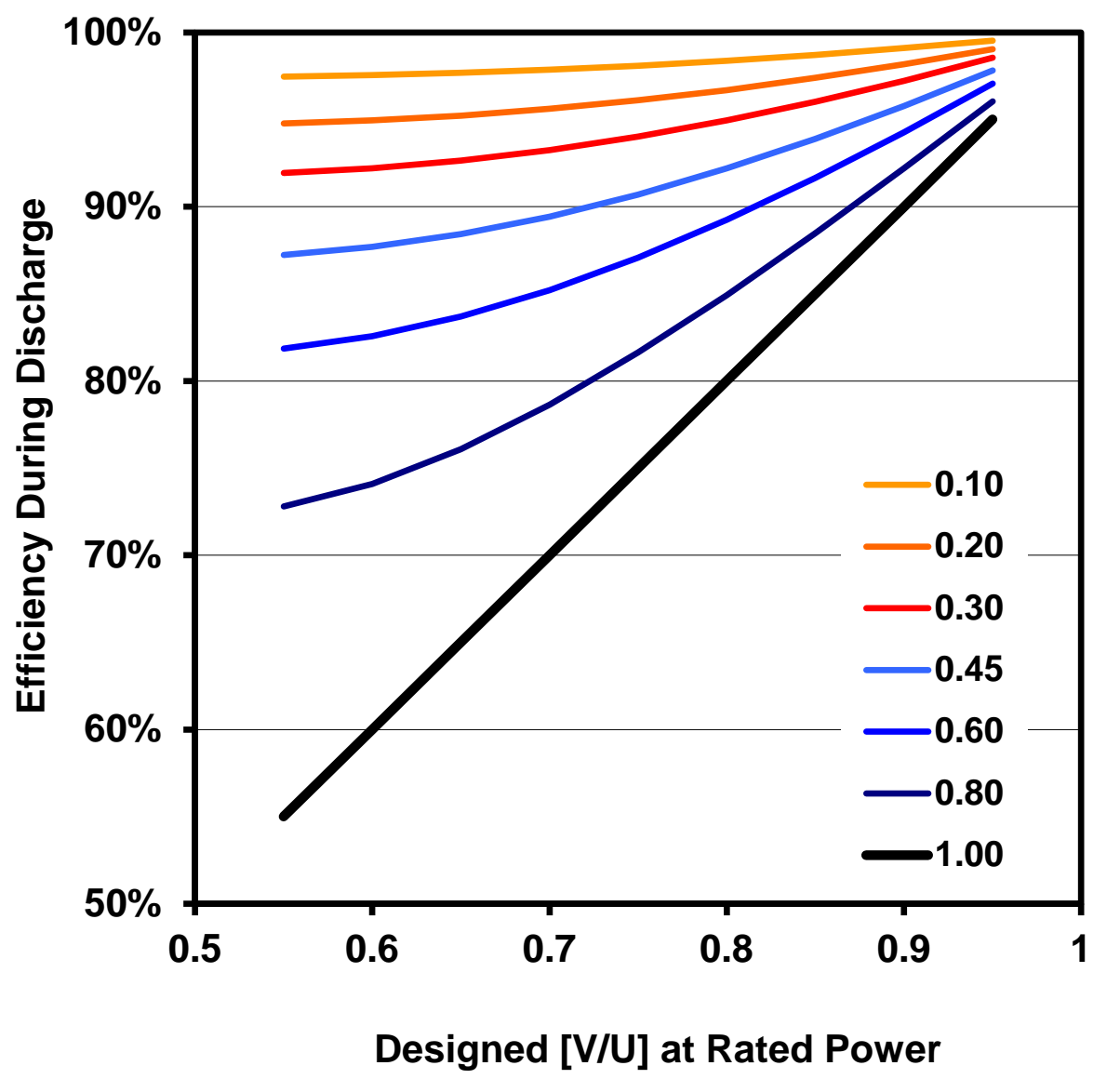

Figure 5.4 Efficiencies for batteries designed to achieve rated power at different fractions of their open-circuit voltage. Comparative efficiency lines are shown for equivalent power demands over a period of battery operation.

\subsection{Governing Equations}

The five coupled, algebraic equations that govern the battery design are presented in this section. While these equations are perhaps the most important, many other equations are used to fully define the battery mass and volume. These other equations will be specified where necessary in the following subsections. 
The user of the model specifies the required maximum rated power, $P_{\text {batt }}$, of the battery. This power is translated to a current density, $I$, in Eq 5.6 using the area of the positive electrode, $A_{\text {pos, }}$ the

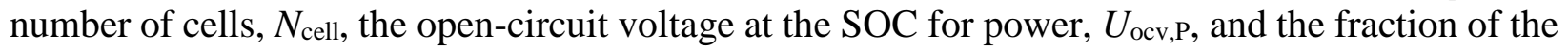
open-circuit voltage at which the designed power is achieved, [V/U].

$$
I=\frac{P_{b a t t}}{A_{p o s} N_{c e l l} U_{o c v, P}\left[\frac{V}{U}\right]}
$$

The relationship between capacity and battery energy is described by Equation 5.7. Formally, the energy of a battery is the product of the capacity and the average voltage at which the energy is obtained. The average cell voltage is approximated in Eq. 5.7 by subtracting the polarization from discharging the battery at a $\mathrm{C} / 3$ rate from the open-circuit voltage at the SOC for energy, $U_{\text {ocv,E} \text {. }}$ The energy for all batteries designed by the model is calculated at a $\mathrm{C} / 3$ rate and the average opencircuit voltage at $50 \%$ SOC. The remaining necessary values are the capacity of the cell, $C$, ASI

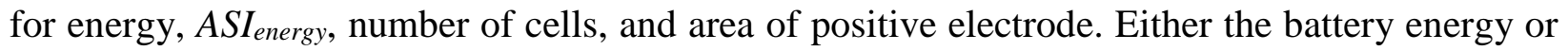
capacity may be specified. The energy may alternatively be determined from a stated range, fraction of total energy available, and energy usage rate for the vehicle (Wh/mile).

$$
E=N_{c e l l} C\left(U_{o c v . E}-\frac{C}{3} \frac{A S I_{\text {energy }}}{A_{p o s}}\right)
$$

The area of the positive electrode in Eq. 5.8 is determined largely by the area specific impedance for power, $A S I_{\text {power, }}$ and resulting voltage drop. The voltage of cell at rated power, $V_{\text {cell,P, }}$ is found from the product $[\mathrm{V} / \mathrm{U}] U_{\mathrm{ocv}, \mathrm{P}}$, where $U_{o c v, P}$ is the open circuit voltage at the SOC for max power. In general, the area of the electrodes will increase if the ASI for power increases. The areas of the negative electrode and separator are determined from the area of the positive electrode. The negative electrode is taken to be $1 \mathrm{~mm}$ larger than the positive electrode in both height and width to alleviate concerns of lithium plating during charge pulses. The separator area is slightly larger than the negative electrode to prevent the electrical shorting of the two electrodes.

$$
A_{\text {pos }}=\frac{A S I_{\text {power }} P_{\text {batt }}}{N_{\text {cell }}\left(U_{\text {ovv }, P}\right)^{2}\left[\frac{V}{U}\right]\left(1-\left[\frac{V}{U}\right]\right)}
$$

The positive electrode thickness, $L_{\text {pos, }}$ in Eq. 5.9 is determined from the capacity of the cell, $C$, specific capacity of the electrode material, $Q$, volume fraction of active material, $\varepsilon_{\text {act, }}$ bulk density of the active material, $\rho$, and the positive electrode area. The negative electrode thickness is determined by its specific reversible-capacity and the designed excess-capacity to prevent lithium plating during charging. We have chosen a ratio of 1.25 negative to positive reversible-capacity (N/P ratio) for the default value for the cells with graphite negative electrodes. LTO negative electrode based cells are designed at a $1.1 \mathrm{~N} / \mathrm{P}$ ratio because of the previously mentioned minimal possibility of lithium deposition. The maximum allowable electrode thickness is a user defined 
value. The calculation for the electrode area changes when the designed thickness is greater than the maximum allowed (Section 5.6).

$$
L_{\text {pos }}=\frac{C}{Q \rho \varepsilon_{\text {axt }} A_{\text {pos }}}
$$

Finally, the ASI for power (and for energy to a lesser extent) is calculated using an expression that is based on the electrode thicknesses, the current density, and the C-rate. The exact expression will be discussed in the next section. The ASI in Eq. 5.10 shows the basic dependencies with $\alpha$ and $\beta$ being constant valued parameters.

$$
\mathrm{ASI}=\frac{\alpha+f(I)}{L_{\text {pos }}}+\beta
$$

\subsection{Calculation of the ASI}

In most battery design scenarios, the ASI and [V/U] directly determine the electrode thickness and area to meet a specified power-to-energy (P/E) ratio and capacity requirement. Clearly, the ASI plays a significant role in the design of a battery and particularly in the case of the P/E ratios required by automotive applications. However, the ASI is not an inherent constant of a specific battery chemistry or cell design. The measured value of the ASI is a complex combination of resistances within the battery resulting from the physical processes occurring at different length and time scales. Consequently, the measured value is a function of many factors (state of charge, pulse length, current density, C-rate, particle size, transport and kinetic parameters, etc). The calculation used for the ASI in this battery design model has been discussed in detail and validated against experiments elsewhere [15]. The physical meaning of the equation will be discussed but those interested in the derivation are directed to the separate publication. We note that the ASI described here is slightly different than the one addressed in the paper. The thermodynamic component is removed that originated from the change in open-circuit potential with concentration for the intercalation materials. Equation 5.11 contains the definition of the ASI used in this document. $I_{t 1}$ is a positive valued current density for a discharge pulse. $I_{t 2}$ is equal to zero as it is during the relaxation period after the pulse. The subscripts are as follows: time $0, t 0$, is the time just before a current pulse begins, time $1, t 1$, is the time just before the current pulse ends, and time 2 , $t 2$, is the time long after the current pulse when the cell is at open-circuit and the concentration gradients have relaxed. Therefore, this ASI measurement is not troubled by accounting for a

$$
A S I=\frac{V_{t 2}-V_{t 1}}{I_{t 1}-I_{t 2}}
$$

change in open-circuit voltage with the passage of current. In general, the ASI defined by this definition is similar, although slightly smaller in value, than that obtained with the more standard definition used elsewhere. 
The ASI for the electrochemical charge and discharge process is referred here-in as ASI $I_{\text {echem }}$. Our calculation approach for both the ASI for power and for energy involves adding three components together to reach the $A S I_{e c h e m}$, Eq. 5.12. The first two factors include impedance that arises from the interfacial charge transfer and transport. The third factor is a lumped parameter used to capture the remaining impedance.

$$
A S I_{\text {echem }}=A S I_{\text {inff }}^{\text {pos }}+A S I_{\text {inf }}^{\text {neg }}+A S I_{\text {const }}
$$

The interfacial impedance for positive and negative electrodes both contain the charge transfer resistance component $\bar{R} T /\left(i_{o} a L F\right)$ as shown in Eq. 5.13 and 5.14. Here, $i_{o}$ is the exchange current density related to the interfacial area and $a$ is the ratio of interfacial area to electrode volume. An approximation often used for $a$ relates the parameter to the volume fraction of the active material and the particle radius, $a=3 \varepsilon_{\mathrm{acc}} / \mathrm{r}_{\mathrm{p}}$. The variables $i_{o}$ and $a$ should be specified to relate to the same area as they are often not independently determined. $\bar{R}$ and $T$ correspond to the universal gas constant and absolute temperature respectively. $F$ is Faraday's constant. The influence of the interfacial impedance is that the ASI $_{\text {echem }}$ increases as the electrode thickness is reduced. This behavior is typically observed at electrode thicknesses less than 30 microns for common Li-ion battery materials.

$$
\begin{gathered}
A S I_{\text {inf }}^{\text {nag }}=\frac{\bar{R} T}{i_{0} a L_{\text {nag }} F} \\
A S I_{\text {inff }}^{\text {pos }}=\frac{\bar{R} T}{i_{0} a L_{\text {pos }} F}\left\{\left(1-\frac{I}{I_{\text {lini }}^{\text {ionic }}}\right)\left[1-\left(\frac{r_{C}}{r_{C, \text { lim }}}\right)^{2}\right]\right\}^{-0.5}
\end{gathered}
$$

The positive electrode interfacial impedance also includes two factors that account for the physical limitations that occur from depleting the concentration of the reactants within the porous electrode. The $I_{\lim }^{\text {ionic }}$ term is the limiting ionic current for lithium cation transport through the porous separator. The $r_{C, \text { lim }}$ term is the limiting C-rate for solid state diffusion of lithium in the active materials. The C-rate may be related to the current density with Eq. 5.15.

$$
I=r_{C} Q \rho \varepsilon_{a x t} L_{p o s}
$$

Here, the specific capacity, $Q$, the active material density, $\rho$, active material volume fraction, $\varepsilon_{a c t}$, and the electrode thickness, $L$, are used. If either the limiting C-rate or limiting ionic current are approached, the ASI will begin to approach an infinite value. This assumes the cell and material design is such that the transport limitations all occur on the positive electrode. The parameters required for the ASI expression are fit to experimental measurements, corrected for the interfacial contributions present during measurements. Resent results of teardown studies (for instance Ricardo Inc. [25]) in measuring the impedance of cells from electric-drive vehicles have indicated lower impedances than those on which $\mathrm{BatPaC}$ was based in the past and accordingly we have adjusted our input values on the Chem worksheet. 
The cell ASI for energy, $A S I_{\text {energy }}$, and power, $A S I_{\text {power, }}$ are determined by adding the $A S I_{\text {echem }}$ to that of the current collectors, $A S I_{c c}$, as discussed in the next subsection. The difference between $A S I_{\text {energy }}$ and $A S I_{\text {power }}$ is that the limiting currents are not important during the $\mathrm{C} / 3$ discharge for energy and the $A S I_{\text {const }}$ is a different value for the two cases. $A S I_{\text {energy }}$ will always be higher than $A S I_{\text {power }}$ if a battery is operated far from the limiting current. The higher impedance is due to the formation of significant concentration polarizations during the longer time scale of the energy

discharge. The teardown studies mentioned above [25] indicated a reduction in the ratio of $A S I_{\text {energy }}$ to $A S I_{\text {power }}$ as compared to the values in past versions of $\mathrm{BatPaC}$ and we have reflected that change in the new values in the Chem worksheet.

\subsubsection{Current Collection Resistance}

The resistance from the conductors used to collect the current must be accounted for as they can contribute significant ohmic drop to the battery. The ASI used to calculate the required cell separator area, ASI power, is larger than the ASI for the electrochemical charge and discharge

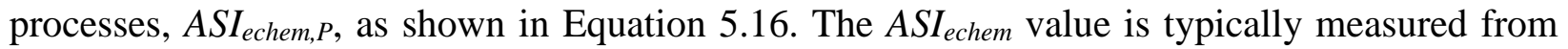
experiments and must be added to the external resistances that arise from the materials used to conduct the electric current. These resistances come from current collection in the cell and also those on the module and battery pack level.

$$
A S I_{\text {power }}=A S I_{\text {echem }, P}+A S I_{c c}+A S I_{\text {term }}^{\text {cell }}+\frac{R_{c n c t} A_{\text {pos }}}{N_{c e l l s}}
$$

The current collector foil impedance, $A S I_{c c}$, is determined from an analytical expression, Eq. 5.17, which accounts for the coated and uncoated region of the foil, labeled act for active and $t a b$ respectively. The resistance factor, $R_{f}$, and the resistance of the current collector foils, $R_{c c}$, are also shown for clarity in Eq 5.18 and 5.19. The factor of 2 in the $R_{f}$ term is due to assuming half of the foil thickness carries the current produced on one side of the foil. While all of the current passes through the tab region, the magnitude of the current varies along the height of the coated foil as the reaction area continually contributes current to the foil. An equivalent length for the resistance calculation may be determined so that multiplication by the total current for a cell will give the correct ohmic drop. This equivalent length is $\mathrm{H} / 3$ if the current density is relatively constant over the entire area. The derivation of this equivalent length as well as an in-depth discussion of the voltage and current distribution in the foils may be found in subsection 5.4.2. Also in the later subsection, the assumption of constant current density is verified with numerical modeling.

$$
\begin{gathered}
A S I_{c c}=H_{a c t} W_{a x t} R_{c c}=R_{f}\left(\frac{\left(H_{a c t}\right)^{2}}{3}+H_{a x t} H_{t a b}\right) \\
R_{f}=\left(\frac{2}{\sigma_{\text {foilneg }} L_{\text {foil }, n e g}}+\frac{2}{\sigma_{\text {foil pos }} L_{\text {foil pos }}}\right) \\
R_{c c}=R_{f}\left(\frac{H_{a c t}}{3 W_{a c t}}+\frac{H_{\text {tab }}}{W}\right)
\end{gathered}
$$


The cell terminals are ultrasonically welded to the ends of the current collector foil tabs. While the welding removes this contact resistance, the ASI of the terminal must be included in the total cell resistance. The ASI of the cell terminals, is the summation of the positive and negative cell terminals as shown in Eq 5.20. The dimensions for these terminals are set by the calculated width of the cell and the user defined terminal thickness (default, $1.0 \mathrm{~mm}$ ) and height (extension from the electrode coating, a function of the cell thickness).

$$
A S I_{\text {temm }}^{\text {cell }}=\left(\frac{1}{\sigma_{\text {term, neg }}}+\frac{1}{\sigma_{\text {term pos }}}\right) \frac{H_{\text {term }}}{W_{\text {term }} L_{\text {term }}} A_{\text {pos }}
$$

The ASI for connection losses is the last term in the ASI summation stated in Eq. 5.16. This ASI value is calculated by multiplying the ratio of cell positive electrode area to number of cells by the summation of the resistances, $R_{\text {cnct }}$, for cell terminals, module terminals, module interconnects, and batteries terminals. In this way, each cell shares in the burden of overcoming the system losses from carrying the electric current. The calculation of $R_{\text {cnct }}$ is detailed in Eq. 5.21 with the individual sources of connection losses shown. The voltage drop resulting from cell-to-cell contact resistance, $R_{\text {cntct }}^{\text {cell }}$, is taken to be $10^{-4} U_{\text {ocv,E }}$ in Eq. 5.22, a small fraction of the open-circuit voltage. A battery manufacturer would only tolerate a minimal voltage drop from cell-to-cell contact. One connection method is to physically press the two cell terminals together. This resistance could be lowered by increasing the physical pressure and contact area, or by laser welding the terminals together. Regardless, the value used in the model is left to the choice of the user to leave as is or to change to a different value.

$$
\begin{gathered}
R_{c n c t}=N_{c e l l} R_{c n t c t}^{c e l l}+N_{\text {mod }} R_{\text {term }}^{\text {mod }}+\left(N_{\text {mod }}-1\right) R_{\text {incnt }}^{\text {mod }}+R_{\text {term }}^{\text {batt }} \\
R_{c n c t}^{c e l l}=10^{-4} \frac{N_{c e l l} U_{o c v, E}}{L A_{\text {pos }}}
\end{gathered}
$$

The module terminal resistance, calculation in Eq. 5.23 is shown as an example of how the terminal and interconnect resistances are calculated for the module and battery pack. The size of the terminals and thus their resistances are determined from a calculation based on a pre-determined allowable rate of temperature rise for the conductor. This approach is explained in more detail in subsection 5.4.3.

$$
R_{\text {temm }}^{\text {mod }}=\frac{H_{\text {term }}}{\sigma_{\text {term }} \pi\left(r_{\text {term }}\right)^{2}} N_{\text {term }}^{\text {mod }}
$$

\subsubsection{Potential and Current Distribution in the Current Collection Foils}

The designed current collection system was evaluated using a numerical simulation package. Equations 5.24-5.26 were solved for a steady state, isothermal, and 1-D simulation. Here, the conductivity, $\sigma_{\mathrm{j}}$, is the effective conductivity of $1 / 2$ of the foil (the other half carries the current from the opposite side). The bulk conductivity value, $\sigma_{\mathrm{j}}{ }^{0}$, is multiplied by the thickness of the conductor, $L_{\mathrm{j}} / 2$, to lower the dimension of transport. 


$$
\begin{gathered}
I_{n}=\frac{U_{o c v}-\left(\Phi_{1, \text { pos }}(x)-\Phi_{1, \text { neg }}(x)\right)}{A S I_{\text {echem }}} \\
\nabla \cdot\left(\sigma_{\text {pos }} \nabla \Phi_{1, p o s}\right)=-I_{n} \\
\nabla \cdot\left(\sigma_{\text {neg }} \nabla \Phi_{1, n e g}\right)=I_{n}
\end{gathered}
$$

The boundary conditions were set for both ends of each foil. The tab ends of the foils were set to a specified voltage and the opposite ends of the foils were restricted to a no flux condition. The simulation was performed using as representative foils: 12 micron thick copper foil and 20 micron

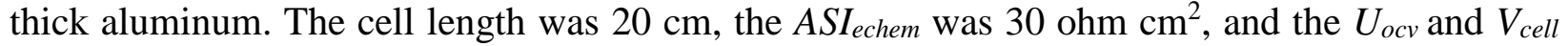
were set to 3.72 and $3.57 \mathrm{~V}$ respectively. Figure 5.5 shows the current and potential distribution in the foils and in the cell resulting from the simulation. The cell potential along the length of the foil varies only by $1.5 \mathrm{mV}$ from maximum to minimum difference. The $0.04 \%$ variation in voltage results in a $0.9 \%$ variation in current density. This verifies the current density is uniform along the length of the foil. This is also obvious from the linear relationship of current with foil height in Fig. 5.5. The assumption of constant current density was tested in cell heights up to $100 \mathrm{~cm}$ and found to be satisfactory. The assumption should be reasonable as long as the $A S I_{\text {echem }}$ is at least twice the value of $A S I_{c c}$. The simulated resistance of the foils is found to raise the $A S I_{\text {echem }}$ by 0.7

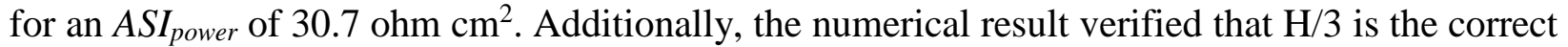
equivalent length to represent the $A S I_{c c}$ for the cell. This may also be found analytically, Eq. 5.275.29, if you assume an even current distribution. We have shown that to be a reasonable assumption.

$$
\begin{gathered}
\Phi_{1, p o s}=V_{\text {cell }}+\frac{I_{n}}{2 \sigma_{\text {pos }}}\left(H^{2}-x^{2}\right) \\
\Phi_{1, n g g}=\frac{I_{n}}{\sigma_{\text {neg }}}\left(\frac{x^{2}}{2}-x L\right) \\
A S I_{\text {echem }}+A S I_{c c}=\frac{1}{H} \int_{0}^{H} \frac{\Phi_{1, p o s}-\Phi_{1, n e g}}{I_{n}} d x=\frac{V_{c e l l}}{I}+\frac{H^{2}}{3}\left(\frac{1}{\sigma_{\text {pos }}}+\frac{1}{\sigma_{\text {neg }}}\right)
\end{gathered}
$$



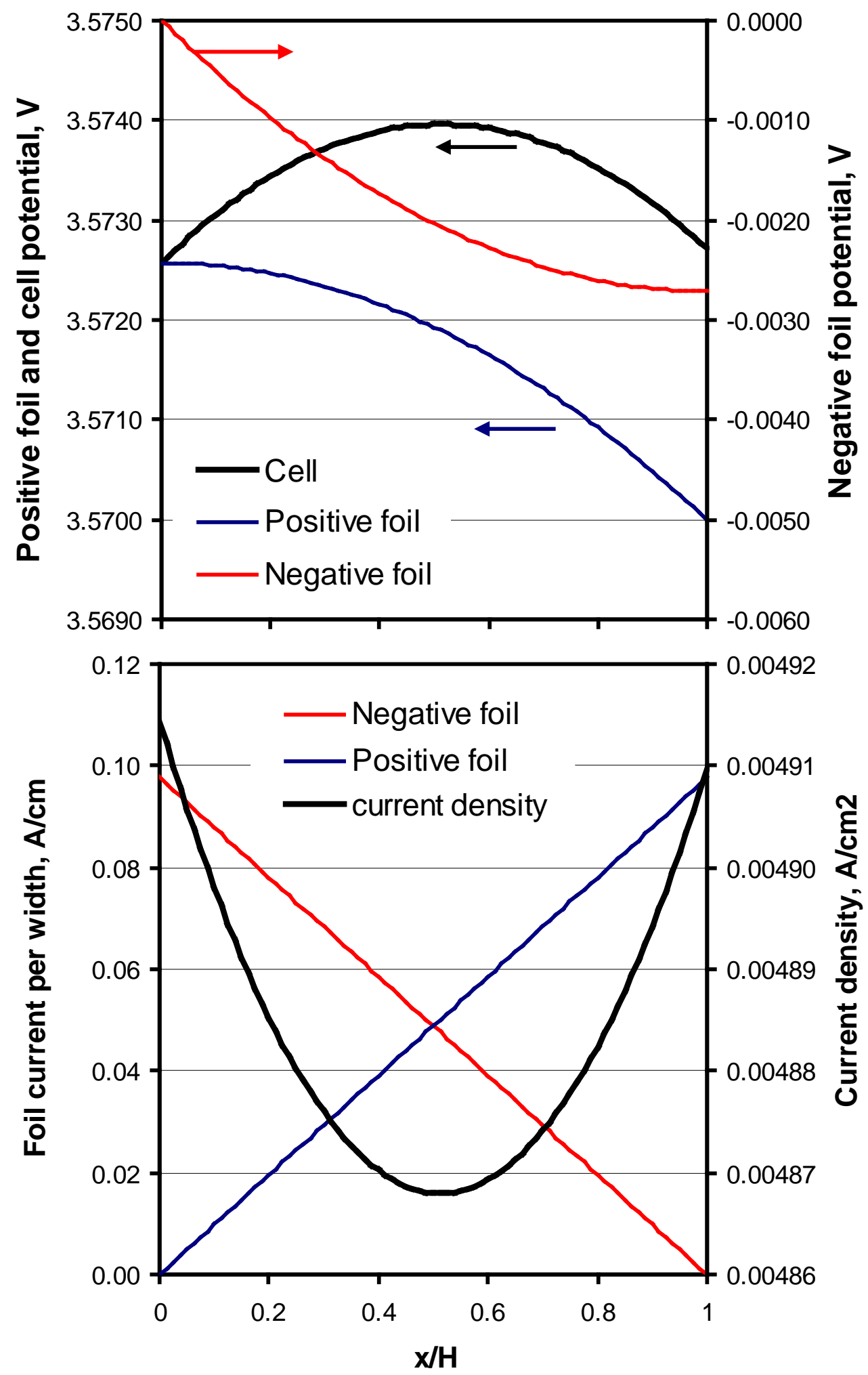

Figure 5.5 The change in current and potential within the positive and negative foils. The current collection design results in a uniform current distribution along the length of the foil. 
An analogous problem has been solved by Euler and Nonnemacher and then communicated repeatedly by Newman et al. [26,27]. The analytical solution they presented may be used after a slight alteration to dimensionalize the current density to the geometry of our concern, Eq. 5.30 and 5.31. This solution was reached assuming linear polarization behavior and is valid for cases where the current density varies along the height of the current collector foil. Thus, this approach is a more general solution than the one we use in the design model.

$$
\begin{gathered}
\mathrm{ASI}_{e c h e m}+\mathrm{ASI}_{c c}=\frac{U_{o c v}-\left(\Phi_{1, p o s}-\Phi_{1, n g g}\right)}{I}=\frac{H^{2}}{\sigma_{n e g}+\sigma_{p o s}}\left[1+\frac{2+\left(\frac{\sigma_{\text {neg }}}{\sigma_{p o s}}+\frac{\sigma_{p o s}}{\sigma_{\text {neg }}}\right) \cosh v}{v \sinh v}\right] \\
v^{2}=\frac{H^{2}}{A S I_{\text {echem }}}\left(\frac{1}{\sigma_{\text {pos }}}+\frac{1}{\sigma_{\text {neg }}}\right)
\end{gathered}
$$

\subsubsection{Sizing of Module Terminals, Battery Terminals, and Module Inter-connects}

An important factor for setting the resistances of a module terminal, battery terminal, or module interconnect is the allowable rate of temperature rise in the conductor at full power. We set the acceptable rate of temperature rise, $\mathrm{dT} / \mathrm{dt}$, at $0.2{ }^{\circ} \mathrm{C} / \mathrm{sec}$ or a $2{ }^{\circ} \mathrm{C}$ rise for a 10 -sec power burst under adiabatic conditions. The heating rate, $q$, is then used to determine the mass, $m$, of the terminal required for the designed battery in Eq. 5.32. Since the heating rate may also be determined by Eq. 5.33, we may determine the cylindrical terminal radius and mass by assuming a length, $H_{\text {term. }}$. In this way, the size of the module terminal is redesigned during each simulation to meet the specified power requirements and allowable temperature rise, Eq. 5.34. The mass of the conductor is found to be inversely proportional to the allowable temperature rise.

$$
\begin{gathered}
q=m C_{p} \frac{d T}{d t} \\
q=\frac{H_{\text {termm }}}{A_{\text {term }} \sigma_{\text {term }}}\left(L A_{p o s}\right)^{2} \\
A_{\text {term }}=L A_{p o s}\left[\rho_{\text {term }} \sigma_{\text {term }} C_{p} \frac{d T}{d t}\right]^{-1 / 2}
\end{gathered}
$$

A copper busbar must also be sized for batteries using a single row of modules. We have somewhat arbitrarily assumed a $\Delta V_{b b}=30 \mathrm{mV}$ drop across the busbar to be allowable at maximum current. This value may be easily changed by the user. Equation 5.35 is used to calculate the mass of the 
busbar, $m_{b b}$. The complicated expression for the volume of the busbar is derived from the voltage drop, conductivity, busbar width, $w_{b b}$, and required busbar cross-sectional area.

$$
m_{b b}=\rho_{b b} \frac{I_{t o t}\left(w_{b b}\right)^{2}}{\Delta V_{b b} K_{b b}}
$$

\subsection{Calculation of Battery Dimensions}

The goal of the model is to quantify how the various components of a specific battery design sum to make the mass and volume of the battery pack. In this way, a true energy and power density can be calculated as well as the exact materials requirement to meet this design. Summing the mass of the components is relatively straight forward. Determining the total volume that contains the components and required free volume is not as obvious. The exact calculations used in the design model are detailed below for the cell, module, and battery pack.

\subsubsection{Cell Dimensions}

The number of layers in each cell is determined in Eq. 5.36 by accounting for the compression factor, $X_{\text {comp }}$, and the individual thicknesses of the current collector foils, $L_{\text {foil }}$, electrodes, $L_{\text {pos }}$ and $L_{n e g}$, separator, $L_{\text {sep }}$, and container, $L_{\text {cont }} . X_{\text {comp }}$ is usually taken to be 0.97 . The Li-ion battery chemistries for which this model was designed are assumed to undergo negligible volume change at the cell level. Slight volume changes can be accommodated as mentioned in Section 2.5.

$$
N_{\text {lavers }}=X_{\text {comp }} \frac{L_{\text {cell }}-2 L_{\text {cont }}+L_{\text {foil }}^{\text {neg }}}{L_{\text {foil }}^{\text {neg }}+L_{\text {foil }}^{\text {pos }}+2\left(L_{\text {sep }}+L_{\text {neg }}+L_{\text {pos }}\right)}
$$

The $N_{\text {layers }}$ calculation is necessary as the cell thickness is a user defined parameter. The aspect ratio of the cell is also user defined; therefore, solving for the width also determines the height of the cell as seen in Eq. 5.37. The width is calculated from the number of layers and the aspect ratio, $H / W$. The factor of 2 enters the denominator as both sides of the foil are assumed to be coated.

$$
W_{\text {pos }}=\sqrt{\frac{A_{\text {pos }}}{2 \frac{H}{W} N_{\text {lavers }}}}
$$

Having determined the width and height of the electrode, the rest of the cell dimensions are relatively straightforward, Eq. 5.38 and 5.39. The width of the cell, $W_{\text {cell, }}$, is $2 \mathrm{~mm}$ wider than the positive electrode to allow for the larger separator area and pouch seals. The thickness of the folded edge, $L_{e}$, is also included in the width dimension. The seals on the sides of the pouch are folded up, pressing along the inside wall of the module casing. The height of the cell, $H_{\text {cell, }}$, is the height of the positive electrode in addition to the distance for the terminals and connections to the foil tab, $L_{\text {term,cnt. }}$ Our assumed design requires $15 \mathrm{~mm}$ for this distance at each end of the cell for a total of $30 \mathrm{~mm}$. The volume of the cell is the product of the three dimensions. 


$$
\begin{gathered}
W_{\text {cell }}=W_{\text {pos }}+2+2 L_{\varepsilon} \\
H_{\text {cell }}=H_{\text {pos }}+2 L_{\text {terment }}
\end{gathered}
$$

\subsubsection{Module Dimensions}

The module dimensions are defined by Eq. 5.40-5.42. The height and length of the module are both just $2 \mathrm{~mm}$ wider than the cell dimension. The width of the module is related to the total thickness from all of the cells with allowance for a SOC controller, which has the same thickness as a cell and is located at one side of the module.

$$
\begin{gathered}
H_{\bmod }=W_{\text {cell }}+2 \\
L_{\text {mod }}=H_{\text {cell }}+2 \\
W_{\text {mod }}=L_{\text {cell }}\left(N_{\text {cell } / \bmod }+1\right)+1
\end{gathered}
$$

\subsubsection{Battery Pack Dimensions}

The battery pack volume includes all of the modules, spacing for connections between modules, channels for the coolant to flow, $H_{\text {cool }}$, thickness of the module compression plates, $L_{\text {comp }}$, and the battery pack jacket, $L_{j a c k}$ (Eq. 5.43-5.45). $L_{j a c k}$ includes a 10 -mm thick insulation layer sandwiched between two aluminum walls for the container. The thickness of the aluminum wall increases from 1 to 1.5 to $2 \mathrm{~mm}$ as the battery volume increases from $<20 \mathrm{~L}$ to $<40 \mathrm{~L}$ to larger dimensions. The layout of the modules, number per row, $N_{\text {mod/row }}$, and number of rows, $N_{\text {row }}$, is also included. The final volume of the battery is the product of the three dimensions. The space left for connections between modules, $L_{g a p}$, is a function of the number of rows of modules. $L_{g a p}$ is equal to 8,10 , or 20 depending if there is one, two, or four rows of modules. Three rows of modules are not allowed as the positive and negative terminal for the battery would be on opposite ends and thus not very practical. A number greater than four rows of modules is deemed unnecessary.

$$
\begin{gathered}
H_{\text {batt }}=H_{\text {mod }}+2 H_{\text {cool }}+2 L_{j a c k} \\
L_{\text {batt }}=N_{\text {modrow }} W_{\text {mod }}+H_{\text {cool }}+2 L_{\text {comp }}+2 L_{j a c k} \\
W_{\text {batt }}={ }_{\text {Nrow }} L_{\text {mod }}+L_{\text {gap }}+2 L_{j a c k}
\end{gathered}
$$

\subsection{Maximum Electrode Thickness}

A practical limitation exists for the maximum achievable electrode thickness. This limitation may be set by manufacturing capabilities, ionic and electronic current transport within the porous electrode, susceptibility to plating lithium on the negative electrode, or aging characteristics related to adhesion to the current collector. Some of these challenges are discussed in more detail in the following subsection. When the maximum electrode thickness, $L_{\max }$, has been reached on either 
the positive or negative electrode, the electrode area equation is modified as shown in Eq 5.46. The electrode thickness, $L_{t g t}$, is the largest electrode thickness, negative or positive, calculated at the targeted fraction of the $\mathrm{OCV}[\mathrm{V} / \mathrm{U}]$.

$$
A_{\text {pos }}^{L \max }=\frac{L_{\text {tgt }}}{L_{\max }} A_{\text {pos }}
$$

The area of the electrode is now determined by the cell capacity requirement to meet the battery energy demands and not the target voltage at rated power. As a consequence, the battery pack will operate at a higher [V/U] than originally selected by the battery designer. The new $[\mathrm{V} / \mathrm{U}]$ may then be calculated from Eq. 5.47 which is the solution to the quadratic found in Eq. 5.48.

$$
\begin{gathered}
{\left[\frac{V}{U}\right]=\frac{1}{2 U_{c e l l}}\left[U_{c e l l}+\sqrt{\left(U_{c e l l}\right)^{2}-4 \frac{P_{\text {batt }} A S I_{\text {power }}}{N_{c e l l s} A_{\text {pos }}}}\right]} \\
V_{\text {cell }}=U_{\text {cell }}-\frac{P_{\text {batt }} A S I_{\text {power }}}{V_{c e l l} N_{c e l l i s} A_{\text {pos }}}
\end{gathered}
$$

The maximum electrode thickness may have a large impact on the energy density and cost of cells designed for high energy and range. Nelson et al. demonstrated this concept in 2009 assuming a 100-micron maximum electrode thickness [12,19]. In 2010, Santini et al. relaxed this assumption to 300-micons; although, the thickest electrode discussed in the paper was a 225 micron graphite electrode in the LMO-Gr EV with 100 mile range [13]. In conversations with manufactures, 100 microns appears to be the general electrode thickness used for EV type cells at the present time. However, Santini et al. has shown substantial increases in energy density and decreases in cost if larger electrode thicknesses may be utilized. The challenges to achieving thick electrodes, in addition to those already mentioned, relate to fast charging while avoiding lithium metal deposition, utilizing all of the materials reversible capacity, removing gases formed during formation cycling, wetting the full porosity of the electrode, achieving defect free coatings, and drying the thick electrode at high rates. Our opinion is that the successful cell manufacturers will engineer ways to overcome these challenges to increase energy density and lower cost, for some applications and thus we have set the maximum thickness at 200 microns for this version of BatPaC.

Dependent upon the battery chemistry and designed P/E ratio, the maximum achievable electrode thickness (loading) may have a significant effect on the end cost and energy density of a battery pack. For batteries designed at low $\mathrm{P} / \mathrm{E}$ ratios or for cell chemistries with low volumetric capacities, the designed electrode thickness based on the target efficiency is often larger than what is feasible during operation in a transportation environment. This subsection explores some of the challenges that arise in the electrochemistry when larger electrode thicknesses are utilized.

Argonne gained a wealth of experience in the NCA-Gr in 1.2 M LiPF 6 3:7 EC:EMC cell during the Advanced Technology Development program sponsored by the US Department of Energy (DOE). Dees and coworkers developed a world-leading parameter set for a numerical model through exhaustive electrochemical measurements, ex-situ characterization techniques, and multi- 
scale modeling activities [28-37]. The resulting phenomenological cell model founded on the methodology originating from John Newman (UC Berkeley) may be used to evaluate the electrochemical behavior of cells using thick electrodes [38]. The coupled, non-linear partial differential equations are solved with the finite element method using FlexPDE.

Simulated discharge capacity for the $\mathrm{C} / 1$ and $\mathrm{C} / 3$ discharge rate is shown in Figure 5.6 as a function of electrode thickness. For reference, the target positive electrode thicknesses for this cell operating at a $5 \mathrm{C}$-rate and a $[\mathrm{V} / \mathrm{U}]=0.8$ is 142 microns. The line of $100 \%$ capacity utilization is also shown as a means to judge the deviation from theoretical capacity. As expected, the $\mathrm{C} / 1$ rate deviates more strongly than the $\mathrm{C} / 3$ rate with increasing electrode thickness. The loss in capacity is a result of the cell hitting the discharge voltage cut-off, $3.3 \mathrm{~V}$, before all of the lithium has been transported from the negative to the positive electrode.

Figure 5.7 displays the normalized concentration profile of the electrolyte salt, $\mathrm{LiPF}_{6}$, at the end of a $\mathrm{C} / 1$ and $\mathrm{C} / 3$ discharge for an electrode thickness of 245 microns. The $\mathrm{C} / 1$ discharge results in a positive electrode starved of electrolyte salt. This transport limitation results in the cell prematurely reaching the voltage cutoff. In order to overcome this limitation, the electrode would need to be engineered with significantly reduced tortuosity [39] or utilize an electrolyte with better mass transfer characteristics. This behavior is exacerbated by lower temperatures, such as those experienced during winter driving conditions. The fraction of theoretical discharge capacity begins to lower significantly at thicknesses greater than 100 microns, $3.4 \mathrm{mAh} / \mathrm{cm}^{2}$, at the $\mathrm{C} / 1$ rate and 175 microns, $6.4 \mathrm{mAh} / \mathrm{cm}^{2}$, at the $\mathrm{C} / 3$ rate. The electronic transport properties of the cathode material also play an important role in determining the current distribution within the electrode. While the NCA material has a reasonably high conductivity, other cathode materials have lower valued electronic conductivities and, depending on the conductive additive properties, may have different current distributions and limitations within the electrode. 


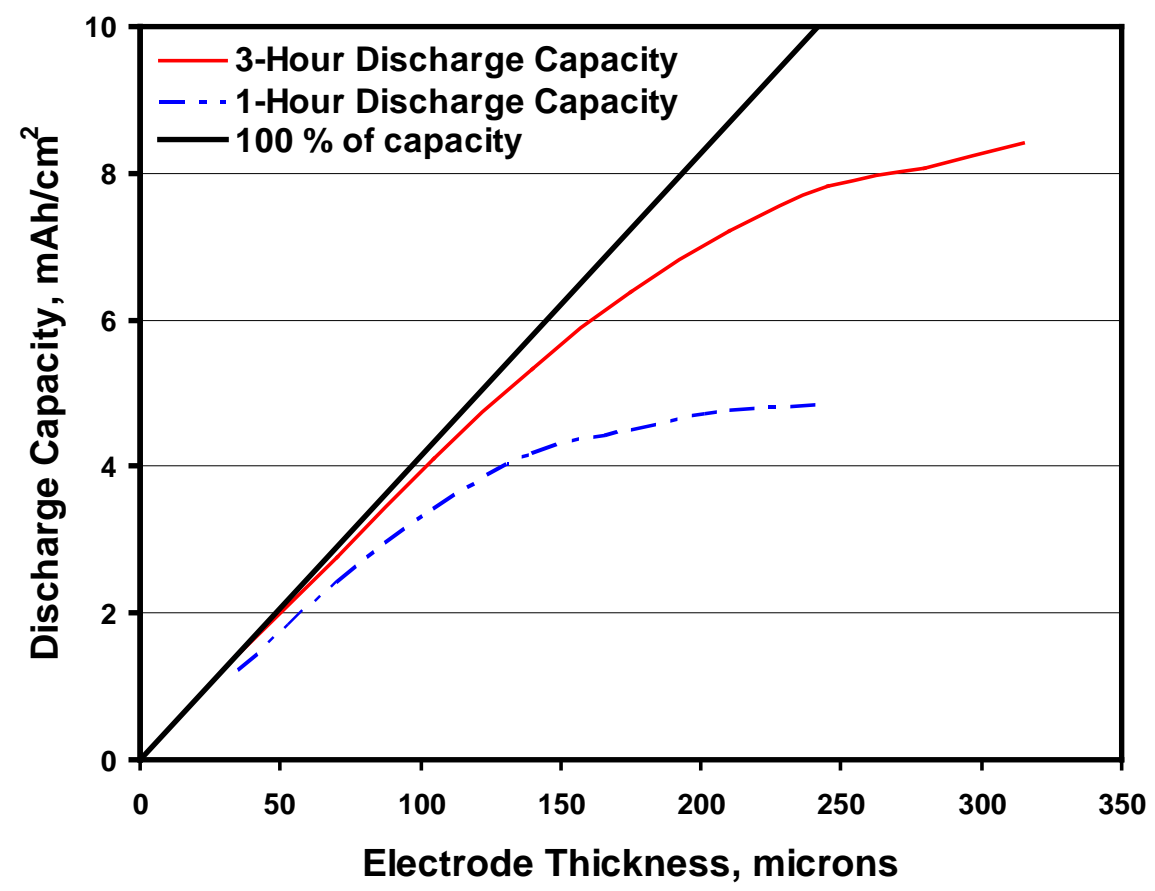

Figure 5.6 Cell capacity simulated at the $\mathrm{C} / 1$ and $\mathrm{C} / 3$ rate as a function of electrode thickness (loading) for NCA-Gr.

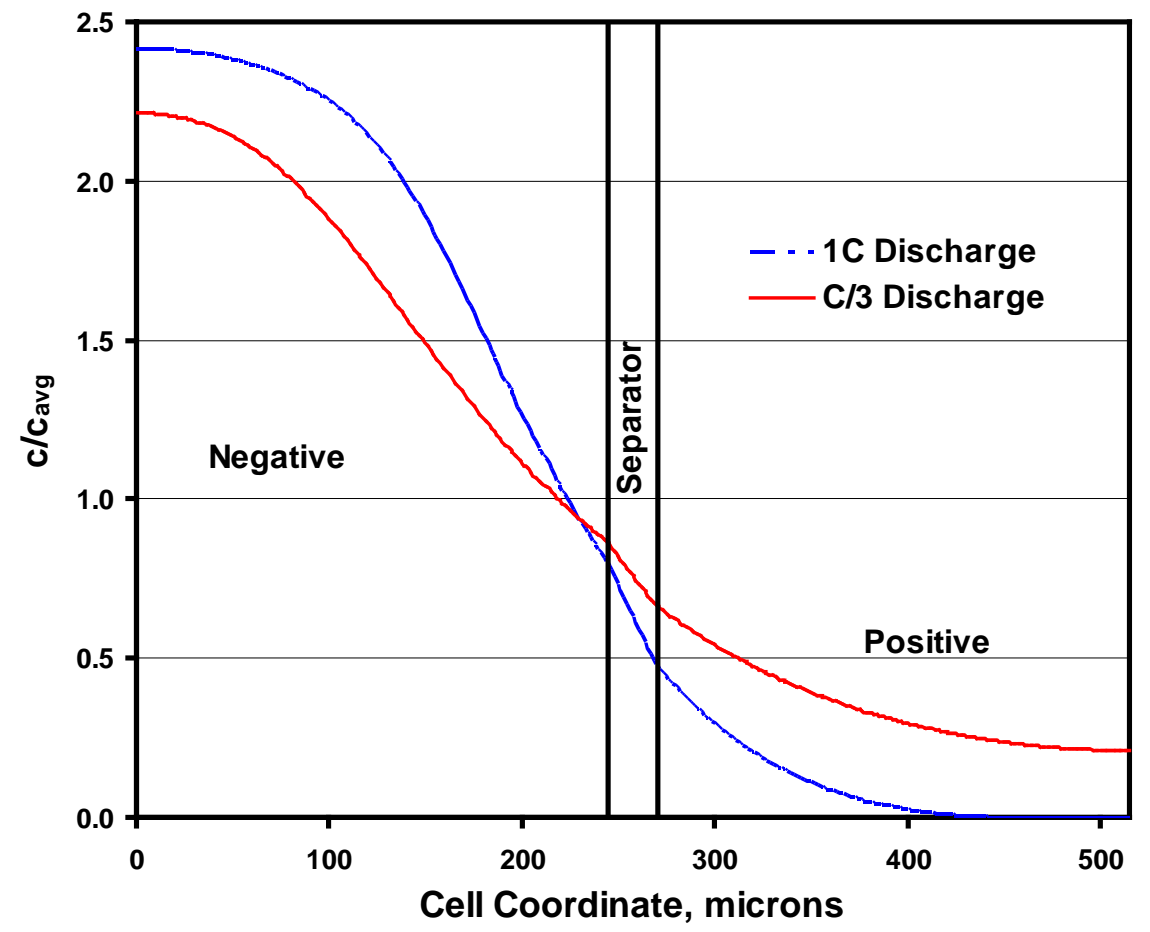

Figure 5.7 Normalized electrolyte salt concentration at the end of discharge at the C/1 and C/3 discharge rates. The second half of the positive electrode next to the current collector is starved of the $\mathrm{LiPF}_{6}$ salt resulting in a lower utilization of the inherent cell capacity. 
The simulated ASI for a 5C, 10-s discharge pulse at $60 \%$ SOC is shown in Figure 5.8 as a function of electrode thickness. The initial decrease in the ASI is a mathematical result of diminishing significance of the interfacial impedance as more current is passed in the same geometric area. The ASI then remains constant from 75 microns to nearly 400 microns. The constant ASI results from ohmic losses that behave linearly with applied current. The dramatic increase in the ASI at the largest electrode thicknesses results from limitations in electrolyte transport within the porosity of the positive electrode. This is similar to what is displayed in Fig 5.7 above during the constant discharge at the $\mathrm{C} / 1$ rate for an electrode thickness of 245 microns.

The most significant issue for pulse power operation with thick electrodes occurs on the negative electrode during a charge or regen pulse, Figure 5.9. The potential of the negative electrode may drop below that of a hypothetical lithium reference electrode during a charge pulse, inferring an undesirable side reaction of lithium plating on graphite [40]. This behavior is exacerbated by increasing electrode thickness. Operation at higher SOC and lower temperatures will also increase the probability of lithium plating. The lithium reference electrode is taken to be in the center of the separator layer. The two times shown in the graph, 1-s and 10-s, represent different polarization measurements for the electrode. The 1-s value includes all of the interfacial impedance and minor contributions from concentration polarization. The longer time value includes additional changes in potential due to the concentration gradient in the electrolyte. The 1-s time is the more accurate valuation of the tendency of the electrode to plate lithium.

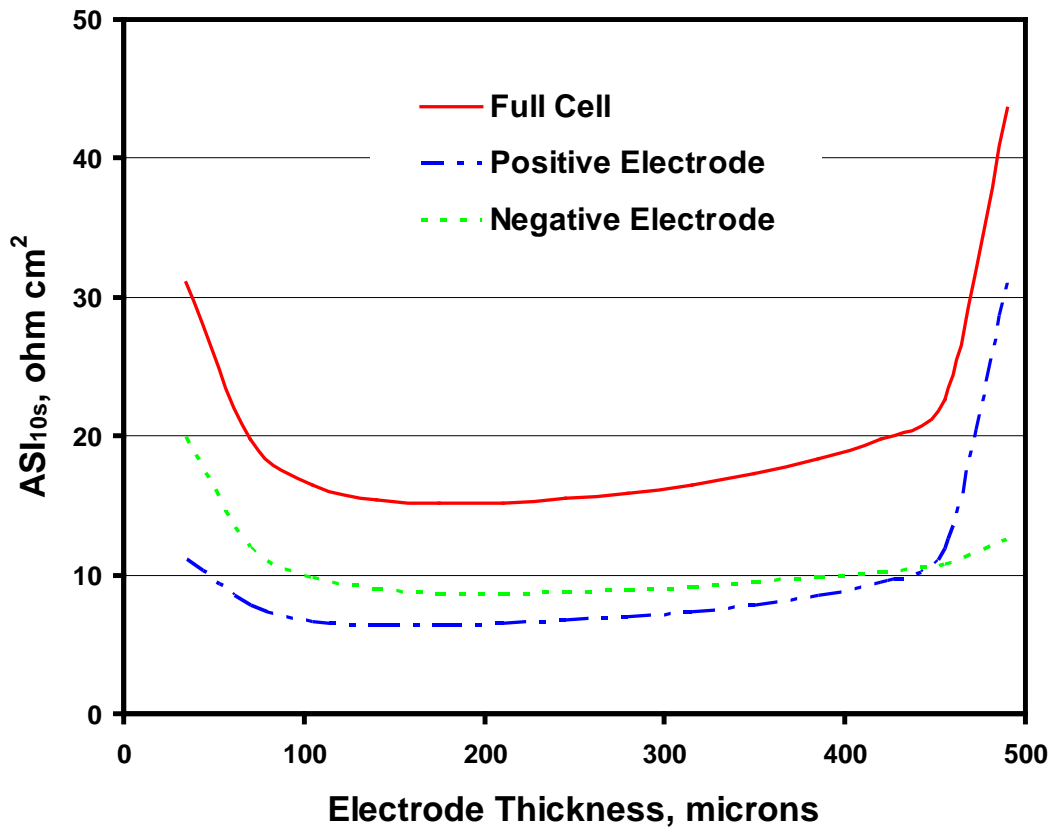

Figure 5.8 Calculated ASI from a simulated 10-s, 5C discharge pulse for the NCA-Gr cell couple at $60 \%$ SOC. Positive and negative electrode thicknesses are similar in value for this cell design. Transport within the electrolyte is not limiting until the electrode thickness approaches 450 microns for these simulation conditions. 


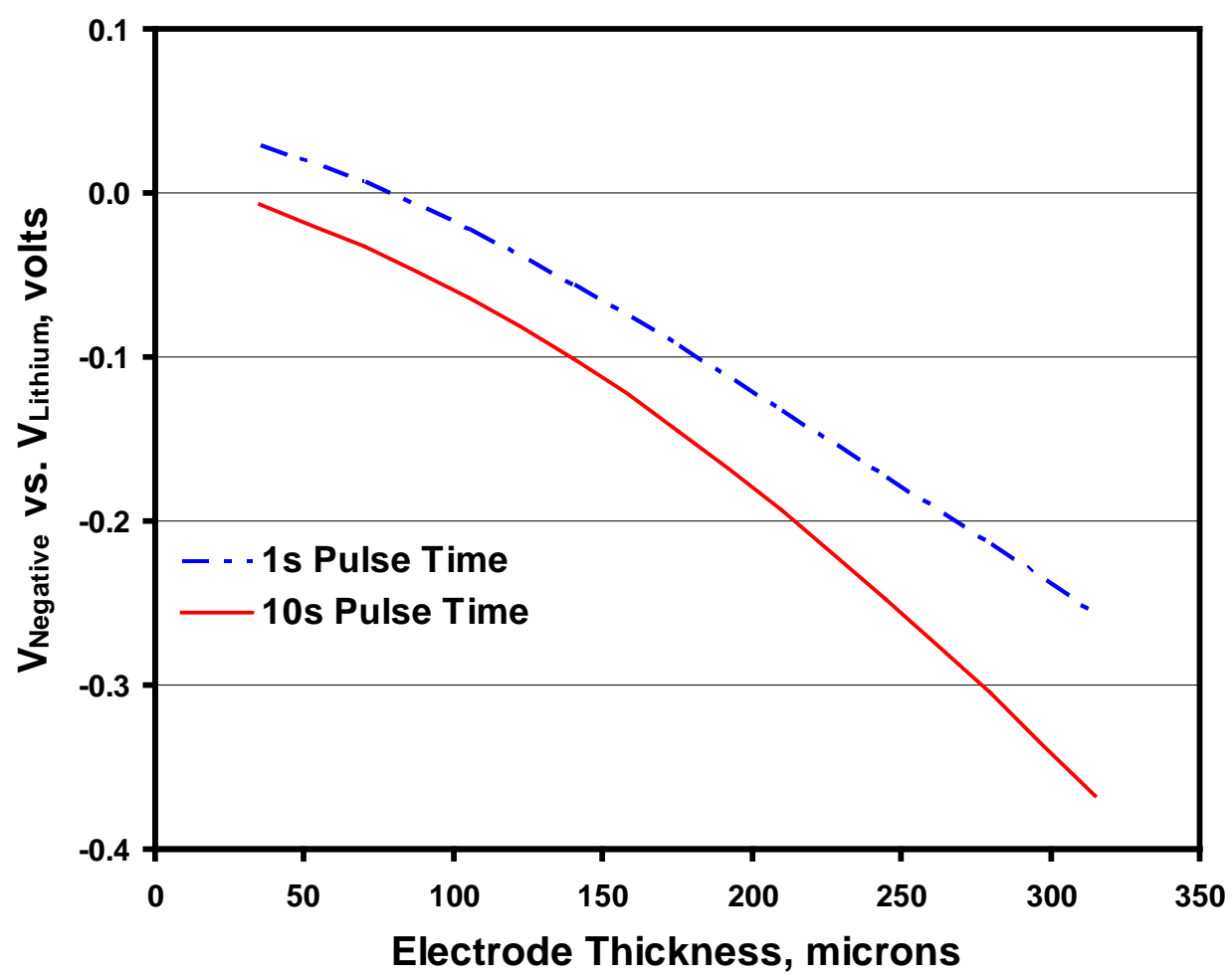

Figure 5.9 The potential of the negative electrode versus a hypothetical lithium reference electrode located in the center of separator during a 5C charge pulse for the NCA-Gr couple. 


\section{THERMAL MANAGEMENT}

The power and life of Li-ion batteries are more drastically affected by temperature than most other batteries including those based on lead-acid, nickel-cadmium, and nickel metal-hydride systems. It is important that the temperature of a Li-ion battery be controlled at all times, even when the battery is at rest. Developing schemes for effectively controlling the pack temperature at minimum cost will certainly be important in the success of this technology. The most difficult problem is the removal of heat generated within the battery, principally by ohmic heating. Avoiding excessive temperature rise during idle periods in hot ambient conditions is also a problem. Either of these conditions might raise the temperature to well above $40^{\circ} \mathrm{C}$, which enhances degradation reactions and shortens the battery life. In fact, maintaining the battery near the minimum temperature for adequate power will prolong battery life by retarding degradation reactions. Because the battery has poor power at low temperatures, heating the battery from a very cold condition is necessary and especially difficult for large EV battery packs for which no assistance is available from the engine. For electric-drive vehicles to be competitive in the market with conventional vehicles, these thermal control problems must be solved at moderate costs by means that do not compromise the safety of the vehicle or battery system.

The BatPaC model has a separate worksheet for designing the thermal management system. The results are transferred to the Battery Design worksheet to calculate the mass, volume and materials requirements for the battery pack.

\subsection{Heat Generation Rates in the Battery Pack during Driving}

During driving, the heat generation rate depends on the drive cycle and the power of the battery relative to the demands of the cycle for the vehicle being driven. As discussed below in section 6.2 , fluctuations in the temperature of the pack are smoothed out by the battery heat capacity. The rate that the cooling system must handle is the average rate for the most difficult sustained driving conditions to which the battery pack will be subjected.

There are two types of driving profiles that will generate high heating rates in the battery pack. One is a drive cycle such as the US06 that has rapid acceleration and deceleration, including periods at high speeds. The average heat generation rate for such driving profiles is difficult to evaluate and is best done by vehicle simulation studies. These studies require a battery impedance algorithm that makes possible accurate estimates of internal battery heating during vigorous driving patterns. The results of vehicle simulation studies of battery heating can be entered on line 37 in the Thermal worksheet to override the estimated default values. A second driving profile that causes a high rate of battery heating is driving at a high, constant speed for a prolonged period (i.e. $>5$ minutes). Battery heating is easier to estimate for this condition because the battery power requirement is a direct function of the vehicle speed and the battery impedance approaches a constant value after a few minutes of driving.

Vehicle simulations were completed by Argonne's Advanced Powertrain Research Facility with the Autonomie model. The battery energy required to support all-electric driving was compared for the US06 driving cycle and a constant speed of $70 \mathrm{mph}$ based on a vehicle similar to the Chevrolet Volt. In that study the impedance of the LMO-G battery was determined with a model 
that had been derived from HPPC data. The model has an ohmic resistance and two polarization resistances with time constants of 15 and 270 seconds, respectively. The model is useful for calculating the changing impedance during a complex driving cycle such as the US06 cycle and it reproduces the impedance values entered in the "Chem” worksheet for the stated conditions. Table 6.1 shows the results of this study including the parameters derived to enable calculation of the heat generated in the battery operated at constant speed.

The first column of values shows the results of the study for the Autonomie model for both the US06 cycle and constant speed driving at $70 \mathrm{mph}$. The sum of the power for accessories, rolling friction and aerodynamic drag was divided by the total power determined in the Autonomie model to obtain a vehicle efficiency factor. This factor accounts for power losses in the power converter, the motor and the gears. This vehicle efficiency factor is assumed to be sufficiently constant over the vehicle speeds of interest for the purpose of establishing battery cooling requirements and the associated cost.

The energy demand per mile of travel for the vehicle of Table 6.1 was calculated to be $250 \mathrm{Wh} / \mathrm{mile}$ from the useable battery energy of $10 \mathrm{kWh}$ for 40 miles of travel on the Urban Dynamometer Driving Schedule (UDDS). As shown at the bottom of the first column of figures, the estimated constant speed at which this energy demand would result is $57.85 \mathrm{mph}$. The second column of figures shows how the key parameters from the first column have been adjusted to round numbers that are suitable for the approximations required in $\mathrm{BatPaC}$, and these values are highlighted in yellow. BatPaC then calculates the remaining parameters in close agreement to Autonomie.

The electric energy consumptions (Wh/mile) for the two types of driving are almost the same, but the higher average speed at $70 \mathrm{mph}$ indicates a higher energy consumption per unit time (higher power) for this constant speed than for the US06 cycle (average speed of $48.4 \mathrm{mph}$ ). Also, a high heating rate results because constant rate discharge of the battery pack results in higher battery impedance than short power bursts. The US06 cycle has long periods of high speeds resulting in elevated battery impedance, but this increase in impedance is mitigated by periods of low power demand during which the impedance decreases. Thus, driving at a constant high speed for an extended time results in the maximum heat generation rate in the battery and justifies our emphasis on this source of battery heating, which fortunately is the easiest to calculate.

For microHEV battery packs, heat generation is intermittent and substantial periods of little or no heat generation exist in the load profile. The model estimates the heat generation rate for 25-kW microHEV batteries at $100 \mathrm{~W}$, which is entered on line 36 in the Thermal worksheet. For the larger battery packs (HEV-HP, PHEV and EV), the BatPaC model calculates the vehicle constant speed at which the centerline of the hottest cells in the battery will reach the maximum allowed temperature with steady state cooling, which is set at $35^{\circ} \mathrm{C}$ in the sample calculation on line 19 of the Thermal worksheet. That speed is deemed to be the maximum speed that the vehicle can be driven without damaging the battery by overheating. The battery control system should be designed to limit the battery output as this condition is approached.

This maximum speed will depend on vehicle design parameters, the type of electric drive (HEVHP, PHEV or EV), the battery maximum power, the type of cooling system, (cabin air or liquid) and the battery design as it affects the efficiency of cooling. 
Table 6.1 Energy Requirements for EREV Midsize 40AER similar to Chevrolet Volt. Highlighted values are the parameters required by $\mathrm{BatPaC}$ to estimate heat generation.

\begin{tabular}{|c|c|c|}
\hline & $\begin{array}{c}\text { Autonomie } \\
\text { Values }\end{array}$ & $\begin{array}{c}\text { Adjusted for } \\
\text { BatPaC }\end{array}$ \\
\hline \multicolumn{3}{|l|}{ Vehicle Parameters } \\
\hline Mass, kg & 1850 & \\
\hline Power for accessories, kW & 0.472 & 0.5 \\
\hline Rolling resistance, $\mathrm{kg} / \mathrm{kg}$ & 0.008 & \\
\hline Factor for rolling resistance power, kW/mph & 0.0647 & 0.065 \\
\hline Coefficient of drag, CD & 0.311 & \\
\hline Frontal area, $\mathrm{m}^{2}$ & 2.372 & \\
\hline Factor for aerodynamic drag, kW/(mph) ${ }^{3}$ & $4.060 \mathrm{E}-05$ & 4.0E-05 \\
\hline \multicolumn{3}{|l|}{ Parameters for LMO-G Battery } \\
\hline Battery power, kW & 100 & 100 \\
\hline Battery energy, kWh & 15.0 & 15.0 \\
\hline Usable battery energy, kWh & 10.0 & 10.0 \\
\hline Designated electric range, miles & 40.0 & 40.0 \\
\hline Standard energy demand, Wh/mile & 250 & 250 \\
\hline \multicolumn{3}{|l|}{ Autonomie Results } \\
\hline \multicolumn{3}{|l|}{ US06 Cycle } \\
\hline Electric energy consumption, Wh/mile & 327.3 & \\
\hline Average power (excluding stopping and regeneration), $\mathrm{kW}$ & 25.2 & \\
\hline Maximum power, $\mathrm{kW}$ & 126.4 & \\
\hline \multicolumn{3}{|l|}{70 mph Constant Speed } \\
\hline Power, kW & 22.67 & \\
\hline Electric energy consumption, Wh/mile & 323.8 & \\
\hline \multicolumn{3}{|l|}{ Constant Speed Results from Vehicle Parameters } \\
\hline \multicolumn{3}{|l|}{$70 \mathrm{mph}$} \\
\hline Power for accessories, $\mathrm{kW}$ & 0.472 & 0.5 \\
\hline Power for rolling friction, $\mathrm{kW}$ & 4.53 & 4.55 \\
\hline Power for aerodynamic drag, $\mathrm{kW}$ & 13.93 & 13.72 \\
\hline Vehicle efficiency factor* & 0.835 & 0.833 \\
\hline Total power, kW & 22.67 & 22.53 \\
\hline Electric energy consumption, Wh/mile & 323.8 & 321.9 \\
\hline \multicolumn{3}{|l|}{ Speed for $250 \mathrm{Wh} / \mathrm{mile}$ Energy Demand } \\
\hline Estimated Speed $\left(S_{o}\right), \mathrm{mph}$ & 57.85 & 58.0 \\
\hline Power for accessories $\left(P_{a}\right), \mathrm{kW}$ & 0.472 & 0.5 \\
\hline Power for rolling friction $\left(P_{f}\right), \mathrm{kW}$ & 3.74 & 3.77 \\
\hline Power for aerodynamic drag $\left(P_{d}\right), \mathrm{kW}$ & 7.86 & 7.80 \\
\hline Vehicle efficiency factor $(e)^{*}$ & 0.835 & 0.833 \\
\hline Total power $\left(P_{o}\right), \mathrm{kW}$ & 14.46 & 14.49 \\
\hline Electric energy consumption, Wh/mile & 250 & 250 \\
\hline
\end{tabular}


Since it has been established that the maximum battery heating will occur when the vehicle is driven at a high, constant speed, it is necessary to estimate the power needed to drive the vehicle at any desired speed and the resultant battery heating. For this purpose, approximate equations are needed for vehicle parameters including accessory power, rolling friction and aerodynamic drag. A starting point for deriving these equations is the battery power calculated from the energy requirement per mile, $\dot{E}$ (Wh/mile) entered on the Battery Design worksheet, line 196.The battery power, $P_{s 0}(\mathrm{~kW})$, which is calculated on line16 of the Thermal worksheet, will sustain a vehicle speed of $S_{0}$ at the designated value of $\dot{E}$.

$$
P_{s 0}=S_{0} \cdot \dot{E} / 1000
$$

The total battery power for maintaining the designated speed for the energy requirement is the summation of power demands for accessory power $\left(P_{a}\right)$, rolling friction power $\left(P_{f}\right)$, aerodynamic drag power $\left(P_{d}\right)$ and power losses resulting from inefficiencies in the electrical and mechanical components of the powertrain system. From the calculations described in Table 6.1 we estimate the efficiency $(e)$ from the battery to the wheels and accessories to be approximately constant at 0.833 . The accessory power is estimated to be constant at $0.5 \mathrm{~kW}$, but the model user may wish to increase this value to allow for air conditioning in warm climates and battery cooling.

For midsized sedans, crossovers and small SUVs, the power to drive the vehicle can be approximated from the energy requirement per mile, $\dot{E}$ (Wh/mile), as the starting point with the values in Table 6.1. First we assume that the mass of the vehicle and the factor for the rolling friction power, $f_{P f}(\mathrm{~kW} / \mathrm{mph})$, is proportional to $\dot{E}$, using the values from Table 6.1:

$$
f_{P f}=0.065 \cdot \dot{E} / 250
$$

And, the power to overcome rolling friction, $P_{f}(\mathrm{~kW})$, is:

$$
P_{f}=f_{P f} \cdot S
$$

The power to overcome aerodynamic drag is proportional to the frontal area of the vehicle, which we believe is less than proportional to the vehicle mass and volume and so we have used the power factor of 0.7 for the relationship between drag power factor, $f_{P d}$, and $\dot{E}$ from the default value of $0.00004 \mathrm{~kW} /(\mathrm{mph})^{3}$ :for $\dot{E}$ of $250 \mathrm{Wh} / \mathrm{mi}$ :

$$
f_{P d}=0.00004 \cdot(\dot{E} / 250)^{0.7}
$$

The power to overcome aerodynamic drag, $P_{d}$, at any vehicle speed, $S$, may be calculated with the expression:

$$
P_{d}=f_{P d} \cdot(S)^{3}
$$

The battery power, $P_{s}$, at any specified sustained vehicle speed can then be calculated from:

$$
P_{s}=\left(P_{a}+P_{f}+P_{d}\right) / e
$$


Eq. (6.1) and (6.6) are solved simultaneously for $S_{0}$ by iteration on lines 8 and 9 of the Thermal worksheet. $S_{0}$ is used to calculate $f_{P f}$ and $f_{P d}$ by means of Eq. (6.2) and (6.4).

For battery packs other than microHEV battery packs, the BatPaC model calculates the heat generation rate, $q(\mathrm{~W})$, from the battery current, $I_{\text {total }}(\mathrm{A})$, and the battery resistance for a sustained constant discharge, $R_{b s}$ (ohms).

$$
q=\left(I_{t o t a l}\right)^{2} \cdot R_{b s}
$$

The value of $R_{b s}$ for PHEV and EV batteries (line 28, Thermal worksheet) is calculated from the total ASI for the energy of the cell (taken at the $\mathrm{C} / 3$ rate and an average resistance assumed to be the same as that at $50 \%$ SOC). This value is equivalent to the sum of the ohmic and polarization resistances for the impedance model used in the Autonomie vehicle simulation study described above. For HEV-HP applications, the battery is operated for an estimated 30 to 60 seconds and the value of $R_{b s}$ is estimated to be $20 \%$ more than for the battery resistance at maximum power. Also the average battery heat generation rate is conservatively estimated as $60 \%$ of $q$ as defined by Eq. (6.7) because only about $60 \%$ of the power for the vehicle is delivered from the battery; the balance of the power for the vehicle comes from the engine by direct coupling to the drivetrain or through a generator and motor. For PHEV and EV batteries, the heat generated in the battery pack is calculated directly from Eq. (6.7). Battery current and voltage, $V$, are calculated as follows:

$$
\begin{gathered}
I_{\text {total }}=1000 * P_{s} / V \\
V=\frac{-U_{o c v, E}+\sqrt{\left(U_{o c v, E}\right)^{2}-4 * 1000 * P_{s} * R_{b s}}}{2}
\end{gathered}
$$

The heat generation rate in the battery is selected on line 38 in the Thermal worksheet from three possible values: (1) for microHEV batteries it is $100 \mathrm{~W}$ (line 36), (2) for batteries that have been modeled in a vehicle simulation program to determine maximum sustained heat generation and the result entered on line 37, or (3) for all other battery packs, the heat generation rate calculated on line 34 (based upon Eq. 6.7 and modified as discussed above for HEV-HP batteries).

As a check on the practicality of estimating the heat generation in the battery by the method described above, another calculation was done by Argonne's Advanced Powertrain Research Facility with the Autonomie model. In that calculation, the vehicle was an advanced sedan with an energy demand of only $201.8 \mathrm{Wh} / \mathrm{mile}$ on the UDDS cycle resulting from a vehicle weight of only $1625 \mathrm{~kg}$, rather than $1850 \mathrm{~kg}$ as in the initial study (Table 6.1). The drag factor was only slightly lower than previously (i.e. $3.7 \times 10^{-5}$ vs. $4.0 \times 10^{-5}$ ). A comparison of the results of calculations on Autonomie and BatPaC are shown in Table 6.2. 
Table 6.2 Comparison for calculated heat generation by Autonomie and BatPaC

\begin{tabular}{l|c|c|} 
& Autonomie & BatPaC \\
\hline Energy demand $(\dot{E}), \mathrm{Wh} / \mathrm{mile}$ & 201.8 & 201.8 \\
Constant speed at $\dot{E}$, mph & 53.4 & 53.2 \\
Battery power at $75 \mathrm{mph}, \mathrm{kW}$ & 24.4 & 24.3 \\
Heat loss in battery at 75 mph 50\% SOC, W & 1343 & 1516 \\
Average heat loss on 2nd US06 cycle, W & 1062 & \\
Average heat loss on 3rd US06 cycle, W & 1082 &
\end{tabular}

It is noted that $\mathrm{BatPaC}$ accurately reproduced the Autonomie results for constant vehicle speed, for the standard energy demand, and for battery power at $75 \mathrm{mph}$. BatPaC slightly over estimates the heating at 50\% SOC because it calculates the impedance for the parameters at that SOC. The Autonomie calculations take into account the lower values of the parameters at lower SOC and the time delay in adjusting to the ever increasing parameters with increasing SOC. The calculations in Autonomie illustrate, again, the higher rate of heat generation for high speed continuous driving than on the US06 driving cycle.

With the determination of the heat generated in the battery as a function of vehicle speed, as described above, the vehicle speed and the associated maximum temperature at the cell center are determined by the model in the following iterative procedure. A default value of $35^{\circ} \mathrm{C}$ for the maximum acceptable cell centerline temperature (which may be changed by the user) is entered on line 19 and the model calculates the maximum sustained battery power, line 30, the internal battery heat generation rate, line 34, and the maximum sustained vehicle speed associated with those values, line 21. In this process, the heat generation value is transferred to the liquid cooling section beginning on line 68 or the cabin-air cooling section beginning on line 114, as determined by the type of cooling entered on line 60 of the Battery Design worksheet and repeated on line 67 of the Thermal worksheet. In carrying out this calculation, if the temperature calculated is higher than the temperature target on line 19 , the vehicle speed is automatically adjusted by the program and the process is repeated until agreement is reached between the calculated temperature on line 20 and the target on line 19. The maximum temperature at the center of the cells is calculated at the end of the heat transfer calculations for the liquid-based and the cabin-air based thermal management approaches (lines 113 and 175, respectfully).

The overall adequacy of the cooling is estimated on line 40 as a function of the maximum temperature of the battery at steady-state cooling as follows:

$\begin{array}{cc}\text { Maximum Cell Temperature } & \text { Cooling Adequacy } \\ 35^{\circ} \mathrm{C} \text { or less } & \text { Excellent } \\ \text { Over } 35^{\circ} \mathrm{C} \text { to } 40^{\circ} \mathrm{C} & \text { Good } \\ \text { Over } 40^{\circ} \mathrm{C} \text { to } 45^{\circ} \mathrm{C} & \text { Fair } \\ \text { Over } 45^{\circ} \mathrm{C} & \text { Poor }\end{array}$

\subsection{Heating under Adiabatic Conditions}

A factor to be considered in thermal management is the substantial heat capacity of the battery pack. The thermal mass of the battery evens out temperature fluctuations resulting from power 
bursts so that the heat dissipation system need only handle the average heat generation rate for the most extreme driving profiles the battery is likely to encounter. For large PHEV and EV batteries the heat capacity of the battery will limit the temperature rise of the centerline of the cells by distributing the heat throughout the battery. For a large EV battery with power of $220 \mathrm{~kW}$ and energy of $65 \mathrm{kWh}$, the average temperature rise of the cells under adiabatic conditions would be only about $5^{\circ} \mathrm{C}$ for a complete discharge and certainly less with a cooling system even if that system is only moderately effective. It is clear that the main need for a cooling system for EV batteries is for high-rate charging (section 6). For HEV batteries, which have high power-to-energy ratios, the main effect of the heat capacity will be to smooth out temperature fluctuations.

\subsection{Active Thermal Management Systems}

Several heat transfer fluid types have been considered for battery pack thermal management including air from the cabin, which may be heated or cooled, ethylene-glycol/water (EG/W) solutions and dielectric liquids such as transformer fluids. Additionally, cooling plates in contact with surfaces on the cells or the modules may be cooled directly with refrigerant. Air is the least expensive, but it is less effective than the liquid coolants because of its poor conductivity, the need for large flow passages and high pumping power. Dielectric liquids are expensive, but have the advantage of being compatible with terminals and other parts at electrical potential. A 50/50 EG/W solution is inexpensive and has better properties as a coolant (thermal conductivity, heat capacity, and viscosity) than typical transformer fluids. Cooling directly with a refrigerant would eliminate the need for an intermediate heat transfer fluid and may be the most efficient of the systems, but it is more technically complex to access, which was not attempted here. In this study we consider thermal management with heat transfer fluids of either cabin air or EG/W solution. To evaluate cooling with a dielectric fluid, it would only be necessary to substitute the properties of the dielectric fluid for those of EG/W solution (lines 84-87) and to increase the cost of the thermal management system to allow for the higher cost of the heat transfer fluid. Cooling and thermal management will be used interchangeably in this report. However, we emphasize the need of the thermal management approach to allow for both cooling and heating of the battery.

For both the liquid-based and the cabin-air based thermal management approaches, we selected a general cell design that can be adapted to all of the electric-drive batteries from micro-HEVs packs to EV packs (section 2). For all types of batteries, the liquid-based design incorporates a hermetically sealed module closure. This design can be effectively cooled by liquids and requires that only the module terminals and connectors be protected from contact with a conducting coolant, thus accommodating EG/W coolant. Aluminum heat conductors in contact with the broad surfaces of the cells transfer heat to and from the module surface (Fig. 2.4) that is in contact with the heat transfer fluid.

The module enclosure does not have sufficient surface area to be cooled effectively by air. For cabin air based thermal management, heat-transfer fluid flow passages are included between the cells, which add considerably to the pack volume. That design feature permits air cooling for microHEV and HEV-HP batteries. Air based approaches might also be used for some combinations of vehicle parameters and PHEV and EV battery configurations that result in low heat generation rates. However, air cooling is much less effective than liquid cooling and may not 
be effective in high heat generation applications (e.g. continuous all electric drive at autobahn speeds).

\subsubsection{Thermal Management with Ethylene-Glycol/Water Solution}

For the assumed format, the battery pack coolant is contained by the battery jacket and thus severely limits the practical pressure drop in the coolant circuit. The pack is on the suction side of the pump so the module structure assists in supporting the walls of the battery jacket. This approach is simple to calculate and appears to result in a workable design of low cost. Alternatively, cooling plates with built-in flow channels and capable of withstanding high pressure may be used with EG/W heat-transfer fluid reducing the likelihood of this electrolyte contacting cell or module terminals. Leaks in any system using an electrolyte fluid are a serious danger. For that reason alone, such fluids may have to be replaced by a dielectric fluid in future batteries.

\subsubsection{Heat Transfer from Cell to Module Wall}

As described in section 2, the cells transfer heat to the cooled walls of a hermetically sealed module with the aid of an aluminum heat conduction channel. Some of the heat is transferred through the sides of the cell to the channel and from there to the module wall. Other heat is transferred directly through the seal edge of the cell to the conduction channel flange which is in contact with the module wall. Calculation of heat transfer in this two-dimensional array through several materials is complex requiring a numerical model. The spreadsheet iterates many times in reaching a solution for the electrical and physical parameters for the battery as discussed in section 3. Each of these iterations results in a slightly different cell design. Thus, it would be impractical to imbed a numerical model directly, which may increase the total calculation time to many minutes. Instead, a software program based on the finite element method, FlexPDE 6.15 by PDE Solutions Inc., was employed to calculate heat transfer rates for 70 cell configurations. The resulting simulations were empirically correlated so that simple equations occupying a few cells in the spreadsheet could rapidly calculate the heat transfer rate with only a small error.

An important requirement for calculating heat transfer rates within the cell is to estimate the composite conductivities of the cell layers both parallel to the layers and across the layers. The resulting conductivities vary considerably with the relative thicknesses of the layers as shown in Table 6.3, for which the results are consistent with the literature [41-45]. These values for conductivities and a range of cell dimensional parameters (Table 6.4) were employed in selected arrangements for calculating heat transfer rates with the FlexPDE model for 70 representative cells that covered a broader range of variables than is needed for practical cells.

For each of these cells, the FlexPDE model calculated the temperature difference between the cell center and the module housing per unit of heat generation, $\Delta T / q\left({ }^{\circ} \mathrm{C} / \mathrm{W}\right)$, and the fraction of the total heat that was transferred through the edge of the cell, $q_{e} / q$. The balance was transferred through the side of the cell to the aluminum conductor, $q_{s}$. The heat transferred by the two routes is represented by the equation:

$$
q / \Delta T=q_{e} / \Delta T+q_{s} / \Delta T
$$


Table 6.3 Sample calculations of composite thermal conductivities of cell structures across layer and parallel to layers

\begin{tabular}{|l|c|c|c|c|}
\hline & Cell 1 & Cell 2 & Cell 3 & Cell 4 \\
\hline Layer Thicknesses, microns & & & & \\
Positive foil & 20 & 20 & 20 & 20 \\
Negative foil & 12 & 12 & 12 & 12 \\
Positive coating & 30 & 75 & 150 & 220 \\
Negative coating & 40 & 100 & 200 & 300 \\
Separator & 20 & 20 & 20 & 20 \\
Total bicell structure & 212 & 422 & 772 & 1112 \\
\hline Thermal Conductivities, W/cm-K & & & & \\
Aluminum & 2.0 & 2.0 & 2.0 & 2.0 \\
Copper & 3.8 & 3.8 & 3.8 & 3.8 \\
Positive coating & 0.013 & 0.013 & 0.013 & 0.013 \\
Negative coating & 0.013 & 0.013 & 0.013 & 0.013 \\
Separator & 0.0020 & 0.0020 & 0.0020 & 0.0020 \\
\hline Across layers, $k_{x}$ & 0.00689 & 0.00899 & 0.01045 & 0.01112 \\
Parallel to layers, $k_{y}$ & 0.4127 & 0.2138 & 0.1228 & 0.0892 \\
\hline
\end{tabular}

Table 6.4 Range of parameter values for calculating heat transfer rates in FlexPDE model

\begin{tabular}{|c|c|c|c|c|}
\hline & \multicolumn{4}{|c|}{ Parameter Levels Evaluated } \\
\hline & 1 & 2 & 3 & 4 \\
\hline Conductivities, W/cm-K & & & & \\
\hline Across layers, $k_{x}$ & 0.00689 & 0.00899 & 0.01045 & 0.01112 \\
\hline Parallel to layers, $\left.k_{y}\right\}$ & 0.4127 & 0.2138 & 0.1228 & 0.0892 \\
\hline $\begin{array}{l}\text { Cell edge, } k_{e} \\
\text { Cell Dimensions, cm }\end{array}$ & 0.10 & & & \\
\hline $\begin{array}{l}\text { Cell Dimensions, cm } \\
\text { Cell thickness, } L_{\text {cell }}\end{array}$ & 06 & 10 & 14 & \\
\hline Cell width, $W$ & 8 & 12 & 18 & \\
\hline Cell edge thickness, $L_{e}$ & 0.1 & & & \\
\hline Aluminum conductor thickness, $L_{A l}{ }^{(b)}$ & 0.03 & 0.06 & 0.10 & \\
\hline
\end{tabular}

(a) The $k_{x}$ and $k_{y}$ values are calculated as in Table 6.3 and were, thus, paired together in the Flex PDE model calculations.

(b) The total conductor thickness consists of the conductor thickness itself plus twice the thickness of the aluminum layer within two adjacent pouch containers.

Estimated values for $q_{e} / \Delta T$ and $q_{s} / \Delta T$ were determined by empirical correlation of the results obtained for the calculation of the 70 cells by the FlexPDE model with the result shown in Fig. 6.1. Empirical values of these estimated values resulted in the equations:

$$
q_{e} / \Delta T=3.917 k_{y}{ }^{0.58} k_{x}{ }^{-0.19} L_{c e l l}{ }^{1.2} W^{-0.75}
$$




$$
q_{S} / \Delta T=1628 k_{y}{ }^{0.55} k_{x}{ }^{0.58} L_{c e l l}{ }^{-0.21} W^{-0.7} L_{A l} 0.72
$$

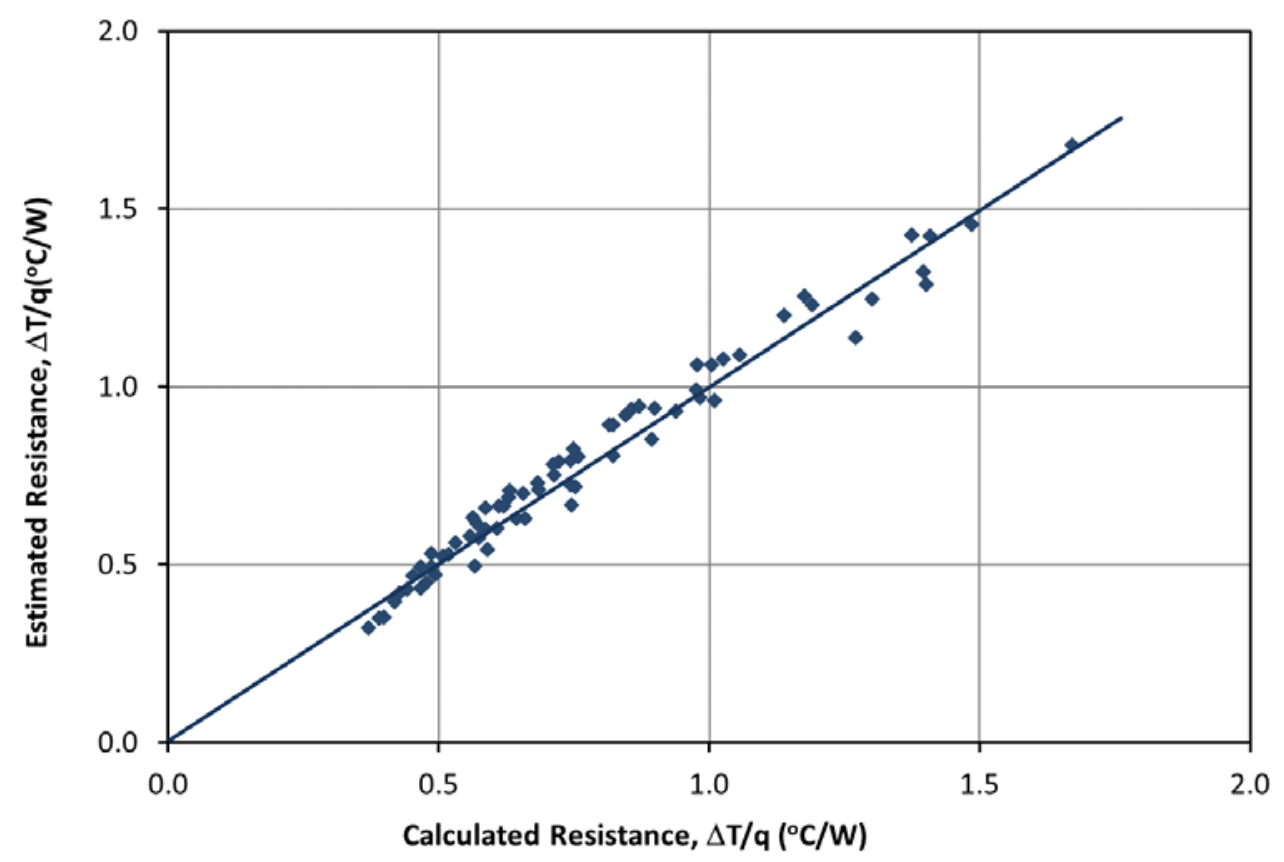

Figure 6.1 Plot comparing the estimated resistance to heat transfer from the cell center to the cooled surface of the module to that calculated by the FlexPDE model.

It was of interest to note that the FlexPDE model for the 70 cases studied calculated that between $13 \%$ and $65 \%$ of the total heat, q, was transferred as, qe, through the edge of the cell to the module wall heat transfer surface and that the balance, (35\% to 87\%) was transferred as, $\mathrm{q}_{\mathrm{s}}$, through the side of the cell to the aluminum conductor. The average error in the estimated total $\Delta T / q$ compared to the values calculated by the FlexPDE model was $6.0 \%$ and the maximum error was $13.0 \%$. This accuracy was deemed to be satisfactory in that for all practical battery designs, the error in estimating the difference in temperature between the cell center and the module housing, $\Delta T$, will be only a fraction of a Celsius degree.

\subsubsection{Heat Transfer from Module Wall to Flowing Coolant}

The model directly calculates the temperature drop between the module wall and the heat transfer fluid for a set pressure drop, fluid (coolant) temperature rise, and fluid physical properties. A 50/50 ethylene glycol, deionized water (EG/W) mixture was selected based on the low cost and contemporary use in coolant systems. The default pressure drop was taken to be 10 millibar, but may be changed by the user if desired. The gap in which fluid flows is sized to maintain the target pressure drop without going below a minimum gap height of $3 \mathrm{~mm}$. A coolant temperature rise during flow through the battery jacket of $1^{\circ} \mathrm{C}$ was selected to establish a mass flow rate, but also may be changed by the user. 
Calculation of the heat transfer coefficient allowed for determination of the temperature difference between the module and average coolant temperature. A schematic of the flow passageway and change in temperature profile with distance is shown below in Fig. 6.2. The outer wall of the flow passage is assumed to be perfectly insulated. The inner wall (module casing) is assumed to have a constant heat flux perpendicular to the wall. Laminar flow was assumed to simplify the calculation of the velocity profile (parabolic).

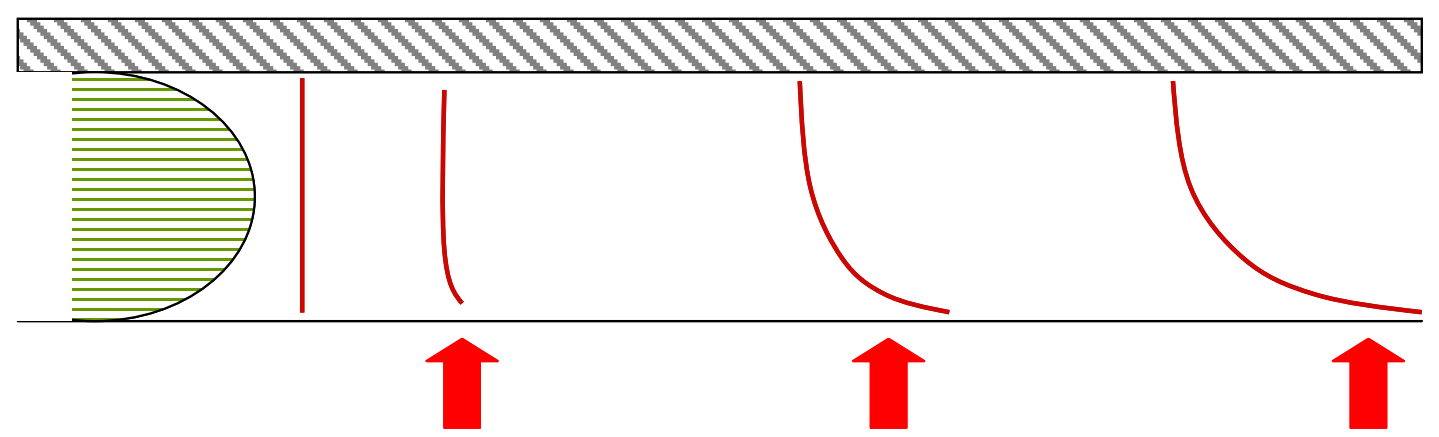

Figure 6.2 Heat transfer from the module wall to the laminar flow heat transfer fluid. The temperature profile of the fluid is shown at different lengths down the flow path.

Frequent use of dimensionless numbers was necessary to adequately correlate the numerical results into a generally useable form. We define the Reynolds, Prandlt, Graetzl, and Nusselt numbers here for completeness [46]. The Reynolds number, Re, is the ratio of inertial to viscous forces. The Reynolds numbers were always less than 1000 confirming laminar flow. The Prandlt number, Pr, is the ratio of the momentum diffusivity to thermal diffusivity. The Prandlt number for the EG/W mixture is approximately 38 . The Graetz number, $\mathrm{Gz}$, is directly proportional to the product of the Reynolds and the Prandlt numbers. Moreover, the $\mathrm{Gz}$ value is inversely proportional to the distance down the fluid flow path, $l$, resulting in higher values near the start of the flow path. Finally, the Nusselt number, $\mathrm{Nu}$, is the ratio of the convective to conductive heat transfer. Here $u_{a v e}$ is the average fluid velocity, $d_{H}$ is the hydraulic radius (twice the flow gap), and $\mu$ is the viscosity. The heat capacity, $c_{p}$, thermal conductivity, $k$, and heat transfer coefficient, $h$, are the critical heat transfer values. The mass flow rate, $G$, and the width of the channel, $W$, are the remaining parameters.

$$
\begin{gathered}
\operatorname{Re}=\frac{\rho u_{\text {cres }} d_{H}}{\mu} \\
\operatorname{Pr}=\frac{c_{p} \mu}{k} \\
\mathrm{Gz}=2 \frac{G c_{p} d_{H}}{k W l}=2 \frac{d_{H}}{l} \operatorname{Re} \operatorname{Pr} \\
\mathrm{Nu}=\frac{h d_{H}}{k}
\end{gathered}
$$

Coupled momentum and heat transfer has been solved previously by determining a number of the eigenvalues of an analytical series solution for a vast number of various geometrical configurations related to pipe, duct, and parallel plate flow $[47,48]$. We have chosen to reach the solution 
numerically and then fit a correlation between the Graetz number and the mean Nusselt number. The empirical form provided by Nickolay and Martin provides an accurate means of correlating the results over many orders of magnitude [49]. The correlation, shown in Eq. (6.17), relates the Graetz number and the limiting solution, $\mathrm{Nu}_{\infty}=5.385$, to the mean Nusselt number. Then, the mean heat transfer coefficient may be directly calculated from $\mathrm{Nu}$. Here $n$ and $C_{1}$ are fitting parameters.

$$
\mathrm{Nu}=\left[\left(\mathrm{Nu}_{\infty}\right)^{n}+\left(\mathrm{C}_{1} \mathrm{Gz}^{1 / 3}\right)^{2}\right]^{\frac{1}{n}}
$$

The numerical model was solved with the finite element method using FlexPDE software. We note that the bulk or "cup mixing" fluid temperature in Eq. (6.18), the average temperature of the fluid normalized by the fluid velocity profile, was necessary to reach the proper values.

।

$$
T_{\text {avg }}=\frac{1}{2 u_{\text {avg }}} \int T(y) u(y) \partial y
$$

The following important assumptions were used to reach a solution.

1. Flow of incompressible heat transfer fluid is laminar

2. Thermal diffusion is allowed up and down stream of the heat transfer (for convergence)

3. Boundary conditions: $\mathrm{dT} / \mathrm{dy}=0$ at insulation; $\mathrm{q}=$ constant at module casing

4. Negligible radiative energy transfer

5. Steady state conditions reached

Figure 6.3 displays the temperature profile between the module casing and the insulated wall for various distances along the flow channel. The average temperature of the fluid has risen $1{ }^{\circ} \mathrm{C}$ at the end of the flow path even though the maximum and minimum temperature is separated by nearly $5{ }^{\circ} \mathrm{C}$. The simulated change in average temperature down the length of the flow channel allows the calculation of the average heat transfer coefficient and thus Nusselt number. The correlation, Eq. (6.17), determined from various simulations conditions is shown in Fig. 6.4. An excellent fit is obtained allowing for implementation of the correlation into the design and cost model. This correlation now enables efficient and accurate calculations of the heat transfer coefficient to be made in the spreadsheet, informing the user of the effectiveness of the thermal management in the design.

In general, the heat transfer from the module is improved by increasing the contact area and increasing the fluid flow rate. The contact area may be increased by using cells with a higher aspect ratio. This also results in a smaller temperature gradient within the cell as discussed previously in section 6.3.1.1. Increasing the fluid flow rate is accomplished by using a lower temperature rise and/or a larger target pressure drop. The gap height may prevent a change in a single parameter from having a significant effect on the temperature drop. Physical limitations of implementing a cooling system should be considered when moving to higher flow rates and pressure drops. The user should note that raising both of these parameters will increase the cost of the battery design in ways that the model does not consider (e.g. more expensive pump and increasing structural integrity). 


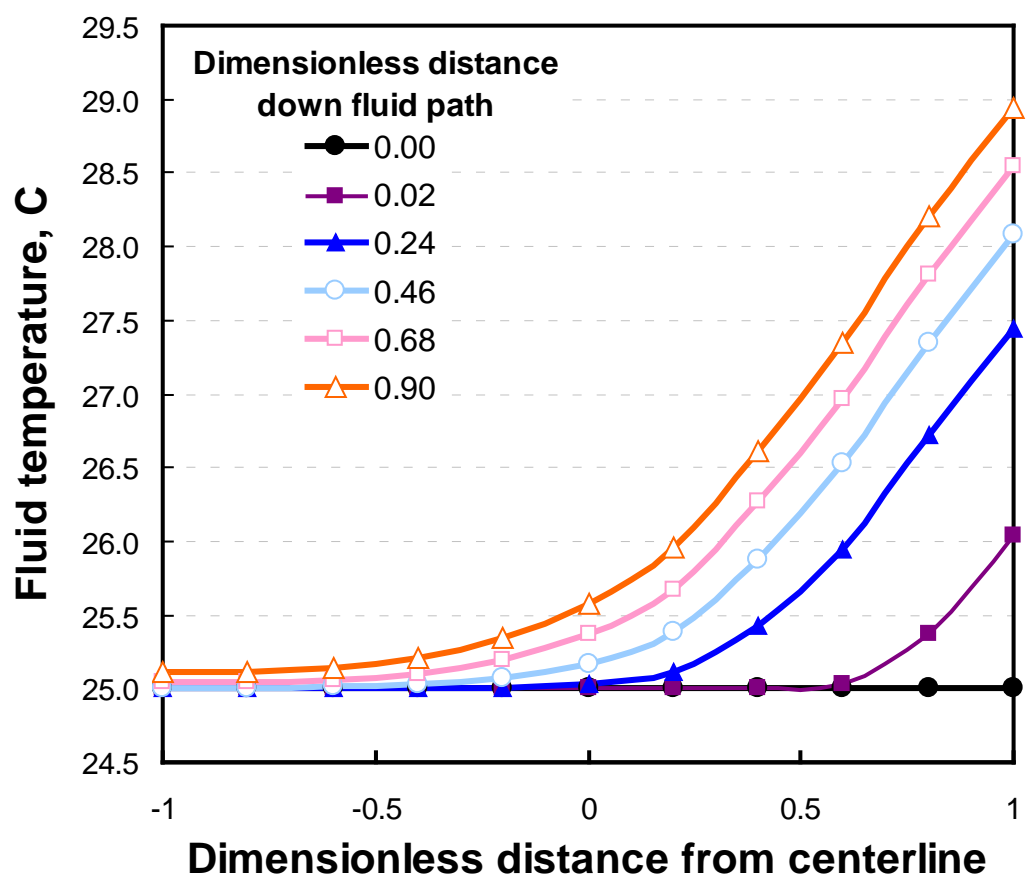

Figure 6.3 Temperature profile in the heat transfer fluid for various fractions of the dimensionless path length.

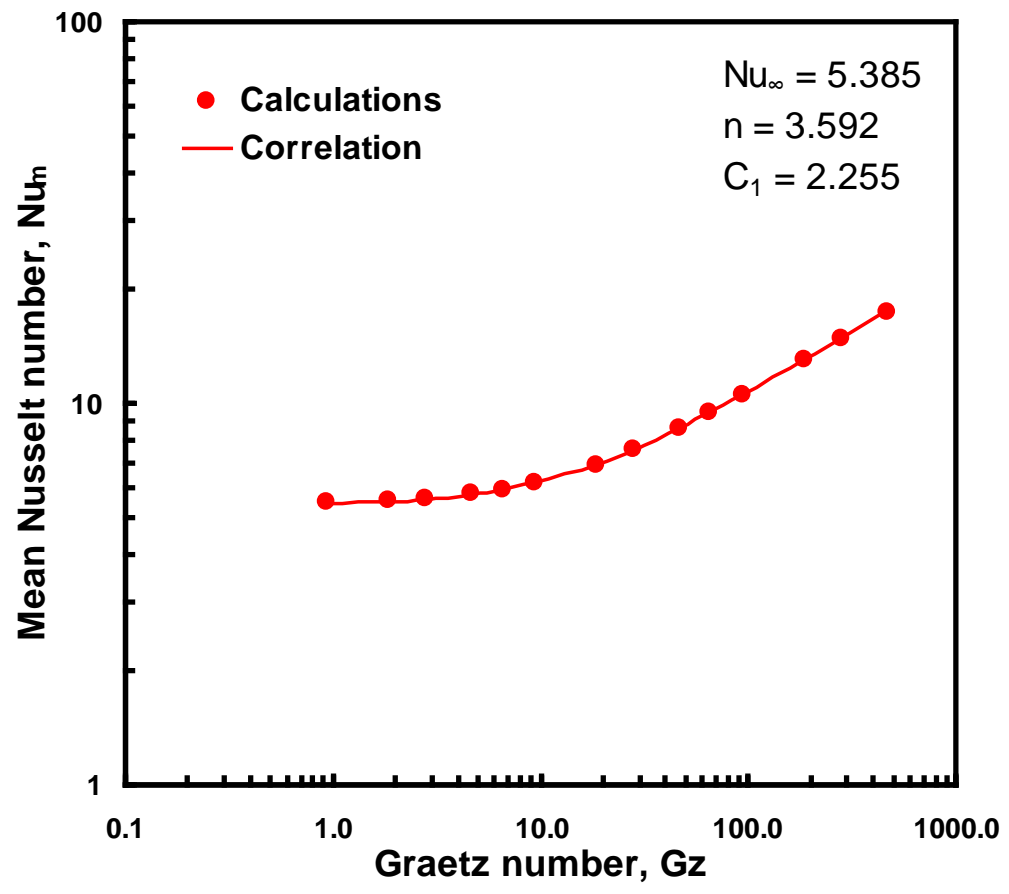

Figure 6.4 Correlation of model simulation results relating the Graetz number and mean Nusselt number for laminar flow between an insulated surface and the module casing. 
For high speed driving or very aggressive driving cycles, the temperature difference between the surface of the cooled module and the bulk of the coolant may become fairly large $\left(>10^{\circ} \mathrm{C}\right)$. This coupled with the temperature rise within the cells could result in the cell centerline temperatures being high enough to cause cell degradation. This result can be avoided by controlling the inlet coolant temperature as a variable that is adjusted in a classic cascade automatic control system to control the module wall temperature at the desired value. Thus, the temperature rise at the center of the cells will be essentially held to that resulting from conduction within the cell and will not be greatly influenced by the temperature rise in the coolant. The use of the vehicle air-conditioning system to cool the liquid coolant allows a standard coolant temperature of $15^{\circ} \mathrm{C}$, or even lower if necessary.

\subsubsection{Thermal Management with Cabin Air}

Air-based thermal management requires a much larger heat transfer surface area than that of the liquid thermal management approach discussed in section 6.3.1. In this study the extra surface area was gained by flowing air past the faces of the individual cells as shown in Fig. 2.4 and 2.6. This approach greatly simplifies the calculation of heat transfer from the interior of the cells, which can be solved as a one-dimensional calculation as contrasted with the more complex two-dimensional calculation done for liquid thermal management of the outside of the module (section 6.3.1.1). The air flows in at the bottom of the long side of the battery pack, splits into many flow steams as it flows up the passages between the cells and then recombines and flows out the top of the battery pack.

\subsubsection{Temperature Drop from Cell Center to Cell Wall at Steady State}

The composite conductivity across the cell layers was calculated by dividing the total cell thickness by the sum for all layers of the conductivity of each layer divided by its thickness as illustrated in Tables 6.1 and 6.2.

The temperature drop from the center of the cell to the cell wall, $\Delta T_{\text {cell, }}$, was calculated as follows:

$$
\Delta T_{\text {cell }}=\frac{\frac{q_{\text {cell }}}{2} * \frac{L_{c e l l}}{2}}{k_{x} * H_{A l} * W}
$$

\subsubsection{Heat Transfer from Aluminum Cell Sleeve to Flowing Air}

The length of the cooled section of the cell is taken to be the same as the length of the positive electrode. The number of air flow channels is essentially calculated by dividing this length by the target width of an air flow channel plus that of one web and rounding down to an integral number. The target width was taken to be $1.0 \mathrm{~cm}$, but any width between 1.0 and $2.0 \mathrm{~cm}$ will provide similar results for cooling. The exact width of the channels is calculated from the electrode length and the number of channels. The thickness of the channel is calculated to meet the pressure drop for the required flow rate. The required flow is that which will carry off the heat generated by the cell divided by the number of cooling channels per cell. 
Because of the difficulty in moving sufficient air through the pack to carry out the heat generated in the cells, the air must be allowed to rise in temperature by about $5^{\circ} \mathrm{C}$, whereas a $1^{\circ} \mathrm{C}$ temperature rise is sufficient for liquid-cooled packs. We also used a higher pressure drop to force the air through the pack, 0.02 bar versus 0.01 bar for liquid-cooled packs. The pressure drop for air cooling is divided between that through the channels between the cells (90\%) and that in the large passages across the bottom of the pack where the air enters and across the top of the pack where the air leaves (10\%). This distribution of the available pressure drop, which is achieved by sizing the thickness of the channels between the cells and those at the top and bottom of the pack, provides an even supply of air to all channels between the cells. All of the parameters discussed for managing the air flow are adjustable by the model user, but large deviations from the suggested values may adversely affect the feasibility of the design.

The heat transfer flux to establish the temperature drop from the cell sleeve wall to the bulk air stream is calculated in much the same way as described for the liquid-cooled battery packs (section 6.3.1.2). However, for the air-cooled packs, heat is transferred from both sides of the channel rather than from only one side as for the liquid-cooled modules, which have insulated jacket walls on the opposite side of the cooling channel. For transferring heat from both sides, the value of $N u_{\infty}$ is 8.235 rather than 5.385 for use in Eq. (6.17).

\subsection{Cooling and Heating Required to Maintain Pack Temperature}

When parked in the sun for several hours, the internal vehicle temperature and, thus, that of the battery may become so hot that the life of the battery is reduced. To avoid this with liquid-cooled systems, the vehicle air conditioning system may be actuated automatically to cool the battery. By allowing the temperature of the battery to fluctuate by several degrees, it is only necessary to actuate the cooling system about once per hour for a few minutes. For a $25^{\circ} \mathrm{C}$ increase between the ambient temperature and the desired battery temperature and with the default insulation thickness $(10 \mathrm{~mm})$ and default thermal conductivity $(0.00027 \mathrm{~W} / \mathrm{cm}-\mathrm{K})$, BatPaC calculates the average cooling requirement to be about $80 \mathrm{~W}$ for PHEV-40 batteries. The performance coefficient of the vehicle air-conditioning system might reduce the actual energy draw to less than half that, but heating of the system outside of the battery during the hour-long downtime periods would be a counter-acting factor. The BatPaC calculates the energy required for cooling of all types of electric-drive vehicle batteries. However, most HEVs, even if cooled by liquids, may not have electrically driven air-conditioning units and some other method might be needed to avoid very high battery temperatures during parking such as thicker insulation and fan cooling during parking. Batteries for any type of electric vehicle that are cooled by air would require similar measures or some method of connecting the air cooling to an electrically-driven air-conditioning system or dedicated refrigeration system. The additional cost for any special system to deal with high ambient temperature that is not a part of the system to remove heat generated within the battery has not been provided in the BatPaC model.

If the battery is to deliver full power at startup, it must be at a temperature of at least $5^{\circ} \mathrm{C}$. This minimum temperature can be maintained by heaters and circulation of the coolant, whether air or liquid. The BatPaC calculates the amount of power required to maintain the battery temperature for any set of battery and ambient temperatures. PHEV-40 batteries would require about $50 \mathrm{~W}$ of heat to maintain the battery temperature at $20^{\circ} \mathrm{C}$ above that of the ambient under steady-state 
conditions. During a period when the battery is connected to a charger, this should be easily done for 20 hours at a cost of $\$ 0.10$ with an energy cost of $\$ 0.10$ per $\mathrm{kWh}$. If the vehicle is not at a source of power for recharging, limited energy (say 1-2 kWh) can be drawn from the battery (if not blocked by a switch actuated by the driver) and then automatically shut off after maintaining the battery temperature for one to three days, depending on the ambient temperature.

\subsection{Heat-up from Cold Ambient Conditions}

All of the batteries for the various types of electric-drive vehicles will occasionally be exposed to very cold temperatures, which will require special heat-up procedures. All but the EV batteries can be heated with the aid of the engine. This can be done with electric heaters operated from power taken from the generator or from glycol solution from the engine cooling system. If the latter, it might be prudent to isolate the engine coolant from the battery coolant by means of a plastic heat exchanger.

MicroHEV and HEV-HP batteries that are air cooled require electric heaters for a cold startup. Without electric heaters, vehicles with such batteries have poor energy efficiency (low mpg) even 30 minutes after startup. Therefore, BatPaC provides 1.0-kW electric heaters for such batteries, which is sufficient to heat the battery by $20^{\circ} \mathrm{C}$ in 3 to 8 minutes, depending on the mass of the battery. The largest batteries would have higher power and would be affected only moderately by low temperature. HEV-HP batteries having glycol solution for heat-transfer medium should have no need for electric heaters because of the speed and efficiency of transferring heat from the engine.

PHEV batteries are normally either connected to a charging station or are exposed to cold weather for a few hours during which they can be maintained at a suitable temperature by electric heaters (section 6.4). BatPaC provides a 1.0-kW heater for this purpose and to assist the engine in heating the battery with glycol solution after a very long exposure to cold temperature. Similarly, EV batteries are provided with 2.0 - to $3.0-\mathrm{kW}$ electric heaters depending on the mass of the battery.

To avoid delay in starting vehicles from a cold startup, the driver could initiate heating by means of a remote device, such as a cell phone. By this means, heating could be initiated either from heat drawn from the engine or by electric heaters. Remote initiation of heat-up would be especially important for an EV away from a charging station in that an engine is not available to assist heating and the large size of the battery would result in a long heating period with electric heaters. BatPaC provides estimates of the time required for heating the battery with electric heaters for each battery being designed on line 193 of the Thermal worksheet. 


\section{HIGH-RATE CHARGING OF ELECTRIC VEHICLE BATTERIES}

Many new electric vehicles are being equipped for receiving high-rate charging. It has become standard even on the lowest priced Tesla vehicles. Until recently, it was standard only on the more expensive 85-kWh model. Tesla and others are building charging stations throughout America and Europe that are capable of charging the battery at up to $135 \mathrm{~kW}$ of continuous power. Sufficient energy can be added to the Tesla Model S in 30 minutes for 180 miles of travel, about $68 \%$ of the range of the $85-\mathrm{kWh}$ model. The USABC has shown interest in fast charging by tentatively listing a goal of charging $80 \% \Delta$ SOC in 15 minutes for EV batteries with $45 \mathrm{kWh}$ energy (EOL, $~ 53 \mathrm{kWh}$ BOL).

As noted below, we have set a maximum areal charging rate of $9.0 \mathrm{mAh} / \mathrm{cm}^{2}$ after reviewing the literature. To meet this requirement for large EV batteries, it is usually necessary to increase the cell area by reducing the electrode thickness. BatPaC automatically makes this change and calculates the additional cost compared to a battery without the fast charging requirement.

\subsection{Restrictions on the Charging Rate}

The main restrictions on the charging rate are the following:

- The overpotential throughout charging must be safely below that at which lithium deposition would occur.

- The maximum power of the charging unit may not be sufficient to meet the specified charging rate.

- The battery temperature must not exceed an upper limit of about $40^{\circ} \mathrm{C}$.

Of these, the cell overpotential limit to avoid lithium deposition is the most restrictive for typical cell chemistries and EV battery designs. The charging rate may be improved while meeting the above restrictions by battery redesign to provide more cell area or by providing a more powerful charger, but at higher cost.

\subsubsection{Overpotential Limits}

The area-specific impedance (ASI) of the battery cells is higher during continuous charging than on acceleration or regenerative braking. The overpotential needed for continuous charging is the sum of the overpotentials for (1) cell ohmic resistance in the electrolyte, (2) electrolyte salt concentrations, (3) positive electrode charge transfer and (4) negative electrode charge transfer. Of these, modeling has shown that the overpotentials for the electrode charge transfers, especially that for the negative electrode, are the major contributors to the total [50].

Modeling studies at Ford Motor Company [50] of high-rate charging have shown that for 59.1- $\mu \mathrm{m}$ graphite negative electrodes and $\mathrm{Li}(\mathrm{NiCoMn}) \mathrm{O}_{2}$ positive electrodes and for the configurations that are also typical of the default values in $\mathrm{BatPaC}$, the avoidance of excessive overpotentials requires restricting the current density to about $4.2 \mathrm{mAh} / \mathrm{cm}^{2}$ for charging to $67 \%$ of full capacity. Additional charging may be done at reduced current densities such as imposed by constant voltage. 
On the other hand, in a recent study [25] much higher charging rates were reported in a teardown study of 96-Ah NMC-G cells from a Ford C-MAX Energi battery. These cells with 64.5- $\mu \mathrm{m}$ positive electrode coatings could be charged to the charge cutoff voltage of $4.2 \mathrm{~V}$ at a constant $5 \mathrm{C}$ rate from 0 to $80 \%$ charge in about 9.6 minutes. This rate was equivalent to $13.6 \mathrm{mAh} / \mathrm{cm}^{2}$, much higher than the limiting rate of $4.2 \mathrm{mAh} / \mathrm{cm}^{2}$ cited in the previous paragraph. Whether such charging would shorten the life of the battery due to high lithium activity at the negative interface is uncertain. However in other tests in that study, charging from $0 \%$ SOC to $4.2 \mathrm{~V}$ at the much higher rates of $10 \mathrm{C}$ and $17 \mathrm{C}$ did no reported damage during the relatively few cycles when the tests were conducted. On the basis of these results, the maximum current density for charging has been set at $9.0 \mathrm{mAh} / \mathrm{cm}^{2}$ in $\mathrm{BatPaC}$.

The actual charging rate that can be applied without damaging the battery is uncertain at this time. Therefore, a specific battery to be manufactured, should be tested to determine if the high-rate charging conditions would affect the battery life.

The maximum power of the charger may limit the charging rate to a lower level than the limiting current density. Also, for some batteries it may be advantageous to restrict the power at the charger to avoid excessive battery heating.

\subsubsection{Battery Heating Limits}

A high charging rate $(>2 C)$ causes more battery heating than very aggressive driving. This heating may be accommodated by efficient cooling and accordingly, BatPaC has been changed from earlier versions to call for cooling of $6 \mathrm{~kW}$ to be available for all $\mathrm{EV}$ batteries. Another way to accommodate the heat generation is to allow the battery temperature to rise to $40^{\circ} \mathrm{C}$ before restricting the charging rate. This approach can be enhanced by precooling the battery to $15^{\circ} \mathrm{C}$. BatPaC has always assumed that the normal battery operating temperature is $15^{\circ} \mathrm{C}$, rather than a higher temperature, to achieve the maximum service life of the battery and to accommodate long parking periods during summer without need for cooling. Typically, if the battery is precooled to $15^{\circ} \mathrm{C}$, the battery will accept a charge of $60 \% \Delta$ SOC (15\% SOC to $75 \%$ SOC) in 10 min without exceeding a temperature of $40^{\circ} \mathrm{C}$ under adiabatic conditions. Thus, it may not be necessary to cool during charging, if the battery temperature is at $15^{\circ} \mathrm{C}$ at the start of charging.

\subsubsection{BatPaC Calculations for High-Rate Charging}

To illustrate the characteristics of electric vehicle batteries during high-rate charging, four NMC622-G batteries were designed for different types of EVs (Table 7.1). The Battery pack number at the top of the columns in Table 7.1 are those from the illustration table for EV batteries at the right side of the Battery Design worksheet in BatPaC. The results for the four sedan batteries, including Battery 4 in the illustration table were discussed in Section 4.3. The batteries illustrated here for high-rate charging have considerably different energy requirements, power and costs. 
Table 7.1 Electric vehicle battery packs with NMC662-graphite cell chemistry designed for charging $60 \% \Delta$ SOC (15\% SOC to $75 \%$ SOC) in 10 minutes

\begin{tabular}{|l|c|c|c|c|}
\hline \multicolumn{1}{|c|}{ Battery Pack } & $\mathbf{4}$ & $\mathbf{5}$ & $\mathbf{6}$ & $\mathbf{7}$ \\
\hline EV Vehicle Type & Sedan & Compact & $\begin{array}{c}\text { Sport } \\
\text { Sedan }\end{array}$ & SUV \\
\hline Range, miles & 300 & 100 & 270 & 300 \\
\hline Energy usage, Wh/mile & 250 & 200 & 250 & 350 \\
\hline Battery energy, kWh & & & & \\
Total & 88.2 & 23.5 & 79.4 & 123.5 \\
Available & 75.0 & 20.0 & 67.5 & 105 \\
\hline Battery pack power, kW & & & & \\
10-s pulse & 300 & 120 & 400 & 360 \\
30-s pulse & 287 & 115 & 383 & 344 \\
\hline Ratio V/U at full power, \% & 95.4 & 93.8 & 93.2 & 96.3 \\
\hline Electrode thickness, microns & & & & \\
Positive & 58.0 & 57.5 & 58.0 & 58.0 \\
Negative & 65.0 & 64.5 & 65.0 & 65.0 \\
\hline Price to OEM at 100 k/year, \$ & 11,700 & 4,610 & 10,940 & 15,830 \\
\hline
\end{tabular}

To calculate the capability of the lithium-ion EV batteries for receiving high-rate charging, a new worksheet, EV Charging, has been added to BatPaC and the results for the battery packs of Table 7.1 are illustrated in Figure 7.1. At the top of the worksheet, parameters relevant to charging are copied from the Battery Design worksheet. The next section of the worksheet deals with the adjustments to the battery design that are required to meet the designated charging rate. For a low charging rate of $1 \mathrm{C}$, no adjustment is needed to the battery designed in the Battery Design worksheet to meet the discharge requirements. This charging rate value is employed when a value of " 0 " is entered in cell E10. When the value in E10 is changed to " 1 ", the spread sheet calculates the positive electrode thickness (line 22) that is needed to meet the charging rates that are set below in this worksheet. This electrode thickness is also entered in the Battery Design worksheet (line 108) so that the entire battery design and price calculation takes into account the needs of highrate charging.

The most limiting restriction on charging $60 \% \Delta S O C$ is shown on line 23 and is selected from the following: (1) the requirements for discharge, (2) the limiting current density to avoid lithium deposition on charging, or (3) the power of the charger. For the small battery pack in the compact vehicle (Battery 5), the discharge conditions are slightly harder to meet than those for charging and, therefore the pack can be recharged in 9.9 min (cell J28). For the other batteries, avoiding lithium deposition is the most limiting constraint as noted on line 23. 


\begin{tabular}{|c|c|c|c|c|c|c|c|c|}
\hline \multicolumn{9}{|c|}{ Rapid Charging of Electric Vehicles (EVs) } \\
\hline & & & & & Sedan & Compact & Sport Sedan & SuV \\
\hline \multicolumn{4}{|c|}{3 Basic Battery Design to Achieve Discharge Requirements } & & Battery 4 & Battery 5 & Battery 6 & Battery 7 \\
\hline \multicolumn{3}{|c|}{4 Battery capacity at $\mathrm{C} / 3, \mathrm{Ah}$} & & & 98.5 & 45.0 & 88.6 & 153.2 \\
\hline \multicolumn{3}{|c|}{5 Battery energy storage, $\mathrm{kWh}$} & & & 88.2 & 23.5 & 79.4 & 123.5 \\
\hline 6 & \multicolumn{2}{|c|}{ Equivalent number of cells in series } & & & 240 & 140 & 240 & 216 \\
\hline 7 & \multicolumn{2}{|c|}{ Battery open-circuit voltage at $50 \%$ SOC, $\mathrm{V}$} & & & 900.0 & 525.0 & 900.0 & 810.0 \\
\hline 8 & \multicolumn{2}{|c|}{ Battery open-circuit voltage at $20 \%$ SOC, V } & & & 855.6 & 499.1 & 855.6 & 770.0 \\
\hline \multicolumn{4}{|c|}{9 Battery Design Adjustments Needed for Rapid Charging } & & & & & \\
\hline 10 & \multicolumn{3}{|c|}{ Charging rate: $1 \mathrm{C}$ rate $(0)$, desired charging time (1) } & 1 & & & & \\
\hline 11 & \multicolumn{4}{|c|}{ Current density to achieve desired charging time with design for discharge, $\mathrm{mA} / \mathrm{cm}^{2}$} & 15.5 & 8.9 & 14.7 & 15.5 \\
\hline 12 & \multicolumn{3}{|c|}{ Maximum current density to avoid lithium deposition, $\mathrm{mA} / \mathrm{cm}^{2}$} & & 9.0 & 9.0 & 9.0 & 9.0 \\
\hline 13 & \multicolumn{4}{|c|}{ Battery Impedance during charge for selected positive electrode thickness, ohms } & 0.1274 & 0.1467 & 0.1387 & 0.0703 \\
\hline \multicolumn{3}{|c|}{14 Area of parallel cell group, $\mathrm{cm}^{2}$} & & & & & & \\
\hline 15 & \multicolumn{2}{|c|}{ Designed for discharge } & & & 22,944 & 18,159 & 21,765 & 35,683 \\
\hline 16 & \multicolumn{2}{|c|}{ Area including fast charging limits } & & & 39,399 & 18,159 & 35,456 & 61,274 \\
\hline 17 & \multicolumn{3}{|c|}{ Battery current to meet charging time requirement for $60 \%$ SOC } & & 354.59 & 162.02 & 319.10 & 551.46 \\
\hline 18 & \multicolumn{2}{|c|}{ Battery current limited by lithium deposition } & & & 354.59 & 163.43 & 319.10 & 551.46 \\
\hline 19 & Positive electrode th & hickness, mm & & & & & & \\
\hline 20 & Thickness as desi & igned to meet discharge re & direments and for $\mathrm{C} / 1 \mathrm{cha}$ & & 99.5 & 57.5 & 94.4 & 99.5 \\
\hline 21 & Maximum thickne & ss limited by lithium depos & ion during charging in des & d time & 58.0 & 57.5 & 58.0 & 58.0 \\
\hline 22 & Thickness require & d for charging & & & 58.0 & 57.5 & 58.0 & 58.0 \\
\hline 23 & Thickness limiting & (Discharge requirements, & Deposition or charger po & & Li Deposition & Discharge & Li Deposition & Li Deposition \\
\hline 24 & Charging Time & & & & & & & \\
\hline 25 & Maximum charger $p$ & ower, kW & & & & & & \\
\hline 26 & Charging time for 60 & $\%$ addition to SOC ( 15 to & $\%$ SOC), minutes & & & & & \\
\hline 27 & Desired charging $t$ & time & & & 10 & 10 & 10 & 10 \\
\hline 28 & Minimum charging & g time for selected positive & ectrode thickness & & 10.00 & 9.91 & 10.00 & 10.00 \\
\hline 29 & Charging time limi & ited by charger power & & & 10.00 & 10.00 & 10.00 & 10.00 \\
\hline 30 & Charging time limi & ited by charger power (hold & & & 10.00 & 10.00 & 10.00 & 10.00 \\
\hline 31 & Selected time cha & rging $60 \%$ SOC ( 15 to $75 \%$ & SOC, $71 \%$ useable), mir & & 10.00 & 10.00 & 10.00 & 10.00 \\
\hline 32 & Total time charging & $70 \%$ SOC ( 15 to $85 \%$ SOC & $82 \%$ useable), $\min$ & & 12.2 & 12.2 & 12.2 & 12.2 \\
\hline 33 & Total time charging & $80 \%$ SOC ( 15 to $95 \%$ SOC & $94 \%$ useable), $\min$ & & 15.6 & 15.6 & 15.6 & 15.6 \\
\hline 34 & Initial C-rate for char & rging ( 15 to $75 \%$ SOC), Al/ & & & 3.60 & 3.60 & 3.60 & 3.60 \\
\hline 35 & Second C-rate for ch & harging ( 75 to $85 \%$ SOC, 7 & $\%$ of initial rate), $\mathrm{A} / \mathrm{Ah}$ & & 2.70 & 2.70 & 2.70 & 2.70 \\
\hline 36 & Third C-rate for chars & ging (85 to $95 \%$ SOC, $50 \%$ & of initial rate), $\mathrm{A} / \mathrm{Ah}$ & & 1.80 & 1.80 & 1.80 & 1.80 \\
\hline 37 & Temperature Co & ntrol & & & & & & \\
\hline 38 & Heat generated char & rging $60 \%$ SOC (15 to $75 \%$ & SOC, $71 \%$ useable), min & & 2.671 & 0.642 & 2.355 & 3.561 \\
\hline 39 & Heat generated char & rging $80 \%$ SOC ( 15 to $95 \%$ & SOC, $94 \%$ useable), min & & 3.227 & 0.776 & 2.845 & 4.303 \\
\hline 40 & Charging Efficiency & $(\Delta \mathrm{SOC}=60 \%), \%$ & & & $95.0 \%$ & $95.5 \%$ & $95.1 \%$ & $95.2 \%$ \\
\hline 41 & Charging Efficiency & $(\triangle \mathrm{SOC}=80 \%), \%$ & & & $95.4 \%$ & $95.9 \%$ & $95.5 \%$ & $95.6 \%$ \\
\hline 42 & Heat content of batt & ery at maximum allowed te & perature above initial tem & $\mathrm{kWh}$ & 2.72 & 0.82 & 2.48 & 3.88 \\
\hline 43 & Initial battery tem & nperature, ${ }^{\circ} \mathrm{C}$ & & & 15 & 15 & 15 & 15 \\
\hline 44 & Maximum allowe & ed temperature at center of & ells, ${ }^{\circ} \mathrm{C}$ & & 40 & 40 & 40 & 40 \\
\hline 45 & Estimated heat c & capacity of battery, $\mathrm{J} / \mathrm{g}-{ }^{\circ} \mathrm{C}$ & & & 0.85 & 0.85 & 0.85 & 0.85 \\
\hline 46 & Mass of battery & pack less $50 \%$ of jacket $m$ & $\mathrm{ss}, \mathrm{kg}$ & & 461.0 & 139.7 & 420.4 & 656.7 \\
\hline 47 & Battery temperature & at end of charging $60 \% \mathrm{SC}$ & $\mathrm{C}$ with no cooling, ${ }^{\circ} \mathrm{C}$ & & 39.5 & 34.5 & 38.7 & 38.0 \\
\hline 48 & Battery temperature & at end of charging $80 \% \mathrm{SC}$ & $\mathrm{C}$ with no cooling, ${ }^{\circ} \mathrm{C}$ & & 44.6 & 38.5 & 43.7 & 42.7 \\
\hline 49 & Number of Packs & & & & 1 & 1 & 1 & 1 \\
\hline 50 & Charger power ou & Itput for all packs, kW & & & 319 & 85 & 287 & 446 \\
\hline 51 & Cost of Batteries D & esigned for Fast Chargin & & & & & & \\
\hline 52 & Total battery cost & to OEM for battery designe & for fast charging, $\$$ & & 11,701 & 4,610 & 10,936 & 15,827 \\
\hline 53 & Total battery cost & to OEM for battery designe & for discharge, $\$$ & & 10,593 & 4,610 & 10,011 & 14,257 \\
\hline 54 & Total battery cost & to OEM for battery designe & for discharge (holding) & & 10,593 & 4,610 & 10,011 & 14,257 \\
\hline 55 & Extra cost of meeti & ing fast charging require & ients, \$ & & 1108 & 0 & 925 & 1570 \\
\hline
\end{tabular}

Figure 7.1 Conditions for charging 60\% $\triangle \mathrm{SOC}$ (15\% SOC to $75 \%$ SOC) in 10 minutes for NMC662-graphite battery packs described in Table 7.1

The desired charging time for charging $60 \% \Delta \mathrm{SOC}$ (15\% SOC to $75 \%$ SOC) can be entered on line 27 for each battery under study. To add an additional 10\% SOC, BatPaC reduces the charging rate for that increment from the initial rate by $25 \%$ and for a final $10 \%$ SOC (to a total of $95 \%$ SOC) the rate is further reduced to $50 \%$ of the initial rate. The resulting charging times for $70 \%$ $\Delta$ SOC and $80 \% \Delta$ SOC are shown on lines 32 and 33. 
By changing the value that is entered on line 27, the time required to charge $80 \% \Delta$ SOC (line 33 ) can be adjusted to any desired value within the limitations of the battery couple under study. For instance, if a value of 6.43 minutes is entered on line 26 , the time to charge $80 \% \Delta$ SOC (line 33 ) becomes $10.0 \mathrm{~min}$. This change results in reduction of the positive electrode thickness from $58 \mu \mathrm{m}$ to $37 \mu \mathrm{m}$, which results in changes in the calculated pack design and cost for the batteries as shown in Table 7.2. Table 7.2 summarizes data drawn from BatPaC for three runs for which the time for charging $60 \% \triangle \mathrm{SOC}$ is set at (1) $36 \mathrm{~min}$ (by entering " 0 " in E10), at (2) $10 \mathrm{~min}$ (by entering “ 1 " in E10 and 10 on line 27), and at (3) 6.43 min (by entering 6.43 on line 27), which results in 10 min to charge $80 \% \Delta$ SOC (line 33).

Table 7.2 The effects of charging rate on the design and price of NMC662-graphite battery packs

\begin{tabular}{|c|c|c|c|c|}
\hline Battery Pack & 5 & 6 & 7 & 8 \\
\hline Vehicle Type & Sedan & Compact & Sport Sedan & SUV \\
\hline Range, miles & 300 & 100 & 270 & 300 \\
\hline Energy, kWh & 88.2 & 23.5 & 79.4 & 123.5 \\
\hline \multicolumn{5}{|c|}{ 1C Charge Rate, 36 min for $60 \%$ charge, 58 to $99-\mu \mathrm{m}$ positive electrodes } \\
\hline Mass, kg & 451 & 152 & 415 & 642 \\
\hline Volume, L & 259 & 94 & 240 & 361 \\
\hline Price, US\$ & 10,590 & 4,610 & 10,010 & 14,260 \\
\hline \multicolumn{5}{|c|}{$10 \mathrm{~min}$ for $60 \%$ charge, $58-\mu \mathrm{m}$ positive electrodes } \\
\hline Mass, kg & $489(8.5 \%)^{*}$ & $152(0 \%)^{*}$ & $448(7.7 \%)^{*}$ & $698(8.6 \%)^{*}$ \\
\hline Volume, L & $274(6.0 \%)$ & $94(0 \%)$ & $253(5.4 \%)$ & $382(6.0 \%)$ \\
\hline Price, US\$ & $11,700(10.5 \%)$ & $4,610(0 \%)$ & $10,940(9.2 \%)$ & $15,830(11.0 \%)$ \\
\hline \multicolumn{5}{|c|}{10 min for $80 \%$ charge, $37-\mu \mathrm{m}$ positive electrodes } \\
\hline Mass, kg & $543(20.5 \%)$ & $165(8.9 \%)$ & $495(19.1 \%)$ & $776(20.7 \%)$ \\
\hline Volume, L & $296(14.4 \%)$ & $99(5.6 \%)$ & 273 (13.7\%) & 413 (14.3 \%) \\
\hline Price, US\$ & $13,230(24.9 \%)$ & $5,020(8.9 \%)$ & $12,260(22.5 \%)$ & $17,980(26.1 \%)$ \\
\hline
\end{tabular}

*Percentages in parentheses are relative to values for packs designed to meet the discharge requirements and which can be charged at the $1 \mathrm{C}$ rate for $60 \% \Delta \mathrm{SOC}$.

Battery packs that are only limited by discharge conditions can be recharged at the 1C-rate for 36 minutes for $60 \% \Delta$ SOC (15 to $75 \%$ SOC) without design changes. If limited by only discharge conditions, the four battery types in this study would have positive electrodes varying in coating thickness from 57.5 to $99.5-\mu \mathrm{m}$ (Fig. 7.1, line 20). Providing for charging $60 \% \Delta$ SOC at $3.6 \mathrm{C}$ in 10 minutes (line 27) requires reducing the positive electrode thickness for all of the battery types to $58.0 \mu \mathrm{m}$ to meet the charging restriction of $9.0 \mathrm{~A} / \mathrm{cm}^{2}$. The additional mass, volume and cost for this reduction in thickness are moderate, and a function mainly of the battery capacity or vehicle range (Table 7.2).

For more aggressive charging of $80 \% \Delta \mathrm{SOC}$ in 10 minutes, the positive electrodes must be further reduced in thickness to $37 \mu \mathrm{m}$. This requirement results in considerable increase in the size and mass of the packs and increases the price of the packs by $9.0 \%$ to $25.9 \%$ relative to packs designed only to meet the discharge requirements. 
Returning to Fig. 7.1, the battery temperature at the end of charging after starting from an initial temperature of $15^{\circ} \mathrm{C}$ is calculated in the lower part of the page for both charging $60 \%$ and $80 \%$ $\triangle \mathrm{SOC}$. Even for $80 \% \Delta \mathrm{SOC}$ and no cooling during charging, the temperatures for the batteries that heated the most were only slightly above $40^{\circ} \mathrm{C}$. With cooling, excessive temperatures would be avoided.

On this worksheet in BatPaC, the power requirement for the charging unit for the battery (including multiple packs) is provided (line 50) and the extra cost of meeting the fast charging requirement beyond the $1 \mathrm{C}$ rate is also provided for each battery (line 55).

BatPaC automatically transfers the results of the high-rate charging calculations to the "USABC" worksheet, if the batteries are designated to be "EV" on the "Battery Design" worksheet. For other types of batteries, the times required for high-rate charging are left blank on the "USABC" worksheet. 


\section{MODELING OF BATTERY PACK MANUFACTURING COST}

\subsection{Approach}

The manufactured cost of a battery pack is calculated with input from the design information generated in modeling the cell and battery pack performance. The design modeling determines the annual materials and purchased items requirements. The manufacturing cost is then added to these materials costs, along with a warranty cost, to reach the unit cost of a single battery pack. The manufacturing costs for the designed battery are scaled from a baseline plant. The baseline plant was designed for a battery of intermediate size and production rate so as to establish a center-point for other plants. The baseline plant accounts for the size, speed, number of units, direct labor, and depreciation of the capital cost for each processing step. These costs are adjusted to meet the requirements for a plant producing the battery under study. The process expenses are summed with the additional costs of operating the manufacturing facility. These costs include launch costs, working capital, variable overhead, general, sales, administration (GSA), research and development, depreciation, warranty, and profit. Additionally, the costs for the thermal management, battery management system, and disconnects have been estimated to provide the total cost to the OEM for the integrated battery pack.

The baseline plant produces 100,000 EV battery packs per year with 60-kWh energy and 220-kW power. The plant costs are evaluated at our estimates of present-day unit costs for materials, labor, and capital and plant area. It should be noted, however, that present-day plants are sometimes designed to produce only 30,000 packs per year for which BatPaC would calculate the costs to be considerable higher than for the same packs produced at 100,000 packs per year, especially for labor and capital equipment. In turn, these costs also drive up the overhead costs and the total price per pack. On the other hand, future EV battery plants to be built up to ten years hence may be designed for larger batteries of up to $120 \mathrm{kWh}$ energy storage and produced at 500,000 packs per year. The costs of such batteries would be lower per unit energy than for those produced in the baseline plant because of higher speed production lines that feature greater degrees of automation than in the baseline plant. BatPaC does not attempt to design such production facilities in detail, but the factors that adjust for the scale of production result in lower estimated costs per pack, especially for labor, capital equipment and, as a result, overhead.

In summary, the estimated costs, whether for present-day or future plants are determined for costs in present-day dollars. The price of batteries produced in the future are expected to be lower than if produced today because of the increase in the scale of production. To adjust the costs of future batteries calculated by BatPaC to that of future dollars would require estimates of future inflation rates for the various cost items, which is not done here.

The parameters were determined to provide reasonable estimates for manufacturing rates of 20$500 \%$ of the baseline rate. Thus, for a plant that is far different in size from the baseline plant, for instance a pilot plant having an annual production of only 5,000 battery packs per year, the estimate from this study would be expected to be less accurate than if determined in a study dedicated to that purpose. 


\subsection{Materials Costs, Purchased Items, and Pack Integration}

The end battery pack cost depends significantly on the cost of both the active and inactive materials that compose the design. In this subsection, the assumed material costs and the rationale behind them are presented. We provide for means to scale the materials cost with production volume using the same method used for processing rates as discussed in section 8.4. In general, the materials costs will be largely insensitive to production volume since we have assumed a high volume market already exists. Only the negative and positive electrode active materials are assumed to have a minor benefit for larger scales of production. While we state suggested materials costs and sensitivity to production scale, the users of the cost model may enter any value that they desire.

\subsubsection{Battery Specific Materials Cost}

The largest contributions to the materials cost of the battery are from the following components: positive and negative electrode active material, separator, electrolyte, and current collector foils. The specified requirements for the energy storage and power of the battery are the determining factors in the quantities and sometimes the choice of the various materials available. BatPaC provides default parameters for many choices of positive electrode materials with less attention on the negative electrode. This reflects the current research and manufacturing activities. The separator and the electrolyte are also both active areas of development, but the BatPaC selections are based on a single electrolyte and separator combination. Including the cost and effect of additives and enhanced separators is beyond the scope of this work. The user is always able to modify the dimensions, cost, and ASI that may be required to account for new developments for these materials.

The price of specific battery materials is of some debate. In the future, some of the materials may increase in cost, such as the positive electrode materials that contain cobalt, which is expected to be in short supply if the demand increases as is expected. However, the expected increasing scale of manufacturing for all of these materials will decrease their prices for a set cost of raw materials. The values presented in Table 8.1 compare our estimated costs of major cell materials as presented in the second edition of this manual (2010 costs) and those we now suggest in this third edition (2018 costs).

\subsubsection{Positive Electrode Active Materials}

The cost of a positive electrode material is driven to a large extent by the cost of the raw materials from which it is made. The archetype Li-ion positive electrode material, lithium cobalt oxide (LCO), was the original material commercialized in Li-ion batteries for consumer electronics. LCO has many excellent characteristics but is not considered a viable choice for use in Li-ion batteries for automotive applications. One of the largest drawbacks of LCO, other than safety concerns, is the high and volatile cost of the cobalt. While tolerable in the consumer electronics market, the cost is too high for use in an automobile battery. Many other materials are in a commercially viable state of development and are currently utilized in Li-ion batteries produced today (Table 8.1) such as lithium manganese spinel oxide (LMO) and lithium nickel manganese cobalt oxide (NMC). The relative advantages and disadvantages of each material will not be discussed here. 
Table 8.1 Comparison of costs for major cell materials as estimated in the second and third editions of the BatPaC Manual

\begin{tabular}{|c|c|c|c|c|c|}
\hline \multirow[b]{2}{*}{ Material } & \multirow[b]{2}{*}{ Chemistry } & \multirow[b]{2}{*}{ Abbreviation } & \multirow[b]{2}{*}{ Unit } & \multicolumn{2}{|c|}{ Unit Cost, \$ } \\
\hline & & & & 2010 & 2018 \\
\hline $\begin{array}{l}\text { Cathodes } \\
\text { Manganese spinel } \\
\text { Phospholivine } \\
\text { Layered oxide }\end{array}$ & $\begin{array}{l}\mathrm{Li}_{1.06} \mathrm{Mn}_{1.94-x} \mathrm{M}^{\prime}{ }_{x} \mathrm{O}_{4} \\
\mathrm{LiFePO}_{4} \\
\mathrm{Li}_{0.80} \mathrm{Co}_{0.15} \mathrm{Al}_{\mathrm{x}} \mathrm{O}_{2} \\
\mathrm{Li}_{1.05}\left(\mathrm{Ni}_{1 / 3} \mathrm{Mn}_{1 / 3} \mathrm{Co}_{1 / 3}\right)_{0.95} \mathrm{O}_{2} \\
\mathrm{Li}_{1.05}\left(\mathrm{Ni}_{4 / 9} \mathrm{Mn}_{4 / 9} \mathrm{Co}_{1 / 9}\right)_{0.95} \mathrm{O}_{2} \\
\mathrm{Li}_{1.05}\left(\mathrm{Ni}_{0.6} \mathrm{Mn}_{0.2} \mathrm{Co}_{0.2}\right)_{0.95} \mathrm{O}_{2}\end{array}$ & $\begin{array}{l}\text { LMO } \\
\text { LFP } \\
\text { NCA } \\
\text { NMC-333 } \\
\text { NMC-441 } \\
\text { NMC-622 } \\
\end{array}$ & $\$ / \mathrm{kg}$ & $\begin{array}{l}10.00 \\
20.00 \\
33.00 \\
31.00 \\
26.00\end{array}$ & $\begin{array}{l}10.00 \\
14.00 \\
24.00 \\
20.00 \\
\\
17.00\end{array}$ \\
\hline $\begin{array}{l}\text { Anodes } \\
\text { Synthetic graphite } \\
\text { Lithium titanate spinel }\end{array}$ & $\begin{array}{l}\mathrm{C}_{6} \\
\mathrm{Li}_{4} \mathrm{Ti}_{5} \mathrm{O}_{12}\end{array}$ & & $\$ / \mathrm{kg}$ & $\begin{array}{l}19.00 \\
12.00\end{array}$ & $\begin{array}{l}12.50 \\
12.00\end{array}$ \\
\hline Electrolyte & 1.2 $\mathrm{M} \mathrm{LiPF}_{6}$ in EC:EMC & & \$/liter & 21.60 & 15.00 \\
\hline Separator & $\mathrm{PP} / \mathrm{PE} / \mathrm{PP}$ & & $\$ / \mathrm{m}^{2}$ & 2.00 & 1.10 \\
\hline $\begin{array}{l}\text { Current collector foil } \\
\text { Positive } \\
\text { Negative }\end{array}$ & $\begin{array}{l}\text { Aluminum } \\
\text { Copper (Al for } \mathrm{Li}_{4} \mathrm{Ti}_{5} \mathrm{O}_{12} \text { ) }\end{array}$ & & $\$ / \mathrm{m}^{2}$ & $\begin{array}{l}0.80 \\
1.80\end{array}$ & $\begin{array}{l}0.30 \\
1.20\end{array}$ \\
\hline
\end{tabular}

Important factors in determining the usefulness and value of a battery pack for an electric-drive vehicle are cell voltage and ASI and the specific capacity $(\mathrm{mAh} / \mathrm{g})$ of the electrodes. For a given design approach, these factors determine the weight and volume of the battery pack for any desired power and energy. Some of the most expensive materials provide the best performance, life and safety. The amounts of cobalt and nickel in the positive electrode material, as well as its ease of manufacture, control its price. For example, the NMC-622 is less expensive than the NMC-333 as the cobalt quantity is significantly reduced. The market prices for cobalt and nickel metals vary dramatically from year to year. Reducing the quantities of these materials in the positive electrode will reduce the total price and price volatility.

Combinations of the expensive materials with less expensive materials may result in satisfactory performance, life and safety at less cost. In general, earth-abundant elements should be the dominate transition metals used if a low cost positive electrode is desired. Both iron and manganese are abundant and inexpensive transition metals for intercalation materials. LMO is relatively easy to manufacture. In contrast, LFP requires a reducing atmosphere and a carbon coating step to reach the end product. The increased complexity in the manufacturing process is realized in the price. However, the manufacturing cost decreases with larger scales of production as indicated by the decrease in the estimated cost of LFP from 2010 to2018 (Table 8.1).

\subsubsection{Negative Electrode Active Materials}

While several negative electrode materials exist for Li-ion batteries, carbon materials in the form of graphite and/or hard carbon are still used in the vast majority of commercial cells. Graphite offers the greatest energy density while hard carbon is said to enable high rate capability with decreased risk of lithium plating (an undesired side reaction) during high charge rates. We have 
chosen synthetic graphite as a generic carbon electrode in our model. Significant differences in cost and performance will exist between synthetic, natural, and coated-natural graphite. The method of production and necessary heat-treatment will control the end cost. Many manufacturers use a proprietary blend of natural and synthetic graphite and/or hard carbon in the negative electrode of their cells. The user of the model may feel free to vary the price depending on the application of interest.

The lithium titanate electrode, LTO, offers an interesting option compared to graphite. Unlike graphite, LTO operates within the stability window of the electrolyte. The higher electrode potential, $1.5 \mathrm{~V}$ vs Li, dramatically reduces or eliminates the formation of the solid electrolyte interphase (SEI). As a result, nanoparticle-based LTO may be implemented without concerns of increased side reactions with the electrolyte. The reduced nanoparticle dimensions increase the available surface area for reaction while simultaneously shortening the diffusion length. Both of these factors combined with the lack of SEI dramatically reduce the impedance of the electrode. Because of the reduction of cell voltage with the LTO negative electrode from the voltage for a graphite electrode, the cell specific energy is also greatly reduced, and therefore this option can only be considered for low-energy, high-power batteries such as for HEV batteries.

\subsubsection{Electrolyte and Separator}

The electrolyte used in this model is based on a lithium hexafluorophosphate salt, $\mathrm{LiPF}_{6}$, dissolved in a carbonate based solvent system. The carbonate solvent system is a blend of ethylene carbonate, EC, and a linear carbonate such as ethyl methyl carbonate, EMC, or dimethyl carbonate, DMC. Other chemical additives may be used to limit the capacity and power fade of the battery over time. Polymers may be added to the electrolyte as either a minor or major component. This is not discussed in any further detail in this work. The price of $\$ 15 /$ liter is only for the base electrolyte (i.e. no additional additives).

The separator is typically a porous membrane based on polypropylene (PP) and sometimes includes a polyethylene (PE) middle layer. PP and PE are very inexpensive raw materials, but the relatively high cost of $\$ 1.10 / \mathrm{m}^{2}$ is in large part due to the manufacturing process required to form the porous network in the membrane. As safety is a major concern for Li-ion batteries, the separator plays a key role in isolating the oxidant from the fuel. If the two charged electrodes contact each other (short), then a run-away reaction is possible. Separators have been designed to "shut-down" or melt at key temperatures. The middle PE layer is the shut-down feature in our default separator. Ceramic coatings have also been used to ensure structural integrity. Many other approaches are being developed to increase the safety of Li-ion batteries. The user of the cost model should account for the specific separator technology in the price and dimensions (thickness and porosity) of the separator as needed.

\subsubsection{Current Collector Foils}

The current collector foils are based on copper metal for the negative electrode and aluminum for the positive electrode. However, the LTO anode material, because of its high voltage relative to lithium, enables the use of aluminum as the negative electrode current collector. The price of these foils is based on raw materials and manufacturing costs. The aluminum foil is produced by rolling 
of thicker stock foils into thinner and thinner sheets. On the other hand, copper foil is more likely to be produced through an electrodeposition process. The foils have been reduced in thickness to 10 microns and 15 microns thick for the copper and aluminum current collectors respectively from those we suggested in 2010 ( 12 microns for $\mathrm{Cu}$ and 20 microns for $\mathrm{Al}$ ). This change resulted from progress made in battery manufacturing during that period. The foils used in batteries have additional requirements beyond the cheapest product available. Surface treatments are often necessary to promote adhesion of the composite electrode to the foil surface. In addition, alloying of the foil may be necessary to achieve the required material properties for long life.

The raw material contributions to the foil price will vary with the volatility of the market price for the metals. The values for both aluminum and copper tend to vary significantly over the time. The price for copper is both higher and more volatile than that of aluminum. As the market price for raw materials changes, so will the price for the finished product.

Conversations with manufacturers and suppliers lead us to estimate prices of $\$ 1.20$ and $\$ 0.30$ per $\mathrm{m}^{2}$ for battery grade copper and aluminum foil respectively. The current metal ingot price is only a minor fraction of the end foil price; increases in ingot prices would only moderately increase the foil prices.

\subsubsection{Additional Electrode Components}

The binder and conductive additive in the positive and negative electrodes add a small but real cost to the battery. The conductive additive, more common for the positive electrode, was priced at $6.80 \$ / \mathrm{kg}$ for a high purity and moderate surface area carbon black material. The binder, PVDF, is estimated to cost $9.50 \$ / \mathrm{kg}$. The $N$-Methyl-2-pyrrolidone (NMP) solvent for the PVDF binder is estimated to be $3.10 \$ / \mathrm{kg}$. Most of the NMP is recovered after evaporation and recycled as discussed in section 8.3.3. Only the small amount lost in processing need be replaced. No cost is assumed for water used in the electrode slurry processing.

\subsubsection{Purchased Items Cost}

To simplify the cost calculations, it was assumed that all hardware items for the cells, modules and battery will be purchased from a vendor specializing in similar products. The costs for these items were estimated to be a fixed value plus an additional value proportional to the mass of the item, which are estimated on the Battery Design worksheet. In mature manufacturing plants of the future, toward which this study is directed, some items which are assumed to be purchased in this study might actually be internally manufactured from raw materials. This would increase the number of processing steps needed in our manufacturing simulation and thus complicate the cost calculations. Assuming that some parts would be purchased if they would actually be produced from raw materials would tend to underestimate capital and labor costs and overestimate purchased items expenses. However, the net effect would likely be only a small change to the overall unit cost of the battery pack.

Table 8.2 lists the purchased items for the cell module and battery jacket. The cost of a SOC controller for each cell, or group of parallel cells, is $\$ 2.50$ plus a small factor for capacity (Ah), which provides for more capable circuits for larger balancing currents. The other component costs 
include a fixed amount plus an additional factor, which is proportional to their mass, $m_{i}$. The cell negative terminal and parallel cell group connection are both made from nickel plated copper sheet and thus have the same cost equation. The costs shown for the terminals include an allotment for isolation tape that is necessary to protect the electrical connection. The bus bar is a fixed cost and is only charged if a single row of modules is used. A single row of modules requires a bus bar in order to locate the positive and negative terminals at the same end of the battery.

Table 8.2 Cost equations for purchased items

\begin{tabular}{|l|l|l|}
\hline Component, $\boldsymbol{i}$ & Cost Equation, \$/unit & Cost per unit \\
\hline SOC controller & $2.50+0.01 C$ & cell or parallel cell group \\
\hline Cell positive terminal & $0.25+4 m_{i}$ & cell \\
\hline Cell negative terminal & $0.25+6 m_{i}$ & cell \\
\hline Cell container & $0.20+3 m_{i}$ & cell \\
\hline Aluminum heat conductor & $0.10+4 m_{i}$ & cell \\
\hline Parallel cell group connection & $0.25+6 m_{i}$ & parallel cell group \\
\hline Module terminals & $0.75+5 m_{i}$ & module \\
\hline Balance of module (casing) & $1.00+3 m_{i}$ & module \\
\hline Module gas release provision & 1.50 & module \\
\hline Module interconnect & $1.00+5 m_{i}$ & module \\
\hline Battery terminals & $15.00+0.02 I_{\text {total }}$ & battery pack \\
\hline Bus bar for one module row & 20.00 & battery pack \\
\hline Battery jacket & $30.00+7 m_{i}$ & battery pack \\
\hline
\end{tabular}

\subsubsection{Pack Integration Cost}

Various additional components are necessary to integrate the battery into the electric drive system, which adds cost. While it is not clear what should and should not constitute the cost of the "battery pack," we present these additional items in Table 8.3 in an attempt to be complete. After all, the cost of the entire system is of interest both to the vehicle manufacture and the final consumer of the product. The calculated total battery cost to the OEM may be directly compared to battery pack level goals as set by the U.S. Advanced Battery Consortium. This category in BatPaC includes the battery pack as well as the battery management system and disconnects. However, thermal management additions outside of the pack are only included in the total system cost to the OEM. The general conclusion is that the pack integration costs have the largest consequence for the smallest batteries.

\subsubsection{Battery Management System}

The battery management system (BMS), in our assumed battery design, integrates the modules and battery into the overall electric drive system. The BMS includes measurement and control features such as the following:

- Measurement of battery pack current and voltage

- Balancing of the module voltages (cell balancing is done within the module) 
- Estimation of battery pack state-of-charge (SOC) and state-of-health (SOH)

- Estimation of module SOC and SOH

- Monitoring and signaling of battery thermal management

The cost of the BMS will scale with magnitude of battery current and with the need to charge from the electrical grid. Therefore the PHEV and EV batteries will have a higher burden from the BMS. The micro-HEV is assumed to have less complicated management and thus less cost than the HEV-HP.

\begin{tabular}{|c|c|c|c|}
\hline \multicolumn{2}{|c|}{ Battery Pack Integration System } & & PHEV \\
\hline & MicroHEV & HEV-HP & and EV \\
\hline Current and voltage sensing, $\$$ & 40 & 70 & 100 \\
\hline Module controls, $\$ /$ module & 10 & 10 & 20 \\
\hline Auto. battery disconnect, $\$$ & 50 & 70 & 200 \\
\hline Manual disconnect per pack, $\$$ & 15 & 15 & 15 \\
\hline \multicolumn{3}{|c|}{ Additional for parallel modules and packs, \$ per string } & 100 \\
\hline Thermal Controls & & & PHEV \\
\hline & MicroHEV & HEV-HP & and EV \\
\hline Baseline thermal system*, $\$$ & 30 & 80 & 120 \\
\hline Additions to AC system $\star \star \star ~ \$ / k W$ & 40 & 40 & 40 \\
\hline Heating system ${ }^{\star \star}, \$ / \mathrm{kW} /$ pack & 20 & 20 & 20 \\
\hline \multicolumn{3}{|c|}{ Additional for multiple packs, \$/additional pack } & 100 \\
\hline \multicolumn{3}{|l|}{ *\$60 additional for each added pack } & \\
\hline \multicolumn{2}{|l|}{${ }^{\star \star}$ No charge for cabin air cooling } & & \\
\hline
\end{tabular}

Table 8.3 Costs to integrate battery pack into vehicle drivetrain. $\$ / \mathrm{kW}$ numbers reflect maximum $\mathrm{kW}$ of cooling or heating required.

\subsubsection{Manual and Automatic Disconnects}

The manual and automatic disconnects integrate a high-level of safety and electrical management into the electric drive system. The manual disconnect breaks the current flow pathway from the high-voltage terminals to the outer system allowing for the safe service of the vehicle and battery pack. This disconnect is designed to be operated when the electrical system is de-energized. The automatic disconnect is much more complex. This unit contains the connections for the highvoltage system to the rest of the vehicle's electrical system: drivetrain, grid charging (if applicable) and accessories (high and low voltage). Fuses are present as a hard-wired safety device to prevent unusually large current spikes from damaging the battery or drivetrain. Multiple contactors are used to appropriately channel electrical current depending upon normal operation or grid-charging. Engaging the contactors requires that multiple safety interlocks are established including isolation of the high voltage bus from the vehicle chassis and an inertia based sensor (crash protection). Finally, a small circuit is provided to prevent arcing of the current across the high-voltage contactor when the high-voltage circuit is closed.

The relative cost of the automatic disconnect amongst the various battery designs is driven by the pack voltage, maximum battery current, and the need for charging from the grid. It is suggested 
the voltage of the pack be limited to $1000 \mathrm{~V}$. Above $1000 \mathrm{~V}$, insulation and provisions for safety become more expensive than is provided in the $\mathrm{BatPaC}$ estimates. On the other hand, high battery currents generally increases the cost of electronics and conductors. The additional complications arising from grid-charging adds a significant additional cost to the PHEV and EV systems. It is unclear to the authors at this time what other factors may enable a lower burden of external safety controls. These additional costs in the automatic disconnect unit have the most pronounced effect on the cost of smaller batteries, as the burden amounts to a significant fraction of the total cost.

\subsubsection{Balance of Thermal Management System}

The thermal management of the battery is crucial to meeting the life and safety requirements of transportation applications. The complexity of this system must be minimized to reduce the cost and size burden on the vehicle. A single refrigerant compressor is used for both the cabin air and the battery cooling applications. Likewise, the same radiator and fan are used both for the cabin cooling and for the battery cooling refrigerant. Most OEMs appear to use an electric compressor for all full-HEVs (HEV-HP) and PHEVs/EVs that are liquid cooled. The incremental cost for an electric compressor at high volume in year 2020 will likely be \$200-300 more than the commonly used $\$ 100$ belt driven compressor. We do not include this incremental cost in our thermal management system cost; however, we state it here for completeness. The additional cost to the compressor for the battery cooling capacity is insignificant compared to the burden of transitioning to the electric compressor. Experts in the field have informed us that the electric motor and highvoltage invertor are the largest contribution to the incremental cost of the electric compressor.

An expansion valve on the refrigerant line and a heat exchanger (chiller) transfers the thermal energy from the heat transfer fluid to the refrigerant loop. A 50/50 DI-water/ethylene-glycol solution is selected as the heat transfer fluid. The assumed battery design has the heat transfer fluid pumped over the module casings to transfer heat from and to the cells. The cells are in good thermal contact with the casing as described in section 6.3 Active Thermal management Systems. The battery may be heated by either a positive thermal coefficient (PTC) or flexible mat heater. The PTC heater would directly raise the temperature of the heat transfer fluid in a reservoir while the matt heater would be placed between the battery jacket insulation and the internal metallic jacket sheet.

The PHEV and EV batteries will likely have both active and passive thermal management modes requiring some additional monitoring and an electrically actuated valve. We have assumed lower cooling costs for the HEV-HP and microHEV systems than for the larger batteries without explicitly dictating where the savings originate. In general, one would expect smaller batteries to have a less complicated control system and lower flow rates. 


\subsection{Baseline Manufacturing Plant}

As discussed above, the model's baseline plant is designed for a battery of intermediate size and production scale so as to establish a center-point for other plants. The baseline plant produces EV battery packs of NMC622-G chemistry for a sedan of moderate power and range at a manufacturing rate of 100,000 battery packs per year. These packs have 220 cells of 67-Ah capacity, providing a total pack power of $220 \mathrm{~kW}$ and total energy of $60 \mathrm{kWh}$. The battery will provide about 204 miles of vehicle travel with $85 \%$ of the pack energy for a vehicle requiring energy of $250 \mathrm{Wh} / \mathrm{mile}$. The schematic diagram of the plant (Fig. 8.1) is designed to illustrate the flow of materials through the plant and the relative floor areas for the processing steps rather than representing a realistic plant layout. The annual rate of 100,000 battery packs per year is achieved by operating for three shifts at the equivalent of 300 days per year of full production; some days will be more or less than $100 \%$ effective. The exceptions to three-shift operation are for sections Cell and Scrap Recycling, Receiving, and Shipping, which are active for only two shifts per day.

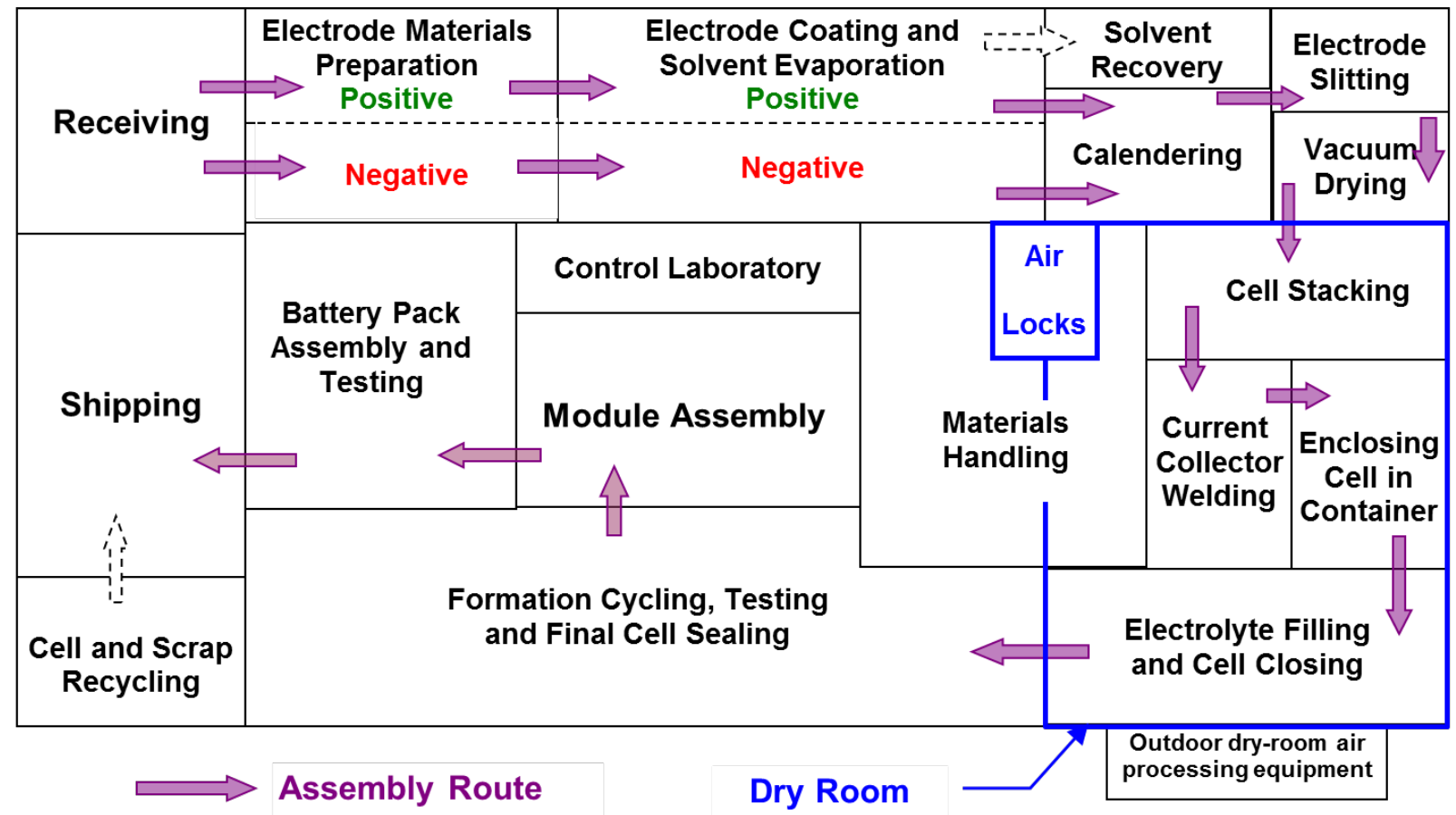

Figure 8.1 Schematic diagram of baseline lithium-ion battery manufacturing plant. Manufacturing rate: 100,000 NMC622-G battery packs per year, 60-kWh pack energy, 220-kW power, 67-Ah capacity, 240 cells in series. Operating year: 300 days per year with three 8-hr shifts.

The cost factors for the individual manufacturing steps in the baseline plant are summarized in Table 8.4 and discussed in detail in the sections that follow. Most of the operations are carried out with normal factory atmosphere, but the cell assembly is completed in a dry room atmosphere. The main processing rate for each step is shown in the second column. The requirements for direct labor, capital equipment and plant area, which are shown in detail in the subsections below, are summarized in the table. It is seen that the plant requires a total of about 144 workers per shift, $\$ 258,800,000$ worth of capital equipment, and 26,750 square meters of plant area to manufacture the baseline battery at a rate of 100,000 battery packs per year. 


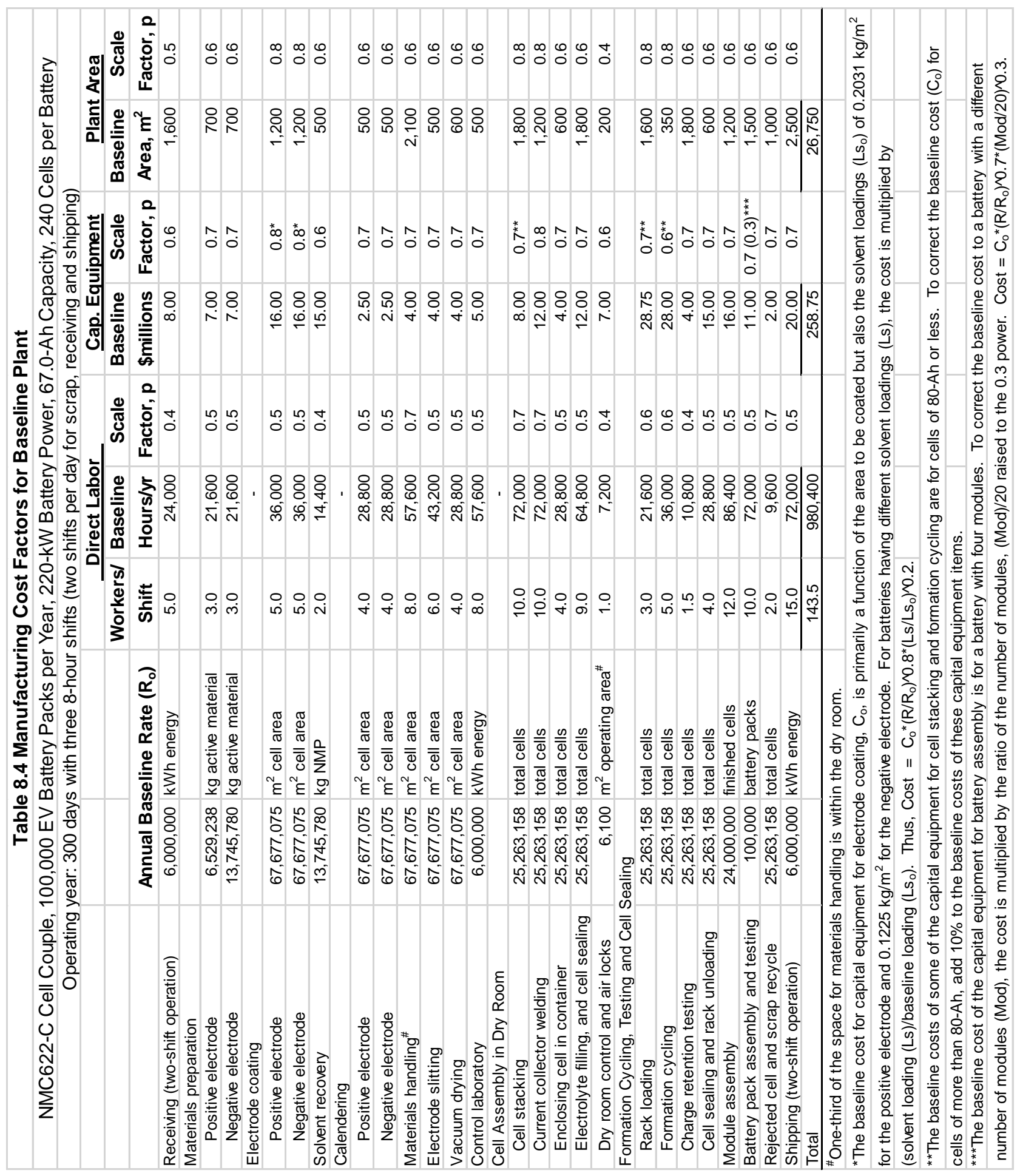




\subsubsection{Receiving and Shipping}

These operations incorporate the moving equipment and storage facilities common for such factory facilities. The Receiving section handles about 37,000,000 kg of materials per year and stores some of the electrode materials in a dry atmosphere. The Shipping section is required to enclose the battery packs in crates, which requires some automated equipment and more labor than is required for Receiving. Shipping also handles about 2,300,000 kg of scrap each year, which is bundled and prepared for shipping in the Rejected Cell and Scrap Recycle section. The estimated resources needed for the Receiving and Shipping sections are shown in the table below.

\begin{tabular}{|l|c|c|c|c|}
\hline & Rate Factor & Direct Labor & Capital Equip. & Plant Area \\
\hline Receiving & $6,000,000 \mathrm{kWh} / \mathrm{y}$ & 5 per shift & $8.0 \mathrm{mil} \$$ total & $1,600 \mathrm{~m}^{2}$ \\
Off-loading & & & 2.0 & \\
Moving & & & 2.5 & \\
Storage & & & 3.5 & \\
& & & & \\
\hline Shipping & $6,000,000 \mathrm{kWh} / \mathrm{y}$ & 15 per shift & $20.0 \mathrm{mil} \$$ total & $2,500 \mathrm{~m}^{2}$ \\
\hline
\end{tabular}

*Total cost including installation

\subsubsection{Electrode Materials Preparation and Delivery to Coating}

The electrode materials, which consist of active material, carbon, binder and binder solvent, are well mixed in small batches in portable tanks. At the design production rate in the baseline plant, each shift requires seven tanks each holding about 3,000 liters of positive electrode material mix and six tanks each holding about 3,000 liters of negative electrode material mix. The section must be capable of exceeding this design rate of production by at least $25 \%$ to catch up in case of unscheduled downtime. This could be done by preparing about two extra tanks of each electrode mix per shift during the catchup period. The tanks of prepared materials are moved to the Coating section and pressurized to push the coating paste into the coating mechanism. The estimated resources needed are the following:

\begin{tabular}{|l|c|c|c|c|}
\hline Materials Prep. & Rate Factor & Direct Labor & Capital Equip.* & Plant Area \\
\hline Positive Materials & 10,195,000 kg/y & 3.0 per shift & 7.0 mil\$ total & $700 \mathrm{~m}^{2}$ \\
& active material & & & \\
Storage tanks & & & $2.5 \mathrm{mil} \$$ & \\
Continuous mixer & & & 0.5 & \\
Moving equip. & & & $7.0 \mathrm{mil} \$$ total & $700 \mathrm{~m}^{2}$ \\
\hline Negative Materials & 6,529,000 kg/y & 3.0 per shift & & \\
& active material & & & \\
\hline
\end{tabular}

*Total cost including installation

\subsubsection{Electrode Coating on Current-Collector Foil}

The positive and negative electrode structures are formed by coating both sides of the current collector foil. In the baseline plant, the coating lines are 1.5-meter wide continuous roll-to-roll coating processes carried out at a line speed of $40 \mathrm{~m} / \mathrm{min}$. The first set of coating and drying 
stations coats one side of the current collector foil, drives off the solvent in a heated oven, and turns the foil over while transferring it to a second set of stations. The second set of coating and drying stations applies and dries the remaining coating. The negative and positive coating lines are very similar. However, some of the negative material is coated only on one side to provide the electrodes at the end of the cell stacks. For the baseline plant, a total of $67,677,000 \mathrm{~m}^{2} / \mathrm{y}$ of coating (annual cell area) is required for the positive electrode, which allows for the $5 \%$ loss of cells expected to fail testing and inspection. The negative electrode coating area is only slightly larger than the positive area. The total foil area fed to the coaters is larger than the coated area to allow for the part of the foil that is not coated (about 10\%) to provide uncoated materials for tabs for welding to the terminals and also to allow about $8 \%$ for trimming losses during electrode slitting. Also, about $28 \%$ excess coating capacity is needed to permit catching up after unscheduled downtime. Two coating lines are needed for each electrode type to meet these needs. All coating lines are capable of coating either electrode.

As noted in a footnote on Table 8.4, both the area to be coated and the amount of binder solvents to be evaporated determine the cost of the capital equipment for electrode coating. The oven sections of the coating line are designed to dry coatings about 100 microns thick at the coating speed of $60 \mathrm{~m} / \mathrm{min}$. even though the coating line normally runs at only $40 \mathrm{~m} / \mathrm{min}$. A thicker coating would require longer ovens at additional capital cost.

The binder solvent for the positive electrode in the baseline plant is NMP, which must be recovered by condensation and recycled. To avoid the buildup of decomposition products, about $0.5 \%$ of the binder solvent is combusted with a thermal oxidizer and is replaced by fresh solvent. For the negative electrode the binder solvent is water, which need not be recovered. The estimated resources to meet these needs are the following:

\begin{tabular}{|l|c|c|c|c|}
\hline Electrode Coating & Rate Factor & Direct Labor & Capital Equip.* & Plant Area \\
\hline Positive Electrode & $\begin{array}{c}67,677,000 \mathrm{~m}^{2} / \mathrm{y} \\
\text { cell area }\end{array}$ & 5.0 per shift & $16.0 \mathrm{mil} \$$ total & $1,200 \mathrm{~m}^{2}$ \\
$\begin{array}{l}\text { Uncoated area } \\
\text { Width of coater }\end{array}$ & & & $18 \%$ & \\
$\begin{array}{l}\text { Coating speed } \\
\text { Number of } \\
\text { 2-sided coaters } \\
\text { Excess capacity }\end{array}$ & & & $1.5 \mathrm{~m}$ & \\
\hline Negative Electrode & $67,677,000$ & 5.0 per shift & $16.0 \mathrm{mil} \$$ total & \\
& & & & \\
\hline Solvent Recovery & $13, \mathrm{y}$ cell area & & $200 \mathrm{~m}^{2}$ \\
\hline
\end{tabular}

*Total cost including installation

\subsubsection{Calendering}

Typically the materials leaving the coaters would go directly to the calendering process. Alternatively, they would be wound onto large rolls and stored in Materials Handling. In 
calendering, the coatings are compressed by rolling to meet the specified void volume fraction, which will later be filled with electrolyte. The calendering equipment must match the output of the coating equipment producing $67,677,000 \mathrm{~m}^{2} / \mathrm{y}$ of cell area with sufficient excess capacity to meet contingencies as in coating. We estimate eight workers are necessary to collectively operate the four pieces of equipment, two for each type of electrode. The estimated resources to meet these needs are the following:

\begin{tabular}{|l|c|c|c|c|}
\hline Calendering & Rate Factor & Direct Labor & Capital Equip.* & Plant Area \\
\hline Positive Electrode & $\begin{array}{c}67,677,000 \\
\mathrm{~m}^{2} / \mathrm{y} \text { cell area }\end{array}$ & 4.0 per shift & $2.5 \mathrm{mil} \$$ total & $500 \mathrm{~m}^{2}$ \\
\hline Negative Electrode & $\begin{array}{c}67,677,000 \\
\mathrm{~m}^{2} / \mathrm{y} \text { cell area }\end{array}$ & 4.0 per shift & $2.5 \mathrm{mil} \$$ total & $500 \mathrm{~m}^{2}$ \\
\hline
\end{tabular}

*Total cost including installation

\subsubsection{Inter-Process Materials Handling}

For all processes in Fig. 8.1, work in progress must be transported and occasionally stored to permit nearly-continuous operation of the equipment. Storage areas must be provided both inside and outside of the dry room. Raw materials must also be moved to the processing sites, which for those in the dry room means through a separate air lock for materials transfer. One-third of the total space for Inter-Process Materials Handling is within the dry-room for the baseline plant and also for all other plants. The estimated resources to meet these needs are the following:

\begin{tabular}{|l|c|c|c|c|}
\hline Materials Handling & Rate Factor & Direct Labor & Capital Equip.* $^{*}$ & Plant Area \\
\hline & $\begin{array}{c}67,677,000 \\
\mathrm{~m}^{2} / \mathrm{y} \text { cell area }\end{array}$ & 8 per shift & 4.0 mil\$ total & $2,100 \mathrm{~m}^{2}$ \\
\hline
\end{tabular}

*Total cost including installation

\subsubsection{Electrode Slitting}

The coated electrode foils are slit into strips between the coated sections and then into individual electrodes as shown in Fig. 2.2. The estimated scrap loss of foil for this process is about 8\%. The estimated resources to meet these needs are the following:

\begin{tabular}{|l|c|c|c|c|}
\hline Electrode Slitting & Rate Factor & Direct Labor & Capital Equip.* $^{*}$ & Plant Area \\
\hline & $\begin{array}{c}67,677,000 \\
\mathrm{~m}^{2} / \mathrm{y} \text { cell area }\end{array}$ & 6 per shift & $4.0 \mathrm{mil} \$$ total & $500 \mathrm{~m}^{2}$ \\
\hline
\end{tabular}

*Total cost including installation

\subsubsection{Final Electrode Drying}

In the absence of electrolyte, no permanent harm is done by exposing the electrodes to normal factory air; however, the electrodes will absorb moisture, which must be removed by heating under vacuum prior to cell assembly. Maintaining extremely low moisture conditions during cell assembly is believed to be very important in achieving long battery life. The final drying step coupled with dry room conditions ensures minimal moisture content in the final product. The 
pertinent processing rate in determining the resources necessary for drying is the total cell area processed per year. The total electrode area dried is twice that area. The individual electrodes exiting from the electrode slitting process are separated into stacks by polarity, loaded into vacuum drying ovens, dried for several hours, and unloaded directly into the dry room. The estimated resources to meet these needs are the following:

\begin{tabular}{|l|c|c|c|c|}
\hline Electrode Drying & Rate Factor & Direct Labor & Capital Equip.* & Plant Area \\
\hline & $67,677,000$ & 4 per shift & $4.0 \mathrm{mil} \$$ total & $600 \mathrm{~m}^{2}$ \\
Dryer capacity & $\mathrm{m}^{2} / \mathrm{y}$ cell area & & & \\
Number of dryers & & & $20,000 \mathrm{~m}^{2} / \mathrm{shift}$ & \\
Excess capacity & & & 10 & \\
\hline
\end{tabular}

*Total cost including installation

\subsubsection{Control Laboratory}

The purpose of the control laboratory is to ensure that the raw materials and the electrodes being fabricated meet specifications. Laboratory personnel collect or supervise collection of samples and carry out analyses. The estimated resources to meet these needs are the following:

\begin{tabular}{|l|c|c|c|c|}
\hline Control Lab & Rate Factor & Direct Labor & Capital Equip.* $^{*}$ & Plant Area \\
\hline & $6,000,000 \mathrm{kWh} / \mathrm{y}$ & 8 per shift & $5.0 \mathrm{mil} \$$ total & $500 \mathrm{~m}^{2}$ \\
\hline
\end{tabular}

*Total cost including installation

\subsubsection{Cell Stacking}

The cells are assembled in four steps, which are carried out in a dry room. The first of these steps is cell stacking. The primary rate factor that determines the cost for all steps in cell assembly is the number of cells assembled per year. For cell stacking an additional cost factor is the capacity of the cells; large cells usually require more electrodes of larger area and thus a more capable cell stacking machine. As noted in a footnote for Table 8.4, the stacking equipment for cells of more than 80 -Ah of capacity is estimated to cost $10 \%$ extra. The capacity of the cells is deemed to have only a minor effect on the other steps in cell assembly and is not taken into account for those steps. The electrodes are inserted in a folded separator sheet; the positive-electrode tabs protrude on one side and the negative-electrode tabs on the other. As in other parts of the plant, excess capacity is provided to allow catching up after unscheduled downtime. The estimated resources to meet these needs for the baseline plant are the following:

\begin{tabular}{|l|c|c|c|c|}
\hline Cell Stacking & Rate Factor & Direct Labor & Capital Equip.* & Plant Area \\
\hline & $25,263,000$ & 10 per shift & $8.0 \mathrm{mil} \$$ total & $1,800 \mathrm{~m}^{2}$ \\
Stacking rate/unit & cells/y & & 10 cells/min & \\
Number of units & & & 8 & \\
Excess capacity & & & $37 \%$ & \\
\hline
\end{tabular}

*Total cost including installation 


\subsubsection{Current Collector Welding}

The current collector tabs for the negative and positive electrodes are welded to their respective terminals by ultrasonic welding. This procedure achieves a connection of near-zero resistance and avoids overheating the electrodes during the welding process. The estimated resources to meet these needs are the following:

\begin{tabular}{|l|c|c|c|c|}
\hline Tab Welding & Rate Factor & Direct Labor & Capital Equip. $^{*}$ & Plant Area \\
\hline & $25,263,000$ cells/y & 10 per shift & $12.0 \mathrm{mil} \$$ total & $1,200 \mathrm{~m}^{2}$ \\
Welding rate & & & 10 cells/min & \\
Number of units & & & 8 & \\
Excess capacity & & & $37 \%$ & \\
\hline
\end{tabular}

*Total cost including installation

\subsubsection{Enclosing Cell in Container}

The aluminum foil layer in the pouch container is sufficiently thick (100 microns default thickness) to permit the use of stiff, pre-shaped pouch halves. The pouches are assumed to be purchased as finished parts. Each cell is enclosed in these containers, which are then partially sealed prior to injecting electrolyte. The estimated resources to meet these needs are the following:

\begin{tabular}{|l|c|c|c|c|}
\hline Enclosing cells & Rate Factor & Direct Labor & Capital Equip.* & Plant Area \\
\hline & $25,263,000$ cells/y & 4 per shift & $4.0 \mathrm{mil} \$$ total & $600 \mathrm{~m}^{2}$ \\
Cell rate & & 10 cells/min & \\
Number of units & & & 8 & \\
Excess capacity & & & $37 \%$ & \\
\hline
\end{tabular}

*Total cost including installation

\subsubsection{Electrolyte Filling and Cell Sealing}

At this station, the cells are evacuated, filled with electrolyte and temporarily sealed. The estimated resources to meet these needs are the following:

\begin{tabular}{|l|c|c|c|c|}
\hline Filling \& 1 $\mathbf{1}^{\text {st }}$ Seal & Rate Factor & Direct Labor & Capital Equip.* & Plant Area \\
\hline & $25,263,000$ & 9 per shift & $12.0 \mathrm{mil} \$$ total & $1,800 \mathrm{~m}^{2}$ \\
Cell rate & cells/y & & 5 cells/min & \\
Number of units & & & 8 & \\
Excess capacity & & & $37 \%$ & \\
\hline
\end{tabular}

*Total cost including installation

\subsubsection{Dry Room Management}

Excellent dry-room atmosphere is required for lithium-ion cell assembly. A maximum dew point temperature of $-40^{\circ} \mathrm{C}$ is maintained in the room. The load on the dry-room drying apparatus is determined by diffusion of water vapor through the walls, entry of air through the air locks, the 
number of workers in the room, and the need to admit some fresh air to limit the buildup of contaminants such as electrolyte solvent vapor. We estimate that the total effect of these load factors is approximately proportional to the room area. The plant area of the dry room has already been accounted for by the area required by the operations going on in the dry room, except that the personnel airlock adds an additional $200 \mathrm{~m}^{2}$. We allow an air turnover rate in the dry room of 10 room volumes per hour. The equipment for circulation and purification of the dry air is located outside of the plant building, adjacent to the dry room. The estimated resources to meet these needs are the following:

\begin{tabular}{|l|c|c|c|c|}
\hline Dry Room & Operating Area & Direct Labor & Capital Equip. $^{*}$ & Airlock \\
\hline & $6,100 \mathrm{~m}^{2}$ & 1 per shift & $7.0 \mathrm{mil} \$$ total & $200 \mathrm{~m}^{2}$ \\
\hline
\end{tabular}

*Total cost including installation

\subsubsection{Formation Cycling, Charge Retention Testing and Final Cell Sealing}

Cell finishing is expensive because it takes considerable time, we estimate 52 shifts, (2 for rack loading, 6 for formation cycling, and 42 for charge retention testing) and each cell must be monitored separately. We project integration of the finishing steps into a single department monitored from a control room with considerable automation and reduction in labor costs. The cells are (1) loaded into tall racks that are plugged into the electric power and monitoring system, (2) formation cycled under precise temperature controlled conditions, (3) charge-retention tested over a two-week period, which is mainly a holding period and voltage monitoring, and (4) separated from rejected cells and given final cell sealing. The capital cost of the cycling equipment is primarily a function of the annual number of cells to be tested, and to a lesser extent the capacity of the cells; for cells of over 80-Ah capacity, $10 \%$ is added to the cost of both the rack loading and the formation cycling equipment.

The final cell sealing occurs after charge-retention testing. Gas generated during formation cycling may accumulate in the reservoir space that was created during the temporary sealing step. This gas is removed by creating the final seal below the reservoir and trimming off the unwanted portion. The estimated resources to meet these needs are the following: 


\begin{tabular}{|c|c|c|c|c|}
\hline Cell Finishing & Rate Factor & Direct Labor & Capital Equip.* & Plant Area \\
\hline $\begin{array}{l}\text { Rack Loading } \\
\text { (2 shifts) } \\
\text { Number of racks } \\
\text { Rack height } \\
\text { Rack floor area } \\
\text { Rack capacity } \\
\text { Excess racks }\end{array}$ & $25,263,000$ cells/y & 3 per shift & $\begin{array}{c}28.75 \text { mil\$ total } \\
1,375 \\
4.0 \mathrm{~m} \\
1.0 \mathrm{~m}^{2} \\
1600 \text { cells } \\
51 \% \\
\end{array}$ & $1,600 \mathrm{~m}^{2}$ \\
\hline $\begin{array}{l}\text { Formation Cycling } \\
\text { Cell capacity } \\
\text { Number of cyclers } \\
\text { Cells per cycler } \\
\text { Length of tests } \\
\text { Excess capacity }\end{array}$ & $25,263,000$ cells/y & 5 per shift & $\begin{array}{c}28.0 \text { mil\$ total } \\
80 \mathrm{Ah} \\
140 \\
1,600 \\
6 \text { shifts } \\
33 \%\end{array}$ & $350 \mathrm{~m}^{2}$ \\
\hline $\begin{array}{l}\text { Charge Retention } \\
\text { Length of test } \\
\text { Excess capacity }\end{array}$ & 25,263,000 cells/y & 1.5 per shift & $\begin{array}{c}4.0 \text { mil\$ total } \\
42 \text { shifts } \\
33 \%\end{array}$ & $1,800 \mathrm{~m}^{2}$ \\
\hline Final Cell Sealing & $25,263,000$ cells/y & 4 per shift & $15.0 \mathrm{mil} \$$ total & $600 \mathrm{~m}^{2}$ \\
\hline
\end{tabular}

* Total cost including installation

\subsubsection{Module and Battery Assembly}

A total of approximately $5 \%$ of the cells are expected to fail either during the formation cycling or charge-retention tests and these cells are sent to the Rejected Cell and Scrap Recycle section. The accepted cells, 24,000,000 finished cells per year, are assembled into modules. First, an aluminum heat conductor is placed around each cell (Fig 2.3) and the terminals are attached by laser welding or by mechanical joining with spring loaded devices. Electronic circuit packs are attached that have about the same volume and shape as a cell. These operations are carried out at ten automated stations each capable of handling about 420 cells per hour. For the module design being cost estimated in this model, the module is enclosed in an air-tight aluminum container by double seaming. The processing parameter that determines the cost of module assembly is the number of finished cells that must be handled per year.

The finished modules are assembled into battery packs with the aid of automated stations. The total cost of these stations is dependent mainly on the number of battery packs to be assembled per year (100,000 for the baseline plant), but to a lesser extent on the number of modules per pack (see footnote to Table 8.4). After assembly, the packs are moved to testing stations where they are discharged as a final check of impedance and to lower the state of charge to a level suitable for shipping. The estimated resources to meet these needs are the following: 


\begin{tabular}{|l|c|c|c|c|}
\hline Modules and Packs & Rate Factor & $\begin{array}{c}\text { Direct } \\
\text { Labor }\end{array}$ & Capital Equip.* & $\begin{array}{c}\text { Plant } \\
\text { Area }\end{array}$ \\
\hline $\begin{array}{l}\text { Module Assembly } \\
\text { Number of stations }\end{array}$ & $24,000,000$ cells/y & 12 per shift & $\begin{array}{c}16.0 \text { mil\$ total } \\
10\end{array}$ & $1,200 \mathrm{~m}^{2}$ \\
Cells/h/station & & & 420 & \\
Excess capacity & & & $26 \%$ & \\
\hline Battery Pack Assembly & 100,000 packs/y & 7 per shift & 5.0 mil\$ total & $750 \mathrm{~m}^{2}$ \\
Modules/pack & & & 3 & \\
Number of stations & & & $30 \%$ & \\
Packs/h/station & & & $6.0 \mathrm{mil} \$$ total & $750 \mathrm{~m}^{2}$ \\
Excess capacity & & 3 per shift & & \\
\hline Battery Pack Testing & 100,000 packs/y & & & \\
\hline
\end{tabular}

* Total cost including installation

\subsubsection{Rejected Cell and Scrap Recycle}

Scrap is generated in preparing the electrodes and in rejection of $5 \%$ of the cells that go through formation cycling and charge-retention tests. The yields of materials in the various processing steps are shown in Table 8.5.

Table 8.5 Materials yields during electrode and cell fabrication

\begin{tabular}{|l|c|c|c|c|c|c|}
\hline \multicolumn{1}{|c|}{ Material } & $\begin{array}{c}\text { Material } \\
\text { Mixing }\end{array}$ & Coating & $\begin{array}{c}\text { Electrode } \\
\text { Slitting }\end{array}$ & $\begin{array}{c}\text { Cell } \\
\text { Stacking }\end{array}$ & $\begin{array}{c}\text { Electrolyte } \\
\text { Filling }\end{array}$ & Total \\
\hline Positive Electrode & 99 & 95 & 99 & 99 & & 92.2 \\
\hline Negative Electrode & 99 & 95 & 99 & 99 & & 92.2 \\
\hline Positive Current Coll. & & 99 & 92 & 99 & & 90.2 \\
\hline Negative Current Coll. & & 99 & 92 & 99 & & 90.2 \\
\hline Separator & & & & 98 & & 98.0 \\
\hline Electrolyte & & & & & 94 & 94.0 \\
\hline
\end{tabular}

The scrap is gathered and packaged for shipment to a recycling center for recovering the materials having value and disposing of the waste. In the BatPaC model, no credit is taken for the value of the scrap nor are costs charged for shipping the scrap or disposal of worthless or toxic materials it may contain. The main costs for this department are in gathering the scrap from the other departments and packaging it for shipment. The treatment of the scrap is minimal. The costs are deemed to be a function of the number of cells produced per year, which is proportional both to the number of cells rejected (5\%) and approximately to the rest of the scrap generated. The estimated resources needed for scrap recycle are the following: 


\begin{tabular}{|l|c|c|c|c|}
\hline & Rate Factor & Direct Labor* & Capital Equip.** & Plant Area \\
\hline Scrap Recycle & $\begin{array}{c}25,263,000 \\
\text { cells/y }\end{array}$ & 2 per shift & $2.0 \mathrm{mil} \$$ total & $1,000 \mathrm{~m}^{2}$ \\
Scrap rate & & $4,163 \mathrm{~kg} / \mathrm{shift}$ & \\
\hline
\end{tabular}

*based on two shifts per day. ** Total cost including installation.

\subsection{Adjustment of Costs for Varying Production Volumes}

Production volume may affect the end price of the battery in two distinct ways. First, the user of the model may change the annual production volume and every processing step will be affected. Somewhat differently, as the performance requirements and thus the battery design are changed, the production of individual steps will change in non-uniform ways. As noted in Table 8.4, there are many processing rates that must be considered in addition to the overall number of battery packs manufactured per year. Each of these rates affects the costs of one or more steps in the process and may have no effect upon the costs of other steps in the process. For instance, when the user of the model increases the power of the battery packs without increasing the number of cells or their capacity, the model increases the area of the cells and decreases the electrode coating thicknesses. Such changes would result in an increase in the cost of the coating equipment, the floor area occupied by the equipment, and in the direct labor for that step in the process. It would have no effect on the cost of mixing the materials to be coated because the amounts of these materials per battery pack are unchanged under the assumed conditions.

The general approach to cost estimation of multiplying a known cost by the ratio of processing rates raised to a power has also been applied to the capital cost of individual items of equipment [51].

$$
C=C_{\mathrm{o}}\left(R / R_{0}\right)^{p}
$$

Here, $C_{0}$ is the capital cost of an installed equipment item designed for the baseline processing rate, $R_{0}$. The power factor, $p$, relates the capital investment cost and the processing rate for the manufacturing step.

If the value of $p$ were 1.0, it would imply that the cost of the equipment item, or the equipment items if there are several in parallel, would be directly proportional to the processing rate and the cost of equipment per unit of production would be independent of the processing rate. However, the value of $p$ for the cost of equipment is frequently about 0.6 to 0.7 for many manufacturing process steps because the equipment is larger for processing rates higher than that of the baseline and the total equipment cost is less than if the cost were directly proportional to the processing rate. This results in the unit cost being lower as the production rate increases. For process steps requiring the addition of many identical pieces of equipment for scale up, the value of $p$ may be as high as 0.9 . The value of $p$ is unlikely to reach 1.0 because the equipment cost includes installation, for which there is some savings even in installing multiple units of the same processing capacity. The relationships between cost and processing rate for two-fold and three-fold rate changes are 
illustrated in Table 8.6. The unit cost is determined by dividing the total cost by the production rate, thus the total cost for twice the baseline rate for $p=0.7$ is 1.624 times the baseline cost, but the unit cost is lowered to $1.624 / 2$ or 0.812 times the baseline unit cost.

Table 8.6 The effect of processing rate $(R)$ on costs for various scale factors

\begin{tabular}{|c|c|c|c|c|}
\hline & \multicolumn{2}{|c|}{$\begin{array}{c}\text { Total Process Cost Ratio } \\
C / C_{o}=\left(R / R_{0}\right)^{p}\end{array}$} & \multicolumn{2}{c|}{$\begin{array}{c}\text { ost Ratio per Unit } \\
\text { Produced } \\
C / C_{o}=\left(R / R_{\mathrm{o}}\right)^{p-1}\end{array}$} \\
\hline Scale Factor, $p$ & $R / R_{0}=2$ & $R / R_{0}=3$ & $R / R_{0}=2$ & $R / R_{0}=3$ \\
\hline 0.25 & 1.19 & 1.32 & 0.596 & 0.439 \\
\hline 0.3 & 1.23 & 1.39 & 0.616 & 0.463 \\
\hline 0.4 & 1.32 & 1.55 & 0.660 & 0.517 \\
\hline 0.5 & 1.41 & 1.73 & 0.707 & 0.577 \\
\hline 0.6 & 1.52 & 1.93 & 0.758 & 0.644 \\
\hline 0.7 & 1.62 & 2.16 & 0.812 & 0.719 \\
\hline 0.8 & 1.74 & 2.41 & 0.871 & 0.803 \\
\hline 0.9 & 1.87 & 2.69 & 0.933 & 0.896 \\
\hline 1.0 & 2.00 & 3.00 & 1.000 & 1.000 \\
\hline
\end{tabular}

Similar equations have been applied for determining the effect of processing rate on the annual hours of labor and the plant area required for a manufacturing step. In general, the value of $p$ is low for the labor equation, usually only 0.4 to 0.5 , because only a relatively small addition to the labor crew permits operation of larger equipment or of operating several more units of the same processing capacity [51]. The value of $p$ for the plant area required for a processing step is slightly less than that for the capital cost of the equipment. The floor area required for larger equipment or for more equipment items of the same size is proportionately less than the increase in the processing rate because of the more efficient use of the space occupied by the equipment and the savings in aisle area. The value of the scale factors (i.e. $p$ factors) for labor, capital equipment, and floor area were estimated for each of the processing steps (Table 8.4).

For most processing steps, increasing the processing rate beyond that in the baseline plant would result in a decision to increase automation or use faster equipment to mitigate the costs of higher levels of throughput. Decreasing the processing rate would have the opposite effect. Some steps in the process such as cell stacking, welding of current collectors, and formation cycling do not appear to be easily automated beyond the level intended in the baseline plant and, thus require a higher value for the scale factor of 0.8. This higher scale factor results in achieving less cost reduction per battery pack with increasing production volume. Additionally, a higher $p$ factor results in a less severe penalty for lower production scale for an individual step in the process.

There are six processing steps for which the cost of the capital equipment is affected by factors other than the main processing rate for that step. These are discussed in the footnotes at the bottom of Table 8.4. For these steps, the costs that have been adjusted for the changes in the processing 
rate from the baseline rate are further adjusted to take into account other cost factors. The costs of the coating equipment for both the positive and negative electrodes are adjusted for the amount of solvent to be driven off; thicker coatings need longer, more expensive ovens to drive off the additional binder solvent or the coater must be operated at lower speeds. The costs of the cell stacking equipment and the formation cycling equipment, for which the main cost factor in both cases is the number of cells to be fabricated annually, are also adjusted for the capacity of the cells; larger cells require more expensive equipment. The cost of the capital equipment for battery assembly is primarily a function of the number of cells in the battery, but it is also a function of the number of modules that must be interconnected. This dependence is accounted for in the model with an additional multiplying factor.

A breakdown of the baseline plant capital equipment costs listed in Table 8.4 is illustrated in Fig. 8.2. The largest costs for capital equipment are for formation cycling and testing, electrode coating and cell assembly in the dry room. These capital costs are likely to be dominant in any lithium-ion battery plant in the near future.

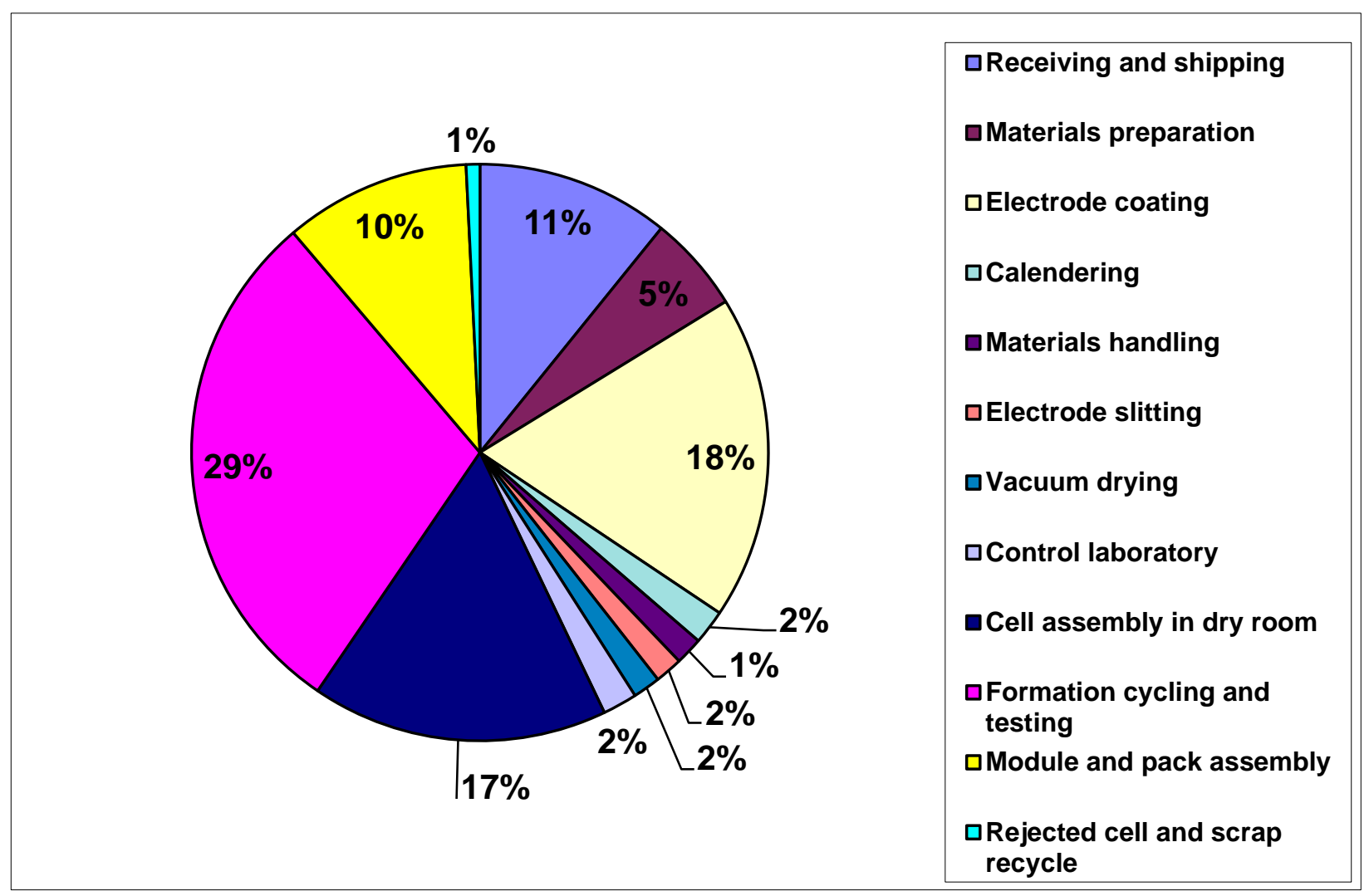

Figure 8.2 Breakdown of installed capital equipment costs for the baseline plant, which produces $100,000 \mathrm{EV}$ batteries per year, a total of $6.0 \mathrm{MWh} /$ year. 


\subsection{Plant Investment Costs}

In this model, the calculated investment costs are defined as those directly related with building and operating the plant (Table 8.7). Other costs that may require investment, such as research and development, are added separately to the unit cost of the battery. The largest investment cost is for the installed capital equipment. Each cost item for the battery under design is adjusted from the estimate of the baseline plant. The plant cost is done in a similar way with a cost of $\$ 3,000$ per square meter of plant area (\$280/sq. ft), which includes the cost of land and installed utilities. Launch costs include plant start-up, employee training and materials that are spent or recycled in early stages of production, beyond the normal amounts. Launch costs are estimated to be $5 \%$ of annual materials costs plus $10 \%$ of annual direct labor and variable overhead (Section 8.6). Working capital is needed to cover the costs of payroll, receivables, and the inventories of raw materials, work in progress and finished product. These working capital costs are partially offset by bills that are payable. We estimate the working capital to be $15 \%$ of the annual variable costs.

Table 8.7 Battery pack manufacturing investment costs

\begin{tabular}{|l|l|l|}
\hline \multicolumn{1}{|c|}{ Investment Costs } & \multicolumn{1}{|c|}{ Description } & \multicolumn{1}{c|}{ Method of Calculation } \\
\hline Capital Equipment & $\begin{array}{l}\text { Equipment costs including } \\
\text { installation }\end{array}$ & $\begin{array}{l}\text { Estimates of costs for each } \\
\text { processing step at baseline rates } \\
\text { adjusted for actual rates. }\end{array}$ \\
\hline Plant Floor Space & $\begin{array}{l}\text { Space includes aisles and space } \\
\text { for unfinished processing } \\
\text { inventory plus land and utility } \\
\text { costs. }\end{array}$ & $\begin{array}{l}\text { Estimates of costs for each } \\
\text { processing step at baseline rates } \\
\text { adjusted for actual rates. }\end{array}$ \\
\hline Launch Costs & $\begin{array}{l}\text { Plant start-up, training, out-of- } \\
\text { spec product. }\end{array}$ & $\begin{array}{l}5 \% \text { of annual materials cost, } \\
10 \% \text { of direct labor plus } \\
\text { variable overhead. }\end{array}$ \\
\hline Working Capital & $\begin{array}{l}\text { Cash to meet payroll, } \\
\text { receivables, inventories of raw } \\
\text { materials and of unfinished and } \\
\text { finished product, minus } \\
\text { payables. }\end{array}$ & \\
\hline
\end{tabular}

\subsection{Unit Costs for Battery Pack}

The unit costs of the battery pack are calculated as summarized in Table 8.8. The main goal of the $\mathrm{BatPaC}$ model is to estimate the unit cost. In estimating some of the items, costs are determined as percentages of other costs rather than directly estimating the capital or labor required. Thus, although the total unit cost is our best estimate, the total plant investment and the number of laborers required per shift are probably underestimated by 10 to $20 \%$.

\subsubsection{Variable Costs}

The costs of the materials and purchased items are based on the costs discussed in section 8.2, and the annual amounts of materials are adjusted for the yields of materials and cells (section 8.3.16). 
The direct labor is the sum of the labor cost for each step in the process, which are calculated for the baseline plant and adjusted for the rate associated with the battery under study for that step in the process. Variable overhead is the cost of indirect materials and labor, utilities, and plant maintenance. It is estimated to cost $40 \%$ of direct labor costs and $20 \%$ of total depreciation.

\subsubsection{Fixed Expenses}

Fixed expenses include General, Sales, and Administration (GSA), research and development, and depreciation. The cost of GSA includes the plant office, taxes on income and property, cost of sales and insurance. It is estimated by the model as $25 \%$ of direct overhead and depreciation. Research and development (R\&D) must be carried out to ensure that the battery packs that are produced in the plant and the means of production continue to be competitive in the world market with respect to battery performance and price. The greater the investment in the plant and its equipment, the greater is the need to be successful in the $R \& D$ effort. Thus, the $R \& D$ expenditure has been set at $40 \%$ of the depreciation expense. Depreciation expense provides funding available for future investment in this plant to replace equipment or for another venture. The equipment and plant are depreciated at straight-line rates for 6-year life (16.7\% per year) and 20-year life (5\% per year), respectively.

Table 8.8 Unit cost of battery pack

\begin{tabular}{|c|c|c|}
\hline Variable Costs & Description & Method of Calculation \\
\hline $\begin{array}{l}\text { Materials and Purchased } \\
\text { Items }\end{array}$ & $\begin{array}{l}\text { All materials and purchased } \\
\text { items in finished product and } \\
\text { lost in processing. }\end{array}$ & $\begin{array}{l}\text { Based on prices of materials, } \\
\text { cost equations for purchased } \\
\text { items and yields. }\end{array}$ \\
\hline Direct Labor & $\begin{array}{l}\text { Labor costs for operations and } \\
\text { immediate supervision. }\end{array}$ & $\begin{array}{l}\text { Estimates of costs for each } \\
\text { processing step at baseline rates } \\
\text { adjusted for actual rates. }\end{array}$ \\
\hline Variable Overhead & $\begin{array}{l}\text { Indirect materials, labor, } \\
\text { utilities, plant maintenance }\end{array}$ & $\begin{array}{l}40 \% \text { of direct labor cost plus } \\
20 \% \text { of depreciation }\end{array}$ \\
\hline \multicolumn{3}{|l|}{ Fixed Expenses } \\
\hline $\begin{array}{l}\text { General, Sales, and } \\
\text { Administration (GSA) }\end{array}$ & $\begin{array}{l}\text { Plant office, taxes on income } \\
\text { and property, cost of sales and } \\
\text { insurance expenses. }\end{array}$ & $\begin{array}{l}\text { 25\% of direct labor and variable } \\
\text { overhead plus } 25 \% \text { of } \\
\text { depreciation. }\end{array}$ \\
\hline $\begin{array}{l}\text { Research } \\
\text { Development }\end{array}$ & $\begin{array}{l}\text { On-going research needed to } \\
\text { upgrade product and maintain } \\
\text { competitive position. }\end{array}$ & $40 \%$ of depreciation \\
\hline Depreciation & $\begin{array}{l}\text { Provides funds for new } \\
\text { investments to replace those in } \\
\text { current equipment and plant. }\end{array}$ & $\begin{array}{l}16.7 \% \text { of capital equipment cost } \\
\text { plus } 5 \% \text { of plant floor space } \\
\text { cost. }\end{array}$ \\
\hline Profit & $\begin{array}{l}\text { Return on invested capital after } \\
\text { taxes. }\end{array}$ & $5 \%$ of total investment costs. \\
\hline Warranty & $\begin{array}{l}\text { Funds set aside for reimbursing } \\
\text { customers for battery pack } \\
\text { failures. }\end{array}$ & $\begin{array}{l}5.6 \% \text { added to price based on } \\
\text { present worth of projected } \\
\text { payments. }\end{array}$ \\
\hline
\end{tabular}




\subsubsection{Profits}

The profit goal for this type of venture varies with the financial structure of the company, especially regarding long-term debt. For the model, the profit is set to provide a 5\% return on the total investment, which is an approximate average for mature manufacturing as vehicle battery production is expected to be in 2020 and beyond. In general, the chosen cost structure and the resulting margin are similar to a Tier 1 supplier in the automotive industry.

\subsubsection{Battery Pack Warranty Costs}

If a battery module or an entire pack fails, the replacement will cost much more than the original price paid by the OEM. It is important that such events are rare, but provision must be made to reimburse the vehicle owner, especially in the early years of the projected battery life. The extra costs of replacing the battery will result from labor for testing and replacing the battery, inventory costs for stocking replacement batteries, and servicing the battery controller if the new battery is slightly different than the old battery. It is likely that the battery manufacturer will be responsible for the cost of the new battery, which we assume will be equal to the cost of the original battery. The other costs of replacing the battery, to the extent that they are covered by the warranty, are assumed here to be covered by the automobile manufacturer and the dealer and, thus are not included in the battery warranty cost reflected in the battery price. The goal for average battery life is 15 years. It seems appropriate to provide a warranted life of 10 years, with full replacement in the first five years and shared cost of replacement for the last five years. The vehicle owner would pay an increasing share of the cost from between $0 \%$ at 5 years to $100 \%$ at 10 or more years. With these assumptions, the cost to the battery manufacturer will be equal to the present worth of the future costs of the new battery or modules as provided in the warranty. The rate of battery failure will vary over the life of the battery with a slightly higher rate early in life, then a low failure rate followed by a gradually increasing failure rate. For purposes of calculation we assume a failure rate of $1.0 \%$ per year throughout the warranty period. With an internal rate of return of $8 \%$ compounded on a monthly basis, the present value of the future costs would be about $5.6 \%$ of the price of the battery before adding the warranty cost.

\subsection{Uncertainties in Price Estimates}

The potential uncertainty in estimating the price of lithium-ion batteries depends upon many factors. In BatPaC, the error bars for the 95\% confidence intervals for the price charged to an OEM for the battery pack are automatically calculated at the bottom of the Summary of Results worksheet. The two major categories of uncertainty in the default calculation of battery price are:

- Input costs of materials and capital equipment for which we estimate the total error to be about $\pm 10 \%$

- The limit on the thicknesses of the electrode coatings and the capacity limit on cells for which we estimate an additional $\pm 5 \%$.

\subsection{Breakdown of Costs}

BatPaC assists in showing the relative importance of cost items by providing cost breakdowns from several perspectives as detailed in the Cost Breakdown worksheet. The costs are distributed in several ways and then graphed with pie charts to illustrate the relative importance of the cost items. This is a useful way of judging the importance of cost items. 
The Cost Breakdown worksheet illustrates the costs for Battery 1 and Battery 7 as they are designed on the Battery Design worksheet. (The modeler may change the selection of battery on the chart by selecting the pie image on the chart and then changing the Excel column for the cost values.) The batteries selected for this illustration, are those for $\mathrm{EV}$ batteries in $\mathrm{BatPaC}$ as distributed. Battery 1 is for an EV sedan of moderate range (180 miles), power (180 kW) and energy (52.9 kWh): Battery 7 is for an EV SUV of long range (300 miles), high power (360 kW) and high energy (123.5 kWh).

The first set of graphs (Fig. 8.3) for Battery 1 and Battery 7 shows the overall distribution of costs as calculated in the "Summary of Results" worksheet.
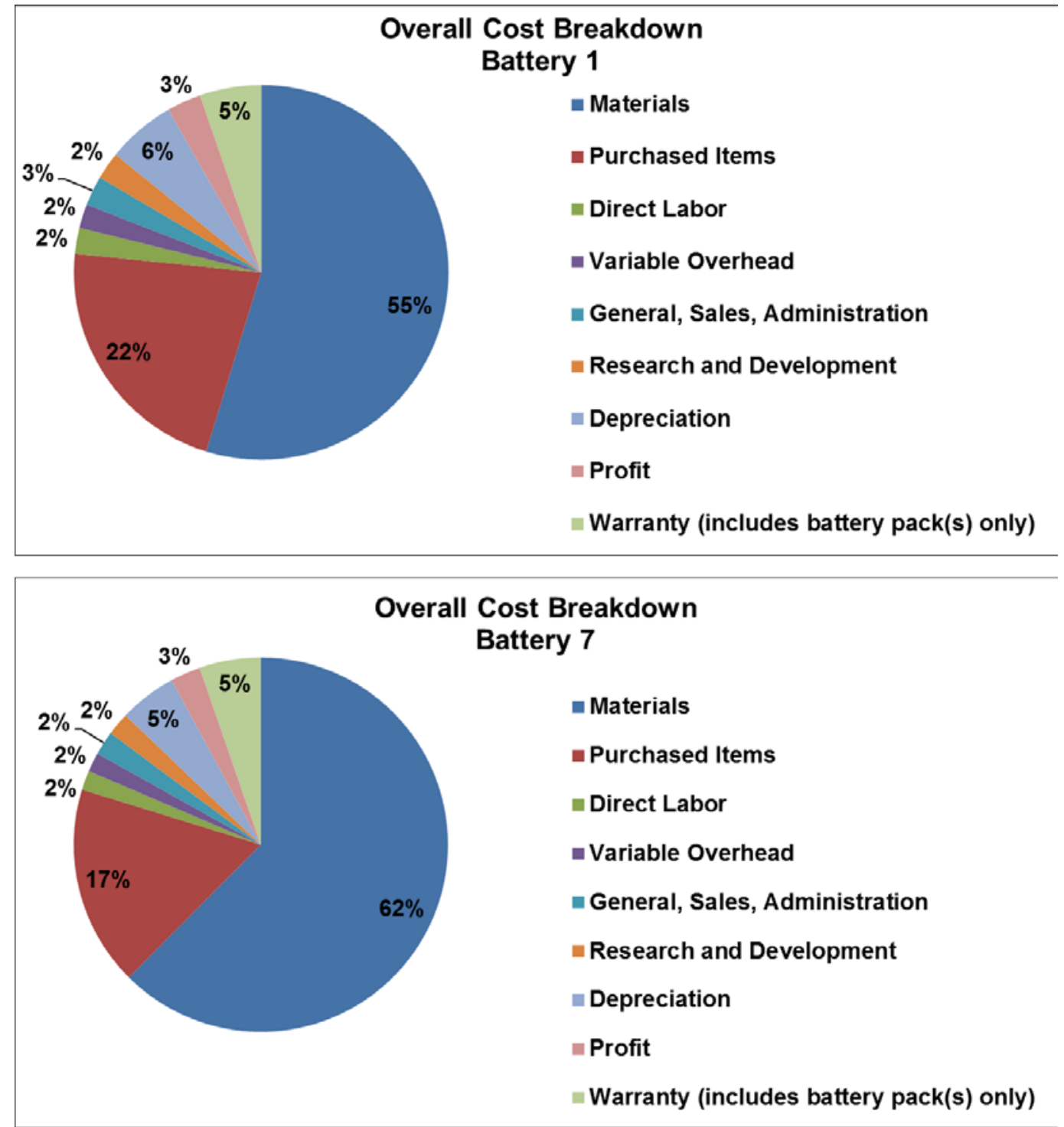

Figure 8.3 Overall distribution of costs of manufacturing battery packs, not including pack integration system. 
These graphs illustrate that materials and purchased items compose a large fraction of the total battery pack price for a mature battery plant producing 100,000 packs per year. This effect is stronger for the large SUV battery (Battery 7), which has a larger fraction of expensive cell materials than the smaller sedan battery (Battery 1 ).

The second set of graphs (Fig. 8.4) illustrates the breakdown of costs for the materials and purchased items only. For both batteries, the costs of active materials and electrolyte are substantial. It should also be noted that the cost of separator material is greater than the total costs of the current collection foils.

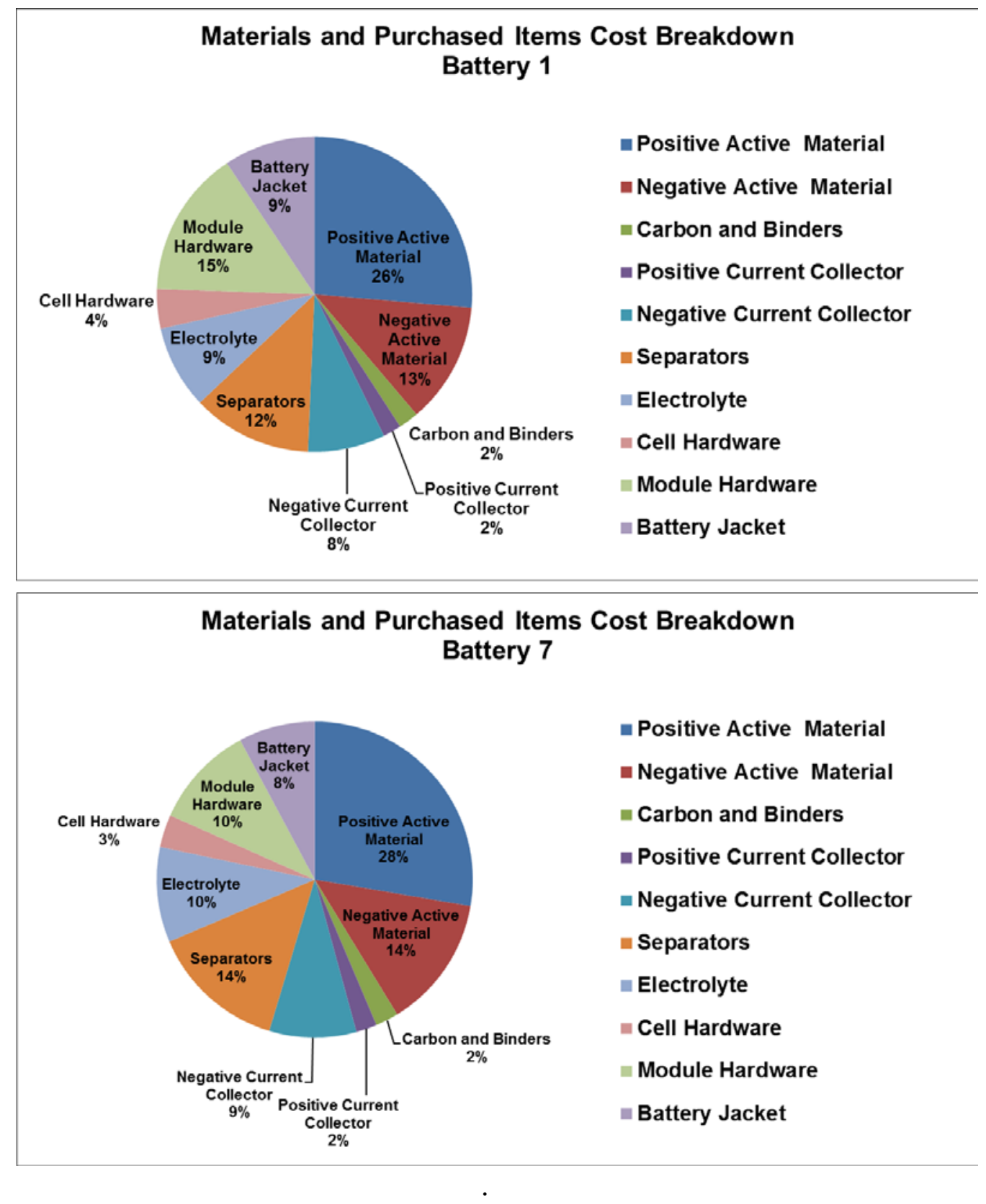

Figure 8.4 Distribution of materials and purchased items for the battery pack. 
Sections 8.5 and 8.6 discuss the derivation of fixed and variable overhead costs by the use of multiplying factors on the costs of (1) materials and purchased items, (2) direct labor, (3) capital equipment, and (4) building, land and utilities. These overhead costs can be redistributed back to their origins by applying the constant multipliers shown in Table 8.9 which is a reproduction from the "Cost Input" worksheet.

The next set of charts (Fig 8.5) in the printout of the Cost Breakdown worksheet, shows the distribution of the price of the battery pack to materials, purchased items, and the individual manufacturing processes and operations.
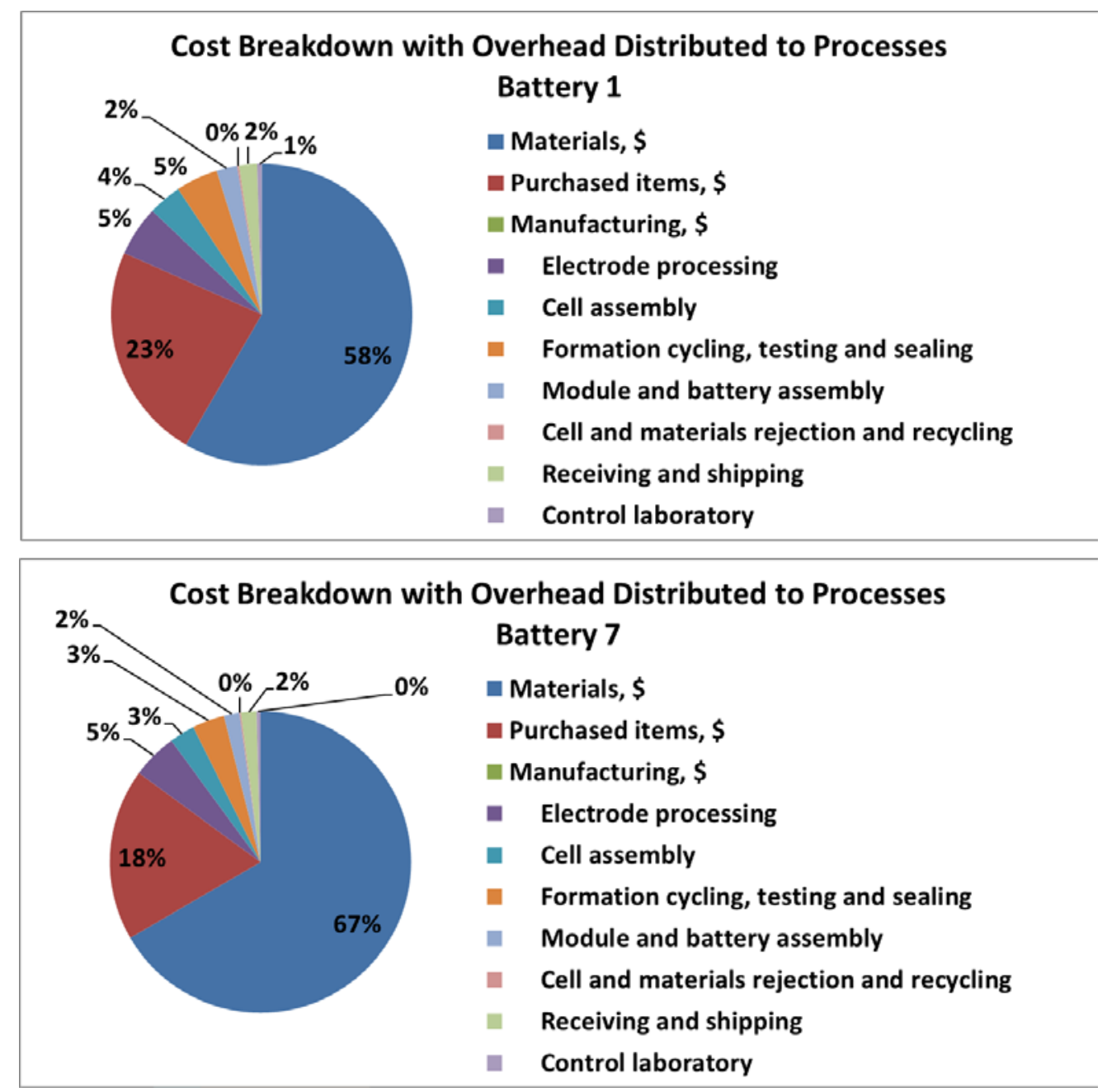

Figure 8.5 Distribution of overhead costs to materials, purchased items, and individual processes.

The materials and purchased item costs have a small effect on overhead cost, namely launch costs and working capital costs. Thus in preparing Fig. 8.6, we have distributed back to the materials and purchased items a small amount, which accounts for the fraction of the cost of materials and purchased items being slightly higher in the charts of Fig. 8.6 than in those of Fig. 8.4. The other costs are redistributed to the individual processes and operations. 
The costs of the three major manufacturing operations of (1) electrode processing, (2) cell assembly, and (3) formation cycling, testing and sealing estimated by $\mathrm{BatPaC}$ for a manufacturing scale of 100,000 battery packs per year in 2020 is lower than their actual costs at the time this report is in writing. If these projected costs are reached, there can be only small percentage reductions in cost after that by further optimization and automation for even larger scales of production, unless there are substantial reductions in the basic raw materials costs.

In Fig. 8.6, the costs are distributed to the basic cost factors of (1) materials, (2) purchased items, (3) labor, and (4) capital equipment and building by means of the factors in Table 8.9.

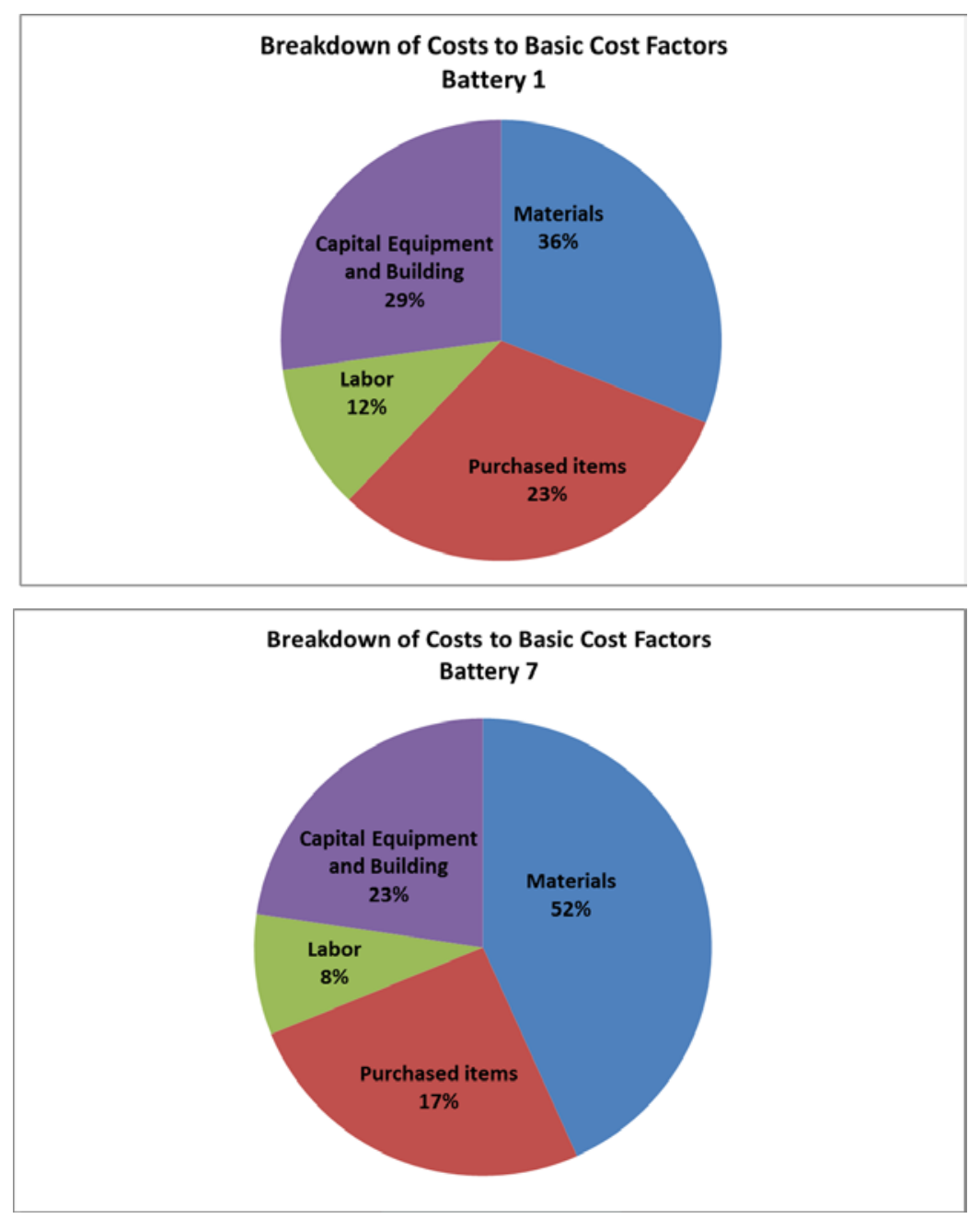

Figure 8.6 Redistribution of costs to basic cost factors

The total effects of the direct labor costs are greater than indicated in Fig. 8.3 because of the influence of labor costs on overhead as indicated in Table 8.9. Foreign battery plants may have lower labor cost than plants in the United States, which may give them an advantage even 
considering shipping costs. However, the advantage would be small and further automation may overcome such an advantage.

Clearly, the major opportunities for cost reduction are in the areas of materials costs and what BatPaC calculates as "purchased items." Improvements may come as materials are produced at higher scale and there may be ways of producing the purchased items within the battery plant at lower costs than projected by BatPaC. Without considerable reductions in these costs, further deduction in the cost of battery manufacturing by increasing scale and automation would result in only a minor percentage reduction in the unit cost of the battery.

Table 8.9 Table for converting overhead costs back to their origins

\begin{tabular}{|l|c|}
\hline \multicolumn{1}{|c|}{ Multipliers for Overhead to Basic Costs } \\
\hline \multicolumn{1}{|c|}{ Basic Cost Factors } & Multiplier \\
\hline Materials and purchased items, \$/pack & 1.0666 \\
\hline Direct labor, \$/pack & 1.8665 \\
\hline Capital equipment (100K packs/yr*) & 3.8764 \\
\hline $\begin{array}{l}\text { Building, land, utilities (100K packs/yr) } \\
\text { *For other production rates multiply by } 100,000 / \text { rate }\end{array}$ & 1.5325 \\
\hline
\end{tabular}




\section{RECOVERABLE MATERIALS AT THE END OF BATTERY LIFE}

The worksheet "Recycle" was included to aid in assessing the work to be done in recovering materials at the end of the battery life. For each battery, the amounts of valuable metals that are recoverable are listed as well as the amounts of several groups of less valuable materials that must be disposed of.

The electrodes may be leached with aqueous solutions to recover lithium, nickel, cobalt and manganese for which the individual amounts are listed for each battery. The lithium originally in the electrolyte is added to the lithium total. The amounts of the scrap metals aluminum, copper and steel that may be recovered from the cells, modules and battery pack structures are listed separately with their origins.

The balance of the battery, about half of the total mass for most batteries, is separated into eight groups of less valuable materials: (1) graphite in the electrodes, (2) balance of electrodes (oxygen, binder, etc.), (3) electrolyte (less lithium), (4) cell separators, (5) cell containers (multilayer polymer/aluminum) (6) pack insulation, (7) pack coolant, and (8) electrical insulation, pack heaters, etc. Some of the low value metallic elements of the electrodes are included with (2) balance of electrodes including aluminum in NCA electrodes, iron in LFP electrodes and titanium in LTO electrodes. The aluminum foil in the multilayer cell containers is probable not economically recoverable, so the entire container material is listed as disposable. 


\section{REFERENCES}

[1] M. Anderman, F. Kalhammer and D. MacArthur, "Advanced Batteries for Electric Vehicles: An Assessment of Performance, Cost, and Availability," June 2000. [Online]. Available: http://www.arb.ca.gov/msprog/zevprog/2000review/btap report.doc.

[2] B. Barnett, D. Ofer, C. McCoy, Y. Yang, T. Rhodes, B. Oh, M. Hastbacka, J. Rempel and S. Sriramulu, "PHEV Battery Cost Assessment," in 2009 DOE Merit Review, 2009.

[3] B. Barnett, J. Rempel, D. Ofer, S. Sriramulu, J. Sinha, M. Hastbacka and C. McCoy, "PHEV Battery Cost Assessment," in 2010 DOE Merit Review, 2010.

[4] A. Dinger, R. Martin, X. Mosquet, M. Rabl, D. Rizoulis, M. Russo and G. Sticher, "Batteries for Electric Vehicles: Challenges, Opportunities, and the Outlook to 2020," 2010.

[5] L. Gaines and R. Cuenca, "Costs of Lithium-Ion Batteries for Vehicles," Center for Transportation Research, Energy Systems Division, Argonne National Laboratory, ANL/ESD-42, 2000.

[6] F. Kalhammer, B. Kopf, D. Swan, V. Roan and M. Walsh, "Status and Prospects for Zero Emissions Vehicle Technology: Report of the ARB Independent Expert Panel 2007," California Air Resources Board, 2007.

[7] M. Kromer and J. Heywood, "Electric Powertrains: Opportunities and Challenges in the U.S. Light-Duty Vehicle Fleet," Sloan Automotive Laboratory, Laboratory for Energy and the Environment, Massachusetts Institute of Technology LFEE 2007-03 RP, Cambridge, MA, 2007.

[8] P. Mock, "Assessment of Future Li-Ion Battery Production Costs," in Plug-in 2009, Long Beach, CA, 2009.

[9] National Research Council of the National Academies, "Transitions to Alternative Transportation Technologies - Plug-in Hybrid Electric Vehicles," he National Academies Press, Washington, D.C., 2010.

[10] TIAX LLC, "Cost Assessment for Plug-In Hybrid Vehicles (SOW-4656)," Report to US DOE Office of Transportation Technology," 2007.

[11] M. Anderman, "The Plug-In Hybrid and Electric Vehicle Opportunity Report: A critical assessment of the emerging market and its key underlying technology: Li-Ion batteries," Advanced Automotive Batteries, 2010.

[12] P. Nelson, D. Santini and J. Barnes, "Factors Determining the Manufacturing Costs of Lithium-Ion Batteries for PHEVs," in International Electric Vehicles Symposium EVS-24, Stavanger, Norway, 2009.

[13] D. Santini, K. Gallagher and P. Nelson, "Modeling the Manufacturing Costs of Lithium-Ion Batteries for HEVs, PHEVs, and EVs," in International Electric Vehicles Symposium EVS-25, Shenzhen, China, 2010.

[14] K. Gallagher, P. Nelson and D. Dees, "PHEV battery cost assessment," in 2011 DOE Merit Review Presentation, Washington, DC, 2011.

[15] K. Gallagher, P. Nelson and D. Dees, "Simplified Calculation of the Area Specific Impedance for Battery Design," Journal of Power Sources, vol. 196, p. 2289, 2011.

[16] P. Nelson, I. Bloom, K. Amine and G. Henriksen, "Modeling thermal management of lithium-ion PNGV batteries," Journal of Power Sources, vol. 110, p. 349, 2002.

[17] G. Henriksen, K. Amine, J. Liu and P. Nelson, "Materials Cost Evaluation Report for High-Power Li-Ion HEV Batteries," Electrochemical Technology Program, Chemical Technology Division, Argonne National Laboratory, ANL-03/05, Argonne, IL, 2002.

[18] P. Nelson, K. Amine, A. Rousseau and H. Yomoto, "Advanced Lithium-Ion Batteries for Plug-in HybridElectric Vehicles," in International Electric Vehicles Symposium, EVS-23, Anaheim, CA, 2007.

[19] P. Nelson, "Modeling the Manufacturing Costs of Lithium-Ion Batteries for PHEVs," in Plug-in 2009, Long Beach, CA, 2009.

[20] P. Nelson, D. Dees, K. Amine and G. Henriksen, "Design modeling of lithium-ion battery performance," Journal of Power Sources, vol. 110, p. 437, 2002.

[21] A. Jansen, K. Amine and G. Henriksen, "Low-Cost Flexible Packaging for High-Power Li-Ion HEV Batteries, ANL-04/09," Electrochemical Technology Program, Chemical Technology Division, Argonne National Laboratory, Argonne, IL, 2004. 
[22] P. Nelson and A. Jansen, "Comparative Costs of Flexible Package Cells and Rigid Cells for Lithium-Ion Hybrid Electric Vehicle Batteries, ANL-06/43," Electrochemical Technology Program, Chemical Technology Division, Argonne National Laboratory, Argonne, IL, 2006.

[23] P. Nelson, S. Ahmed, K. Gallagher and D. Dees, "Cost savings for manufacturing lithium batteries in a flexible plant," Journal of Power Sources, vol. 283, pp. 506-516, 2015.

[24] K. Zaghib, A. Mauger, H. Groult, J. Goodenough and C. Julien, "Advanced Electrodes for High Power Li-ion Batteries," Materials, vol. 6, pp. 1028-1049, 2013.

[25] Ricardo Inc., "2013 MY Ford C-Max Energi, Battery Cell Teardown Analysis," 2016.

[26] J. Euler and W. Nonnemacher, "Stromverteilun in Porösen Elektroden," Electrochimica Acta, vol. 2, p. 268, 1960.

[27] J. Newman and C. Tobias, "Theoretical Analysis of Current Distributions in Porous Electrodes," Journal of the Electrochemical Society, vol. 109, p. 1183, 1962.

[28] "Diagnostic Examination of Generation 2 Lithium-Ion Cells and Assessment of Performance Degradation Mechanisms, ANL-05/21," Chemical Engineering Division, Argonne National Laboratory, Argonne, IL, 2005.

[29] D. Dees, E. Gunen, D. Abraham, A. Jansen and J. Prakash, "Alternating current impedance electrochemical modeling of lithium-ion positive electrodes," Journal of the Electrochemical Society, vol. 152, no. 7, p. A1409, 2005.

[30] D. Dees, E. Gunen, D. Abraham, A. Jansen and J. Prakash, "Electrochemical Modeling of Lithium-Ion Positive Electrodes during Hybrid Pulse Power Characterization Tests," Journal of the Electrochemical Society, vol. 155, no. 8, p. A603, 2008.

[31] D. Abraham, S. Kawauchi and D. Dees, "Modeling the impedance versus voltage characteristics of LiNi0.8Co0.15Al0.05O2," Electrochimica Acta, vol. 53, pp. 2121-2129, 2008.

[32] D. Abraham, S. Poppen, A. Jansen, J. Liui and D. Dees, "Application of a lithium-tin reference electrode to determine electrode contributions to impedance rise in high highpower," Electrochimica Acta, vol. 49, p. 4763, 2004.

[33] D. Abraham, E. Reynolds, E. Sammann, A. Jansen and D. Dees, "Aging characteristics of high-power lithiumion cells with LiNi0.8Co0.15Al0.05O2 and Li4/3Ti5/3O4 electrodes," Electrochimica Acta, vol. 51, p. 502, 2005.

[34] D. Abraham, J. Liu, C. Chen, Y. Hyung, M. Stoll, N. Elsen, S. MacLaren, R. Twesten, R. Haasch, E. Sammann, I. Petrov, K. Amine and G. Henriksen, "Diagnosis of power fade mechanisms in high-power lithium-ion cells," Journal of Power Sources, vol. 119, pp. 511-516, 2003.

[35] D. Abraham, R. Twesten, M. Balasubramanian, J. Kropf, D. Fischer, J. McBreen, I. Petrov and K. Amine, "Microscopy and spectroscopy of lithium nickel oxide-based particles used in high power lithium-ion cells," Journal of the Electrochemical Society, vol. 150, no. 11, p. A1450, 2003.

[36] A. Andersson, D. Abraham, R. Haasch, S. MacLaren, J. Liu and K. Amine, "Surface characterization of electrodes from high power lithium-ion batteries," Journal of the Electrochemical Society, vol. 149, p. A1358, 2002.

[37] D. Abraham, J. Knuth, D. Dees, I. Bloom and J. Christopherson, "Performance degradation of high-power lithium-ion cells - Electrochemistry of harvested electrodes," Journal of Power Sources, vol. 170, p. 456, 2007.

[38] J. Newman and K. Thomas-Alyea, Electrochemical Systems, 3rd ed., New York: Wiley Interscience, 2004.

[39] W. Lai, C. Erdonnez, T. Marinis, C. Bjune, N. Dudney, F. Xu, R. Wartena and Y.-M. Chiang, "UltrahighEnergy-Density Microbatteries Enabled by New Electrode Architecture and Micropackaging Design," Advanced Materials, vol. 22, pp. E139-E144, 2010.

[40] P. Arora, M. Doyle and R. White, "Mathematical Modeling of the Lithium Deoposition Overcharge Reaction in Lithium-Ion Batteries Using Carbon-Based Negative Electrodes," Journal of the Electrochemical Society, vol. 146, no. 10, pp. 3542-3553, 1999.

[41] Y. Chen and J. Evans, "Thermal Analysis of Lithium-Ion Batteries," Journal of the Electrochemical Society, vol. 143, no. 9, pp. 2708-2712, 1996. 
[42] S. Chen, C. Wan and Y. Wan, "Thermal Analysis of lithium-ion batteries," Journal of Power Sources, vol. 140, pp. 111-124, 2005.

[43] H. Maleki, S. Hallaj, J. Selman, R. Dinwiddie and H. Wang, "Thermal Properties of Lithium-Ion Battery and Components," Journal of the Electrochemical Society, vol. 146, no. 3, pp. 947-954, 1999.

[44] M. Sievers, U. Sievers and S. Mao, "Thermal modelling of new Li-ion cell design modifications," Forsch Ingenieurwes, vol. 74, pp. 215-231, 2010.

[45] T. Bandhauer, S. Garimella and T. Fuller, "A Critical Review of Thermal Issues in Lithium-Ion Batteries," Journal of the Electrochemical Society, vol. 158, no. 3, pp. R1-R25, 2011.

[46] R. Bird, W. Stewart and E. Lightfoot, Transport Phenomena, 2nd Ed., New York, NY: John Wiley \& Sons, Inc., 2002.

[47] R. Shah and A. London, "Laminar Flow Forced Convection in Ducts," in Advances in Heat Transfer Supplement, New York, NY, Academies Press, 1978.

[48] R. Siegel, E. Sparrow and T. Hallman, "Steady Laminar Flow Heat Transfer in a Circular Tube with Prescribed Wall Heat Flux," Applied Scientific Research, Section A, vol. 7, pp. 386-392, 1958.

[49] M. Nickolay and H. Martin, "Improved approximation for the Nusselt number for hydrodynamically developed laminar flow between parallel plates," International Journal of Heat and Mass Transfer, vol. 45, pp. 3263-3266, 2002.

[50] R. Chandrasekharan, "Quantification of Bottlenecks to Fast Charging of Lithium-Ion-Insertion Cells for Electric Vehicles”, Journal of Power Sources," Journal of Power Sources, vol. 271, pp. 622-632, 2014.

[51] R. Perry, D. Green and J. Maloney, Perry’s Chemical Engineers’ Handbook, Sixth Edition, 1984, pp. 25-68. 



\section{Argonne}

Electrochemical Energy Storage Department Chemical Sciences and Engineering Division

Argonne National Laboratory

9700 South Cass Avenue, Bldg. 200

Argonne, IL 60439

www.anl.gov 